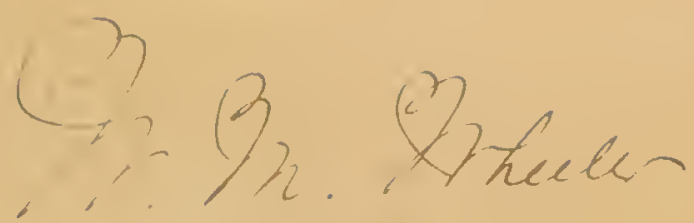 \\ II 6.99
}

\section{Der Dottersack des Huhnes}

von

Hans Virchow.

Hierzu Tafel X-XIV. 



\section{II id mull g.}

Beim Niederschreiben der nachfolgenden Seiten musste ich auf's Lebhafteste an die Zeit erinnert werden, da ich meine aus Würzburg mitgebrachten Präparate über den Dottersack des Huhnes auf dem Berliner pathologischen Institut durcharbeitete, um sie zur Grundlage meiner Dissertation zu machen. Wie ich hoffe, hat die Erziehung zum selbständigen Arbeiten und zum ernsthaften Durchdenken, welche den Unterricht an jener Instalt durchdrangen, damals auch auf mich gewirkt; und ich bemerke mit Freude, dass meine bruchstückartigen Nitheilungen sich doch in einen grösseren Aufbau fügen, ohne einer Umarbeitung zu bedürfen. Vielleicht hat der Geist der Kritik und Besonnenheit, den wir immer vor Augen hatten, meinen Blick geschärft und mich veranlasst, Weniges 'zu bringen, aber Sicheres, mich nicht in Speculiren zu crgehen, obwohl ich einen grösseren physiologischen Zusammenhang ror Augen behielt. So möge denn diese neue Arbeit, in welcher die Kenntniss vom Dotterorgan des Huhnes weiter geführt, aber nicht abgeschlossen ist, Dir, mein lieber Vater; als eine Gabe bei einer so schönen Veranlassung dargebracht sein. 



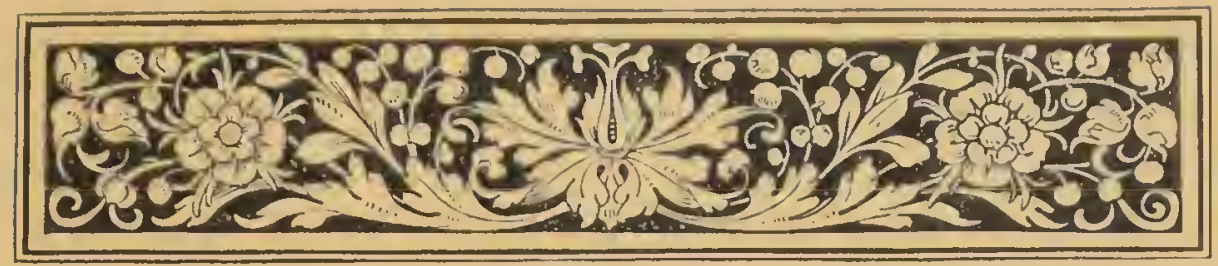

Einl eitung.

D

as Dottersackepithel des Huhnes bot den Ausgangspunkt meiner Untersuchung und steht im Mittelpunkte meiner Darstellung. Diese Frage ist aber mit zahlreichen anderen Fragen im Zusammenhang; es sind so viele Betrachtungen theils mit Recht, theils mit Unrecht mit ihr verknüpft worden, und es ist in die natürliche und einfache Betrachtung des Dottersackentoblasten als solchen, d. h. als Entoblasten, so gewaltsam eingegriffen worden von fremdartigen Auffassungen aus, dass es sich kaum umgehen lässt, auch zu letzteren Stellung zu nehmen. Ich will daher die Gesammtheit derjenigen Fragen, welche uns theils durch die Natur des Gegenstandes, theils durch die litterarische Situation rorgelegt sind, aufführen, damit der Leser die Stellung unserer Aufgabe innerhalb eines grösseren Zusammenhanges ermesse.

I. Das Studium des Dottersackepithels schliesst die Aufgabe ein, die Entwicklung desselben zurückzuverfolgen bis zu dem in Furchung begriffenen Keim.

2. Bei dem Studium dieser Entwicklung muss man sich klar werden über die so viel genannten "Dotterzellen".

3. Da das Dottersackepithel bestimmt ist, Dotter aufzunehmen und zu verarbeiten, so muss man auch die Beschaffenheit des letzteren in den verschiedenen Stufen der Entwicklung kennen lernen. Diese. Untersuchung ist natürlich nicht nur eine morphologische, sonclern elonso, oder vielleicht mehr noch, eine chemische. Ich habe daher schon im Anschluss an meine Dissertation begonnen, mich mit der chemischen Untersuchung des I)otters zu befassen in dem chemischen 
Laboratorium des hiesigen pathologischen Institutes unter Leitung des Herrn Professor Salkowski. Ein schöner Neurin-J'atinchloriclkrystall ist in der Sammlung des Institutes als Spur dieser Untersuchung erhalten geblieben, doch musste ich dic letztere fallen lassen.

4. Die Endschicksale des Dottersackes, insbesondere seines Epithels, Zeit und Art seines Zugrundegehens müssen gteichfalls verfolgt werden.

5. Die Aufsuchung der Orte, in welche die aufgenommenen Dotterbestandtheile zunächst gelangen, und $(\mathrm{er} T \mathrm{~T} \mathrm{ege}$, auf welchen dies geschieht, ist die nothwendige Ergïnzung der vorausgehenden Betrachtung. Unter diesen Orten verricth sich schon makroskopisch die Leber des jungen Hühnnchens durch Grössc und Farbe, aber auch im Bindegewebe findet man Anhaltspunkte für das Studium. Fine Kenntniss in der angedeuteten Richtung ist nicht allein an sich interessant, sondern für clie Beurtheilung des Dottersackepithels selhst nothwendig, da wir nur dadurch erfahren können, in welchem $Z_{\mathfrak{u} \text { - }}$ stande die von dem Epithcl aufgenommenen Dotterbestandtheile dasselbe wieder verlassen.

6. Der Mechanismus, durch welchen der Dottersack in die Lecibeshöhle des zum Ausschlüpfen reifen Hühnchens aufgenommen wird, ist bisher nicht bekannt.

7. Wenn man die lintwicklung des Dottersackes verfolgt, so stösst man in der Litteratur auf die verschiedenen "parablast ischen" Lehren. welche ja während mehrerer Jahre, wenigstens in Deutschland, so riel Jinfluss gewonnen hatten. Der Leser wolle nur beriicksichtigen, class Toldt in der neusten Auflage seines Lehrbuches der Gewebelehre (27. S. 5) den Unterschied archiblastischer und parablastischer Cewebe zur Grundlage seiner Eintheilung macht, und dass Rindfleisch (22. S. 62) auch in die Geschwulstlehre die Hissche Ausdruckwcise ron archiblastischen und parablastischen Geweben eingeführt hat; und man wird ermessen, class der Einfluss der parablastischen Lehren vicl weiter gedrungen ist, als man gemeinhin glaubt.

8. Aus dem ,org"nnisirten keimwall" (His), d. h. aus cler lormation, welche der Vorlüufor des I)ottersackepithels ist, hat man dic Blutzcllen abgeleitet. Das haben sehr viele liorscher, nicht nur P'arablastiker, sondern auch andere gethan, und man liann sie in zwei Gruppen sondern, inclem ein Theil dersclhen die 13lutzellen aus dem 1)otter, der andere 'Theil sic aus dent Entoblasten entstchen lïsst.

9. Die Frage des Giffissendothels und des Mesoderms, so leicht sie sich theretisch von der ker Blutz/len trennen lïsst, muss 
dexle wegen der nahen räumlichen liczichungen mit berücksichtigt werden, wenn man die Entstchung der lilutzellen untersucht.

Io. Auch die Coclombitdung müsste bei rler Lntersuchung mit beachtet werden, da in den vorderen Theilen der Keimscheibe die bildung des Aussencoeloms mit der der blutinschn gleichzeitig auftritt, wïhrend im linteren Theile der lieimhaut dic Blutinseln früher auftreten.

Ir. Jas Studium des Dotterorganes der ïbrigen Wirbelthiere lïsst sich in Zusammenhange unserer frage kaum ungehen, und zwar aus folgendem Grunde. I'erschiedene Forscher, in erster I inie His und II aldeyer (31. S. 32) haben anscheinend eine Bestätigung ihrer parablastischen Ideen bei anderen dotterreichen Wirbelthieren, den Selachicrn und Knochenfisehen gefunden; es ist daher nothwendig; auch diese Positionen aufzusuchen und anzugreifen. Wr ir würden clanit fortschreiten zu einer Untersuchung, dic nicht nur negativen oder kritischen $\mathbf{W}$ erth besitzt, sondern auch positiven; eine solche Untersuchung muss dahin führen, an Stelle der zwar vergleichenden aber nicht morphologischen Betrachtung ron $\mathrm{His}$ und $\mathrm{IV}^{r}$ aldeyer eine wirklich vergleichend morphologische zu setzen. $L^{\top}$ cber das Ergebniss einer solchen sei einstweilen nur Folgendes bemerkt: das Dotterorgan der Vögel ist mit dem der übrigen Amnioten und der Amplibien im strengeren Sinne homolog; und es finden sich allmähliche Lebergänge, welche von dem Dotterorgan der Amphibien mit dotterarmen Eiern (Batrachier, Tritonen) über das der Amphibien mit dotterreicheren Eiern (Salamandra), Ichthyophis, Reptilien und Vögel bis zu dem der S̈̈ugethiere hinführen. Das Dotterorgan der Sclachicr und Knochenfische dagegen ist zwar dem der höheren Wirbelthiere wohl auch in letzter Linie homolog; aber doch nicht in so engem Sinne. Iis bestehen also in Hinsicht des Dotterorganes dieselloen nahen bezichungen einerseits und entfernteren Bezichungen andererseits, wie sie nach der Stellung der Thiere im System zu erwarten waren. Nithin geht es nicht an, die Verhältnisse der Knochenfische und Selachier auf die der Tögel mit Ueberspringung der Amphibicn zu beziehen und die einen aus den anderen zu erlïiren. Im Iinblick auf die von IV aldeyer in dem iufsatze Archiblast und Parablast (31) entwickelten Ideen sei nuch besonders bemerlit, dass die Trorgänge an Jotterorgan der Selachier und Knochenfische verschierlen sind von denen der Reptilien und Tügel, obwohl die Eicr der einen wie der anderen meroblastisch sind; dass dagegen dic Torgäinge am Dotterorgan aller höheren Wirbelthiere von den Amphibien aufwirts im engeren Sinne homolog sincl, obwohl die lier vieler Amphibien und die der Süugethiere holoblastisch, die

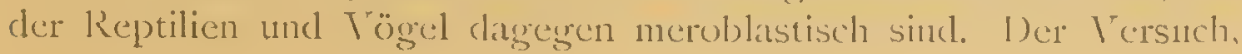


unter Vermittelung der ,secundären Furchung" diese im Sinne von $\mathbb{I V}^{r}$ aldeyer gefasst, zu der Erklärung des Parablasten zu kommen, also von dem begriff der liurchung aus die Vorgänge an Dotterorgan zu deduciren, fördert uns nicht, sondern führt uns im Gegentheil von dem natürlichen Gange der Betraclitung ab. Ich betone dies umsomehr, da diese deductive, von der Furchung ausgehende Art der Betrachtung für embryologische Vorlesungen schr verlockend ist, und da sie demgemäss auch in das Hertwig'sche Jehrbuch der Entwicklungsgeschichte Eingang gefunden hat.

Obwohl ich von den aufgeführten Fragen nur einen Theil berïcksichtigt, einige genauer behandelt, einige gestreift habe, so wollte ich sie doch alle nennen, weil dadurch der grössere Zusammenhang klar wird, in welchen sich meine Mittheilung einreiht.

Allem Uebrigen roran möchte ich drei Bemerkungen machen, clurch welche ich hoffen kann, die Gedanken des Lesers in die Bahn hineinzuschieben, in welcher sich meine Auseinandersetzungen bewegen. Ton diesen Bemerkungen betrifft die erste die Area pellucida, dic zweite die subgerminale Höhle und den perilecithalen Spalt, die dritte die Wülste des Entoderms.

I. Area pellucida. - Die Area pellucida ist am Ende des ersten und an Anfang des zweiten Tages, wie man sich gewöhnlich ausdrückt, birnförmig gestaltet, d. h. sie besteht aus einem grösseren vorderen und einem kleineren hinteren fielde. Wohl zu beachten ist clabei, dass die Gestalt der Area pellucida und ihre Ausdehnung individuell ausserordentlich wechselt bei gleicher Stufe der Entwicklung der Keimscheibe; das ist insofern von Bedeutung, als in dem cinen Falle ein geringerer, in dem anderen ein grösserer Theil der Bhutinseln in die Area pellucida fällt. Ueber den Unterschied des Entoderms in der Area pellucida und in der Area opaca ist, wie man weiss, unendlich vicl geschrieben worden, aber dic Frage ist nicht entschieden, was die Area pellucida bedeutet. Ja meines $W$ issens ist diese Frage überhaupt niemals aufgestellt worden, nie ist untersucht worden, warum die Area pellucida diese eigenthümliche birnförmige Gestalt besitzt. Fis ist allerdings dargestellt worden, class sich dieselbe ursprünglich lireisförmig begrenzt, und dass durch Aufhellung von Theilen der $\Lambda$ rea opaci am hinteren Rande der ursprünglichen Anlage die Birnform entsteht, aber das ist ja keine "Jikklärung", sondern nur eine Thatsache, die cben der lirklärung bedirf; es könnte ja ganz ebensogut dic Aufhellung ringsherum gleichmässign vor sich gehen.

Dic Jirklätrung für dic eigenthïmliche Form der Area pellucicla findet man erst, wenn man spätere Stufen der Jintwicklung berücksichtigt, und ich lege hier die Abbildung eines Hühnchens rom 
sechsten Tage mit dem Annios vor: (las den Embryo einschliessende Annnios stellt eine bohnenförmig gestaltete Blase dar, die jedoch in

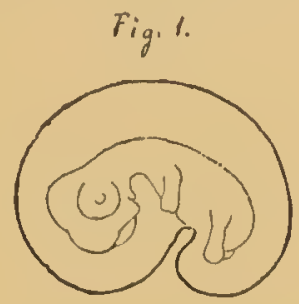

ihrem rorderen Abschnitt stärker ausgedehnt ist, als in ihrem hinteren Abschnitt; der Nabelgegend entsprechend ist dieselbe stark eingezogen. Dort nun, wo diese Blase gegen den Dottersack drückt, also dem Koppende und dem Schwanzende des Embryo entsprechend, findet man am Dottersack plattes Epithel, dort aber, wo das Amnios keinen Druck gegen das proximale Dottersackfeld ausübt, den Wreichen des Thieres entsprechend, springt das hohe Epithel des Dottersackes in Form einer Ecke zwischen das vorclere grössere und hintere kleinere Feld der Area pellucida vor. Diese Ecke entspricht genau der Stelle, an welcher die A. vitellina die Area opaca betritt. In den späteren Stadien der Entwicklung verwischt sich der Unterschied zwischen der Area opaca und Area pellucida allmählich. Das Epithel am proximalen Pole des Dottersackes bleibt zwar niedriger als das am Aequator, aber es geht doch die extreme Abplattung der Zellen und die scharfe Abgrenzung beider Höfe verloren.

Die „Erklärung", welche ich für die Gestalt der Area pellucida gebe, ist also eine teleologische, sie ist keine histiogenetische, auch keine causalmechanische, denn das flache Epithel des proximalen Dottersackfeldes bildet sich ja bereits zu einer Zeit, wo der Druck des Embryo und des Amnios noch gar nicht auf diese Stelle wirkt. Wir können diesen in so frühe Stufen der Entwicklung zurückreichenden Einfluss einen cänogenetischen nennen. Eine in gewisser W eise ähnliche Erscheinung bemerken wir an dem Ectoderm der Säugethiere: hier bildet sich sehr frühzeitig, bevor eine Spur der Amniosfalten hervortritt, eine Differenzirung im Ectoderm aus; in cinem proximalen Felde bleibt das Ectoderm flach, in einer angrenzenden Zone dagegen, welche beim Kaninchen hufeisenförmig, bei der Fledermaus ringförmig (v. B eneden) gestaltet ist, wircl es hoch. Die Erklärung für diesen Unterschied ergicbt sich erst später, indem sich beim Erheben der Amniosfalten zeigt, dass das niedrige Epithel in die Amnioshöhle zu liegen liommt, das hohe dagegen mit der Placentarstelle in nïhere Verbindung tritt.

Meine Erklärung der Form der Area pellucida wird nicht all- 
gemeincn Anklang tinden, ja mancher wird überhanpt nicht begreifen, was ich sagen will. Die Augen der Beobachter sind so sehr auf die Anfänge der Entwicklung gerichtet, dass man meiner Aufforderung; die Sache rom andern Ende zu betrachten, nicht wird folgen wollen. Auch hat man sich so schr gewöhnt, in dem Unterschicd der Area pelluciclit und Area opaca etwas Principiclles und Hochwichtiges zu sehen, dass man sich schwer entschliessen wird, eine so lieb gewordene Torstellung aufugeben. Ich sehe mich daher veranlasst, auf dic übrigen Amnioten hinzwweisen, um damit die Auffassung zu begründen, dass wir in der Area pellucidán nichts Wesentliches, weder von histiogenetischer noch von morphologischer Bedeutung sehen dürfen.

Bei Säugethicren (Kaninchen) treffen wir zwar keinen Dotter; die Arca pellucida aber hat, wenn auch nicht die gleiche, doch eine ähnliche Gestalt wie beim Huhne, und zwar deswegen, weil ähnliche licdingungen in der Gestalt und Krümmung des Thieres rorliegen. liei der Eidechse ist die Area pellucida sehr gross, sowohl verglichen mit der Embryonalanlage wie mit dem Volum des Eies; und Jcr primäre Gefässbezirl fällt ganz in die Area pellucida (Stralıl). Sie ist lireisförnig begrenzt odcr auch elliptisch, im letzteren Falle aber in der Richtnng der Eiachse gestreckt. Da nun die Embryonalachse rechtwinklig zur Eiachse steht, so schneiden sich in letzterem Falle Embryonalachse und langer Durchmesser der Area pellucida gleichfalls rechtwinklig, wonit cin gerade entgegengesetztes V'crhalt. $n$ wie beim Huhn hergestellt ist. Aber auch bei der Eidechse findein wir die Erklärung durch das Verhalten späterer Stufen. WTenn nänlich das Thier sich ron der Keimhaut abgrehoben hat und grösser geworden ist, verändert es seine Lage derart, dass die Schnauze dem eincn und die Schwanzgegend dem andern Eipole zugewentet ist. Dann stellt das Amnios einen länglichen prall gespannten İall ror, der clurch scinen Druck am Dottersack eine rundliche oder elliptische Grube erzeugt, und dieser Grube entspricht die ursprüngliche Gestalt der Arca pellucicla. Noch anders und eigenartig liegei die Verhältnisse bei der Schildkröte. Jine Area pellucida wird hier nicht gebildet, oder vielleicht richtiger, sie ist ungehener gross. 13ereits im Stadium der Gastrula nämlich trifft man, wie ich bei limys europaca und Testudo gracea fand, und wie Clark (r) ganz richtig abbilelet, eine ausserordentich ticfe, mit Flüssigkicit erfüllte Höhle, „subgerminale Höhle". Sowcit diese reicht, 1. l. in linearer Ausckehnung etwa den dritten, mindestens aber den vicrten Theil des Imfanges der ganzen D)ettermasse cinnchmend, trifft man flaches Fintoderm, 1. 12. cine sehr auserectehnte Area pellucida. Vine Erklïrung für diese ungewöhnliche dusclehnung vermag ich nicht zu 
goben, da es mir nicht gelang, Material aus spüteren Stufen der intwicklung zu erhalten. Es bestätigt aber auch diescr licfund, diss die Gestalt der Area pellucicla bei den einzelnen Gruppen der Imnioten sehr wechselt, unct dass ihr eine ticfore morphologische Bedeutung nicht zukommt.

2. Subgerminale Höhle und perilecithaler Spalt. - Auch die subgerminale Höhle ist von den späteren Stadien aus meiner Meinung nach leicht zu erklären. lis ist bekannt, dass die Dottermasse in den ersten Tagen der Bebrütung zunimmt. Diese Zunahme ist sogar sehr bedeutend und clauert nach der Angabe von Bacr (2. S. 106) etwa bis zur Mitte der Brütezeit. Ehenso ist bekannt, dass diese Vermehrung dadurch zu Stande kommt, dass sich Flüssigkeit auf die Oberfläche des Dotters ausscheidet, eine dünne wässrige Flüssigkeit, durch Dotterbestandtheile milchig getrübt. Schon Gruithuisen sprach daron, wie Pander (20 S. 2r) anführt, dass der „Eiclotter in eine der Milch vollkommen ähnliche Flüssigkeit verwandelt" werde. Es entsteht also zwischen dem Dotter und cler Wand ein mit Flüssigkeit gefüllter Spalt. Da ich auf ihn noch zurïckzukommen habe, so nenne ich ihn perilecithalen Spalt. Das Verhältniss ron subgerminaler Höhle und" perilecithalem Spalt ist nun sehr einfach zu bezeichnen: Der perilecithale Spalt ist die peripherische Fortsetzung der subgerminalen Höhle, oder, anders ausgedrückt und für meinen Zusammenhang besser, die subgerminale Höhle ist nichts Anderes als der Anfang des perilecithalen Spaltes. Damit verlieren für mich die Vergleiche der subgerminalen Höhle mit anderen Höhlen und Spalträumen, wie Furchungshöhle und Urdarmhöhle, sehr an Bedeutung.

Werfen wir wieder den Blick auf andere Amnioten, so ist ron der Schildkröte schon hervorgehoben, dass die subgerminale Höhle ron gewaltiger Ausdehnung ist. Bei der Eidechse dehnt sich der perilecithale Spalt nicht um den ganzen Dotter herum aus (Strahl), dagegen ist die subgerminale Höhle von grosser Ausdehnung. Später verschwindet dieselbe, indem Dach und Boden sich vereinigen.

3. Wülste des Entoderms. - Der Dottersack, wenn er die Höhe seiner Jusbildung erlangt hat, trägt an seiner inneren Fläche hohe durchbrochene Blätter oder Gitter, welche von einem reichen Gefässnetze eingenommen und ron cinem cinschichtigen Epithel bedeckt sind. Ton ihnen wird spiiterhin gesprochen werden. (S. $25+$ f.) llier will ich nur wieder den leser aufforlern, dasselbe zu thun wie rorher, nü̈nlich von dem einfachen, klaren, auselrucksvollen bilale des fertigen Zustandes rückschauend die Anfänge der lintwicklung zu betrachten. Wem man dis thut, so wird manches klar, was bis dahin 
unverständlich war, und die Quellen mancher Irrthümer sind verstopft. Die Anfänge der erwähnten, ron Gefässnetzen eingenommenen Blätter oder Gitter sind frühe erkennbar; betrachtet man am Encle des ersten oder in Beginne des zweiten Tages die Area opaca, so bemerkt man eine grosse Zahl dunkler Flecke, das was man gewöhnlich schlechthin ,Blutinseln" nennt. Aber dicse Flecke des Fläichenbildes sind nicht die Blutinseln, sie sind mehr; sie setzen sich zusammen aus zwei Componenten, aus den wirklichen Blutinseln und aus Wülsten des Entoblasten. Wenn man daher von diesen Verhältnissen sprechen will, so muss man zuerst das Flächenbild analysiren, man muss die Blutinseln und die Wiilste von einander trennen. Es ist so unendlich viel über die Blutinseln und ihre Entwicklung geschrieben worden, und doch ist diese allergröbste Betrachtung, welche ich soeben angedeutet habe, und welche die nothwendige Vorbedingung für jede genauere Untersuchung sein sollte, niemals durchgeführt worden. Wenigstens ist mir nicht bekannt, dass irgendwo wirklich genaue Abbildungen der Blutinseln einerseits und der Entodermwïlste andrerseits gregeben worden sind. Ich habe mich deswegen bemüht, auf der Taf. XII zwei Figuren rorzulegen, welche diese Lücke ausfüllen könnten. Ich habe zwei Keimscheiben ausgewählt, von denen die eine (Fig. 23) die Blutinseln, die andere (Fig. 24) die Entodermwülste besonders deutlich zeigte. Ich gebe zu, dass es noch besser gewesen wäre, eine einzige Keimscheibe zu Grunde zu legen und ron ihr in einer Figur die Blutinseln, in einer anderen die Entodermwülste zu zeichnen. Aber wenn die Wülste sehr deutlich sind, so verdecken sie zu viel von den Blutinseln, daher können solche Keimscheiben für letztere nicht gut verwendet werden.

Ueber die beiden Figuren der Tafel XII sei nun Folgendes bemerkt: von dem ersten Präparat - Keimscheibe nit 4 Urwirbeln von 3 I bis 32 Stunden - wurde zunächst eine I 8 fach vergrösserte Photographie genommen und diese der Zeichnung zu Grunde gelegt; das zweite Präparat - Keimscheibe mit II (I2) Trwirbeln von 46 Stunden - wurde mit dem Prisma bei I 4 facher Vergrösserung abgezcichnet. Beide Zeichnungen wurden sodann mit Aufwand ron schr viel Zeit und Mühe durch Herrn Ey rich ausgeführt unter beständiger Ucherwachung meinerseits, und um die grösste Sicherheit bei der Wiedergabe zu haben, wurde für diese die Heliogravüre gewählt. Her Beschauer wird einen körperlichen Eindruck am besten erlalten, wenn cr die Figuren aus einiger Entfernung betrachtet.

Auf dem Prïparat zu ligur 23 ist vorn ein Stück der Area opaca bis an den Rand der Arca pellucida abgebrochen; die Area pellucirla, auf der Figur durch die Linie p bezcichnet, ist in dem vorliegenden lalle sehr breit, so dass ein sehr grosser Theil des Gefïss- 
bezirkes in die Area pelluciela fällt. Die libutinseln sind in der Area opaca grösser als in cle Area pellucida und in dem hinteren Theil der Area opaca zahlreicher, als in dem vorderen. Auf der rechten Seite der Figur, vorn am Rande, war es nicht möglich, die Blutinseln in der Area opaca deutlich abzugrenzen, und es ist deswegen hier die äussere Grenze des Gefässbezirlies der Area opaca nur durch eine punktirte Linie bezeichnet, Blutinseln aber sind nicht eingetragen. Man sieht ferner den zackigen Rand des vorwachsenden Mesoderms (mi) und ror dem Kopfe in der Area pellucida eine Gruppe ron kleinen Entodermwülstcn (E).

Im Interesse der Deutlichkeit muss ich hier eine Bemerkung über die Auschucksweise einschieben: Wir unterscheiclen die Area pellucida ron der Area opaca. Die Area opaca ist, soweit sich Blutinseln in ihr bilden, von Wülsten bedeckt und dadurch hier noch dunkler als in den peripherischen Abschnitten. Wir kiönnten daher diesen proximalen Abschnitt der Area opaca wohl auch als Area opaca s. str. bezeichnen, wie es gelegentlich geschehen ist, und ihn dem Dotterhof (Area vitellina) gegenüberstellen; oder wir können auch von einem gewulsteten Theil der Area opaca (Area opaca villosa) sprechen, im Gegensatz zu dem angrenzenden gratten Theil (Area opaca laevis), welch' letzterer dann der Innenzone des Dotterhofes entsprechen würcle. Dagegen ist es nicht statthaft, wie es von älteren Autoren geschah, und wie es auffallenderweise ron neuem wieder in dem Hertwig'schen Lehrbuche geschieht (III. Auflage S. I55), den proximalen Abschnitt der Area opaca als Area vasculosa zu unterscheiden, denn Blutinseln treten, wie man seit langem weiss, nicht nur in der Area opaca, sonclern auch in der Area pellucida auf. Es empfiehlt sich claher auch überhaupt nicht, von einer Area vasculosa zu sprechen, sondern hier ein anderes Wort zu wählen. Ich spreche also nicht ron eincm Gefässhof, sondern von einem Gefässbezirk. Dieser zerfällt in den Gefüssbezirk der Area opaca und in den cler Area pellucida oder abgekïrzt in den dunklen und den hellen Gefässbezirk.

Nach dieser Zwischenbemerkung hebe ich zur Erläuterung der Figur 24 noch liolgendes hervor: die Area pellucida zeigt die charakteristische Einschnürung und ist so eng, dass ihre Grenze in der Mitte bis an den Embryonalbezirk heranreicht; vorn in der Mitte ist der gewulstete dunkle Hof sehr schmal. Dic auf der Figur hervortretende dicke Grenzlinie (IV) des äusseren Randes entspricht nicht etwa der Vena terminalis, welche als solche überhaupt nicht geschlossen angelegt wird, wie Figr. 23 zeigt, sonclern einen1 ringförmigen Entodermwulst, dem „Grenzwulste des Ciefïshofes" ron Kölliker (Lehrbuch S. 17t). 
Ich gehe nun etwas genauer auf die Wïlste des Entoderm cin, die ja daclurch, dass wir sie als Vorläufer der Blätter ansehen müssen, eine erhöhte ljedcutung gewinnen. Sie sind aluf der Stufe cler İntwicklung, welche wir ror uns haben, in ihrer Ausbildung ausserordentlich rerschieden, und diese Verschiedenheiten sind nicht an die Stufe der Entwiclilung gebunden. Es mag sein, dass die Art der fär-bung das mikroskopische Bild beeinflusst, aber eine sehr weitgehende individuelle Verschiedenheit bleibt zweifcllos. Ich kinn jedoch diese V'erschiedenheiten nicht anders auffassen, als unwesentliche individuelle Schwankungen, die sich aus eincm zeitlichen Forauseilen olcr Zurückbleiben erklären; Differenzen, die in dem Maasse schwinden, als durch ein kräftiges Hervortreten functioneller Inanspruchnahme eine grössere Strenge im Bau gefordert wird.

Diese ITïlste sind zuweilen halbkugelig; meist jedoch länglich, leistenförmig oder lappenförmig, z. Th. geschlängelt, häufig nach einer Scite umgelegt, ron wechselnder Höhe und Länge. In ihrer Anordnung ist of cine Regel nicht zu erkennen; daun siud diejenigen ron ihnen, welche am inneren Rande der Area opaca rorspringen, besonders lilar. In anderen Fällen ist in ihnen eine netzartige Anorclnung frül bemerkbar, entsprechend dem Netze, zu welchem die Blutinseln schon früh zusammentreten. Zuweilen hebt sich unter ihnen eine Gruppe durch besondere Anordnung $a b$, indem eine radiäre Convergenz an der einspringenden Ecke cles Randes zu sehen ist, welche die Grenze zwischen dem vorderen breiten und hinteren schmalen Felde der Area pellucida bezeichnet. Dá diese Stelle dem Punkte entspricht, an welchem späterhin dic Art. vitellina die Arca opaca betritt, um sich hicr dichotomisch zu rerästeln, so kann man in der erwähnten Anordnung eine Beziehung auf die racliär gestellten, clie Verästelungen der Art. vitellina aufnehmenden Falten erblicken.

Eincn rollkommen plastischen Eindruck erhält man ron den Wiilsten natürlich nur dann, Wenn man sic am nicht aufgehellten l'rïparat bei auffallendem Lichte betrachtet. Nach der Aufhellung dagegen, also an geförbten Lackpräparaten, stellt sich der Anblick sehr wesentlich anders dar: inden das Präparat durchsichtig gemacht und in Jack eingeschlossen wird, gehen dic Schatten, welche die Mülste bezeichneten, zum grossen Theilc verloren, und es tritt cine neue Art der lichtelifferen\% auf, nämlich dicjenige, wchche darlurch berlingt ist, dass bald dickere, bald dünncre Schichten ron lipithel sich dem durchfallenden Lichte entgegenstellen. Aus diesen zwei gan\% rerschiedenen Iïinflüssen: den abgeschwäcliten, aber nicht gänzlich aufgehobenen Schatten, welche das aufallende Licht cr\%cugt, und den 1)unkellueiten, welche im durchfallenden Iichte cntstelien,

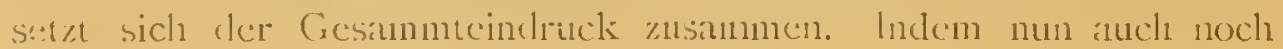


die Bhutinseln als dunkle Flecke erscheinen, entsteht cin Bild, welches wlin erst deutlich versteht, nachdem man sich seine rerschicdenen Componenten klar gemacht hat, und welches auch damn, wenn es rerstanden ist, schwer wiederzugeben ist. Denn der Zeichner kamn nur verständlich sein, wenn er entweder vom auffallenden oder von durchfallenden Lichte herrührende Differenzen wieclergiebt; beide zusammen aber, in ciner Zeichnung vereinigt, müssen sich gegenscitig stören. Dic Figur 24 ist ein Versuch der Wiedergabe, der trotz der darauf verwendeten Mühe unvollkommen ist.

Ueber das topographische Verbältniss der Entodermwülste und der- Blutinscln ist zu bemerken, dass die Blutinseln grossentheils in den Basen der Wülste liegen, dass sie sich jedoch anfänglich in ihrer Form nicht genau entsprechen; eine vollkommene Tebercinstimmung tritt erst in clem Maasse hervor, als unter Vereinigung der Blutinseln zu Strängen und Streckung der letzteren die Anlage des primären Kreislaufes sich anbahnt. Die IVülste mit den zu ihnen gehörenden Gefïssanlagen sind die Vorläufer der Blätter des Dottersaclies mit den in diesen liegenden Gefässnetzen; und da die Mehrzahl der Gefässe späterhin in den Blättern liegt und mit diesen weit in den Dotterraum vorgeschoben wird, so dringen schon schr frühe die Gefässanlagen, nänlich schon in Stadium der „Blutinseln" in die Basen der Entodermwülste ein und springen an der ventralen Seite des Mesoderms vor.

Ich vermeide absichtlich die Stellung der Frage, ob die Entodermwülste durch die cindringenden Gefässanlagen, oder ob das Vorspringen der Gefässanlagen durch die Entodermwülste veranlasst wercle. Es genügt mir, das rein topographische Terhältniss zu betonen: Gefässanlagen und Epithelwülste gehören zu cinander zur Bildung der Blätter, und deswegen müssen sic am gleichen Platze entstehen. Dass aber das Auftreten der Wülste nicht durch die Ge. füssanlagen bedingt sei, das kann man meines Erachtens dadurch beweisen, dass sich die Wülste gelegentlich schon nachweisen lassen zu einer Zcit, wo ron Blutinseln noch nicht die geringste Spur vorhanden ist. Fine solche Kcimscheibe bringe ich in Figur I der Tafel X im Flächenbildc, und in Figur 2 im Schnittbilde zur- Anschauung. Diese Keimscheibe von 27 Stunden zeigt einen Primitivstreifen von noch nicht voll entwickelter I,ïnge; das Mesoderm hat nur den hinteren Theil der Area opaca betreten. Trotzdem bildet die Area opaca im ganzen Ymange der Area pellucida einen schmalen Kranz von kleinen IViilsten, dic schon im Flïchenbilele benerlit wurden und sich im Schnittbilde als solche bestïtigten. In Lä̈ngsschnitten durch eine Keimsclieibe mit $13(14)$ Urwirbeln von 48 Stunde'n finde ich die Wülste hinter der Area pelluciclá reichlich und sehr 
scharf ausgeprägt, ror derselben weniger, so dass sich der hintere Abschnitt der Area opaca in dieser Hinsicht weiter entwickelt zeigt.

Von allen diesen Wulstbildungen wurde eine von Kölliker durch einen besonderen Namen ausgezeichnet: der schon erwähnte „Grenzwulst des Gefässhofes"; er schliesst den Gefässbezirk gegen den Dotterhof hin ab und zeichnet sich dadurch aus, dass er als glatter oder wulstiger Ring rundum läuft. Es ist klar, dass er zu der Vena terminalis in Beziehung steht, obwohl er, wie oben gesagt, schon ausgebildet ist, bevor eine geschlossene Anlage der Vena terminalis existirt. Ich erwähne ihn deshalb besonders, weil auch später noch, nachdem unter Schwund der Vena terminalis sich der primäre Kreislauf in den secundären umgebildet hat, diese Stelle etwas Eigenartiges behält. Ich gebe eine Beschreibung derselben von einer Keimhaut vom vierten Tage. Man trifft am Rande des Gefässbezirkes einen ringförmigen, ziemlich breiten Vulst. Derselbe ist jedoch nicht glatt, sonclern durch feine, zackige Spalten in unregelmässige Stücke (Zellengruppen) zerlegt. Bei auffallendem Licht erhält man ein Bild wie von einem getrockneten, mit Rissen bedeckten, thonigen Boden. Auf der distalen Seite dieses Wulstes, schon im Bereich cles Dotterhofes, trifft man flache Erhebungen, kettenartig verbunden. Auf der proximalen Seite findet man gleichfalls Irrhebungen, wie flache Papillen, durch breitere Spalten von einander getrennt. Auch die Gefässwülste zeigen sich von dieser Bildung gewissermaassen angesteclit; denn während dieselben in den proximalen Theilen des Gefässbezirkes der Area opaca glatt sind, nehmen sie, indem sie sich dem Grenzwulste nähern, einen leicht gewundenen Verlauf an und sind auf ihrer Oberfläche mit Kerben und Runzeln bedeckt. Diese Wulstbildung im Randtheile des Gefässbezirkes ist also von der Anordnung der Gefässe grossentheils unabhängig und scheint einen primitiven Charakter zu bewahren.

Ich habe von den Wülsten des Entoderms etwas ausführlicher, jedenfalls aber nicht zu ausführlich gesprochen. Wir kommen bei der Betrachtung derselben zurück zu ziemlich frühen Stufen der Entwicklung, zu denjenigen Stufen, die man hauptsächlich studirt hat mit Rücksicht auf die liragen des "Nebenkeimes", der Blut- und Gefässanlagen. Jeder, der dias T'orausgehende gelesen hat, wird sich selbst sagen, dass es bei der Anfertigung und Auswahl von Schnitten durch die Area opaca dringend nöthig ist, auf cliese ITulstbildungen Rücksicht zu nehmen. Derjenige Theil der Litteratur, welcher sich mit den angedeuteten Fragen beschäftigt, zeigt in der That eine grosse Reihe der schwersten Irrthümer, welche aus der Nichtheachtung der topographischen Verhältnisse entstanden sind. 
Dotter und Technik.

Ich rereinige in diesen Abschnitt die Bemerkungen, die ich äber 1)otter und über 'lechnik zu machen habe und zwar deswegen, weil die Teränderungen, welche durch die Behandlung an dem Dotter hervorgerufen werden, mannigfaltige und ticfgreifende sind.

Ich will aber nicht die Frage nach der Beschaffenheit des Dotters ab oro wieder aufnehmen; selbst die Erörterung, über die Unterschiede des gelben und weissen Dotters, welche früher in Arbeiten über die Randtheile der Kiemhaut stehend war, bietet heutzutage, nachdem auch $\mathrm{H}$ is den festen Glauben an die zellige Natur der Elemente des weissen Dotters verloren hat (I3. p. 78), wenigReiz. Ich spreche vom Dotter nur mit Rücksicht auf die ganz bestimmten Zwecke meiner Arbeit, und im Hinblick auf diese beschärtigen mich drei Fragen: I. Giebt es Spalten zwischen den Dotterkugeln? 2. Giebt es Protoplasma im Dotter? 3. Wie verändert sich der Dotter während der Bebrütung? Da nun alle Präparate, die wir untersuchen, mit Reagentien behandelt sein müssen, so sind alle den Dotter betreffenden Fragen von der Vorfrage beeinflusst: welche Veränderungen rufen die Reagentien im Dotter hervor?

Wrenn wir Dotter ohne jeden Zusatz unter das Deckglas bringen, so erhalten wir durch den Druck des Deckglases einen Brei, an dem wir garnichts über die morphologischen Verhältnisse lernen können. Das Nächste ist der Zusatz von Wasser bezw. Kochsalzlösung. Wasser und ebenso Kochsalzlösung bringt die eiweissartige Substanz des Dotters zum Quellen und ruft an der fettartigen Substanz des Dotters Veränderungen der Form und vielleicht auch der Beschaffenheit herror. Man darf sich daher wundern, dass $\mathrm{H}$ is in einer seiner Arbeiten (I I. p. 277) zu der Kochsalzlösung als zu einem besonders geeigneten Reagens griff, ja dass er eine eintägige Maceration in solcher anzuwenden wagte, um das ,interglobuläre Protoplasmanetz" des Keimwalles (I r. Fig. 3) darzustellen.

Ich hatte mir die Sachlage überlegt und mir gesagt, dass man zuvor den eiweissartigen Körper in den Dotterliugeln fixiren müsse, um die WVirkung der Reagentien auf den fettartigen Körper isolirt zur Anschauung zu bringen. Hicrzu bot sich das Kochen und die Behandlung mit Sublimat oder Alcohol als Hülfsmittel dar, am kräftigsten wirksam die Anwendung von heissen Sublimat oder heissem Alcohol. Allerdings sind sellost diese Mittel nicht einwandsfrei; es wäre möglich, dass durch dic starke Erwärmung der fettartige Körper dünnflüssiger und eine andere Art der Vertheilung in den Dotterkugeln herbeigeführt würde; es wäre andererseits nöglich, dass das Sublimat als eine wässrige 1.ösung die Contactwirkungen auf den fettartigen Körper ausübte, wic alle anderen 
wässrigen Reagentien. Doch mit irgend etwas musste probirt werden, und bei diesen V'ersuchen fand ich charakteristische Erscheinungen, über welche ich schon berichtet habe (29).

Es ist für clie Zweele meiner Arbeit nicht nöthig, auf die Chemie des Dotters näher einzugehen; es genügt, wie ich glaube, sich gegenwärtig zu halten, dass im Dotter des Huhnes ein eiweissartiger und ein fettartiger Körper vorhanden ist. Der ,eiweissartige Körper“ wird in Gestalt des Yitellin clargestellt und ist, wie man weiss, in S̈̈uren löslich, worauf ja seine Darstellung fusst; der , fettartige lör-

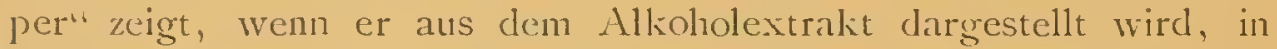
scinem Verhalten Uebereinstimmung mit dem Myclin (30). Wir lï̈nnen behaupten, dass diese beiclen Substanzen in jeder einzelnen Dotterkugel vorhanden sind; wir können auch annehmen, dass die kileineren und grösseren glänzenden Tropfen der fettartigen Substanz, das blassere Stroma der eiweissartigeil Substanz entspreche; aber wir dürfen nicht sicher annehmen, dass sie sich im frischen Zustande genau so zu einander verhalten, wie wir es an Präparaten selhen.

Icl nchme nun aus meiner frïheren Nittheilung das für den vorliegenden Zusammenhang Wrichtige auf.

ז. Alcoholdotter (der rom Eiweiss befreite Dotter wurde, umschlossen ron cler Dotterhaut, $2+$ Stunden hindureh der Einwirkung ron Alcohol ausgesetzt). - Eine l'robe, einige Millimeter unter der Oberflïehe entnommen, zeigt die in ihren ccligen Formen fixirten Dotterkugeln; farblose fettglïnzende Tropfen sitzen ihrer Oberfläche auf. Bei längerer lieobachtung in Alcohol treten noch weitere Tropfen hervor, welche zum Theil frei werten, sich auch zum Theil am Objecträger oler Deckglas ansetzen und sich hier öfters flach ausbreiten. Untersucht man in W'asser, so legen sich die Tropfen noch flacher an das Glas an bezw. an die Oberfläche der Kugeln, es liönnen sich eine volliommene Umhüllung der liugeln oder zierliche Netze auf ihrer Oberfläche bilclen, welche sich durch Osmiumsäure fixiren lassen.

Erlilïrung: durch die verhältnissmässig grosse Cohaesionstendenz zwischen dem fettartigen körper und Alcohol, unterstützt durch den Druck, weleher bei der Schrumpfung (er Dotterkugeln entsteht, wird clcr Austritt der Tropfen reranlasst.

1)er Mlcoholdotter bietet aber zuweilen auch ein ganz anderes likld, nä̈mlich in den tieferen Schichten, in welchen sich die Alcoholwirkung nicht so eingreifend vollzogen hat. Min finclet dort an den gleichfills eckig fixirten Kugeln cine hellere Aussenschicht um die dunklere durch cine runde L inie begrenzte Mitte. Bei der Untersuchung in starkem Aleohol treten an der (H)erfläche der Kugedn 
Tropfen auf, und man sicht oft diese Tropsen, lang ausgezogen, durch dic Aussenschicht hindurchschlüpfen.

Erklïrung: der verdünnte $\Lambda$ lcohol ̈̈bt auf die fettartige Substanz eine abstossende Wirkung und veranlasst das Zurückweichen derselben nach der Mitte der Kugel.

Behandelt man ein mikroskopisches Präparat des Alcoholdotters mit Eisessig, so steigert sich, während die Kugeln quellen, der Austritt von Tropfen und diese fliessen zu grösseren Tropfen zusammen, wobei öfters kleine Kügelchen bezw. Tröpfchen in die grossen Tropfen hineingerathen und darin lebhaft umherfahren. Behandelt man Alcoholdotter mit Kalilauge von $35 \mathrm{pCt}$., so findet gleichfalls Aufquellung der Kugeln und Bildung grösserer Tropfen statt. Salzsäurehaltiger Alcohol erzeugt die Quellung der Kugeln nicht oder doch nur sehr langsam. Im Alcoholdotter ist also das Eiweiss geronnen und wird nur durch stärkere Säure- oder Alkaliwirkung schnell zum Quellen gebracht; der fettartige Körper dagegen ist weder fixirt noch extrahirt.

2. Gekochter Dotter (das Ei ivurde $1 / 2$ Stunde gekocht). - Aus den eckig fixirten, durch gleichmässige Körnelung getrübten Kugeln wird eine fettartige Masse durch Einwirkung starken Alcohols erst allmählich hervorgelockt, und zwar tritt dieselbe hauptsächlich an der dem Beschauer zugewendeten also oberen Seite in wenigen breiten bucliligen Figuren aus.

3. Sublimatdotter (der Dotter, von der Dotterhaut umhüllt, wurde 24 Stunden mit concentrirter Sublimatlösung behandelt). - Die eckig frxirten Dotterkugeln zeigen nur zum Theil fettartige Tropfen an ihrer Oberfläche, grösstentheils sind sie von gleichmässiger Granulirung ganz erfüllt. Bei der Finwirkung von Alcohol treten in den Kugeln und zwar zunächst in der Oberflächenschicht kleine glänzende Tropfen auf; dieselben vergrössern sich durch Zusammenfliessen, dann springen sie halbkuglig über die Oberfläche hervor. In diesem Staclium bietet die Kugel, welche auf ihrer ganzen Oberfläche von den halbkugligen glänzenden Vorsprüngen bedeckt ist, ein eigenthümliches Aussehen. Im Innern der Prominenzen sicht man oft glänzende Kügelchen mit dem Aussehen von Vacuolen.

So grob, als sie hier geschildert wurden, sind nun die Störungen an den Präparaten, die wir zum mikroskopischen Studium verwenden, nicht; aber sie sind vorhanden, und sie sind in sehr verschiedenem Grade vorhanden in verschiedenen Tiefen des Präparates. Denn der Dotter wird von Flüssigkeiten sehr schwer durchdrungen, und dic Wirkung kann daher in der Tiefe eine andere, ja in gewisser Weise entgegengesetzte sein, wie an der Oberfläche. Ja sellost dic cinzelne Dotterkugel wird, wie dic angeführten Versuche 
gezeigt haben, von Flüssigkeiten schwer durchdrungen, und sie zeigt sich claher in ihren Schichten oft nicht gleichmässig beeinflusst. Die in mikroskopischen Präparaten erscheinenden Störungen lassen sich in drei Gruppen bringen, je nachdem sie hervorgegangen sind: I. aus Quellung und Schrumpfung, 2. aus Lösung und Fällung; 3. aus Oberflächenberührung (Contact).

1. Quellung tritt ein durch Säuren, z. B. durch salzsäurehaltigen Alcohol, wenn nicht sehr gut vorher fixirt war. Ebenso durch Salpetersäure, Chromessigsäure, Picrinschwefelsäure; auch durch M üllersche Flüssigkeit. Schrumpfung tritt ein durch Alcohol. Sie ist sehr stark, wenn der Alcohol sofort angewendet wird, aber sie tritt auch ein, wenn vorher anders fixirt wurde. Jede einzelne Dotterkugel schrumpft und es entstehen dadurch zwischen ihr und ihren Nachbaren Spalten; der vorher gelbe Dotter sieht in Folge dessen aus optischen Grünclen weiss aus, noch bevor das Fett und der Farbstoff extrahirt wurde. Geschrumpfter Dotter bekommt an Stelle seines homogenen Aussehens eine eigenthümliche, ich möchte sagen, sandige Beschaffenheit; er fällt leicht ab, was sich am übelsten bei der Bearbeitung der Aussenzone der Area vitellina bemerkbar macht. Quellung und Schrumpfung treten bei manchen Behandlungen in mehrfachem Wechsel ein, namentlich wenn man fixirt, mit Alcohol nachlärtet, mit Boraxcarmin färbt, in salzsäurehaltigem Alcohol auswäscht u. s. w. Die unregelmässigen Formen des Ectoderms in der Aussenzone der Area vitellina sind dasjenige Kunstproduct, welches sich an schwersten vermeiden lässt. Es sei auch auf die sogenannte "mesodermfreie Stelle“ vor dem Kopf des Hühnchens in der Area pellucida aufmerksam gemacht; man kann oft bemerken, wie an dieser ausserordentlich dünnen Stelle, selbst wenn anfänglich die Keimhaut tadellos fixirt war, doch noch durch den Alcohol eine Verbiegung hervorgerufen wird, und zwar dadurch, dass der in den Zellen der Area opaca eingeschlossene Dotter eine concentrische Schrumpfung gegen die Area pellucida hin ausführt. An den Epithelzellen des Dottersackes findet man in Folge des Aufquellens des Inhaltes öfters Einrisse, so dass das Urtheil erschwert wird, ob eine solche Zelle abgeschlossen war, oder nicht. Sogar an aufgekilebten Schnitten ist man noch nicht sicher. Im Allgemeinen darf man, wie ich glaube, behaupten, dass in mikroskopischen Schnitten sämmtliche Dotterkugeln sowie die aus ihnen hervorgegangenen, in Zellen eingeschlossenen eiweissartigen Kugehn geschrumpft sind, d. h. einen kleineren Raum als im frischen $\mathrm{Zu}$ stande einnehmen.

2. Lösung tritt an dem eiweissartigen Körper, nachılem die Priiparate fixirt sind, nicht mehr ein bei denjenigen Methoden, die 
wir behufs der Herstellung mikroskopischer l'räparate anwenden. Dagegen tritt sie an dem fettartigen körper ein; derselbe wird ja, wie bekannt, bei der chemischen V'erarbeitung des Dotters durch Acther aufgenommen. In welchem Grade er bei den für das mikroskopische Studium verwendeten Methoden ausgezogen wird, ist gänzlich unbekannt; ebenso, ob dabei eine chemische Umwandlung desselben stattfindet. Jedesfalls aber wird er nicht unter allen Umständen gänzlich extrahirt, und gerade diese Unsicherheit macht es so schwierig, bei der Deutung der mikroskopischen Bilder über den fettartigen Körper auszasagen. Osmiumsäure würde sehr lange einwirken müssen, um ihn durchzufixiren, und macht dann die Präparate bis zur Unkenntlichkeit schwarz. Während von dem fettartigen Körper in den Dotterkugeln und in den jüngeren Stufen des Dottersackepithels sich an den Präparaten Bestandtheile erhalten, so wird dasjenige Fett, welches in den ausgebildeten Epithelzellen sowie im Dotter der späteren Brüttage vorhanden ist, durch die Behandlung mit Alcohol, Aether und ätherischen Oelen gänzlich ausgezogen. Im frischen Zustande sind die Epithelzellen mit diesem gelben Fett so stark gefüllt, dass die ganze Dottersackwand intensiv gelb gefärbt crscheint; an den Lackpräparaten dagegen, gleichviel ob dieselben aus Paraffin oder aus Celloidin gewonnen sind, bemerkt man von diesen Fettmassen Nichts; an ihrer Stelle entstehen nur leere Räume, runde Vacuolen von verschiedener Grösse, die nur durch ihre Gestalt auf die Fettropfen schliessen lassen, die hier lagen. Es lässt sich aus diesem verschiedenen Verhalten der Schluss ziehen, oder wenigstens lässt sich die Vermuthung aufstellen, dass diese Substanz in den Epithelzellen aus der zweiten Hälfte der Brützeit nicht dem ursprünglichen fettartigen Körper des Dotters gleicht, sondern wirkliches Fett ist.

Fällung kommt gleichfalls zur Beobachtung, namentlich in dem feinkörnigen Gerinnsel des perilecithalen Spaltes und der subgerminalen Höhle. Aber auch innerhalb des Epithels mögen manche der feinen Körnchen, die man an den Präparaten sieht, Niederschläge einer im frischen Zustande gelösten Substanz sein. Diese Niederschläge haben eine kritische Bedeutung bei der Frage nach dem intravitellinen Protoplasma, und wer es mit wissenschaftlichen Beweisen ernst nimmt, wird sich wohl hüten, jede Ansammlung feiner Körnchen in einem Präparate für Protoplasma zu erklären.

3. Die Wirkung der Oberflächenberührung, des Contactes, tritt bei dem fettartigen Körper hervor und äussert sich in doppelter Weise: in der Berührung mit Flüssigkeiten und in der Berührung mit festen Körpern, z.u denen auch die Dotterkugeln selbst zu rechnen sind, nachdem sie fixirt wurden. In den oben mitgetheilten Beobach- 
tungen sind die Erscheinungen geschildert, welche durch den Contact zu Stande kommen. Es sei hier aoch besonders bemerkt, dass oft aus dem Innern von Eiern oder Eiabschnitten, wenn dieselben längere Zeit in stärkerem oder schwächeren oder salzsäurehaltigen Alcohol gelegen haben, grössere (bis stecknadelkopfgrosse) ölige Tropfen hervortreten, die nicht schwimmen, sondern schwer zu Boden fallen. An Reptilien-Eiern beobachtet man das noch öfter wie an Togeleiern. Hier ist eine fettartige Substanz aus zahlreichen Dotterkugeln ausgetrieben - nicht gelöst - worden, und hat sich zu diesen grossen Tropfen vereinigt. Zuweilen findet man entweder zwischen den Dotterkugeln oder innerhalb von solehen, oder auch in eiweissartigen Kugeln, die ihrerseits wieder in Zellen stecken, eigenthümliche unregelmässige oder myelinartige Formen des fettartigen Körpers. Hier muss man annehmen, dass der fettartige Körper zunächst durch Contact mit den Reagentien aus seinem ursprünglichen Zustande gebracht, dann aber doch noeh fixirt worden ist.

Nach diesen Vorbemerkungen gehe ich nun auf die oben (S. 239) gestellten drei Fragen ein.

I. Giebt es eine Zwischenflüssigkeit im gelben Dotter? צ. Kölliker behauptet eine solche (Lehrbuch S. 46) und macht sogar noch die genauere Angabe, dass dieselbe in den äusseren Lagen in geringer, in den innersten Lagen oft in reiehlicherer Menge vorkommen. Ich habe nicht die Ueberzeugung gewinnen können, dass in den äusseren Schiehten des gelben Dotters eine solche Zwischenflüssigkeit vorhanden sei, obwohl mir das Vorhandensein einer solehen a priori sehr einleuehtend sein würde, da sonst schwer zu verstehen ist, wodurch die einzelnen Dotterkugeln am Zusammenfliessen gehindert werden. (Von einer zarten Hülle und dichteren Rindenschicht habe ich mich auch nicht überführen können). Solche Verhältnisse können nur an Dottern festgestellt werden, welche rorher gehärtet waren; entweder geschieht dies durch Alcohol, mit oder ohne voraufgegangene Fixirung durch eine andere Flüssigkeit, oder durch Koehen, wie wahrscheinlich bei der Untersuchung von Kölliker. Wie sehr die Dotterkugeln beim Erhärten in Alcohol schrumpfen, hat sich durch die Untersuchungen, über die ich eben berichtete, grezeigt; aber auch, wenn man die Eier kocht und dann Schnitte vom 1)otter anfertigt, erhält man unsichere Ergebnisse; denn die Dotterkugeln können sich im Schnitt sehr leicht lockern. Ich habe imner gefunden, dass wenn man den Dotter einer solchen Behandlung unterwirft, welche die Dotterkugeln sehr schnell zum Erstarren bringt, so dass sic sich bei ihrer Verkleinerung nicht mehr abrunden können, also wenn man durch heissen Alcohol, heisses Sublimat oder Kuchen fixirt, dass damn die Dotterkugeln nicht nur eckig fixirt 
sind, sondern grubig, zaclig, mit Spitzen, so dass nicht nur die Flächen in der allergenauesten Weise den Flächen der anstossenden Kugehn entsprechen, sondern auch noch die Ecken und Spitzen so vollionmen in Spalten zwischen benachbarte Kugch hineinpassen, dass die Tendenz zur Abrundung, welche sich doch an diesen Elementen als an weichen lörpern verrathen müsste, nirgends zur Geltung gelangen kann. An Eiabschnitten, welche mit Reagentien behandelt sind, findet man aber oft diese Spalten trotz der eckigen Begrenzung der Kugeln sehr weit. Von dieser Erfahrung aus muss ich mich gegen die Behauptung von Kölliker aussprechen (Lehrbuch S. 50), class die Zwischenflüssigkeit „unter Umständen in der Nähe des Blastodarms auch in grösserer Menge sich findet". Ich glaube diese Behauptung so erklären zu können, dass v. Kölliker seine Ansichten über die peripherischen Theile des gelben Dotters von Präparaten entnommen hat, an denen die Keimscheibe mit einer Partie Dotter in Zusammenhange fixirt war, während seine Anschauung über die centralen Theile des gelben Dotters von Eiern genommen ist, welche gekocht und deren Dotter dann getrocknet war. Beide Methoden sind jedoch nicht einwandfrei.

Ich habe die Frage nach der Zwischenflüssigkeit hier nur aufgenommen, weil sie für den Zusammenhang meiner Arbeit von Bedeutung ist. Es tritt nämlich während der frühesten Stadien der Entwicklung des Dottersackepithels Zwischenflüssigkeit auf, und daher ist es von kritischer Bedeutung, zu wissen, ob und in welchem Maasse schon vorher an der betreffenden Stelle Flüssigkeit vorhanden war. Aus der Weite der Spalten dürfen wir leider, wie ausgeführt wurde, keine bestimmten Schlüsse ziehen. Trir müssen uns begnügen, hervorzuheben, dass in der Aussenzone der Area vitellina die Dotterkugeln an erhärteten Objecten nicht eckig, sondern kuglig erscheinen, dass also daraus auf eine Zwischenflüssigkeit geschlossen werden darf, deren Menge wir aber nicht kcnnen. Diese Flüssigkeit bedingt Spalten, und das Torhandensein der mit Flüssigkeit gefüllten Spalten verräth sich makroskopisch durch die Farbe, wie weiter unten noch einmal erwähnt werclen wird.

2. Giebt es Protoplasma in Dotter? - Ich stelle mich dieser Frage gegenüber so: ich glaube an die Anwesenheit ron Protoplasma im Dotter, wenn entweder dasselbe an Schnitten gezeigt wircl, oder wenn Verhältnisse nachgewiesen werden, welche auf das Vorhandensein von Protoplasma schliessen lassen. Ich betonc ausdrücklich dieses entweder - oder. Ich verlange nicht unbedingt, das Protoplasma zu sehen, um an dasselbe zu glauben. Dazu bestimmen mich Eirfahrungen, welche von anderen und von mir selbst an anderen Eiern gemacht sind. Ich führe ror Allem die Eier von 
Salamandra an, um von anderen zu schweigen. Bei Salamandra ist es in späten Stadien, wo schon der ganze oder fast der ganze Dotterraum von grossen Zellen eingenommen wird, unmöglich, das Protoplasma dieser Zellen zu erkennen. Vom Huhn selbst bietet sich ein sehr gutes Beispiel in den rielbesprochenen Zellen, die im Innern der subgerminalen Höhle angetroffen werden. Obwohl dies unzweifelhaft Zellen sind, so dürfte es nur in ganz seltenen Fällen möglich sein, etwas von ihrem Protoplasma zu erkennen. Ich gebe also den Boden frei für den indirekten Beweis, - aber nicht für die willkürliche Speculation. Zum Beweise genügt es also nicht, darauf hinzuweisen, dass kleine dotterarme Eier, wie die der Säugethiere und einiger Amphibien, in ihrer ganzen Ausdehnung ron Protoplasma durchzogen sind, oder dass das junge, wachsende Ei der Vögel sich ebenso verhielt; denn es ist ja möglich, dass während des Reifens oder nach erlangter Reife sich das Protoplasma aus dem Nahrungsdotter herausgezogen hat. In diesem Zusammenhange sei auf das Knochenfischei und insbesondere auf die Mittheilung ron M. r. Kowalewski (18. S. 435) hingewiesen. Der genannte Forscher beobachtete beim Goldfisch, dass in den reifen Ei, wenn es in Wasser kommt, das bis dahin gleichmässig vertheilte Protoplasma sich nach einem Pole des Eies sammelt und hier in Gestalt des Keimhügels rorspringt. K. bezeichnet diese Bewegung als ein „Strömen"; und es scheint mir besonders der Betonung werth, dass der Keim an sich die aktive Kraft besitzt, einen Hügel zu bilden, also aus der Kugelform herauszutreten, der er sich nach einfach physikalischen Bedingungen einfügen müsste. In diesem Falle ist allerdings die Trennung des "Bildungsdotters" ron dem "Nahrungsdotter" keine vollständige, da noch netzförmig verbundene Protoplasmafäden in den Dotter hineinreichen, aber der Weg der Trennung ist doch betreten und sehr weit zurückgelegt, und es steht Nichts im. Wege, sich vorzustellen, dass diese Trennung zu einer rollständigen werden könne. Beim Huhn wird nun der grösste Theil des Dotters schon früh durch die in den perilecithalen Spalt ergossene Flüssigkeit ron der Keimhaut abgetrennt, und Nichts spricht dafür, dass in diesen centralen Abschnitten des Dotters wirlsames Protoplasma vorhanden sei. Aber auch in der Dotterrinde sind wir nicht gezwungen, solches anzuerkennen und es im Sinne ron Waldeyer (31. S. 15) zum Sitze einer längere Zeit fortwirkenden „secundären Furchung" zu machen. Wir dürfen und müssen vielmehr, unbeeinflusst durch apriorische Betrachtungen, in's Auge fassen, ob nicht auf andere Weise die peripherische Ausbreitung des Entoblasten denn um diesen und nicht um den "Parablasten" wird sich unsere Intersuchung drehen müssen - zu Stande kommen, 
Ob über den Rand der Keimhaut hinaus cine dünne Protoplasmarincle vor der Bebrütung zwischen Dotterhat und Dotter gelegen sei, diese Frage hestimmt zu entscheiden, halte ich für sehr schwer; jechenfalls darf man auch hier nicht verallgemeinern, und man darf z. B. nicht die Verhälnisse des Inseliteneies, an welchem, wie ich an Präparaten des Herrn Heider gesehen habe, die Protoplasmarinde überaus deutlich ist, auf die Tögel übertragen. Immerhin möchte ich nicht unterlassen, darauf aufmerksam zu machen, dass unmittelbar unter der Dotterhaut beim Ei des Huhnes und der Ente eine Schicht sehr kleiner Dotterelemente gelegen ist.

Wenn ich nun auch, wie Kölliker, der Meinung bin, oder es doch für das Wahrscheinlichere halte, dass sich im Hühnerei das Protoplasma im Beginn der Bebrütung auf einen kleinen Bezirk.am proximalen Pole beschränkt, so glaube ich doch nicht, dass dieser Bezirk oder die "Keimscheibe" scharf (etwa durch eine Membran) abgegrenzt sei gegen den Dotter (weissen Dotter). Ich bin also der Meinung, dass es unmöglich ist, an dem frischgelegten Ei und an dem Eierstocksei des Huhnes genau anzugeben, wie weit das Protoplasma in den weissen Dotter hinabreicht, und ich bin vollkommen überzeugt, dass auch in der Bodenschicht der subgerminalen Höhle und in dem Rande derselben sich eine Furchung abspielt, die man wolll als „Dotterfurchung" bezeichnen kann. Hierzu bestimmen mich die Angaben verschiedener Beobachter, unter denen sich zuerst Götte (9. S. I48) deutlich ausgesprochen hat, und unter denen vor allem Duval (7) die Verhältnisse klar und nach ihrer topographischen Vertheilung dargestellt hat; es bestimmen mich ebenso die Analogien mit der Entwicklung von Lacerta und Ichthyophis, worüber wir Mittheilungen von Strahl (26. S. 289) sowie von P. und F. Sarasin (24. S. I 8 u. 9S) besitzen. Bei Lacerta ist dieser Furchungsvorgang über den ganzen Boden der subgerminalen Höhle ausgebreitet und führt nicht zu unwesentlichen und vorübergehenden Bildungen, sondern zu einer zusammenhängenden Schicht von "Dotterzellen", aus denen späterhin Dottersackepithelzellen werden; bei Ichthyophis aber ist er noch weiter ausgedehnt, indem er allmählich den ganzen Dotter, vielleicht mit Ausnahme einer kleinen centralen Partie crgreift. Beim Huhne ist jedoch, wie ich glaube, dieser Vorgang der Dottcrfurchung zeitlich und räumlich sehr beschränkt, und die peripherische W Weiterbildung des ,Dotterentoblasten " wird durch einen anderen Vorgang vermittelt, der weiter unten geschildert werden soll; ein Vorgang, bei dem es sich, wie ich glaube, nicht mehr um Furchung einer schon vorhandenen Protoplasmamasse, sonclern um ein Linwachsen von Zellen in den Dotter handelt. 
3. Veränderungen des Dotters während der Bebrütung und nach dem Ausschlüpfen. - Die V'eränderungen des Dotters müssen wir berücksichtigen, weil nur dadurch die Aufgabe klar wird, welche die Epithelzellen zu erfüllen haben. Eine V'orbemerhung ist zu machen: häufig wird durch die Einwirliung der Reagentien ein Theil der Dotterkugeln aufgelöst, und die dadurch entstehende Masse breitet sich in den Spalten zwischen den übrigen Dotterkugehn aus; das legt uns eine gewisse Zurückhaltung in der V'erwerthung der Befunde auf. Die erste auffallende Erscheinung nun ist die, dass Fliissiglieit zwischen Dotter und Keimhaut in den perilecithalen Spalt ergossen wird; dünne wässrige Flüssigkeit, durch beigemischte Dotterbestandtheile milchig getrübt. Die Menge derselben ist so bedeutend, dass allmählich gegen die Mitte der Brützeit der Dotterraum fast das Doppelte seines ursprünglichen Volums belommt. Wrahrscheinlich hat diese Flüssigkeit die Bedeutung, die Dotterkugehn aufzulösen; ob ihr Fermente beigemischt sind, durch welche auch eine Umsetzung hervorgerufen wird, muss dahingestellt bleiben. Es liegt nun nahe, zu vermuthen, dass auch in der zweiten Hälfte der Brützeit, wenn unter ciner gesteigerten Resorptionsthätigkeit die Flüssigkeit des perilecithalen Spaltes, wieder verschwunden ist und der Dotter sich in zunehmender Eindickung befinder, trotzdem noch Flüssigkeit in capillarer Schicht ergossen wird, um die Auflösung der Dotterkugeln fortzusetzen. Jedesfalls nimmt die Zahl der letzteren stetig ab, und zur Zeit des Ausschlüpfens und nach derselben findet man an der Stelle des Dotters eine gleichmässige, in Reagentien körnige gerinnende Masse mit zwei Arten noch zu erwähnender Einschlüsse. Um diese Zeit hat der Dotter eine zähe Consistenz, ctwa die einer Schmierseife, und der uneröffnete Dottersack fühlt sich in Folge dessen teigig an; auch behält derselbe jede ihm durch einen äusscren Druck ertheilte Form. Ein solcher Dottersack sinkt in Wasser schwerfällig zu Boden; der Dotter hat also ein hohes specifisches Gewicht. Schneidet man den Dottersack auf, so lässt sich der zähe Inhalt nur schwer von der Wand abspülen, unsomelir, da die später zu schildernden (s. S. 254) Blätter in den Dotter hineingepresst sind. Obwohl der Dotter starli abgenommen hat, so zeigen doch Schnitte, class seine Menge am ersten Tage nach dem Ausschliipfen inmer noch das VTielfache des Gewcbes beträgt, und dass noch am vierten Tage sich reichlich Dotter in den Spalten zwischen den Blättern vorfindet. Zugleich nit der Eindickung nimmt der 1) Otter cinc dunklere Farbe an; ich habe notirt, dass an dritten large nach den Ausschlüpfen der spärliche schmierige Dotter stark durchscheinend, zwischen orange und olivenfarben war, während die Wand sellsst dunkel orange gefärbt erschien; dass am vierten Tage 
beim Anschneiden des 1)ottersackes rlunkelgelbe ölige Tropfen austraten. Bei einem andern (kleineren) 1)ottersack des vierten Tages bemerkte man vor dem Aufschneiden im Innern einen $2 \mathrm{~mm}$ grossen clurchsichtigen, fettartig glänzenden Tropfen; bein Aufschneiden collabirte dieser Dottersack völlig, und es trat eine braungelbe, fast ölige Masse aus demselben hervor, welche bei der mikroskopischen Untersuchung sich durch hohes Lichtbrechungsvermögen auszeichnete. An Schnitten erhärteter Dottersäcke ist von dieser ölartigen Substanz, welche unter chemischer Umsetzung aus dem fettartigen Körper entstanden sein muss, nicht das Geringste zu sehen.

Yon den zwei Arten von Einschlüssen wird die eine gebildet durch körnige Kugeln von sehr verschiedener Grösse, welche zuweilen Vacuolen (wahrscheinlich Fetttropfen) einschliessen. Zwischen ihnen und der umgebenden Masse ist in der Regel ein Spalt vorhanden, woraus zu schliessen ist, dass diese Kugeln durch Alcoholwirkung geschrumpft sind. Man darf in ihnen ungelöste Reste von Dotterkugeln erblicken, nur ist auffallend, dass sie sich durch Hämatoxylin dunkler färben, als die umgebende Masse.

Die zweite Art der Einschlüsse besteht in eigenthümlichen krystallinischen oder concentrischen Concrementen. Diese Körper hat Courty (4. Taf. II, Fig. Io) gesehen, später hat sie Duval (6. p. 235) in den späteren Stadien der Bebrütung aufgefunden und zwar in den unteren Abschnitten des Dottersackes; er bildet sie in Fig. $36 \mathrm{ab}$, erklärt sie auf die Autorität von Dastre hin für Lecithin und findet, dass sie nach der Behandlung der Präparate mit Alcohol strahlig mit schwach concentrischer Zeichnung, nach Behandlung mit Säuren concentrisch geschichtet seien. Ich habe diese Körper in ungeheurer Menge in dem mit dem Nabel verbundenen, also distalen Abschnitt des Dottersackes eines im Ausschlüpfen begriffenen Hühnchens gefunden. Sie lagen hier dicht gedrängt, während der angrenzende Theil des Dottersackes von ihnen fast frei war. Der Theil des Schnittes, wo sie lagen, hatte schon makroskopisch (Lackpräparat) ein characteristisches Aussehen, nämlich bei auffallendem Lichte einen silberweissen Schimmer, den auch Duval hervorhebt; das Messer knirschte beim Schneiden und war nach Anfertigung der Schnitte stumpf. Man könnte daher cliese Gebilde als „Dottersand" bezcichnen, sowie man ja auch von Hirnsand spricht. Ich habe cliese Gebilde auch am 19. Tage angetroffen, jedoch reichlich erst in den Tagen vom Ausschlüpfen an, so am dritten bis vierten und am sechsten bis siebenten Tage, sie clagegen am fünften bis sechsten vermisst, was jedenfalls nur ein Zufall war. Die Orte ihres Torkommens sind verschieden: in den späteren Tagen funden sie sich in ganzen Dotter, am sechsten bis siebenten im Innern des Dottersaclies, z. Th. von 
Leucocyten oder auch ron Bindegewebe eingeschlossen, am ersten bis zweiten Tage habe ich sie merkwürdigerweise im Nabel getroffen, worüber an anderer Stelle näher berichtet werden soll. Was nun die Gestalt dieser Körper anlangt, so wircl man lebhaft an die Bemerkung erinnert, welche Sachs über das Inulin macht (23. p. 405). Ich finde diese Gebilde von ganz kleinen Körnchen an bis zu sehr bedeutender Grösse. In meinen Präparaten, welche sämmtlich mit Alcohol gehärtet, dann nach Boraxcarminfärbung nit salzsäurehaltigem Alcohol behandelt worden waren und dann lange in Alcohol gelegen hatten, überwiegt durchaus die concentrische Streifung; oft ist sie so fein und blass, class ein fast homogenes Aussehen entsteht, in anderen Fällen sind die einzelnen in einander steckenden Schalen durch starke Linien, ja durch Spalten geschieden; oft sind die äusseren Schalen durch das Messer zertrümmert. Radiäre und concentrische Zeichnung sind zuweilen gleich deutlich; in den seltensten Fällen tritt die radiäre Zeichnung allein hervor, und dann ist die äussere Begrenzung nicht glatt sondern buchtig. In Centrum dieser Sphärokrystalle steckt oft ein glänzendes Kügelchen, zuweilen ein zackiger Körper. Ganz auffallend ist es, class ich in Schnitten eines Dottersackes rom sechsten bis siebenten Tage ein vielfach hin und her gebogenes Band von der gleichen Beschaffenheit, also den Durchschnitt einer von der fraglichen Substanz gebildeten Platte, fand. Ueber den Ursprung vermag ich wenig auszusagen, ror Allem nicht, ob die Gebilde durch die Behandlung entstanden oder im frischen Zustande der Dottersäcke ausgeschieden waren. Das eine kann behauptet werden, dass die Bildungsstätte nicht Zellen, sondern der freie Dotter sind.

Ich schliesse nun noch einige Bemerkungen technischen lnhaltes an, erstens mit Rücksicht auf Reagentien und Herstellung der Schnitte, zweitens mit Rücksicht auf Auswahl des Nateriales, Orientirung und Schnittrichtung.

I. In Anbetracht der mannigfaltigen, durch den Dotter hauptsächlich bedingten Schwierigkeiten war ich zu einem vielfachen Wechsel der Methoden veranlasst. Ich fixirte mit Alcohol (heiss und kalt), Sublimat (heiss und kalt), Osmiumsäure, Osmiumgemischen, Chromessigsäure, Picrinschwefelsäure, Salpetersäure, Platinchloricl, Müller'scher Flüssigkeit; färbte mit Boraxcarmin, Alauncarmin, Alauncochenille, l'icrocarmin, Hämatoxylin nach Dela field, Böhmer, Ehrlich, Weigcrt, Saffranin, Saffranin mit Picrinsäure-Nachbehandlung, Saffranin und Hämatoxylin mit Picrinsäure-Nachbehandlung, Eosin, Argentum nitricum; bettete ein in Paraffin und Celloidin (Photoxylin); klebte nach verschiedenen Methoden auf und 
legte Serien an nach Obregia. Einiges sei über diese Methoden bemerkt: dass Alcohol eine Schrumpfung im Dotter erzeugt, ist schon bemerkt worden, ebenso, dass Chromessigsäure, Salpetersäure, Müller'sche Flüssigkeit Quellung hervorrufen. Salpetersäure erleichtert am meisten das Ablösen ron Keimscheiben, giebt aber keine scharfe Zeichnung; Chromsäure giebt sehr seharfe Zeichnung in Keimscheiben und Dottersäcken vom zweiten Tage an; Osmiumsäure ist, wie bekannt, wegen der Schwärzung des Dotters wenig verwendbar. Ton Färbungen ist Boraxcarmin für den fertigen Dottersack, sowie für Präparate des Nabels etc. am bequemsten zu verwenden; für letztere auch Hämatoxylin und Eosin; Saffranin oder Saffranin und Hämatoxylin init Picrinsäure-Naehbehandlung ist sehr gut verwerthbar für den Dottersack vom dritten bis zum zwölften Tage; Höllensteinlösung giebt ganz ausgezeichnete Flächenbilder des Dottersackepithels; für das Studium der Dotterzellen bin ich mit Alauncarmin in Schnittfärbung am besten gefahren.

2. Als ich meine frühere Arbeit über den Dottersack schrieb (Dissertation), beging ich den Fehler, zu kleine und nicht genügend orientirte Abschnitte der Keimhäute zu untersuchen. Dieser Fehler war damals fast allgemein und hatte den grossen Nachtheil im Gefolge, dass nicht nur der einzelne Beobachter oft Zufälliges beschrieb, was keine allgemeine Geltung beanspruchen konnte, sondern dass auch verschiedene Untersucher zu keiner Verständigung gelangten, weil ihren Beobachtungen nicht das gleiche Objekt zu Grunde lag. Heute befinden wir uns allgemein auf einem höheren Standpunkte. In dieser. Hinsicht verdienen die Arbeiten von Duval die höchste Anerkennung. Zwar war die Methode der topographischen Orientirung nicht neu, und besonders von $\mathrm{His}$ war sie schon ausgebildet; aber niemand hat sie mit soviel Geschick und Consequenz und mit so viel Erfolg angewendet wie Duval. Ich will jedoch bemerken, dass die histiologische Verarbeitung bei I) uval nicht auf der gleichen Höhe steht wie die topographische, wovon man im Folgenden einige Beispiele finden wird. Ich selbst habe mich bemüht, meiner Untersuchung die nöthige Breite in zeitlicher und räunlicher Beziehung zu geben; zeitlich, indem ich von dem unbebrüteten Ei bis zu dem Hühnchen am siebenten Tage nach dem Ausschlüpfen, räumlich, indem ich möglichst viele Stellen untersuehte und Schnitte bis zu $20 \mathrm{~mm}$ Länge durch die peripherischen Theile der Keimhaut machte. Keimscheiben untersuchte ich nur unter genauer Orientirung der Schnitte auf die vorher angelegten Flächenbilder. Eine Orientirung cler Keimscheiben unbebrüteter oder kurz bebrüteter İier machte ich anfänglich nach der Methode von Koller (17.), dann nach der von I) ural $(7 \cdot 1) .8)$. 
Der fertige Dottersack; seine Aufnahme in die Leibeshöhle; seine Rückbildung; Eiweisssack; Leber.

In der Ueberschrift dieses Kapitels sind verschiedene Gegenstände vereinigt. Das geschieht, weil zwischen ihnen gewisse Beziehungen theils topographischer, theils physiologischer Art bestehen. Vollte ich in der Aufzählung der in diesem Kapitel behandelten Fragen vollständig sein, so müsste ich auch noch den Bindegewebsring, die Nabelhaut, den Nabel, die Verbindung des Dottersackes mit dem Nabel und den Dottergang nennen.

1. Der fertige Dottersack. Um die Zeit, wo das Hühnchen sich anschickt, das Ei zu verlassen, befindet sich der Dottersack auf der Höhe seiner Entwicklung. Ich sage nicht, dass er um diese Zeit seine höchste. Entwicklung erst erreicht, aber wohl, dass er sie um diese Zeit hat. Wenn daher in dem Hertwig'schen Lehrbuche (III. Aufl. p. 185) gesagt wird: „Im zweiten Abschnitt (der Brützeit) treten hauptsächlich die regressiven Metamorphosen in den Vordergrund. Dieselben machen sich zunächst an Dottersacke geltend;" so ist das ein Irrthum, der auf Unkenntniss und zugleich auf einer unlogischen Folgerung beruht, nämlich auf der Folgerung, dass die Abnahme des Inhaltes eine regressive Metamorphose des Dottersackes selbst anzeige. In Wahrheit ist, so lange noch nemnenswerthe Reste freien Dotters vorhanden sind, der gewebliche Charakter des Dottersackes unverändert. Ja es kann sogar mit einigem Rechte umgekehrt behauptet werden, dass sich die Leistungen des Dottersackes in den letzten Tagen der Brützeit und in den ersten Tagen nach dem Ausschlüpfen steigern, denn die Aufgabe des Dottersackepithels ist anscheinend eine schwierigere, indem sich dasselbe dem zähen, immer mehr eingedickten Dotter gegenibbersieht; nicht, wie in der ersten Hälfte der Brützeit, den durch die Flüssigkeit des perilecithalen Spaltes stark verdünnten Dotterbestandtheilen.

L'm den Dottersack vom Ende der Brützeit genauer kennen zu lernen, muss man ihn aufschneiden, abspülen und ausbreiten. Dann bemerkt man bei der Betrachtung mit blossem Auge und mit der Lupe dreierlei:

I. Die Wand ist ron unverminderter Ausclehnung, so dass sie im Stande wäre, fast eben soviel Dotter zu unfassen, als während der Zeit der grössten Dottermenge vorhanden war; die Länge des Meridians, d. h. der Abstand rom proximalen bis zum distalen Pole, beträgt etwas über $40 \mathrm{~mm}$.

2. Die Mand ist von aussen betrachtet vollkommen glatt, ohne falten. Es ergiebt sich daraus, dass die tiefen Einbiegungen, die man an dem uncröffneten Dottersacke um diese Zeit benerkt, nicht auf einer Structureigenthümlichkeit sciner Wand, sondern auf äusse- 
ren Einwirkungen beruhen. Man darf cliese Einbiegungen nicht ausschliesslich, wie es in cler Litteratur öfters geschehen ist, auf die anliegenden Allantois-Gefässe zurückführen; diese machen sogar of nur ganz seichte Eindrücke. Ich habe diese Furchen in einer Reihe von Fällen genauer betrachtet und dabei gefunden, dass sie zeitlich und individuell sehr stark abändern und durch verschiedenartige Ursachen bedingt sind: Die eigenthümliche Consistenz des Dottersackes im reifen Hühnchen (s. p. 248) und die räumlichen Verhältnisse machen diese Einbiegungen begreiflich. Der Dottersack mit seinem eingedickten, zähen, teigartigen Inhalt verhält sịch wie eine knetbare Masse. Jede Form, die man ihm giebt, bewahrt er, bis eine andere Gewalt ihn in eine andere Form bringt. Vor der Aufnahme in die Leibeshöhle ist es der Druck des Thieres selbst und die Pressung durch die

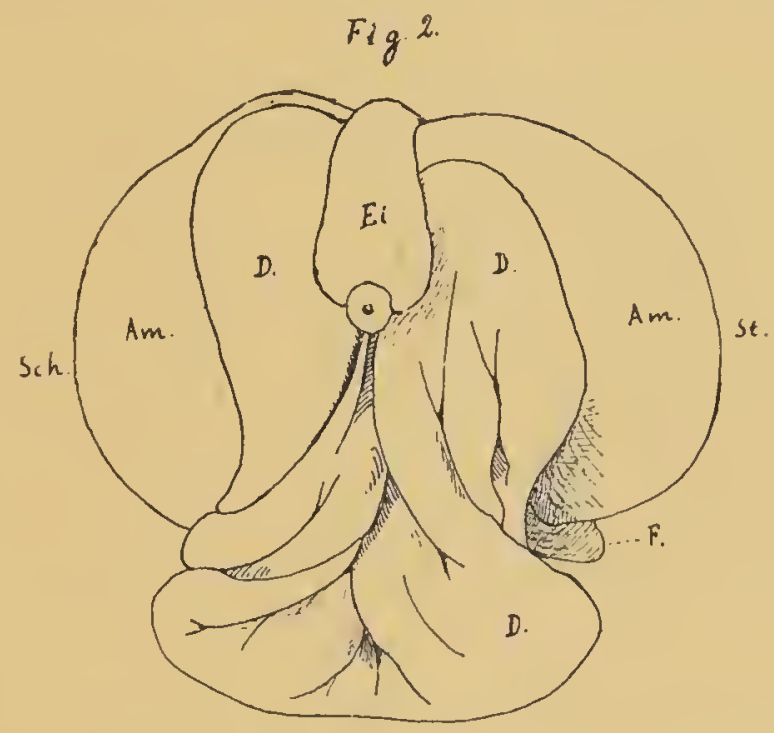

Nabelhaut (s. p. 258), nach der Aufnahme der Druck aller anliegenden Theile, Eingeweide und Gefässe, was seine Form bestimmt. Die Blätter seiner Innenwand werden dabei in den zähen Inhalt hineingepresst und von diesem festgehalten. Ein Beispiel führe ich in Fig. 2 vor, welche den Inhalt eines sechszehn Tage gebrüteten Eies wiedergiebt, von dem auch Fig. 6 u. 7 genommen sind. Das Huhn sellost ist nicht sichtbar, da es im Amnios (Am.) eingeschlossen ist; Sch. ist die Gegend des Nackens oberhalb des Scheitels, St. die Gegend des Rückens oberhalb des Steisses, F. die linke Ferse. Das Hühnchen wird also von der linken Seite gesehen. Die Allantois ist entfernt, nicht nur das äussere sondern auch clas innere Blatt. Der dadurch befreite Dottersack (D.) ist nur so weit abwärts gezogen und auseinandergelegt, dass man die tiefen Faltungen erblicken kann, welche er dadurch erlitten hat, dass er zwischen das vordere und 
hintere Körperende eingekeilt und von dem inneren Blatte der Allantois zusammengepresst war. Die Bezeichnung Ei (Eiweisssack) wird weiter unten ihre Erlilärung finden. Es sei übrigens bemerkt, dass möglicherweise bei Blut- bez. Brutwärnıe der zähe Dotter etwas weicher und der Dottersack daher leichter knetbar ist als bei Zimmertemperatur.

3. An der Innenseite der Wand erheben sich eigenthümlich ge. staltete Blätter, welche um die Mitte der Brützeit zwar als Wülste angelegt waren, sich jedoch erst in der zweiten Hälfte derselben so eigenartig entwickelten. Zu einer Vorstellung dieser Blätter möge man auf folgende Weise gelangen: Man stelle sich die Gefässe des Dottersackes vor, wie sie vom proximalen zum distalen Pole verlaufen, also in radiärer oder mericlionaler Richtung; man stelle sich ror, dass ein Theil der Gefässe (die Venen) von der Wand ab in's Innere rückt und dabei die Wand zu Blättern auszieht, ebenso wie der in's Innere der Bauchhöhle hineinrückende Darmkanal das Mesenterium nach sich zieht. Diese Blätter sind am Ende cler Brützeit bis zu $4 \mathrm{~mm}$ hoch. Man stelle sich drittens vor, dass diese in's Innere hineinrückenden Gefässe sich unter Längenzunahme stark schlängeln, so dass auch dic Blätter, namentlich an ihren freien Rändern, hinund hergebogen werden. Ferner: so wie die Gefässe dichotomisch unter spitzen Winkeln getheilt sind, müssen auch die Blätter gespalten sein. Und endlich stelle man sich vor, dass alle diese Blätter nicht solide, sondern durchlöchert sind, und zwar durchbohrt von so zahlreichen feinen Oeffnungen, dass an die Stelle jedes einzelnen Blattes ein Netz oder Gitter tritt, welches aus runden Fäden oder Balken gebildet ist. Auch über die freien Ränder der Gitter, d. h. über die Gegend der Venen, springen noch Schlingen wie Maschen vor. Es entsteht dadurch ein Gebilde von höchster Zierlichkeit, und es entsteht eine Oberflächenvergrösserung, die nicht reicher gedacht werden kann. Man erhält davon eine lebhafte Empfindung, wenn man den Dottersack eines zum Ausschlüpfen bereiten Hühnchens aufschneidet: überall trifft die Scheere auf die in den zähen Dotter hineingepressten und in ihm festgehaltenen Blätter oder Gitter, und indem man die Wand durchtrennt, verletzt man schon Blätter der gegenüberliegenden Scite. Der Dotterraum ist dadurch in eine unendliche Zahl von feinen Buchten und Spalten zerlegt, und clas resorbirende Epithel in die nächste Beziehung zu dem Inhalte gesetzt.

Ich habe versucht, in Figur 25 der Tafel XIII eine Anschauung dieser Verhältnisse zu gehen. Es ist ein Stück von dem Dottersack einer im Ausschlüpfen begriffenen Ente, zweimal vergrössert. Auf der rechten Seite der Figur sieht man die Blätter umgelegt, also von der Fläche, und man blickt durch all die feinen Löcher hindurch; in 
der Mitte der Figur sieht man die Blätter mehr von den Kanten; ausserdem treten die stark gewundenen, in den Dotter hineinragenden $V^{\top}$ enen und die dünneren glatter verlaufenden, in der Wand gelcgenen Arterien hervor. Die Abbildung ist mit grosser Sorgfalt und Mühe durch Herrn Eyrich angefertigt. Der Beschauer. wird anfänglich einen wenig plastischen Eindruck erhalten; er kann denselben aber stcigcrn, wenn er den Blick einige Minuten auf der Figur verweilen lïsst, indem er diese aus einer gewissen Entfernung betrachtet. Es bleibt aber auch so eine gewisse Verworrenheit in dem Bilde. Doch diese ist dem Objecte eigen; das letztere ist eben zu verwickelt, zu reich gestaltet, um ohne wcitere Zerkleinerung ganz verständlich zu sein. Ich habe aber gewünscht, eine Abbildung wie die vorliegende in die Litteratur zu bringen, damit man den ganzen Reichthum der Bildung vor Augen habe. Durch eine weitere Figur (Taf. X Fig. 3) welche ein einzelnes Blatt oder Gitter, und zwar das vom Epithel befrecite bindegewebige Gerüst desselben, zur Anschauung bringt, wirl die geschilderte Abbildung wünschenswerthe Ergänzung finden.

Es ist hier der Ort, etwas über die sog. Vasa lutea von Haller zu bemerken. Die Vasa lutea sind keine Vasa, sondern es sind Wülste, die allerdings in ihrer Form durch die Gefässe, insbesondere durch die Venen bedingt sind. Der Durchschnitt belehrt uns aber, 'dass in diesen Wülsten nur die Achse von Gefässen eingenommen ist, und dass der grössere Theil der Dicke durch das hohe einschichtige Epithel gebildet wird. Auch sind die Gefässe, bezw. der Inhalt derselben, nicht gelb, sondern roth, aber das mit gelbem Fett dicht angefüllte Epithel, obwohl es nur einschichtig ist, lässt nicht das mindeste Licht hindurchfallen, so dass das im Inncre gelegene rothe Blut keinen Einfluss auf die Färbung gewinnen kann. Das wird rollkommen deutlich, wenn man die in der Wand gelegenen Gefässe das eine Mal von der inneren, das andere Mal von der äusseren Seite her betrachtet. Auf der Innenseite sind sie gelb, sind „Vasa lutea", auf der Aussenseitc dagegen, wo die Bekleidung mit Epithel fehlt, sind sie roth, wie andere Gefässe auch. Wie es scheint, hat diese vollkommene Verdeckung der Blutfarbe durch das Dottergelb Pander getäuscht und zu dem eigenthümlichen Satze gebracht (20. p. 16): "gegen den fünfzehnten Tag hin scheinen die Gefässe der Keimhaut überhaupt abzusterben". - C. E. v. Baer (2. p. 107) sagt schon ganz klar und richtig: „das gelbe Aussehen leite ich nur vom Ucherzuge her".

Die geschilderten Blätter oder Gitter sind am höchsten am Aequator, gegen den proximalen und distalen Pol hin werden sie niedriger. Die Arterien liegen nicht in den Gittern sondern in der 
Wand, theils in den Basen der Blätter, theils zwischen zwei der letzteren.

Die Bedeutung dieser hochentwickelten Einrichtung wircl man erst. voll ermessen, wenn man sich das Gefässnetz der Gitter vorstellt: in jedem Balken des Gitterwerks liegt ein Gefäss, und es besteht also ein Geflecht von Capillaren, welches ebenso reich ist, wie das Netz. der Gitterfäden selbst. Das Gefäss liegt jedesmal in der Achse und ist ron dem hohen einschichtigen Epithel bekleidet.

Ich will nun das Gesagte dadurch ergänzen, dass ich drei Abbildungen vorführe, welche die Blätter auf einer früheren Stufe ihrer Entwicklung darstellen; alle drei gehören zu cinem Dottersack vom zwölften Tage, welcher mit Höllensteinlösung behandelt war, so dass auch die Zellengrenzen deutlich sinct, was auf den beiden Figuren der Tafel XIV sehr deutlich, auf der Figur 26 der Tafel XIII weniger scharf hervortritt. Die letztere giebt ein Uebersichtsbild über ein grösseres Stück des Dottersackes bei 5,5 facher Vergrösserung; Fig. 28 giebt stärker vergrössert eine Stelle desselben Präparates, welche man leicht in der Nähe des linken Randes der Fig. 26 in Verbindung mit der dicken Vene auffinden wird; Fig. 27 ist ron einer anderen Stelle desselben Dottersackes genommen und stellt ein abgeschnittenes Blatt vor, an welchem links der in der Basis gelegene Arterienwulst, rechts der an der freien Kante gelegene Venenwulst sichtbar ist; $z$ wischen beiden verbindende Balken. In Fig. 28 ist ein solches, sich über die Fläche der Wand erhebendes Blatt halb von der Kante, halb von der Fläche sichtbar, in der Basis desselben schimmert die Arterie deutlich durch die bekleidenden Zellen hindurch. Fig. 26 zeigt diese Verhältnisse in einem grösseren Reichthum, und man wird sich leicht von der z. Th, ausserordentlich starken Biegung der V'enenwülste überzeugen, ebenso wie man auch in der Wand die gerade verlaufenden Arterien auffinden wird; es sei noch besonders darauf aufmerksam gemacht, dass dort, wo die seitlichen V'enenwülste in das Niveau der Wand eintreten, sich häufig in der Fortsetzung derselben perlschnurartig aufgereihte Erhebungen finden. Fig. 27 u. 28 geben einen deutlichen Begriff von dem Grade der Durchlöcherung der Blätter, wie er um diese Zeit besteht. Derselbe ist nicht entfernt zu vergleichen mit dem $\mathrm{Zu}$ stancle, der vorher vom Ende der Brützeit geschildert wurde, und man wird zugeben, das von einer regressiven Metamorphose des Dottersackes während der zweiten Hälfte der Brützeit nicht gesprochen werden kann.

Die geschilderten, so auffallenden Blätter konnten natürlich früheren Beobachtern nicht gänzlich unbeliannt bleiben. Ausser Haller, dessen Erinnerung sich in den Vasa lutea erhalten hat, sei hier 
Pander (20.) genannt, welcher in lig. 6, 7, 8 seiner zehnten Tafel Abbiklungen licfert. v. Bacr (2.) spricht von den libätern auf S. 123. $\Lambda \mathrm{m}$ ausführlichsten sind die Mitheilungen von Courty (4.), in dessen Arbeit man die Sciten 16, 17, 19, 21, 23, 24, sowic die Figg. 1, 2, 4 cler Taf. II, Figg. 1, 2, 6, 10, 11 der 'Taf. III nachsehen mögec.

2. Aufnahme des Dottersackes in die Bauchhöhle. Bevor das Hühnchen das Ei verlässt, hat es den Dottersack in dic Bauchhöhle aufgenommen, und es tritt in die Welt ein mit einem erheblichem Vorrath von Nahrungsmaterial. Diese Thatsache ist so auffïllig, dass sie der Beobachtung nicht entgehen konnte, und jede Bäuerin, die einen Hühnerhof hält, weiss davon. Es hat sich claher auch eine Erinnerung an diese Thatsache in unscren Lehrbüchern erhalten, wenn aueh in abgeblasster und äusserst schematisirter Form.

Bei ciner Ente, die am Aussehlüpfen war, von $4^{6} \mathrm{~g}$ Körperge. wicht, I, I g Lebergewieht, betrug das Gewieht des Dottersackes $6 \mathrm{~g}$. Es wurde schon früher erwähñt, dass zwar der Dotter um diese Zeit an Masse abgenommen hat, der Dottersack aber noch auf der Höhe seiner Entwieklung steht.

Die Einbringung einer so bedeutenclen Masse in die Leibeshöhle, dureh den vorher engen Nabel, ist keine leichte Aufgabe; und die Schwierigkeit wird durch die früher erwähnte teigige Beschaffenheit des Dottersackes gesteigert. Wenn die Thiere, wie es beim Brüten im Kasten sehr oft geschieht, um diese Zeit absterben, so findet man den Dottersack nur zum Theil in der Leibeshöhle, der Rest ragt noeh naeh aussen hervor; zum Beweise, dass bei dem schon lebenssehwachen Thiere sich nicht mehr die Fähigkeit einer Líraftentfaltung fand, wie sie diese schwierige Aufgabe forclerte.

Wo aber sind die Kräfte, die diese Aufgabe vollbringen? In der Regel heisst es, der Dottersack werde dureh den Zug des Dotterganges an den Darm heran und in die Leibeshöhle hineingezogen. Ieh weiss nicht, wer diese Anschauung aufgebraeht hat; wohl aber muss iel mich verwundern, class eine Behauptung so oft hat wiederholt werden können, für die es nieht nur keinen Beweis, sondern auch nicht die mincleste Wahrscheinliehkeit giebt. Der Dottergang sitzt am Darm, der Darm aber hängt lose am Mesenterium; es würcle also dem Dottergange, selbst wenn er sieh auf eine Länge von Null verkïrzen könnte, gänzlieh an einem Stützpunkte fehlen, um cinen so schwerfälligen körper zu bewältigen. Eher könnte man umgekehrt auf die Thatsache hinweisen, dass noch bis zum neunzehnten Tage das 1)armstück, von welehem der Dottergang ausgeht, aus dem Lecibcsnabel hervorlä̈ngt, und man könnte diese Erscheinung so deu- 
ten, class der grosse Dottersack mit seiner trägen Masse semerseits vermittelst des Dotterganges einen Zug auf den durch das Mesenterium lose befestigten Darm ausübt. Auch betrachte man nur ein Hühnchen, welches socben oder seit melheren Stunden das Ei verlassen hat, oder welches ummittelbar vor dem Ausschlüpfen ist. Die beistehenden beiden Figuren sind geeignet, dasselbe anschaulich zu machen. In der ersten der beiden Figuren sieht man das zum Aus-

Fig 3

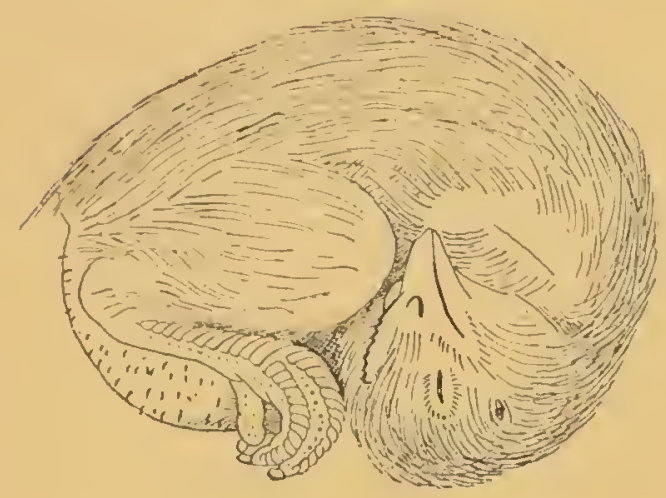

Fig. 4.

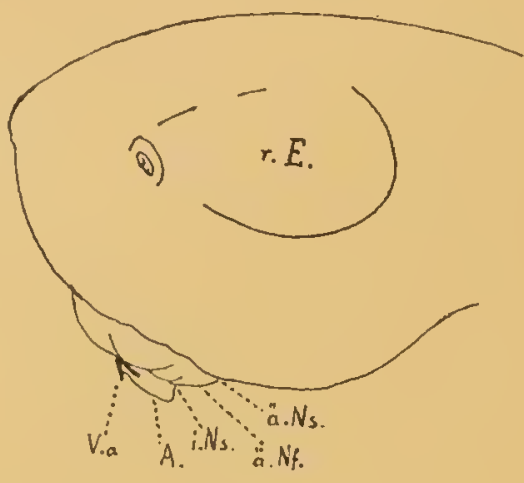

schlüpfen reife Hühnchen in seiner natürlichen Lagerung im Ei ron der rechten Seite. Der Bauch ist durch den Dottersack stark aufgetrieben. In der zweiten Figur erblickt man den Rumpf des gleichen Thicres nach Abtragung der Füsse; in dieser Figur ist r. li.= rechte hintere Extremität, A. = Allantoisrest, $\mathrm{V}$. a. = Allantoisgefässe, i. Ns. = innerer Nabelsaum, ̈̈. Ns. = äusserer Nabelsaum, ̈̈. Nf. = äusseres Nabelfeld. Es ist ohne weiteren beweis einleuchtend, dass der Dottergang niemals einen solchen Finfluss auf den Dottersack ausüben kann, dass dieser nun seinerseits die Ba uchwand nach aussen hervorstülpt. Der Leser wird ohne IVeiteres verstehen, dass diese Kraft nur distal ron dem Dottersacke gelegen sein kann. Und hier treffen wir sie auch in der That an in Gestalt ciner muskulösen Haut, die wir deswegen, weil sie mach der Aufnahme des I)ottersackes zu einem Bestandtheil des Nabels wird, "Nabelhatut" nennen mögen. In der zuletzt vorgeführten Jigur treffen wir diese Haut schon stark verkleinert zwischen dem, ,̈̈usseren" und, ,inneren Nabelsaum" in Ciestalt des, "̈̈usseren Nabelfeldes". Man wird sich wohl sigen, dass wir einen Theil des Amnios vor uns haben. Also das Amnios komnt für die fragliche lecistung auf. Ausser ilum ist aber auch das innere Blatt der Allantois an der lianverleibung des Dottersackes betheiligt, ja clieses sogar anfänglich in viel ausgesprochenerer W $Y$ eise als das Amnios. Um das jedoch reutlich machen zu können, müssen wir 
die lintwicklung der fötalen Anhänge vor unserer Erinnerung vorïberzichen lassen.

Von den drei Blättern, welche sich aus dem Keim entwickeln, spaltet sich das mittlere in die parietale und viscerale Scitenplatte. 1)ic viscerale Seitenplatte verbindet sich mit dem Entoderm, und beide zusammen bilden in dem ausserembryonalen Keimbezirke den Dottersack; die parietale Seitenplatte verbindet sich mit dem Ectoderm, und beide zusammen erheben sich zur Amniosfalte. Aus letz. terer entsteht durch Abschnürung in bekannter Weise das Amnios und die seröse Hülle. Die seröse Höhle oder das Aussencölom ist währenddessen zwischen den beiden Seitenplatten ausgebildet worden und finclet sich zivischen seröser Hülle einerseits, Amnios und Dottersack andrerseits. In die seröse Höhle hinein wäichst die Allantois, und indem diese sich frühzeitig, den räumlichen Verhältnissen entsprechend, abplattet, sondert sich an ihr eine äussere und innere Wand, das äussere und innere Blatt der Allantois, welche beide geweblich und dementsprechend auch functionell von einander verschieden sind. Das äussere Blatt wird Respirationsorgan, das innere erlangt eine mechanische Bedeutung; das äussere verdickt sich und wird Träger der dicken Gefässstämme der Allantois und eines reichen Gefässnetzes; das innere ist zwar auch reich an Gefässen, doch sind diese im Allgemeinen feiner. Das innere Blatt erlangt nicht die Dicke des äusseren, dagegen erzeugt es glatte Muskulatur, während sich das äussere auf die Ausbildung von Schleimgewebe beschränkt. Von Anfang an tritt das äussere Blatt der Allantois mit der serösen Hülle in feste Verbindung, so dass die seröse Hülle ihre Selbständigkeit in demselben Maasse verliert, als clas äussere Blatt der Allantois sich an ihr hinschiebt. Ebenso rerwächst das innere Blatt der Allantois mit dem Amnios, was für unsere weitere Betrachtung (s. p. 2 So f.) von grosser Bedeutung sein wird. Dagegen bleibt dort, wo das innere Blatt der Allantois an den Dottersack grenzt, die seröse Höhle erhalten, ebenso wie dort, wo das Amnios an den I Jottersack anstösst.

Ich möchte auf die mechanische Bedeutung der geschilderten Verhältnisse um so mehr aufmerksam machen, als man es unseren Lehrbüchern anmerkt, dass sie bei dem Capitel der Eihäute, angesichts der verschierlenen Faltenbildungen und Tneinanderschiebungen, im allgemeinen froh sind, wenn sie diese verwickelten Verhältnisse rein schematisch, mit Hülfe farbiger Linien, glïcklich dargestellt haben. Auch das Studium der Eihäute mit Huilfe von Schnitten durch ganze lier (kleiner Vögel), welches Duval mit so grossem Erfolge angewendet hat, so sehr es einerseits die Erkenmung der topographischen Verhältnisse fördert, macht doch anclerscits gar keinen 
Eindruck in Hinsicht der mechanischen Eigenschaften. Ja, Duval hat nicht einmal crkannt, dass das innere Blatt der Allantois eine muskulöse Haut ist. Beim Stuclium von flächenhaft ausgebreiteten Organen, von Hä̈tten, ist dic Präparation und Ausbrcitung im frischen Zustande schr wichtig, weil wir nicht nur durch das Auge, sondern clurch das Gefühl in der lebhaftesten Weise über die Eigenschaften, namentlich ïber clie mechanischen Eigenschaften, unterrichtet werden. IV as clas bei dem inneren Blatte der Allantois besagen will, wird sich sogleich noch zeigen. Hier sei zunächst nur Folgendes betont: dadurch dass cler Dottersack von Amnios und Allantois getrennt bleibt, inneres und äusseres Blatt der Allantois dauernd durch die Allantoishöhle geschieden sind, ist es möglich, dass dlie genannten Theile sich in jedlem Augenblicke gegen einander verschieben; Amnios uncl inneres Blatt der Allantois dagegen können sich nicht gegen cinander verschieben, sie verschmelzen vielmehr zu einer Einheit und haben dementsprechend auch im Wesentlichen übereinstimmende Structur. Sie haben nämlich beide den Charakter von Muskelhäuten, jedes von ihnen bildet eine zusammenhängende Lage von glatten Muskelzellen aus, welche beim Amnios sowie beim inneren Blatte der Allantois aussen (mit Bezug auf clie Höhlen) liegt. Indem sich die genannten beiden Häute mit einander verbinden, legen sich die beiclen Muskelschichten aneinander. Ob sie dann fernerhin noch als getrennte Lagen zu verfolgen sind, und was sonst noch über diese Muskulatur zu bemerken wärc, kann ich unerörtert lassen, da cliese Aufgabe gegenwärtig von anderer Seite verfolgt wircl.

Indem nun die Allantois sich immer weiter distalwärts vorschiebt, trifft sic auf den eingedickten Rest des Eiweisses, welcher sich nach der Mitte der Brützeit in die Gegend des spitzen Eipoles zurückgezogen hat; und nun clringt sie nicht etwa zwischen Eiweiss und Dottersack weiter vor (ich folge hier zunächst in der Darstellung Duval, werde aber Genaueres auf Grund eigener Erfahrungen weiterhin bringen), sondern sie bleibt der Schalenhaut eng angelagert, schiebt sich also zwischen dieser und dem Eiweissreste weiter. Sie erzeugt in Folge dessen cine Falte der serösen Hülle; und indem diese Falte sich schliesst (ich folge hier der Darstellung von Duval), entsteht eine Höhle, ein neues viertes fötales Organ, cler "Wiweisssack", wie ich es nennen will. Schon v. Ba er machte Andcutungen über clieses Verlaciltniss (2. p. 131) mit den Worten (XIV. bis XVI. Tag): „Am spitzen Ende des lïies scheinen dic Ränder des Harnsackes, wenn das Eiweiss sehr fest an der Schalenhaut sitzt, dieses zu durchschneiden, denn man findet zuweilen ein wenig Eiweiss am spitzen Encle des Fies ausserhalb) des Harnsackes, das Uebrige innerhalb dessriben." Aber erst D)uval (6.) machte dadurch, class er clic Eier 
kleiner Vögel im Ganzen schnitt, dic topographischen und geweblichen Verhältnisse klar und zeigte, dass es sich um ctwas Wuscntliches und Typisches handele.

Da diese rerwickelten Verhïlnnisse ohne Abbildung nicht klar \%u machen sind und vor der weiteren Darstellung lilar gelegt werden müssen, so übernehme ich hier die letzte Abbildung des 1) uval' schen Atlas (8. Taf. to Fig. 652), ändere jedoch diese Figur in einigen Punkten ab und zwar aus folgenden Gründen. Duval gewann seine Kenntnisse ron den topographischen Verhältnissen der Eihäute hauptsächlich dadurch, dass er Schnitte durch ganze Eier kileiner Yögel machte; die Ergebnisse sind in einer besonderen Arbeit niedergelegt (6). In den schematischen Figuren der letzten Seite des Atlas sind die Züge, welche man aus den Abbildungren zu jener Arbeit kennt, zum grossen Theile wiederzufinden. Die Abbildungen im Atlas aber erlangten durch die Anwendung verschiedener Farben und durch dicke Linienführung den Anschein von Schemata. In solchen aber ist es nicht nur gestattet, sondern geboten, Unwesentliches fortzulassen und entstellende Zufälligkeiten zu beseitigen. In einem wichtigen Punkte weicht Duval selbst in dem Atlas von seiner Originalarbeit $a b$, nämlich darin, dass er im Atlas das innere Blatt der Allantois mit dem Amnios in Verbindung zeichnet, während er in der Arbeit ausdrücklich betont, dass es dem Amnios zwar anlicge, jedoch von demselben geschieden sei (6. p. 228). Ob Duval bis zur Herstellung der Figuren im Atlas eine bestimmtere und richtigere. Meinung über diesen Punkt gefasst habe, oder ob die Zeichnung durch ein unbeabsichtigtes $V^{\top}$ ersehen den wahren Verhältnissen entsprechender geworden sei, lässt sich nicht beurtheilen, da Duval in dem Text und der Tafelerklärung des Atlas keine Andeutung gicht. Die Punkte nun, in denen ich die Abbildung ändere, sind folgende: 1. 1ch lasse die Darmschlinge, welche den Dottergang trägt, aus dem Leibesnabel hervorliängen, weil ich es bis zum neunzehnten Tage ausnahmslos so gefunden habe. Auch Baer äussert sich ähnlich (2); auf p. 135: "Am neunzehnten Tage hat der Eintritt des Dotters erst begonnen", und p. 136: "Mit dem neunzehnten Tage ungefïlü beginnt dieses Eintreten." 2. Ich lasse die Falten an der Innenseite des Eiweisssackes fort, da sie nach meiner Meinung keine typische Bedeutung haben (s. weiter unten). 3. Ich lasse den Eiweisssack am spitzen lippole offen, weil ich ihn beim Huhne stets so getroffen habe. Uebrigens ist das von keiner eingreifenden Bedeutung. 4. Ich lasse die eigenthümliche Ausstülpung des 1)ottersackes in clen Eiwcisssack, den "Dottersacknabelsack" (sac de l'ombilic ombilical), welchen Duval entdeckte (6. P. 233; Fig. 20 auf Taf. XI) fort, weil ich nicht davon überzcugt bin, dass derselbe constant vorkonmt, und weil ere, 
wenn er constant vorkommt, mir doch etwas Unwesentliches, ja eine Unvollkommenheit darzustellen scheint. Erwähnung wird dieser Punkt noch später finden. Mit den angegebenen Abänderungen ist aus der Dural'schen Abbildung die nebensteliende Figur entstanden, und es gelten für sie folgende Bezeichnungen: $\mathrm{Sch}=$ Schale + Schalenhaut, $\mathrm{Am}=$ freier Theil des Amnios, $\mathrm{Am}-\mathrm{Al}=$ Amnios mit dem inneren Blatte der Allantois vereinigt, $\mathrm{Ai}=$ freier Theil des inneren Blattes der Allantois, As $=$ seröse Hülle mit dem äusseren Blatte der Allantois vereinigt, $s=$ freier Theil der serösen Hülle bzw. der W $W$ and des Eiweisssackes, $\mathrm{A}^{\prime} \mathrm{e}=$ äussere Randfalte der Allantois, $\mathrm{A}^{\prime} \mathrm{i}=$ in-

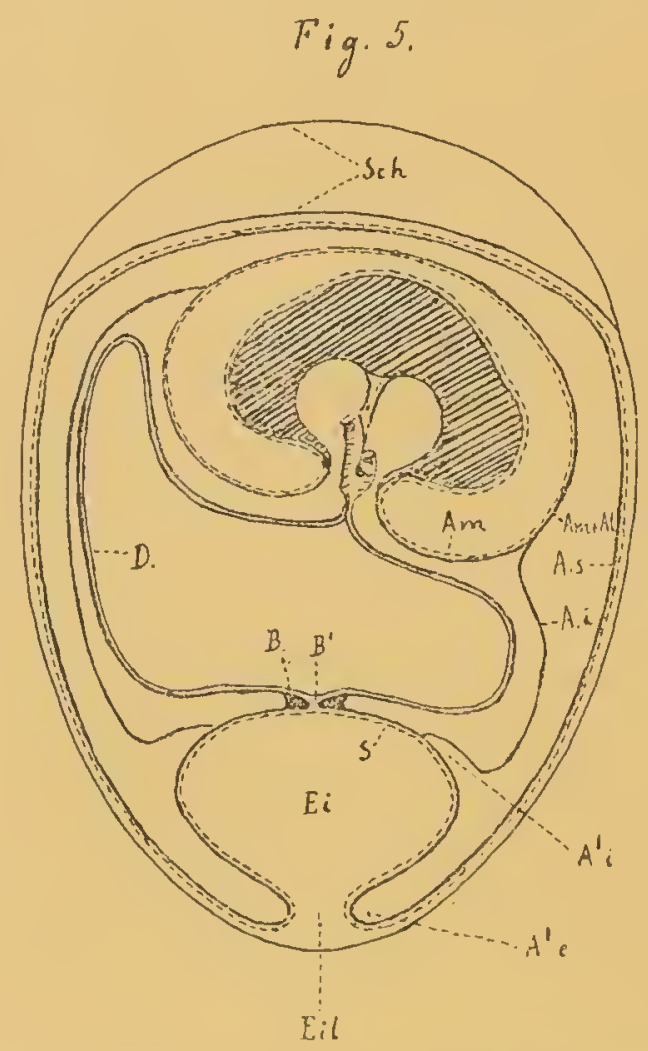

nere Randfalte der Allantois, $\mathrm{Ei}=$ Eiweisssack, Eil = Eiweisssackloch, $\mathrm{D}=$ Dottersack, $\mathrm{B}=$ Bindegewebsring, $\mathrm{B}^{\prime}=$ centrale Oeffnung im Bindegewebsring oder Dottcrsacknabelloch. Das Ectoderm ist durch eine punktirte Linie gegeben; die epitheliale Auskleidung der Allantois ist nicht angedeutet.

3. 1) as Eiwcissorgan. - Das Vorausgehende hat uns auf ein eigenthümliches Organ, clen "Eiweisssack" geführt; und ich gehe auf diesen hier noch in einem besonderen Abschnitte cin, weil wir bei dem Studium der Nabclbildung clavon nicht absehen können, 
und reil ich nach der grundlegenden Arbeit ron D) ural, die uns überhaupt erst mit diesem Organe bekannt gemacht hat, ülser die Verhältnisse desselben bein Huhne noch manches zu bemerlien finde.

I) uval bezeichnet das Organ als "Placenta" oder "placentares Organ" (6. S. 229), und bezeichnet es ausdrücklich (S. 227) als "die erste Spur der wahren Placenta“. Durch Untersuchungen ïber die Eihautentwicklung ron Säugethieren, namentlich des Pferdes (3. Fig. 175), hat sich in cler That eine merkwürdige Analogie, vielleicht Homologie zwischen dem erwähnten Organe des Huhnes und der „Dottersackplacenta" von Säugethieren herausgestellt. Trotzdem ziche ich hier eine Bezeichnung vor, welche die einfach physiologische Bedeutung des Organes innerhalb der Thiergruppe, bei der es sich findet, ausdrückt, und führe den Ausdruck "Eiweisssack" ein. So wie cler "Dottersack" das Organ der Dotteraufnahme, so ist der Eiweisssack das der Eiweissaufnahme. Da aber letzterer sich nicht immer schliesst, also nicht immer ein Sack zu Stande kommt, so wird auch die indifferentere Bezeichnung eines "Eiweissorganes" Anwendung finden müssen.

Meine Angaben über das Eiweissorgan, welche z. T. von denen Durals abweichen, beziehen sich I. auf die Lage; 2. auf die Gestalt; 3. auf das Epithel.

I. Beror wir von der Lage des Eiweissorganes sprechen können, müssen wir über die Lage des Hühnchens selbst und die des Dottersackes einiges vorausschicken. Die Lage des Hühnchens ändert sich während der Bebrütung, und wir können das Nöthige hierüber aus Baer (2) entnehmen. Baer sagt S. I24 (XI. bis XIII. Tag): Der Embryo ist "dem stumpfen Ende näher als dem spitzen. Cewöhnlich liegt er hier in Form eines Ringes, der die Querperipherie des Eies einnimmt"; S. I3I (XIV bis XVI. Tag): "Der enge Raum im Eie erlaubt dem Embryo nicht mehr, in der Querachse des Eies zu bleiben, sondern bei fortgehendem Wachsthum wird er jetzt immer entschiedener mit seiner längsten Dimension in die Längenachse des Eies geschoben." Noch bestimmter prägt sich diese l age in den folgenden Tagen aus; man vergleiche, was $v$. Baer ïber den XVII. bis XIX. Tag (S. I 34), sowie über den XX. und XXI. (S. 136) bemerkt. Die von mir früher gegebene Fig. 3 , sowie einige noch folgende Abbildungen bringen die Lage der letzten Tage zur Anschauung. Duval beschreibt als Endlage nur diejenige, welche $\checkmark$. Baer für den Xl. bis XIII. Tag angiebt, und misst ihr offenbar zu sehr einen bleibenden Werth bei. Dural lässt sich hier ron dem Streben nach einer gewissen Eleganz und Zuspitzung der Darstellung verführen; er spricht von ..drei Etagen" in dem auf der Spitze stehenden lii, von denen die oberste von dem limbryo, die 
mittlere von dem Dottersack und die unterste von dem Eiweiss eingenommen sei; und er deutet an, dass die Schwere einen bestimmenden Einfluss auf diese Schichtung ausübe. Ich möchte demgegenüber bemerken, dass, wenn die Eier kleiner Vögrel im Neste wirklich auf der Spitze stehen, dies nicht durch Vortheile der Eientwicklung, sondern durch den engen Raum bedingt ist, da so clie Eier am wenigsten Flächenraum einnehmen; dass aber die Hühnereier, wenn die Henne brütet, nicht auf der Spitze stehen; und dass die Henne die Eier auch nicht in einer lage belässt, sondern tïglich rührt. Letzteres ist sogar, wie man Weiss, von Wichtigkeit, da sonst leicht schädliche Verwachsungen entstehen. Obwohl aber die Hühnereier nicht auf der Spitze stehend gebrütet werden, so ist trotzdem zu ciner gewissen Zeit die Lagerung des Eiinhaltes in drei Etagen vorhanden. Aber chen nur zu einer gewissen Zeit. Daraus muss man schliessen, dass 1)uval die Endstadien der Entwicklung nicht untersucht hat, weil zufällig seine spätesten Stufen noch nicht bis zu Ende entwickelt waren. Wenn wir unter Zuhilfenahme der Baer'schen Angabe schätzen wollen, wie weit Duval's Eier entwickelt waren, so müssen wir sagen: es fehlte noch reichlich der dritte Theil der ganzen Entwicklung, rorausgesetzt, dass sich die topographischen Verhältnisse so verhalten, wie beim Huhn. Wenn 1) uval seine Untersuchung mit diesen Studium abschloss, so ist ihm daraus kein Vorwurf zu machen, da er ja bei der Erlangung des Materiales rom Zufall abhängig war, wohl aber ist er zu tadeln, dass or die lig. $65_{2}$ in seinem Atlas als die eines Huhnes "nach dem siebzchnten Tage" gab, verführt durch das Bestreben, in dem Beschauer den Anschein zu erwecken, als habe er die Untersuchung bis zum Schluss durchgeführt.

1)as Hühnchen liegt also in typischer Weise in den letzten Brüttagen so, dass sein Rücken einer Längrsseite des Eies anliegt, der Scheitel stösst an die Luftkammer, der Steiss findet in dem spitzen lipole I'latz. Die Lage ron Kopf und Füssen ist dabei nicht absolut streng; wenn der Kopf in cler Regel nach der Seite gedreht ist (s. liig. 3 4. 19), so ist das darlurch bedingt, dass links der Dottersack weiter hinaufreicht, hier also weniger l'latz ist. Doch kann der Kopf auch symmetrisch liegen; wenn or nach rechts gedreht ist, so finclet wieder nicht inmer der Schnabel seinen l'latz unter dem rechten Flügel, sondern zuwcilen auf demselben. Zweimal fand ich Hühner ron der Entwicklungsstufe des zwanzigsten Tages (s. Fig. 12 u. 1.3) mit dem Rücken an der luftkammer anliegencl und mit den Scheitel gegen den spitzen Eipol gewendet, so dass hier möglicher Ireise cine Störung vorgekommen ist, sei es, dass diese Thiere schon vorher 7.4 schwach waren, die nornale Lage an- 
zunchnen, sei es, dass sie durch eine finale Aspluyxic zu gewaltsimen bewegungen veranlasst worden waren.

Nitch diesen Bemerliungen über die Lage des Hühnchens betrachten wir die Lage des Dottersackes in den letzten brüttagen, wozu uns die nebenstehenden beiden Figuren einen Anhaltspunkt bicten mögen. Die Figuren stellen das Hühnchen von der rechten und ron der linken Seite ror, noch umhüllt rom Ammios und clurch dieses hindurchscheinend; das äussere Blatt der Allantois ist bis auf einen kleinen Rest am distalen l'ole entfernt, das innere Blatt ist erhalten geblieben. Für diese beiden Figuren gelten folgencle Bezeichnungen: Sch $=$ Scheitel, $\mathrm{St}=$ Steiss, $\mathrm{D}=$ Dottersack, $\mathrm{Ei}=$ Lïweisssack, A. e = äusseres Blatt der Allantois, abgeschnitten, E il $=$ Loch des Eiweisssaclies, $\mathrm{v}=$ Gefässe der Allantois, r. h. = rechter Lauf, $\mathbf{r} . \mathbf{r}=$ rechter Flügel, $\mathbf{L}=$ rechte Lidspalte. Die punk-

\section{Fig. 6 .}

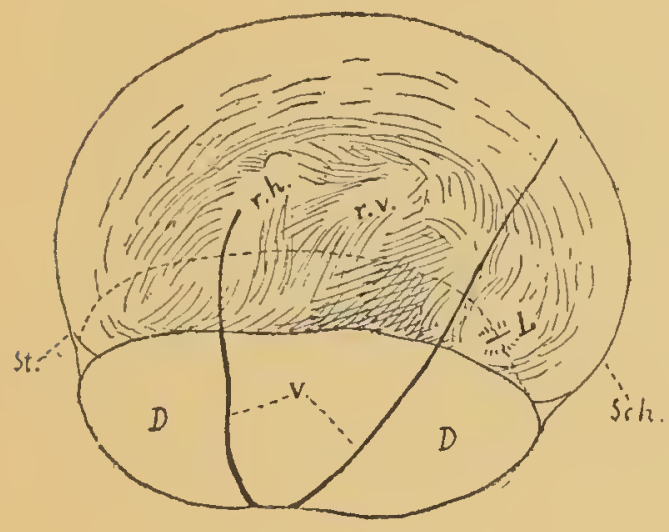

Fig. 7 .

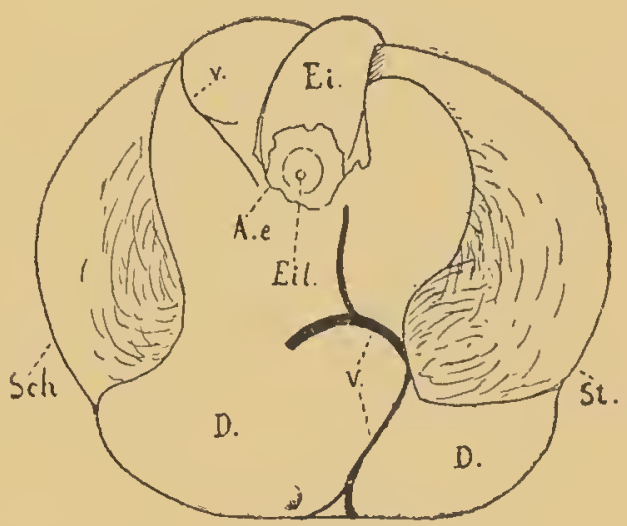

tirte I,inie auf Fig. 6 giebt die Grenze des freien und des mit dem Amnios verwachsenen Theiles des inneren Blattes der Allantois an.

Diese Figuren cnthüllen eine Asymmetrie in der Lagerung des Dottersackes, darin bestehend, dass der Dottersack auf der linken Seite des Thieres weiter hinaufreicht als auf der rechten. Der Grad dieser Asynmetrie ist nicht immer der gleiche, aber die Asymmetrie selbst ist stets vorhanden. Anfangs übersah ich dieselbe, umsomehr, da ja in der lagerung des Thieres und in der Gestalt des Eiweissorganes mancherlei Verschiedenheiten vorkonmen; nachdem ich aber cinmal darauf aufmerksam geworden war, fand ich die Asymmetric stets wieder. In Folge clerselben ist der distale Dottersaclipol weit nath links hinaufgeschoben, und der Abstand von diesem Pole bis zum Amnios ist, wenn man nach links geht, sehr gering, wenn man digegen nach rechts geht, sehr bedeutend. Woher diesc eigenthümliche Asymnetric konme, kann ich nicht sagen; viclleicht stcht 
sie mit dem von Anfang an asymmetrischen Austritt der Allantois und mit der Anordnung der Allantoisgefässe in Verbindung. Diese Asymmetrie erhält sich bis zum Schlusse der Brützeit, und selbst wenn schon der grösste Theil des 1)ottersackes aufgenommen ist, bleibt sie noch sichtbar, wie beistehende Figur der Bauchgegend

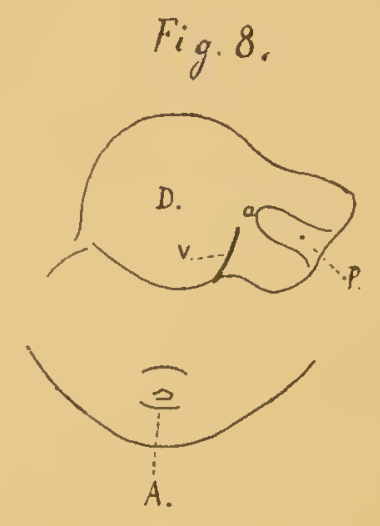

eines Hühnchens vom zwanzigsten Tage zeigt, für welche folgende Bezcichnungen gelten: $A=$ After,$D=$ Dottersack, $\mathrm{P}=$ distales Polfeld desselben, $\mathrm{v}=$ Allantoisgefäss; a entspricht a der Figur 13 und der Punkt bezeichnet die Mitte des Polfeldes. Es ist möglich, dass sich Spuren der Asymmetrie noch nach der Aufnahme des Dottersackes in die Leibeshöhle erhalten, wenigstens habe ich ron einem Dottersacke vom dritten Tage nach dem Ausschlüpfen verzeichnet, dass seine Mericliane nicht gleich waren.

Hicrmit ist dann auch die Lage des Eiweissorganes bezcichnet, da ja dieses mit dem distalen Pole des Dottersackes in $V^{\top}$ erbindung steht. Eine Linie, welche rom Rücken durch den Leibesnabel gezogen wird, trifft also den Eiweisssack nicht, sondern dieser ist weit nach links hinaufgeschoben; ja die Tendenz der Asymmetrie trat sogar in mehreren Fällen an dem Eiweissorgan so stark hervor, dass dasselbe nicht gleichmässig um den distalen Dottersackipol herum sich lagerte, sondern denselben weiter nach links wie nach rechts überschritt, so dass in diesen Fällen (vergl. Fig. 7 und Fig. 10) das liweissorgan sogar linkerseits mit dem Ammios in Berührung trat.

2. Gestalt des livweissorganes. - Es sei yuvor bemerkt, diss ich in den letzten Brüttigen offers noch recht beachtenswerthe Eiweissreste gefunden habe, so dass ich nicht glaube, dass dieselben bis zum Ausschlüpfen noch hätten resorbirt werden können. Die Thiere waren aber sämmtlich im Kisten gebrütet, und da die Mchrzalul der kü̈nstlich gebrüteten Hühnchen, selbst wenn sie bis z.um. Schlusse der Brützeit kimen, doch noch vor dem Ausschlüpfen alstirld, so möchte 
ich sellost die Frage anregen, ob nicht vielleiclit atuch diejenigen Thiere, welche ich lebend und frisch traf, doch an Ausbilcung hinter solchen zurückstanden, die von der Henne gelsrütet werden. lis wäre wohl möglich, dass bei diesen das Eiweiss volliommen resorbirt wird, und dass auch das Fiweissorgan nicht die Verschiedenheiten der Gestalt zeigt, welche ich jetzt besprechen werde. Ich habe das Eiwcissorgan in zwei sehr verschiedenen Formen getroffen, das einemal als einen fast geschlossenen Sack ("Eiweisssack"), das anderental als ein gänzlich offenes feeld (..Eiwcissfeld"). Dass es sich aber immer um das glciche Organ handelte, ging aus dem topographischen und geweblichen Verhalten hervor, aus dem topographischen, insofern als die Beziehungen zur Allantois die gleichen waren, und aus dem geweblichen, insofern als das charakteristische, weiterhin näher zu schildernde Epithel sich scharf gegen das umgebende kleinzellige mehrschichtige Epithel absetzte.

Die eine Form ist im Zusammenlange mit Allantois und Amnios oben (Fig. 7) schon abgebildet worden; es fand sich daselbst ein abgeplatteter Sack, entsprechend der Querebene des Thieres gestreckt, den man auch einen Schlauch nennen könnte. Derselbe besass eine äussere Oeffnung, die weder in der Mitte der äusseren Seite, noch dem distalen Dottersackpole gegenüber, sondern nahe an dem rechten Ende des Schlauches lag. Das linke Ende streckte sich weit gegen den Rücken des Thicres hinauf, so dass es hier mit dem Amnios in Verbindung trat. Die nebenstehende Figur giebt in elffacher Vergrösserung einen Iängsschnitt dieses Sackes, von dem jedoch an der oberen, bzw. linken Seite des Thieres (der rechten

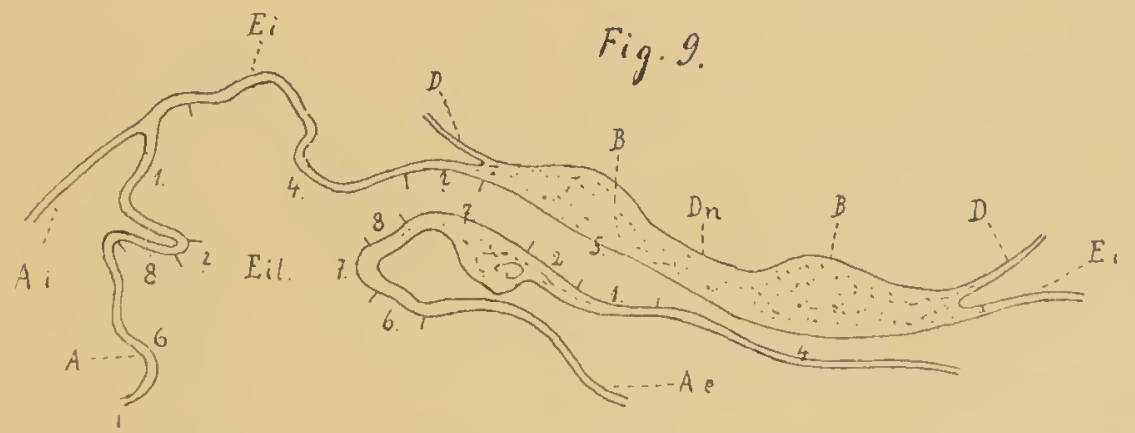

Seite rler Figur) der dritte Theil fehlt. In dieser Figur bedeutet $t$. und $\lambda$. e die Allantois, bezw. das äussere liatt derselben, in V'erbindung mit der serösen Hülle bezw. der Wand des Eivedsssackes; lii. die seröse Hülle, bezw. Mand des Eiweissáckes, soweit sie allantoisfrei ist; Eil. das loch des Eiweisssaclies. lis ist forner $1 \mathrm{i}=$ inneres Blatt der Mllantois, 1) $=$ bindegewebige Wand des 1)otter- 
sackes, $D_{n}=$ Dottersacknabel, $\mathrm{B}=$ Binclegewebsring. Die Zahlen bexiehen sich auf das Epithel und werden weiterhin (S. 276) ihre Iirklärung finden; an den Stellen, wo Fragezeichen stehen, war das Epithel zerstört, oder der Charakter desselben undeutlich.

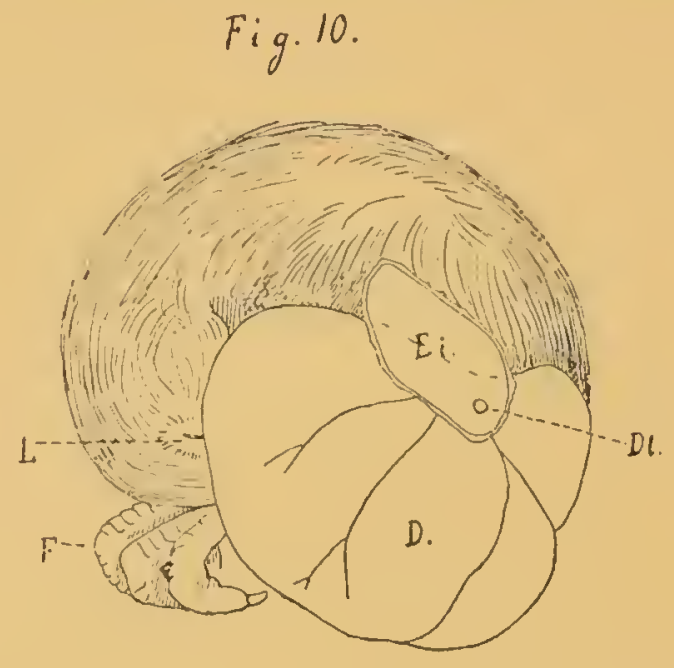

Die zweite extreme Form, die des „Eiweissfeldes", wird durch clie Fig. 10 dargestellt. In dieser sieht man ein neunzehntägiges Hühnchen in seiner natürlichen Lage nebst Dottersack und Eiweissorgan; die Allantois ist hart an Rande des Eiweissfeldes abgeschnitten. Es ist hier $\mathrm{F}=$ linker Fuss, $\mathrm{L}=$ linke Lidspalte, $\mathrm{D}=$ Dottersack, Ei = Eiweissfeld, Dl = Dottersackloch. In diesem Falle ist nämlich die bindegewebige Wand des Dottersackes nicht abgeschlossen, sondern es ist hier eine feine Oeffnung vorhanden, durch welche der Dottersack mit dem Eiweissorgan communicirt. Das Eiweissfeld ist länglich und ragt nit seinem oberen oder linken Ende auf das Amnios hinauf. Von diesem Präparate wurclen Schnitte rechtwinklig zur Längsachse des Eiweissfeldes gemacht, wovon die

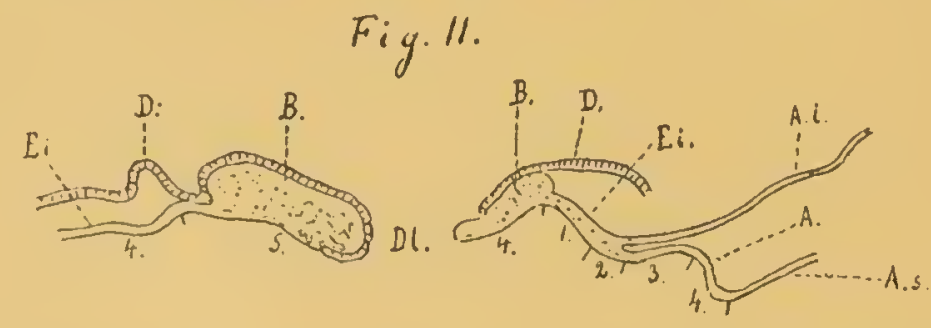

Fig. I cin Bild giebt bei elffacher Vergrösserung; das Eiweissfeld ist jedloch nur nach rechts hin bis zu seinem Rande gezeichnet, linkis fellit cin Stück desselben. In dieser lïgur ist $A=A$ Alantois in $V^{r}$ erbinclung mit dem Eiweissorgan, $A s=$ Allantois in Verbindung mit 
der seröscn Hülle, $\lambda \mathrm{i}=$ inneres Blatt des $\Lambda$ llantois; $\mathrm{Ei}=\mathrm{W}_{\text {and }}$ des Liweissorganes, frei ron Allantois; $\mathrm{D}=$ Dottersack, $\mathrm{Dl}=$ Dottersackloch, $13=$ Bindegewebsring. Dic Zahlen werden weiter unten erklürt werden.

Zwischen beiden formen steht nun eine dritte, von der eine weitere Abbildung eine Vorstellung geben soll, einem Huhne vom zwanzigsten Tage entnommen. Bei ihr bemerkt man gleichfalls ein flaches Feld, dieses von erhelblicher Grösse und kreisförmig begrenzt; geht man aber in diesem Felde nach unten bezw. nach der rechten Seite des Thieres und zugleich etwas nach rorn, so kommt man in eine an den distalen Dottersackpol sich anschliessencle Grube, welche von einer scharf geknickten, an beiden Enden flach auslaufenden Falte von rechts und vorn her zugedeckt wird. I)ie ganze Bildung mag man, um sic durch etwas Bekannteres deutlich zu machen, der Fovea ovalis des Oberschenkels mit cler Plica falciformis vergleichen. Die gleiche Bildung fand ich noch ein zweites Mal, jedoch hier das Feld lileiner, die Grube dagegen geräumiger und den Eingang in dieselbe enger.

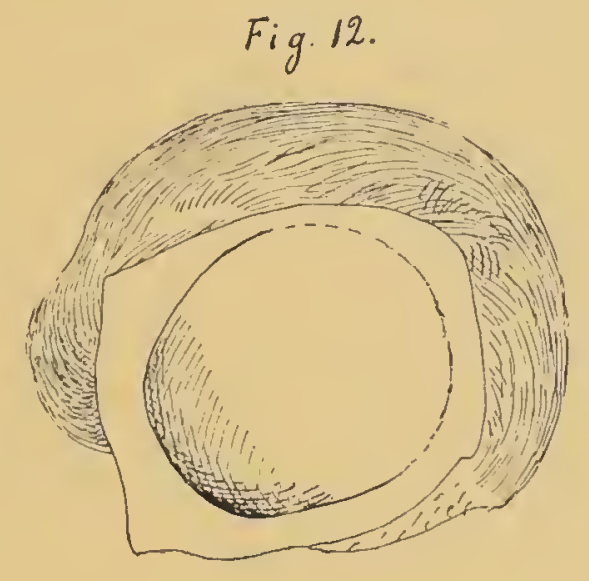

Endlich sei auch eine Form hier vorgeführt, welche sich ron cinfachen Verhältnissen weiter entfernt; und um eine Orientirung zu ermöglichen, sei das von den Eihäuten befreite, jedoch in seiner natürlichen lagge belassene Hühnchen zunächst vorgeführt in Fig. 13. In dieser ist $\mathrm{Sch}=$ Scheitel, $\mathrm{A}=$ Afteröffnung, $\mathrm{D}=$ Dottersack, l. v. = linker Flügel, r. h. = rechter Fuss, 1. h. = linker Fuss, $1 \mathrm{~h}^{\prime}$ $=$ linker Oberschenkel; $\mathrm{a}$ ist der Punkt a der Fig. S. Es ist dies ciner der beiden Fülle, bei denen rler Rüicken gegen den stumpfen Pol und der Scheitel gegen den spitzen l'ol gewendet war; das Ei wurde am zwanzigsten Brüttage geöfnet, das Hühnchen war abgestorben, jorloch der Dottersick schon grösstentheils in die lecibes- 
höhle aufgenommen, die Entwicklung des zwanzigsten Tages also erreicht. Die Fig. 14 zeigt nun dasselbe Ei nach Entfernung der Schale und Schalenhaut, jedoch mit Erhaltung sämmtlicher fötaler Anhänge. Das Eiweiss war in ziemlicher Menge vorhanden und hatte die Gestalt eines flachen Kuchens; dieser reichte mit seinem einen Rande bis an dic (sehr grosse) Luftkammer und lag im Uebrigen der Längswand des Eies und nicht dem spitzen Pole an. In der Fig. It ist zu besserer Orientirung diejenige Querebene des Hühnchens, welche zugteich durch den distalen Dottersackpol geht, durch zwei Pfeile bezeichnct. An der Stelle des Dottersackpoles sellost benerkt man einen Punkt; die umgebende Linie A. bezeichnet den

Fig. 13 .

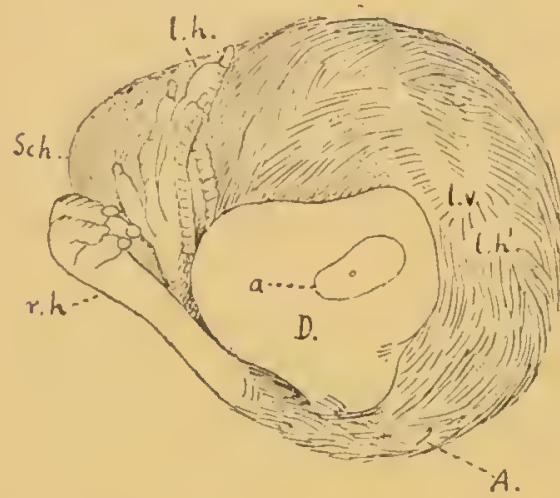

Fig. 14 .

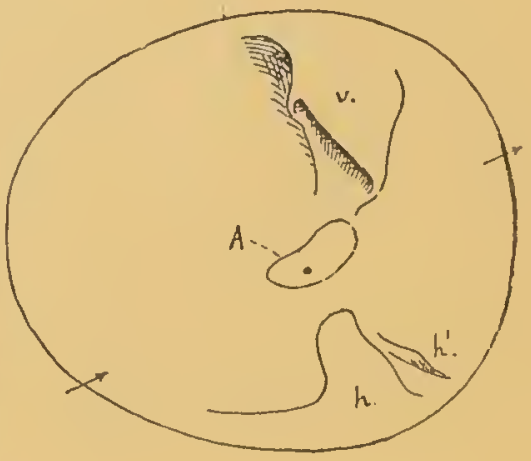

Rand eines flachen ..Polfeldes", vielleicht die Grenze, bis zu welcher die Allantois vorgedrungen ist. (Iine mikroskopische Untersuchung wurde nicht gemacht). Das Eiweissorgan nun wird in diesem Falle gebildet durch ein "Eiweissfeld", an dessen Rande sich jedoch drei unrcgelmïssig gestaltete Lappen erheben. Der eine derselben (v), welcher vor der ()uerebene liegt, hat die Gestalt einer kapuzenförmigen Tasche, in welche ein Theil des lïweisses hineinreichte. 1 lier bildet das äussere Blatt der Allantois nicht nur die Falte, sondern es bekleidet auch clen (irund der Tasche; unterhalb derselben ist "s mit dem inneren Blatte durch ein Dissepiment verbunden, worin möglicher $\mathbb{W}$ eise eine Ursache für die so eigenthümliche Bildung zu suchen ist. Ilinter (ler (uerebene trifft man zwei weitere lirhe:bungen; dic grössere derselloen (h) schieltt sich in Gestalt eines zipfelförmig gestalteten lappens zwischen Schalenhaut und leiweiss ror, die kleinere $\left(h^{\prime}\right)$ hat die Ciestalt einer niedrigen Leiste, welche in elas liwciss hineinragt.

Ich habe meine lirgebnisse über die topngraphischen Verhältnisse des lïweisssackes sowic der fötalen Anhänge überlaupt, ge- 
wonnen, indem ich entweder die Eier frisch in Kochsalylösung prïparirte, oder diesclben nach Entfernmng der Eischale und theilweise auch der Schalenhaut in Alcohol härtete und dann weitur zerlegte. Wer solche L'ntersuchungen macht, wird, gleich mir und anderen, finden, dass man erst eine gewisse Nenge von Naterial zerstört, bevor man sich in den verwickelten Verhältnissen zurechtzufinden und den geeigneten Gang der Intersuchung einzuhalten lernt. Wic ich schon sagte, rerschliesse ich mich nicht der Erwägung, dass möglicherweise beim Brüten unter natürlichen Bedingungen die Verhältnisse des Eiweissorganes beim Huhne regelmässiger und typischer sind, als ich sie gefunden habe. Trotzdem habe ich absichtlich die im $V^{T}$ orhergehenden geschilderten Varianten aufgeführt, weil deutlicher im $\|^{T}$ echsel das Bleibende, in der Variation das Constante hervortritt. Ueberraschend bleibt es mir immerhin, dass Duval nicht nur auf seiner letyten ligur, sondern schon auf der vorhergehenden den Eiweisssack völlig geschlossen zeichnet, während doch, wic oben gesagt, anscheinend noch der dritte Theil der Entwicklung fehlt. Ich habe auch aus clieser Zeit, d. h. vom vierzehnten Tage, vom Huhn einen Befund erhoben (s. Fig. I8), welcher den Eiweisssack weit offen zeigte. Es kann also daran gedacht werden, dass in der Ausbildung des Eiweissorganes die kleinen Vögel bedeutend rom Huhne abweichen, oder dass Duval die Verhältnisse nicht ganz richtig erkannt hat, wie das ja bei Schnitten durch ganze Eier leicht rorkommen kann. Man denke sich z. B., class auf meiner Figur 7 die Schnitte nicht, wie es von mir geschah (s. Fig. 9), in Längsrichtung, sondern in Querrichtung angelegt wurden, so würde ein Schnitt, welcher clen distalen Pol des Dottersackes trifft, nicht clurch das Loch des Eiweisssackes gehen; der Eiweisssack würde auf einem solchen Schnitte geschlossen erscheinen, während er es in der That nicht ist. Ich will nicht gerade behaupten, dass ein derartiger Irrthum bei D ural vorliegt, aber möglich ist es immerhin. Inclem ich nun aber im Vorhergehenden und im Folgenden in mehreren Punliten von Duval abweiche, fühle ich mich bewogen, ausclrücklich zu erklären, dạs ich nicht versuchen will, die Dural'schen Mittheilungen zu verdunkeln: Duval ist es, der das Eiweissorgan entdeckt und in seiner Bedeutung erkannt hat, und was wir noch hinzufügen können, sind nichts weiter als Ergïnzungen und Erläuterungen, die einen secundären Werth besitzen.

Zum Schlusse dieser Auseinandersetzungen gebe ich cin Schema, welches die Lage und die Form des Eiweisssackes in den letzten brüttagen zur Anschauung bringt, sowie sich diesclben nach meinen liefunden, nanentlich von dem sechzchntätgigen Ilühnchen, darstellen. In (liesem Schema ist $\lambda \mathrm{m}=$ Amnios, 1$)=$ Dottersíck, $\mathrm{d}=$ distales 
Polfeld des Dottersackes, A s = äusseres Blatt der Allantois + seröse Hülle, $\mathrm{A} \mathrm{i}=$ inneres Blatt der Nllantois, $\mathrm{Ai} \mid \mathrm{Am}=$ inneres Blatt der Allantois + Amnios, $\mathrm{Ei}=$ Eiweisssack, Eil = Loch des $\mathrm{E}$ iweisssackes; 1 berleutet links, 1 rechts. Eine weitere Erläuterung ist nach dem Trorausgegangenen nicht nöthig.

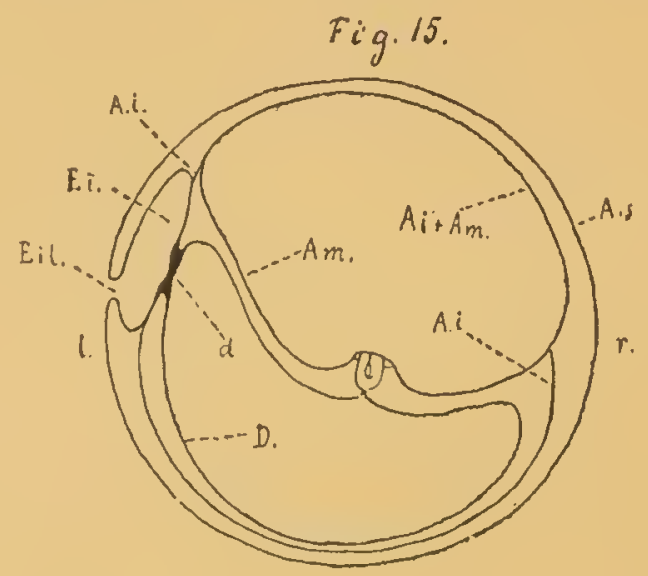

Die vorausgehende Schilderung der Lage und Gestalt des Eiweissorganes mag durch zwei Bemerkungen ihren Abschluss finden, welche die Beziehungen desselben zu den Nachbarorganen, zu Dottersack und Allantois, betreffen.

Bezichung zum Dottersack. - Das Eiweissorgan hängt, seiner Entwicklung gemäss, mit dem distalen Pole des Dottersackes zusammen; hier muss uns der Bindegewebsring sowie das Ectoderm und Entoderm (bzw. der Dotterentolblast) interessiren. Ueber den Bindegewebsring wird weiter unten (P. 278) in einem besonderen Absatze gesprochen werden; üher das Verhalten des Ectoderms und Entoderms sei aus der Litteratur Folgendes bemerkt; in einer früheren Periode, in welcher der Bindegewebsring noch weiter offen steht, als es in der oben gegebenen Fig. 5 der Fall ist, ist nach Duval (6. p. 233) ein Stück Dotter, bekleidet von Ectorlerm und mit Dotterkernen durchsetzt, bruchsackartig in den Eiweisssack vorgestülpt: "Nabelsack des Dottersackes" (sac de l'ombilic ombilical). Ich habe sclbst ïber diese Ausstülpung keine lirfahrungen, doch sind ähnliche Berbachtungen im hiesigen Jaboratorium durch Herrn Fülleborn gemacht. Die älteren, elonso bestimut gehaltenen und auch durch Abbildungen belegten Ansichten von Rauber (21.) über die Verwachsung des Ectoderms sowie die des Entoderms am distalen Dutersackpole lassen sich mit den Mittheilungen von Duval nicht vereinigen, so dass in clieser Hinsicht noch eine Lnklarheit bleibt. lch halte, wie ich schon olsen sagte, diesen rigenthünlichen, von bural geschilderten liruchsack, dic Vorstülpung ron Dotermasse 
in den Eiwcisssack hinein, selbst wenn er constant vorkommen sollte, für eine Unregelmässigkeit, aber mit Rücksicht auf gewisse ron mił bei clen Enclstadien der Entwicklung gemachte Befuncle für beachtenswerth. Während ich nämlich einerseits bei dem Huhne von sechzchn Tagen, dem die Figuren 7 u. 9 entsprechen, den distalen Dottersackpol vollständig geschlossen fand, so war bei dem Huhn von neunzehn Tagen, von welchem die Figuren io u. 1 I gewonnen sincl, in dem Bindegewebsringe noch ein Loch ("Dottersackloch") von o,6 mm Weite rorhanden, an dessen einer Seite das Dottersackepithel, und an dessen anderer Seite das Epithel des Eiweissorganes weiter herumgriff. Auch habe ich mehrfach Dotter aussen von dem distalen Dottersackpole im Eiweiss gefunden. Is scheint mir sonach zum mindesten wahrscheinlich, dass das Dottersackloch sich öfters in einer verzögerten Weise schliesst. Ohnedas würde eine Beobachtung gar nicht verständlich sein, auf welche ich weiter unten noch zurückkomme (s. Fig. 20), bei welcher in dem Nabel eines Hühnchens rom ersten bis zweiten Tage nach dem Ausschlüpfen eine Durchbohrung vorhanden war, welche einerseits nach innen in den Dottersack, andrerseits nach aussen in das, ,innere Nabelfeld" hineinführte. Es kommen also meiner Meinung nach in dem Verschlusse des Dottersackes und damit auch des Eiweissorganes Unregelmässigkeiten ror, die eine tiefere Bedeutung nicht besitzen, die man jedoch kennen muss, um den einzelnen Fall richtig zu verstehen.

Beziehung zur Allantois. - Diese Frage ist weit wichtiger, und hier wird vielleicht eine Abänderung der Anschauungen von Duval nöthig werden. Auf der Fig. $65_{2}$ des Duval'schen Atlas ist eine Falte der Allantois angegeben, welcher der mit $A^{\prime} \mathrm{i}$ bezeichneten Falte meiner Fig. 5 entspricht, die ,innere Randfalte der Allantois", wie ich sie nenne. Sie strebt dem, "Dottersackpol des Eiweisssackes" ebenso zu, wie die äussere Randfalte" (A'e) dem "Schalenpol des Eiweisssackes". Bei fortgesetztem Wachsthum ist zu erwarten, dass die innere Randfalte den Dottersackpol erreichen wird. Duval hat diese innere falte wohl erwähnt, ihr jedoch weniger Beachtung zugewendet, wie der äusseren Falte, da ihm letztere von Bedeutung war für den Verschluss des Eiweisssackes. Mir erging es umgeliehıt: die äussere Falte konnte mir nicht so wichtig erscheinen, da, wie früher ausgeführt, bei meinen Präparaten nie ein vollkommener- Verschluss des Eiweissloches, sondern eine grossc V'ariation in cler Gestalt des Eiweissorganes getroffen wurde; die innere Falte dagegen beschäftigte mich wegen des Mechanismus, (lem der Dottersack seine Aufnahme in clie I,eibeshöhle verdankt. Mit Rücksicht auf diesen ist es von Bedeutung, zu wissen, wo die Grenze zwischen innerem und äusserem Blatte der Allantois liegt, (l. h. ol) das zwischen innerer und 
äusserer Falte gelegene Stück der Allantois zum inneren oder äusseren Blatte zu rechnen sei. Duval erblickt in dem Scheitel der äusseren Falte den eigentlichen Rand der Allantois, es ist aber auch möglich, ihn in clem Scheitel der inneren Falte zu sehen, was insofern jedesfalls natürlicher wäre, als ja das äussere Blatt mit der serösen Hülle verwachsen ist, und die Wand des Eiweisssackes nichts Anderes ist als ein Stück der serösen Hülle. Duval giebt ferner an, dass clieser Theil der Allantois reicher vascularisirt sei, als es dem inneren Blatte sonst rukomme, und auch das würde dafür sprechen, das fragliche Stiick clem äusseren Blatte hinzuzurechnen. Eine sichere Entscheidung könnte jecloch nur durch Feststellung der geweblichen Merkmale geliefert werden, und in dieser Hinsicht müsste das V'erhalten der Muscularis allantoidis entscheidend sein. Ich habe in dieser Richtung keine abschliessende Erfahrung, aber es scheint mir, dass dic Muscularis in dem zwischen den beiden Jalten gelegenen Stücke fehlt, class wir also dieses zum äusseren Blatte rechnen und den eigentlichen Allantoisrand, die Grenze zwischen äusserem und innerem Blatte, in den Scheitel der inneren Falte setzen müssen.

Soweit Allantois und Eiweissorgan an einander anliegen, ist das Bindegewebe beider verschmolzen und in späteren Stadien nicht die geringste Spur von Trennung zu erkennen. Am Scheitel der inneren Falte läuft das Allantoisbindegewebe zugespitzt auf den Eiweisssack aus. Bei diesen Sachverhalt kann man nun wohl daran denken, dass das Gewebe der Allantois, also auch clie Muskelschicht, vom Scheitel der inneren Falte auf die Wand des liveisssackes weiterwächst und den Bindegewebsring früher erreicht, bevor die Allantoishöhle sich bis dorthin ausdehnt; ja es ist sogar möglich, dass die Allantoishöhle überhaupt nicht völlig bis an den Bindegewebsring kommt, dass aber die Muscularis allantoidis bis clorthin vordringt. Das Letztere würde für die Frage des Mechanismus der Dottersackaufnalıme von Bedeutung sein; jedoch brauchen wir es nicht nothwendig anzunehmen, um diesen Mechanismus zu verstehen.

3. Epithel cles Iiviweissorganes. - Duyal bezeichnet als clie charakteristische Eigenthümlichkeit des Eiweisssackes zottenartige Bildungen (6. p. 230), deren Achse ron cinem bindegewebigen Zapfen gebildet werde, der reich an feinen Kapillaren sei; und deren Oberflïche von runden oder polyedrischen Epithelzellen gebildet werde. Nach den Abbildungen finclen sich die letzteren in zwei- bis fünffacher Lage. Anfänglich treten cliese zottenartigen Bilclungen in der Gegend des Mesorlerm-Wulstes auf (S. 22S), später verbreiten sie sich über die ganze Innenfläche mit Ausnahme des von clem Mesorlerm-Wulste distal gelegenen Abschnittes, dessen Ectoderm Schritt 
für Schritt mit der Verengerung des Bindegewebsringes zu Cirunde geht.

Meine eigenen Erfalırungen stehen clamit nicht in allen Punkten in Uebcreinstimmung. Es stehen mir brauchbare Präparate von sieben Eiweissorganen des Huhnes zur V'erfügung, von denen zwei dem XII., zwei dem XIIT., je eines dem XIV., XVI., XIX. Tage angehören. Bei diesen finde ich an den Präparaten des XII. und XIII. Tigges die zottenartigen Bildungen auch hauptsächlich am Bindegewebsringe cntwickelt, also so, wie es Duval auf Fig. if abbilclet; dagegen in den späteren Tagen finde ich entsprechende Bildungen mehr proximal, am XVI. Tage sogar in der Nähe des Einganges in clas Eiweissorgan und an XIX. Tage zwischen diesem und dem Bindegewebsringe, jecloch dem Eingange näher. Vor allem aber finde ich diese Formation in den späteren Tagen weniger entwickelt als am z.wölften und dreizehnten 'Tage. Wenn ich also auf Grund dieser Erfahrungen einen Schluss machen wollte, so müsste ich sagen, dass die zottenartigen Bildungen mit der Entwicklung nicht zu-, sondern abnehmen, und dass in ihnen nicht das charakteristische Merkmal des Eiweissorganes gesucht werden kann. Ich halte jedoch, wie ich schon oben sagte, die in Kasten gebrïteten Eier, welche mir allein zur Verfügung standen, nicht für ganz einwandfrei; und ich würde dengemäss auch die Mittheilungen von Duval als maassgebend angenommen und von meinen eigenen Erfahrungen gänzlich geschwiegen haben, wenn ich nicht meinerseits an dem Epithel gewisse charakteristische Merkmale gefunden hätte, welche mir der Erwähnung werth zu sein scheinen. Nach meinen Erfahrungen ist das Epithel des Eiweisssackes zweischichtig und wird gebildet in typischer Weise durch eine obere Lage cylindrischer und eine untere Iage platter Zellen. J)ie Figur 4 auf Taf. X möchte ich dieser Betrachtung zu Grunde legen. Die oberen Zellen, d. h. diejenigen, welche dem Hohlraum zugewendet sind, springen mit mehr oder weniger gerundeten Kuppen gegen den Eiweisssack ror; die Kerne sind kuglig oder ellipsoidisch und liegen in der Mitte oder in der Kuppe der Zelle. Indessen findet man die Gestalt diescr Zellen in wciten Grenzen variabel; nicht nur sind dieselben bald höher, bald niedriger cylindrisch, sondern sie entfernen sich auch weit von dieser Grundform. Einerseits können sie sich so seh" verlängern, dass man sie als fadenförmig, und indem sie sich an ihren freien Enden verbreitern, als keulenförmig bezeichnen muss, anderer-. seits können sie so niedrig werden, dass sie den Namen von kubischen, ja von platten \%ellen verdienen. Ausser dieser Variation der Höhe giebt es auch eine solche des Aussehons, während nänlich dic gewöhnliche fiorm ein protoplasmatisches Aussehen zeigt, können 
die Zellen auf manchen Strecken ein blasiges Ausschen annehmen. Hieraus ergeben sich acht verschiedene Varianten: I. niedrig cylindrisches, 2. hoch cylindrisches, 3. fadenförmiges und zottenbildendes Epithel, 4. kubisches, 5. plattes, 6. kleinblasiges, 7. grossblasiges, 8. sehr hohes blasiges Epithel. Auf den Figuren, welche ich vom Eiweissorgan entworfen habe, sind Zahlen angebracht, und diese bezeichnen die eben aufgeführten Modificationen des Epithels. Zwei dieser Figuren, eine dem sechszehnten Tage (Fig. 9) und eine dem neunzehnten Tage (Fig. I I) entsprechend, sind schon mitgetheilt;

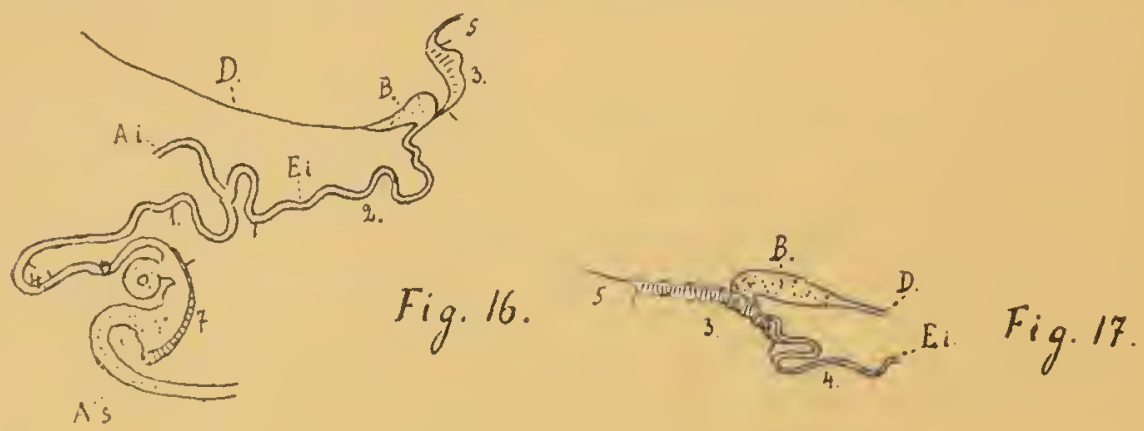

zwei weitere, dem zwölften und dreizehnten Tage entsprechend, mögen hier bei elffacher Vergrösserung folgen. Die beiden letzteren geben nur diejenigen Stücke des Eiweissorganes wieder, welche an den Binclegewebsring angrenzen. Es gelten für dieselben die gleichen Zeichenerklärungen, wie für Figur 9.

Die tiefere Lage, die der platten Zellen, änclert gleichfalls etwas ab; zwar bleiben diese Zellen immer niedrig, so dass ihre Ilöhe höchstens die Hälfte ihrer Breite beträgt, aber nach der anderen Seite hin können sie so stark variiren, dass sie völlig flach werden, so dass es schwer wird, sie auf dem Schnitt von spindelförmigen Bindegewebszellen zu unterscheiden. Ich vermag nicht nachzuweisen, ob diese untere Zellenlage überall vorhanden ist, jedenfalls ist sie es aber so überwiegend, dass ich sie für typisch halten muss. An diesen Zellen der unteren lage fand ich nun noch an der mit 4 bezeichneten Stelle der Fig. I7 (13. Tag) eine beachtenswerthe Erscheinung, welche ich in gleicher Deutlichkeit an anderen Präparaten nicht wieder gesehen habe, nümlich fadenförmige Fortsätze, mit denen diese Zellen in's Bindegewebe 1rineingreifen. Die Zellen erheben sich in ihrer Mitte zu kegelförmigen Vorsprüngen; diese Kegel laufen in Spitzen aus, uncl diese in Fïiden, welche rechtwinklig zur Wand in die Tiefe gehen. Sie scheinen die ganze, hier nicht dicke parietale Seitenplatte zu durchsetzen, und vielleicht stehen sie mit Auslïufern der Endothelzcllen, welche die Innenwand der parietalen Scitenplatte bekleiden, in Verbindung (s. 1\%ig. 5 Taf. X). 
Verschiedene Varianten des geschilderten zweischichtigen Epithels finclet man auf den Figuren 4 bis 9 der Taf. $X$ al)gebildet.

Die Epithelzellen des Eiweisssackes zeichnen sich, abgesehen ron der blasigen Modifikation, durch ein eigenthümlich homogenes protoplasmatisches Aussehen ror anderen Zellen aus, und sie nehmen in Carmin eine verhältnissmässig starke Färbung an. Oft findet man aber in ihnen runde blasse Vacuolen (I) uval spricht von körnigen Kugeln), und diese Vacuolen liegen unterhalb des Kernes; besonders charakteristisch ist in dieser Hinsicht Fig. 6 der Taf. X wo die ganzen unteren Theile der Zellen unterhalb der Kerne blass sind, so dass ausser den Kuppen nur ein schmaler, leicht körniger Mantel die Carminfärbung festgehalten hat.

Es muss nun sehr auffallen, dass Duval weder von der unteren Lage platter Zellen noch von den fadenförmig verlängerten und am Ende keulenförmig angeschwollenen Zellen etwas erwähnt; es ist unmöglich, anzunehmen, dass die so charaliteristischen, von mir gefundenen Formationen etwa durch eine abnorme Bildung bedingt sein sollten, und ebensowenig, dass dieselben bei den von Duval untersuchten Vögeln fehlen sollten. Es kanı daher der Verdacht entstehen, dass die von Dural beschriebenen Präparate nicht die genügende Deutlichkeit besassen, und dass er an Schiefschnitten untersuchte, wie sie ja bei Durchschnitten durch ganze Eier so leicht entstehen können, und welche ihn veranlassten, an Stelle von hohen cylindrischen und fadenförmigen Zellen ein geschichtetes Epithel rundlicher Zellen zu finden. Es kommen in dieser Hinsicht die Figuren $25,26,28,29$ und $3 \mathrm{I}$ von $\mathrm{D}$ ural in Betracht, aber diese Figuren sind so schematisch gehalten, dass sie der Kritik keine Anhaltspunkte zu bieten vermögen. Ich kann nur auf Grund meiner eigenen Präparate sagen, dass es mir sehr leicht geworden ist, mich von der Anwesenheit langgestreckter Epithelzellen zu überzeugen, dagegen unmöglich, die Anwesenheit einer gefässhaltigen bindegewebigen Achse in den Zellen mit Sicherheit anzunehmen oder auszuschliessen.

Noch gegen eine Ausdrucksweise möchte ich Einspruch erheben, nämlich dagegen, dass $1 \mathrm{Du} v \mathrm{val}$ die in Fig. 28 und $3 \mathrm{I}$ abgebildeten Stadien als in Rückbildung begriffene bezeichnet. Es hat hier allerdings der Inhalt des Eiweisssackes abgenommen, aber in der Beschreibung von Duval finden sich keine Anhaltspunkte, von einer Atrophie des Eiweisssacles selbst zu sprechen, und ich habe gleichfalls in den ron mir untersuchten Fällen Nichts von einer solchen bemerkt. Ich muss daher annehmen, dass das Eiweissorgan sich bis zum Schlusse der Entwicklung funktionsfähig erlält und dann das Schicksal der Allantois und des Amnios theilt, d. h. dass es beim 
Ausschlüpfen zerrissen wird und nun z. Th. in der Eischale zurückgehalten wird, z. Th. am Nabel hängen bleibt und vertrocknet.

4. Der Bindegewebsring. - Der Bindegewebsring, welcher auf meiner schematischen Fig. 5 mit B. bezeichnet ist, entspricht dem "Mesoderm-Wulst" von Duval. Die Entstehung desselben ist einfach und leicht verständlich und von Duval genau geschildert. Ich will daher nur für diejenigen Leser, welche mit der Arbeit von Duval nicht bekannt sind, kurz das Wesentliche hervorheben. Man weiss, dass die parietale und viscerale Seitenplatte, während sie im Uebrigen durch das Cölom von einander getrennt sind, an ihrem Rande verbunden bleiben, das Mesoderm mithin mit ungespaltenem Rande weiterwächst. In früheren Schemata liess man jedoch nach vollendeter Umwachsung die Spaltung zu einer vollständigen werden, so dass clann die parietale von der visceralen Seitenplatte, oder anders ausgedrïckt, dass die seröse Hülle vom Dottersack vollkommen geschieden war. Das entspricht jedoch nicht der Wahrheit: am distalen Pole findet niemals eine Trennung der beiden Seitenplatten statt. Vielmehr verdickt sich cler Mesodermrand schon zu der Zeit, wo etwa die Hälfte des Dotters umwachsen ist, und diese Verdickung nimmt mit der Umwachsung zu. Der so entstandene ringförmige II'ulst verengt sich immer mehr, und das durch ihn gebildete "Dottersackloch" schliesst sich endlich völlig. Dass meinen Beobachtungen nach bei diesem Verschluss Verzögerungen auftreten können, habe ich schon angeführt (s. p. 273).

Das Gewebe des Bindegewebsringes ist ein eigenthünlich dichtes Gewebe, welches reich ist an kurzen spindelförmigen Zellen. Duval vergleicht es mit Recht dem Narbengewebe. Obwohl die Fig. 22 von Duval, welche dasselbe wiedergiebt, sehr schematisch gehalten ist, so ist doch keine Veranlassung; genauer auf die Formation einzugehen; nur sei bemerkt, dass die Zellen in denjenigen Theilen des Ringes am dichtesten sind, welche den inneren (distalen) Rand bilden, und welche dem Epithel des Eiweisssackes anliegen.

Die Bedeutung des Bindegewebsringes findet Duval darin (6. p. 224), dass durch die einer Narbenschrumpfung vergleichbare Verengerung desselben der Dottersack zum Verschlusse gebracht werde; wobei schliesslich die ganze Area vitellina zu Grunde gehe unter Vorstülpung derselben in den früher erwälnnten (p. 272) Dottersacknabelsack. Wenn wir diese Anschaunng annehmen wollen, so haben wir in dem Vorgange der Unhüllung des Dotters zwei Stadien zu unterscheiden: erstens die Umwachsung und zweitens den endgültigen Verschluss clurch T'erengerung des Ringes. In Wahrheit halte ich es für sehr schwierig, diese bciden Vorgänge gegen eịnander abzu- 
grenzen; ich halte es bis jetzt für wahrscheinlich, dass auch zu eincr Zeit, in welcher der $\mathrm{IT}^{r}$ ulst schon deutlich entwickelt ist, sich doch das Mesoderm noch in den proximal davon gelegenen Abschnitten durch Flächenwachsthum weiterschiebt, und dass zum mindesten grosse Abschnitte der Area vitellina für den Gefässbezirli gewonnen werden. Man kann sich daher auch wundern, da doch die Unwachsung sich von Anfang an so wirksam zeigt und in so rapider Weise ror sich geht, warum nicht die Umhüllung des Dotters bis zum Schlusse durch Umwachsung allein soll zu Stande kommen, warum ein neues Moment, das der narbigen Schrumpfung, in Anwendung gelangen soll. Wenn ich daher der Duval'schen Auffassung ron der Bedeutung des Bindegewebsringes auch nicht entgegentreten will, so glaube ich doch, dass die Entstehung eines eigenthümlichen, derben, narbigen Gewebes im Mesorlermrande, für sich betrachtet, nicht recht begreiflich ist, sondern dass sie mit anderen Thatsachen und Betrachtungen in Zusammenhang gebracht werden muss. Ich glaube, dass erstens der im Verschlusse des Bindegewebsringes sich kundgebende Vernarbungsvorgang nur der Anfang von Processen ist, die wir im Dottersaclie und im Körpernabel weiter wirken sehen, und dass zweitens der Bindegewebsring eine Stütze abgiebt, damit die "Nabelhaut" ihre Wirksamkeit entfalten kann.

5. Die Nabelhaut. - Wenn man ein Ei eröffnet, kurz bevor das Hühnchen zum Auskriechen reif ist, so findet man den Dottersack eingeschlossen ron einer starli gespannten Haut von sehr bestimmten Merkmalen. Diese Haut ist vollkommen durchsichtig und lässt die dunkelgelbe Farbe des Dottersackes ungeschmälert durchscheinen, so dass man im ersten Augenblicke glaubt, den Dottersack selbst vor sich zu haben. Schneidet man jedoch die Haut auf, so tritt der Dottersack aus der Wunde hervor und sinkt schwerfällig zu Boden; die Haut selbst dagegen zieht sich stark zusammen, so dass sie nur noch einen kleinen Raum einnimmt. Es ist genau dasselbe, als ob man einen trächtigen Uterus anschneidet, und sich nun die muskulöse Wand ron dem schlaffen in ihr gelegenen Sacke zurückzieht. Die geschilderte Wahrnehmung lässt rermuthen, dass wir es mit einer muskulösen Haut zu thun haben, welcher in hohen Maasse die Fähigkeit und Neigung der Zusammenzichung innewohnt. Und so ist es auch; der wichtigste Bestandtheil dieser Haut ist eine zusammenhängende Lage glatter Muskelzellen. Ich gehe auf cine genauere Schilderung nicht ein, sondern bemerke nur, dass wir im Mesentlichen zwei sich rechtwinklig kreuzende Systeme vor uns haben, von denen aber jedes wieder durch zwei spitzwinklig sich kreuzende Richtungen ersetzt werden kann, 
WTas bedeutet diese Haut? Woher stammt sic, was wird aus ihr, was leistet sie?

Ich gehe zurück auf das Ei vom vicrzehnten Tage und lege der Besprechung desselben die nebenstehende Fig. I 8 zu Grunde. In derselben ist $\mathrm{D}=$ Dottersack, $\mathrm{Ei}=$ Eiweissorgan, $\mathrm{A} 1=$ Allantoishöhle, A.s = äusseres Blatt der Allantois ${ }^{+}+$seröse Hülle, A. i $=$ inneres Blatt der Allantois, Am $+\mathrm{A} . \mathrm{i}=$ Amnios + inneres Blatt der Allantois, $\mathrm{N}=$ Nackengegend, $\mathrm{B}=$ Bindegewebsring,

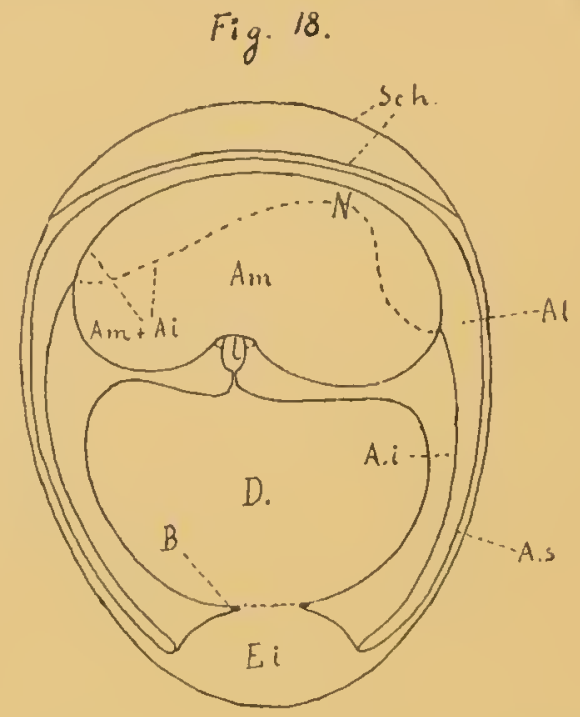

Sch $=$ Schale + Schalenhaut. Die Figur entspricht nicht in allen Punkten den natürlichen Proportionen, jedoch sind die Verhältnisse genauer berüclisichtigt, auf welche es in unserem Zusammenhange ankommt. Erstens ist das Eiweissorgan genau beobachtet; es betrug die Weite cles "Dottersacliloches“, d. h. der von dem Bindegewebsringe umschlossenen Lücke $8 \mathrm{~mm}$; die freie $W$ and des Eiweissackes macht in der Entfernung rom hindegewebsringe bis zur Allantoisfalte 5-6 mm. Zweitens ist die Ausclehnung der Verwachsung von Amnios und innerem Blatte der Allantois genau eingehalten. Dies liess sich nicht ander's darstellen, als indem das (den Embryo verhüllende) Amnios in cler Figur körperlich vorgestellt wurde, so dass man die punktirte Linie, welche die Grenze der Verwachsung angriebt, auf der Seite des Amnios sehen lánn; alle übrigen Theile digegen, Dottersack, Allantois, Eiweisssack, sind durchschnitten zu denken.

Ueber dic Verwachsung ron Amnios und innerem Blatte der Allantois ist num folgendes zu bemerken: dieselbe ist nicht so ausgedehnt, wic dic Aneinanderlagerung beider Häute; sie findet sich iiber dem Rücken des Thicres und entspricht, genatuer betrachtet, 
dem Rücken, Nacken und Scheitel desselben, stcllt also ein längliches, in der Nackengegend eingezogenes Feld dar.

Das innere Blatt der Allantois in seinen freien Theile stellte sich an diesen Präparate als ein dünnes, vollkommen durchsichtiges Häutchon dar, welches sich nach dem Einschneiden mit grosser Intensität zusammenzog, das Amnios lag dem Embryo fast unmittelbar an, so dass nur die zwischen den Körpertheilen vorhandenen Ausbuchtungen überbrückt wurden.

Verfolgen wir nun die Entwicklung weiter bis zu der in Fig. 6 und 7 dargestellten Stufe des sechszehnten Tages, so ist mit der Grössenzunahme des Huhnes auch das Amnios gewachsen und hat sich weiter gegen den distalen Pol des Dottersackes vorgeschoben; entsprechend hat sich auch die Verwachsung zwischen Amnios und innerem Blatte der Allantois ausgedehnt; es ist jedoch immer noch ein sehr erheblicher Theil des Dottersackes ausser Berührung mit dem Amnios. Dieses Verhältniss ändert sich auch nicht sehr wesentlich bis zum neunzehnten Tage. Die Amnioshöhle dringt also bis zum distalen Pole des Dottersackes endgültig erst damn vor, wenn bereits ein beträchtlicher Theil des Dottersackes in die Leibeshöhle aufgenommen ist. Da dies bis zum zwanzigsten Tage geschieht, so erhellt, dass sich zwischen dem neunzehnten und zwanzigsten Tage eine bedeutende Aenderung der topographischen Verhältnisse vollzieht, und dass gerade hier für das Studium ein ausgiebiges Material erforderlich ist. Leider habe ich dieses nicht erlangen können, obwohl ich die Untersuchung in drei verschiedenen Jahren wieder aufnahm; von den im Kasten gebrüteten Hühnern blieb nur ein Theil bis zum zwanzigsten Tage am Leben, und von diesen standen manche noch auf der Stufe des neunzehnten Tages, andere waren in der Entwicklung schon zu weit fortgeschritten. Ich kann mir daher das Bild nur vermuthungsweise ergänzen, und zwar in folgender Weise. Das Amnios verwächst immer weiter mit dem inneren Blatte der Allantois und schicbt sich dadurch immer weiter gegen den distalen Pol des Dottersaclies vor. Dadurch, dass gleichzeitig bereits Theile des Dottersackes in die Leibeshöhle eintreten, wird der $W^{\prime} \mathrm{eg}$, den das Amnios bis zum distalen Dottersackpole zurückzulegen hat, verringert. Uebrigens ist an der linken Seite des Embryo das Amnios schon früher, schon vom sechzehnten Tage an (s. Fig. I5) bis unmittelbar an den Pol herangerückt. Durch die geschilderte V'erbindung mit dem inneren Blatte der Allantois gewinnt das Amnios Beziehungen zu dem Bindegewebsringe und kann, wenn es bis zum distalen Pole vorgedrungen ist, an diesem angreifen. Ist das Amnios so weit entwickelt, so kann man auch an ihm in gewisser IVeise von einem äusseren und inneren Blatte sprechen und als äusseres 
Blatt den mit der Allantois verwachsenen Theil bezeichnen. Der letztere steht einerseits im Leibesnabel mit der Bauchhaut in Verbindung, andererseits endigt er an dem Bindegewebsringe. Natürlich sind diese beiclen „Blätter" nicht geweblich verschieden, sondern nur topographisch, sowie in ihren Leistungen und endlich in ihren Schicksalen; topographisch insofern, als das äussere bilatt mit der Allantois verbunden ist, das innere dagegen die "Nabelhaut" bildet: in ihren Leistungen insofern, als die Nabelhaut in den letzten Stadien allein die Aufnahme des Dottersackes besorgt, wie sich durch die Zugrichtung leicht anschaulich machen lässt; in ihren Schicksalen insofern, als das äussere Blatt beim Verlassen cles Eies abreisst und zurückbleibt, das innere dagegen oder clie Nabelhaut zu cinem Bestandtheile des Körpernabels wird.

Es ist damit auch die oben gestellte Frage nach der Becleutung der Nabelhaut beantwortet und damit gleichzeitig der Mechanismus nachgewiesen, durch den der Dottersack aufgenommen wird. Der Dottersack wird nicht in die Bauchhöhle hineing ezogen clurch einen an seinem proximalen P'ole angreifenden Einfluss, sondern er wird hineingedrückt clurch cine ihn umschliessende und an seinem distalen Pole anpackende Gewalt; er wird vermittelst der Nabelhaut in die Bauchhöhle hineingeboren, wird unter Mühen durch den Bauchnabel hindurchgezwängt.

Man wird jetzt auch die Wichtigkeit der Verbindung zwischen Amnios und innerem Blatte der Allantois begreifen: anfünglich vermag das Amnios nur dadurch, dass clas innere Blatt der Allantois den Zug auf den Binclegewebsring überträgt, auf diesen zu wirken, und erst zuletz, nachdem schon cin Theil der Arbeit gethan ist, genügt die Nabelhaut allein, um den Rest des 1)ottersackes hinein zu befördern.

In der Litteratur fincle ich diese Verhältnisse nicht besprochen; sellsst Baer lïsst in den Angaben über die vier letzten Tage der Bebrütung diejenige Klarheit und Anschaulichkeit vermissen, welche in Uebrigen die Lectüre sciner Angaben über clie fötalen Anhänge so genussreich macht. Man lese seine Bemerkungen auf p. r35 und 137 und man wird immerhin finden, dass Baer die Nabelhaut gekannt hat.

Ueber das Endschicksil dieser Hatut kam nach meiner Meinung ein Zweifel nicht bestehen. Dieselbe verkleinert sich gleichzeitig mit dem Durchtritt des Dottersackes durch den Bauchnabel und zwar so rapicle, dass eben dadurch bei Bacr der Irrthum entstehen konnte, sic (.. lic :̈ussere Hülle des Dottersackes") wercle abgeworfen. Sie wircl thatsïchlich nicht abgeworfen, sondern wird zu einem bestandtheile des Körpernabels, in welchem sie das "äusscre Nabelfeld" 
bildet. Eine so rapicke Verkleinerung einer Hat ist allerelings überraschend, aber nicht ohne beispicl; wir können ihr vielmehr die des Uterus an die Seite setzen.

6. Der Körpernabel. - Der Nabel des Huhnes ist cine zusammengesetzte Bildung; es gehen in ihn ein die Nabelhaut, der Bindegewebsring, der Allantoisrest, der Rest des Eiweisssackes, und ausserdem ist der Dottersack mit ihm verbunden. Der Rest der Allantois und des Eiweisssackes wird bald abgestossen, indem der Nabel "sich reinigt", cler Bindegewebsring und die Nabelhaut verkleinern sich mit erstaunlicher Schnelligkeit, der I)ottersack aber bleibt, so liange er überhaupt besteht, mit dem Nabel in Verbindung.

Betrachten wir zunächst den Nabel eines Huhnes, welches zum Ausschlüpfen reif ist. Es ist dasselbe Hühnchen von unten, welches

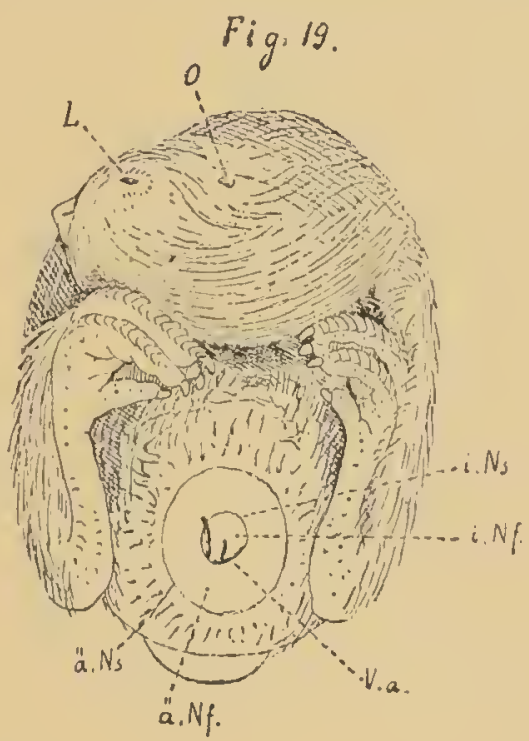

in Fig. 3 von der Seite abgebildet ist. In der Figur ist i. Ns = innerer Nabelsaum, ä. Ns = äusserer Nabelsaum, i. Nf = inneres Nabelfeld, ̈̈. Nf = äusseres Nabelfeld, V.a = Allantoisgefisse, $I_{2}=$ rechte liclspalte, $\mathrm{O}=$ rechte Ohröffnung. Wir bemerlien innerhalh) (ler befieclerten Bauchhat cin clliptisch begrenztes Feld, in sagittaler Richtung $16 \mathrm{~mm}$, in pucrer Richtung 1 I $\mathrm{mm}$ messend, dazu kommt ein $2 \mathrm{~mm}$ breiter Uebergangssaum, welcher dic Verbindung mit der Bauchhaut vermittelt, $d$. h. er ist von cler gleichen beschaffenhcit wic das Nabelfeld, jedoch nicht in der gleichen Weise gewulstet. 1)as letztcre hat nämlich cine starke Völbung (s. Fig. 4); aber clicse beschränkt sich auf einc’n äusseren ringfürnigen $\lambda$ bschnitt (.,̈̈usseres Nabelfeld*), welcher ein rundliches, inneres Nabelfeld" umschliesst. 
An cler Grenze beider im „inneren Nabelsaum" treten die Allantoisgefässe aus. Betrachtet man den Nabel von der Hautseite, so zeigt sich das äussere Nabelfeld regelmässig gestaltet, durch eine feine radiäre Runzelung ausgezeichnet; das innere ist ron unregelmässiger Oberfläche, von einer anhaftenden, in Alcohol weisslich werdenden Masse, Resten von Eiweiss, bedeckt. Bei der Betrachtung von der Bauchfellseite zeigt sich das äussere Feld glatt und frei, von Bauchfell überzogen, das innere dagegen ist mit dem distalen Pole des 1)ottersackes untrennbar verbunden. An dieser Stelle fand ich bei allen untersuchten Thieren, bis zum siebenten Tage nach dem Ausschlüpfen, ein kleines Säckchen von weisslicher Farbe und undcutlichem Inhalt, aber sehr fest; vielleicht einen Theil des Eiweisssackes darstellend, der bei der Nabelbildung mit nach innen gezogen wurde.

Von den schnellen Veränderungen des Nabels mögen folgende Angaben einen Begriff geben.

12 Stunden nach dem Ausschlüpfen. - Das Nabelfeld ist unbehaart, von mattgelber Farbe. Es ist ein flachgewölbter Ring, der ein feines Grübchen ("Nabelgrube") umschliesst. Das Grübchen ist scharf eingesenkt, so dass es den Eindruck eines Loches macht. Auf der Innenseite sitzt dem Nabel ein weisser Knoten (EiweisssackRest:) an. Der Dottersack stösst an den Nabel unmittelbar an. Diese Verbindung hat die Weite von I mm.

36 Stunden nach dem Ausschlüpfen. - Das Nabelfeld hat ein schlaffes Aussehen, ist schmutzig dunkel-olivenfarben. Die Nabelgrube ist scharf eingebohrt; aus ihr ragt ein trockener Zapfen hervor. Ein solcher Nabel sei hier nach einem sagittalen Schnitte bei elffacher Vergrösserung vorgelegt und geschildert. Die vier mit ä Ns bezeichneten Striche bezeichnen die Grenze des Nabelfeldes (äusserer Nabelsaum) gegen die Bauchhaut. Die Nabelgrube zeigt einen engen Eingang und einen weiten Grund und wird rollkommen ron dem Allantoisreste ausgefüllt. Der Eingang in die Grube entspricht nicht etwa dem inneren Nabelsaume der Fig. I9, sondern dieser ist in den Cirund der Grube hineingerückt, und seine Lage ist hier nicht mehr sicher zu bestimmen. Die "Nabelhaut" aber, welche auf Fig. 12 das „äussere Nabelfeld" bilclete, hat sich eingerollt und begrenzt nun ihrerseits den Eingang in die Grube. Mit dem Boden der Grube steht auf der anderen Seite der Dottersack (I) in unmittelbarer Verbinclung; jat es führt sogar noch ein Kanal (.,Nabelloch") aus dem Dottersack bis in den Allantois-Rest hincin. In diesem Kanale bemerkt man cine zum Theil homogene, zum Theil streifige Masse (liiweiss?), welche durch Eosin einen schr starken liarbenton angenommen hat. Der Allantoisrest zeigt noch Reste von 
Gefissen, er firbt sich im Ganzen stark und ist reich an Leucocyten mit Kernzefall; ror allem findet sich dort, wo er sich gegen den

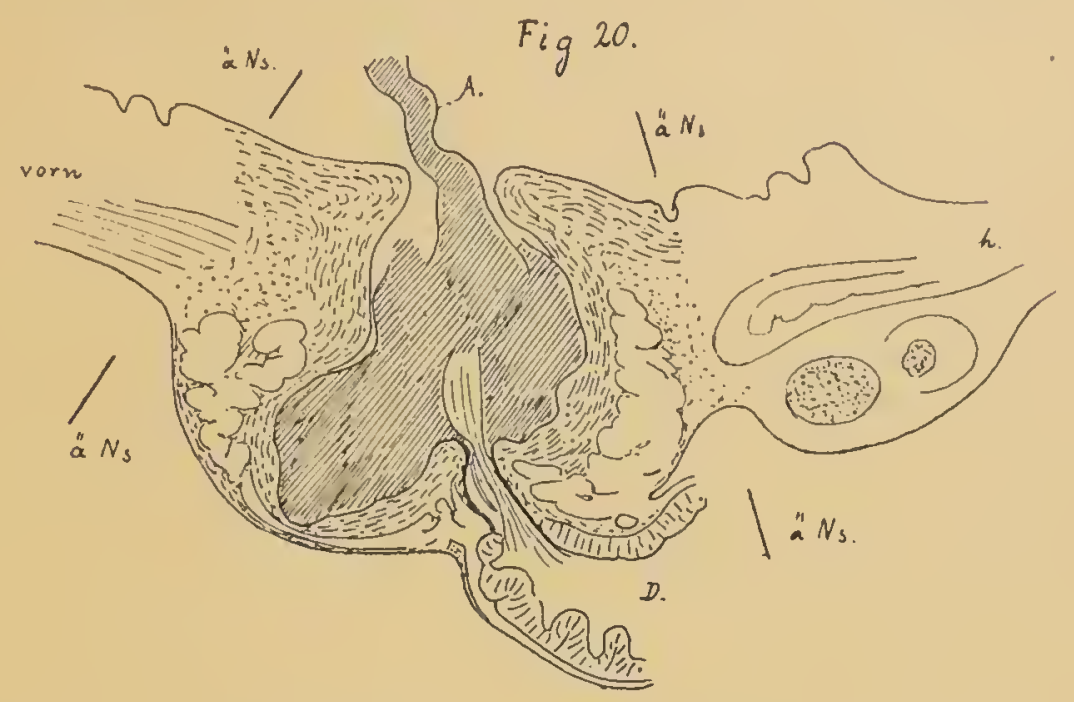

Grund der Nabelgrube absetzt, an diesem Präparate und noch mehr an einem anderen Präparate des ersten Tages eine Zone, die mit Rundzellen stark infiltrirt ist (Demarkationszone). In der Wand der Nabelgrube lassen sich zwei verschiedene Gewebsbestandtheile unterscheiden; an der Bauchfellseite sieht man ein ausserordentlich dichtes, feinfasriges Gewebe, welches eine unregelmässig gestaltete Platte bildet; an der Hautseite dagegen und ebenso an dem Eingange der Grube ein faseriges Gewebe, welches reich ist an stäbchenförnigen Kernen. Es ist zu vermuthen, dass in letzterem die Muskelschicht der Nabelhaut enthalten ist, doch ist der Charakter der Muskelzellen nicht mehr deutlich erkennbar. Woher das dichte Narbengewebe der peritonealen Seite stammt, ist nicht gan\% deutlich, es ist jedoch beachtenswerth, dass sich dasselbe nicht nur bis an das Nabelloch heran fortsetzt, sondern auch ohne Unterbrechung in ein ebenso gestaltetes Gewebe übergeht, welches man in der IVand des Dottersackes antrifft. Hierauf bezog sich eine frühere Aeusserung (S. 278), dass der im Bindegewebsringe zuerst sichtbare VernarbungsVorgang auf den Nabel und auf den Dottersack übergreife. Endlich wurden auf diesem Präparate auch die concentrischen Körper wiedergefunden, von denen ich früher (S. 249) gresprochen habe, und zwar nicht nur im Dottersacke, sondern auch in der Wand des Nabelloches und in der in den Allantoisrest hineinragenden homogenen Masse. Ol) sie an diese Stellen church Austritt ius dem Dottersacke gelangt, oder ob sie in loco gebildet seien, nuss unentschieden bleiben.

3 Táge nach dem Ausschlüpfen. - Die Nilbelhaut ist schlaff, 
schmutzig gelblich bis graubraun. Das Nabelfeld hat die Gestalt einer kilcinen sagittal gestellten Ellipse, welche nach vorn und hinten in eine I inie (Naht) ausläuft; es misst ohne diese Verlängerungen $5,5 \mathrm{~mm}$, mit denselben I I, $5 \mathrm{~mm}$. Die Nabelgrube ist scharf, in ihr ein trockener Zapfen, der Allantoisrest. Das Nabelfeld ist mit dem Dottersacke innig verbunden, und an der Stelle der Verbindung liegt cin weisslicher Vorsprung mit gelblichen Einschlüssen.

Am vierten Tage. - Der Nabel hat äusserlich die gleiche Beschaffenheit.

Am sechsten Tage. - Der Nabel hat sich noch mehr in eine sagittal gestellte Naht umgewandelt, und es ist nur noch ein kleines Nabelfeld vorhanden. Dieses ist von einer hohen Lage trockener, in Abschuppung begriffener İpidermis bedeckt. Indem diese abgehoben wird, folgt zugleich eine feste ziemlich trockene Masse, und es bleibt ein Grübchen zurück. Es ist dasselbe, als wenn man einen etwas tiefgehenden Schorf von der Haut abhebt.

Iron diesem Nabel gicht liig. 2 I cin Bild auf Grund cines clffach vergrösserten (Querschnittes. Man sieht, wenn man diese Figur

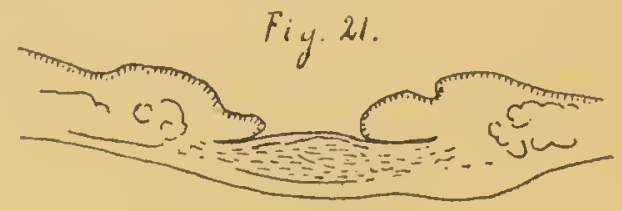

mit der vorausgehenden vergleicht, eine bedeutende V'eränderung: die Nabelgrube hat sich verlicinert; nicht nur hat sic sich verflacht, indem ihr Grund sich gehoben hat, sondern ihre Ränder haben sich ancinandergelegt. Der Boden der Grube wird von einer Platte gebildet, in welcher wir drei Lagen unterscheiden. Dic mittlere Lage besteht aus einem dichten fibrillären lBindegewebe, welches an spindelförmigen Kernen reich ist; von dort nach aussen folgt eine schmale noch dichter faserige und intensiver sich färbende Schicht, und an der Innenscite liegt eine mehr lockere, an Blutgefïssen reiche Schicht.

Am sichenten Tage fand ich dic Verhältnisse noch ebenso wie an sechsten; doch trat ich bei cincm viertägigen Hühnchen einer anderen Brut den Nabel nur noch clurch eine sagittale Spalte clargestellt, deren l,änge sich nicht melı genau feststellen liess.

Wir können diesen Vorgang durchaus einer V'crnarbung vergleichen: dic ursprünglich tiefe Grube reinigt sich und kommt z. Th. durch Abflachung des Grundes zum Verschluss; damit verschwindet zugleich die Vorwölbung, welche der Nabel in den ersten Tagen gegen die Bauchhölle hin bildete. In kurzer Zeit ist in der befiederten Bauchhaut keine: Spur mehr aufrufinden, und nichts lässt darauf 
schliessen, dass cine so bedeutende und wichtige Bildung wie die Nabelhaut an dem Aufbau des Nabels betheiligt gewesen war.

7. Der vitello-amniotische Faden. - Ausser dem \%usammenhange der übrigen liragen mache ich eine Mittheilung über cinen eigenthümlichen Faden, der vom proximalen Pole des Dottersackes zum Amnios zieht. Er liegt in der sagittalen Ebene und zwar vor dem Inttergange. Ich beschreibe ihn vom Hühnchen von I6 Tagen. Fir ist hier $18 \mathrm{~mm}$ lang, sehr fein aber fest und heftet sich am Dottersacke $2 \mathrm{~mm}$ vor dem Dottergange, am Amnios $20 \mathrm{~mm}$ vor dem Nabel an. Er besteht gänzlich aus längsverlaufenden schmalen Spindeln, anscheinend glatten Muskelzellen, welche am Amnios zwischen dic glatten Muskelzellen dieser Haut ausstrahlen; in der Achse läuft ein feines Gefäss.

Ich fand diesen Faden auch am siebzehnten und neunzehnten Tage. Bei einem Hühnchen des siebzehnten Tages war er I 2 mm lang und befestigte sich am Dottersack dicht am Dottergange, am Amnios $6 \mathrm{~mm}$ vor dem Bauchnabel.

Ueber die Bedeutung dieses Fadens kann ich nichts aussagen, auch nicht, ob derselbe mit dem Ligamentum vitello-intestinale Panders (20. S. 26) gleichbedeutend ist.

Eine A usstïlpung des Dottersackes sei hier gleichfalls erwähnt. Ich fand dieselbe bei einem Huhne von siebzehn Tagen. Die Ausstülpung hatte die Gestalt eines Trichters, der von den Seiten her plattgedrückt war und grössere Ausclehnung in sagittaler Richtung besass. Dieser verschmälerte sich zu einem Gange, der ron der Mitte der Ausstülpung an gleich weit blieb und sich so blind an clas Amnios ansetzte. Die Stelle der Ausstülpung lag am Dottersacke $9 \mathrm{~mm}$ vor der Anheftung des Dotterganges, die Stelle der Anheftung am Amnios $9,5 \mathrm{~mm}$ vor dem Leibesnabel; die Länge betrug 9 1mm, die Weite des Trichtereinganges in sagitaler Richtung $4 \mathrm{~mm}$, die Weite des Ganges in seinem Iindabschnitte $0,5 \mathrm{~mm}$. Die ganze Ausstülpung war mit I)otter erfüllt.

8. Rückbildung cles Dottersackes. - Diesc Aufgabe bestcht in drei Theilen: es ist der noch vorhandene freie Dotter, der in den Zellen enthaltene Dotter und endlich der Dottersack selbst zu resorbiren. Da, wic oben benerkt wurcle, der Dottersack des Hühnchens, welches das $\mathrm{Ei}$ verlässt, noch cinen grossen Umfang besit\%, so ist dic Aufgabe bedeutend und sie wird erstaunlich schnell vollbracht. Das lässt sich am besten durch Zahlen anschaulich machen. Ich gebe die letzteren in Form einer kleinen 'labelle, in welche sechs Hühner einer Brut aufgenommen sind, sämmtlich kräftige, gut befiederte Thierchen, von der llenne ausgelnrütet. 


\begin{tabular}{|c|c|c|c|c|c|}
\hline I 2 & Stunden & alt & $\begin{array}{c}\text { Ges.-Gew } \\
37,2 \mathrm{~g}\end{array}$ & $\begin{array}{l}\text { Gew. d. Ds. } \\
5,34 \mathrm{~g}\end{array}$ & $\begin{array}{l}\text { Gew. d. Leber. } \\
\text { I, I } 5 \mathrm{~g} \text {. }\end{array}$ \\
\hline $3^{6}$ & $"$ & $"$ & 35,33 " & 3,34 & $\mathrm{I}, 2 \mathrm{I}$ \\
\hline 3 & Tage & $"$ & 33,75 & $2,5^{\circ}$ & I, 25, \\
\hline $3-4$ & , & $"$ & $3^{6,93}$ & $0,60$. & I,62, \\
\hline $6-7$ & $"$ & $"$ & 39,54 & 0,43 & I, 80, \\
\hline $5-6$ & , & $"$ & $43,66$. & 0,05, & $\mathrm{I}, \mathrm{S}_{2} \ldots$ \\
\hline
\end{tabular}

Ich habe das fünf bis sechs Tage alte Hühnchen hinter das sechs bis sieben Tage alte gesetzt, weil es sich in allen Beziehungen weiter entwickelt zeigte; derartige indivicluelle V $\mathrm{T}$ erschiedenheiten können ja nicht Wunder nehmen; von Interesse ist aber, dass das ältere Hühnchen nicht bloss nach Körpergewicht oder Dottersackgewicht oder Leber sondern nach allen drei Beziehungen und ebenso nach der Ausbildung des Dotterganges vor das jüngere gehörte.

Die Gewichtsabnahme in den ersten drei Tagen rührt wahrscheinlich daher, dass die Thiere, wie ich den Angaben einer Geflügelzüchterin entnehme, in den ersten drei Tagen wenig zu fressen pflegen, während sie doch durch Muskelthätigkeit und Athmung an Gewicht verlieren. Möglich ist es aber auch, dass hier individuelle Verschiedenheiten rorlagen; ein sicherer Nachweis würde natürlich nur geliefert werden kïnnen, wenn das gleiche Thier an aufeinanderfolgenden Tagen gewogen würde. Bei einer Ente, die am Ausschlüpfen war, fand ich das Gesammtgewicht $46 \mathrm{~g}$., das Gewicht des Dottersackes $6 \mathrm{~g}$. und das der Leber I. I $\mathrm{g}$.

Wie lange sich noch Reste des Dottersackes beim Huhne überhaupt nachweisen lassen, habe ich nicht verfolgt; auch mag es wohl wie bei allen in Rückbildung begriffenen Organen verschieden sein. Jedesfalls aber kann man sagen, dass schon nach ganz wenigen Tagen der Dottersack des Huhnes als ein irgend wie bedeutsames Organ aufgehört hat zu existiren.

Auffallend ist es dem gegenüber, dass bei straussartigen V’ögeln der Dottersáck zeitlcbens fortbestehen soll, wie Sieboldt und Stannius (25 p. 302) berichten.

Der Torgang der Rückbiklung ist ein eigenthümlicher, und ich glaube nach den Beobachtungen, die ich darüber gemacht habe, dass dabei die schon erw:ïnte ,narbige Schrumpfung" die eigentlich treibende Kraft darstellt, dass also dem Bindegewebe eine active Rolle zufïllt. W'ir müssten also das Bindegewebe des Dottersackes zuvor genauer kennen lernen. Schon am vierten und sechsten Tage findet man in $1 \mathrm{~cm}$ Bindegewebe des Dottersackes eigenthümliche, verïistelte, z. Th. ungcheuer grosse Zcllen. In clen letzten Tagen ist an ihre Stelle eine gleichfalls sehr eigenartige Zellenform getreten: 
ziemlich grosse l'latten, deren Ränder ausgezackt und in Fï̈len fortgesetzt sind. Am ersten Tage nach dem Ausschlüpfen bemerkt man davon nichts mehr, sondern das Bindegcwebe des Dottersackes ist schr dicht geworden und hat einen faserigen Charakter angenommen. Zugleich hat sich die bindegewebige Wand verdickt, und in elieser Wand bemerlit man nun drei Schichten, eine äussere kernreiche, eine mittlere überaus dichte und feinfaserige oder auch undeutich faserige kernarme Schicht, welche auf Schnitten wie ein hin- und her- . gebogenes Band erscheint, und eine innere kernreiche Schicht, welche in das Stroma der Blätter unmittelbar übergeht. Die Gefässe der Wand liegen hauptsächlich in dieser inneren Lage. Die Streifung der mittleren Lage ist senkrecht zur IVand gerichtet.

Die charakteristischen Anhänge der Wand, welche früher (p. 254) als Blätter oder Gitter beschrieben wurden, sind bis zum sechsten Tage zu erkennen; in der bindegewebigen Aclse ihrer einzelnen Balken verlaufen Gefïsse und ein einschichtiges Epithel überzieht sie. Die Epithelzellen selbst, obwohl in ihren Eigenschaften etwas verändert, haben doch noch ihre specifischen Merkmale bewahrt. Allmählich ergreift jedoch der V Verdichtungsprocess auch das Bindegewebe der Blätter, und wic mir scheint wird zuletzt das Epithel durch das Bindegewebe erstickt.

Einige Angaben hierïber mögen folgen.

3 bis 4 Tage. - In den Blättern ist im Allgemeinen das Bindegewebe noch spärlich, doch dringt das narbige Gewebe z. Th. breitcr in die Basen derselben vor.

5 bis 6 Tage. - Das Bindegewebe in den Balken ist dichter und relativ kernreicher.

6 bis 7 Tage. - Anstatt der schlanken Balken des reifen Dottersackes unterscheidet man dicke Zapfen oder Kolben, von dichtem faserigem Bindegewebe (Narbengewebe) gebildet. Innerhalb derselben findet man zahlreiche und weite Gefässe, theils mit farbigen Blutzellen, theils mit Leucocyten strotzend gefüllt. Auch ausserhalb der Balken trifft man vielfach ein bindegewebiges Netz, welches rundliche blasige Räume cinschliesst. Es sieht so aus, als sei das Bindegewebe zwischen die einzelnen Epithelzellen gewuchert und habe diese umschlossen. Leucocyten trifft man frei im Bindegewebe, besonders reichlich in den unteren Partien der Balken; dort, wo sich letztere an die Wand ansetzen, in Form eincr so reichen Infiltration, dass das Bild einer Demarkationszone entsteht. Auch im Innern von Epithelzellen sowie in den freien Resten des Dotters kommen I.eucocyten vor.

Auch bei einem Huhn einer anderen Brut, welches mir als viertägig übergeben wurde, welches aber cine verhältnissmässigr weite Virchow-Festschrift. Bd. 1. 
Entwicklung zeigtc, waren ähnliche Erscheinungen zu beobachten. Die Wand war ausserordentlich dick im Vergleich mit der Weite des Innenraumes, ihr dicht faseriges Gewebe schloss in den inneren Theilen blasige Bildungen ein, welche Reste umwachsener Epithelzellen zu sein schienen. Das Lumen war im Uebrigen nocls von blasigen Zellen ausgeklcidet, welche sich jedoch schon ron dem ursprünglichen Typus weit entfernt hatten.

Es ist dics zugleich der einzige Fall, in welchem ich den Dottersack gegen den Dottergang abgeschlossen fand und zwar durch eine riemlich diclie Platte von fibrösem Bindegewebe. Genau genommen darf ich rielleicht nicht einmal sagen, dass in diesem Falle der Dottersack gegen den Dottergang abgeschlossen gewesen sei, denn dic Form der Zellen in dem distalen Abschnitt des „Dotterganges" liess clarauf schliessen, dass man noch ein Stück Dottersack ror sich habe, class also eine Verwachsung innerhalb des letzteren entstanden sei.

()) dieser Verdichtungsprocess des Dottersackindegewebes ren einer Seitc ausgeht oder in der ganzen Wand gleichmässig Platz greift, kann ich nicht entscheiden. 1ch will aber doch bemerken, dass man in den ersten Tagen nach dem Ausschlüpfen den Dottersack an seinem distalen Pole so zu sagen ,zusammengerafft" findet, wie man einen Beutel durch einen laden zusammenraffen kann. Es macht mir in der That den Eindruck, als wenn von hier der Process ausginge, womit er sich dann anreihte an den Vernarbungsvorgang, den wir am Bindegewebsringe und am Nabel thätig sehen.

9. Leber. - Ich habe in die oben (1). 2SS) gegebene Tabelle die Lcber mit aufgenommen, einmal, weil sie als dis grösste Eingewcide des jungen 'Thieres am bequemsten zum Vergleiche herangezogen werden kann, dann aber und vor allem, weil sie in offenkundigen Beziehungen zum Dottersacke steht, indem sie rorübergehend zu einem Stapelplatze des Dotterfettes benutzt wird. Darauf deutet mit Sicherheit ihr Ausschen, nämlich ihre schwefelgelbe oder postwagengelbe Farbe; ein Cielb, welches ebenso satt als rein ist. Ich habe darüber folgendes rerzeichnet: Bei einem Huhn, welches zum Ausschlüpfen reif war, - rein gelb; I 2 Stunden und 36 Stunden später - orange; am dritten 'Tage - grauliche Beimischung zum reinen Gelb; am vierten — helleres Gelb mit leicht grauer Beimischung; am fünften und sechsten -- mit grauröthlicher Beimischung. Man kann schon aus diesen Befunclen schliessen, dass die leber anfänglich so sehr mit fett beladen ist, dass die Blutfarbe gar keinen lïnfluss auf dic Gesammtfärbung gewinnt, wïhrend nnit der Abnahme des Dottersackes sich das Verhältniss schon zu ändern beginnt. 
Bei der mikroskopischen Lintersuchung des frisch zerzupften Organes benterkt man ausschliesslich fettropfen, diese fast alle gleichgross und von hohem Lichtbrechungsvermögen; neben ihnen blasse Kerne, aber keine Zellenstruktur. Schnitte machte ich von Lebern eines reifen, cines 4 tägigen, cines 5 bis 6 tägigen lluhnes und ciner reifen Ente. Dic l elserzellen sind ziemlich klein, eckig begrenzt. Die Protoplasmanetze sind verhältnissmässig grobmaschig bei den beiden jüngeren Thieren, bei der linte sind die Maschen gleich gross, so dass ein zierliches Bild entsteht; bei dem Huhn ungteicher. Bei dem Huhn ron 5-6 Tagen sind die Maschen so eng; dass dic Zellen mehr lïrnig und ziemlich dunkel erscheinen, bei dem Huhn von vier Tagen sind deutliche Protoplasmafäden nicht vorhanden, sondern mehr eine weiche flockige Zeichnung, welche dicht die Randtheile der Zellen erfüllt, während im Innern der Zellen hellere Räume erscheinen. Die Kerne stehen bei dem Huhne von 5-6 Tagen grossentheils im Centrum der Zellen, bei den drei anderen sind sie excentrisch und zwar den Gefässseiten anliegend.

Io. Verbindung des Dottersackes mit dem Nabel. Diese Verbindung, die weiter oben (p. 284) schon erwähnt wurde, erhält sich stets; unter allen von mir untersuchten Thieren habe ich nicht cin einziges gefunden, bei dem sie gefehlt hätte. Ich muss daher den entgegenstehenden Schemata unserer Lehrbücher jede Berechtigung absprechen. Die Verbindung kann die Form eines dünneren Stieles annehmen, wie ich z. B. bei dem oben erwähnten, angeblich viertägigen, aber verhältnissmässig weit entwickelten Thier zwischen distalem Dottersackpol und Nabel einen 2,5 $\mathrm{mm}$ langen Faden, bei einer zum Ausschlïpfen reifen Ente einen I mm langen Stiel fand, der am Nabel mit einem kleinen Ḱnopfe begann. In der Mehrzahl der Fälle ist jedoch ein Stiel nicht vorhanden, sondern der Dottersack ist mit dem Nabel unmittelbar verbunden, in einer Breite von I mm oder mehr.

1r. Der Dottergang. - Drei liragen sind es, die mich veranlassen, aus dem Zusammenhange meiner Arbeit heraus dem I ottergange Aufmerksamkeit zu schenken. Erstens muss genauer, als bisher bekannt war, festgestellt werden, ob nicht clurch den Dottergang, ähnlich wie es bei Selachiern (19. p. 107 u. I09) zu geschehen scheint, da hier im Dottergange flimmerndes Epithel vorhanden ist, Dotter in den Darm befördert wird, um dort durch clas Epithel aufgenommen zu werden, wenigstens zu einer gewissen Zeit und in einem gewissen Jimfange. Zweitens muss untersucht werden, ob sich in dem Bau des I otterganges Anhaltspunkte dafür finden, dass 
der Dottergang, wie man gewöhnlich behauptet, den Dottersack in die Bauchhöhle hineinziehe. Dazu kommt aber die dritte Frage, die morphologische, ob der Dottergang, zwischen Dottersack und Darm eingeschaltet, eine Mittelstellung zwischen beiden einnehme, oder ob er einem von beiden hinzuzurechnen sei.

Ich habe keine Untersuchung der ganzen Entwicklung des Dotterganges vorgenommen, aber ich habe doch einige Bemerkungen gemacht, welche ein ausreichendes Licht auf diese Fragen werfen. Die. Figuren $10-I_{5}$ meiner Tafel X u. XI geben Abbildungen des Dotterganges aus verschiedenen Stadien, und da alle diese Figuren bei gleicher Vergrösserung gezeichnet sind, so ergiebt schon ein cinziger Blick Aufschluss über die relativen Dimensionen.

Nan muss die Entwicklung des Dotterganges in zwei Perioden theilen. Die erste derselben endigt mit der Aufnahme des Dottersackes in die Bauchhöhle. Bis zu diesem Zeitpunkte ist der Dottergang sehr dünn; die Dottersackgefüsse, welche durch Mesenterien mit ihm verbunden sind, nehmen auf dem Durchschnitt einen grösseren Raum cin, als er. Auch seine Länge ist während dieser Zeit unbedeutend und dabei wechselnd, wie dic folgende kleine Tabelle zeigt:

$\begin{array}{llllllll}\text { I4 } & \text { Tage } & . & . & . & 2,75 & \mathrm{~mm} & \text { lang } \\ \text { I6 } & " & . & . & . & 4 & " & \\ \text { I } 7 & " & . & . & . & \text { I,5 } & " & " \\ \text { I9 } & " & . & . & . & \text { I } & " & "\end{array}$

Die zweite Periode beginnt nach dem Ausschlüpfen des Thieres; ich rerwende hier wieder die sechs Hühnchen einer Brut, von denen schon oben die Rede war.

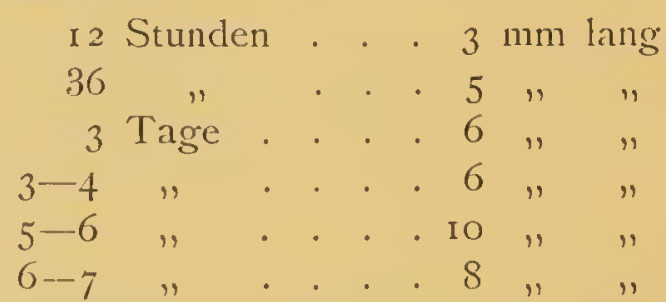

Diese Zahlen enthüllen die überraschende Thatsache, dass der Dottergang mit der Verkleinerung des Dottersackes an Länge nicht ab- sondern zunimmt. Diese Zunahme hält wenigstens bis zum sechsten Tatge an; ja wenn wir auch hier das sechs bis sieben Tage alte Hühnchen vor clas fünf bis sechs Tage alte setzen wollten, was sich ja aus dem oben angeführten (p. 288) (irunde rechtfertigen liesse, so) würden wir zu dem Ergebniss kommen, dass die Stcigerung bis zum Schluss der Reihe fortgeht. leh bedaucre daher sehr, dass meine Untersuchung nicht weiter geführt ist, damit man sehen könnte, was atus dem Dottergange schliesslich wird. Diese Verlängerung wird keineswegs durch eine Abnahme in der Dicke ausge- 
glichen, sondern die Jicke, welche am ersten Tage 0,75 $\mathrm{nm}$ beträgt, wïchst am zweiten Tage auf $1 \mathrm{~mm}$ und bleibt auf dieser lö̈he bis zum siebenten Tage.

Einen einleuchtenden Grund für cliese Zunahme habe ich nicht auffinden können.

Die steigende Entwicklung macht sich sowohl in der IVand wie in Lumen bemerkbar. Schon am vierzehnten Tage ist in der Wand rings um das Lumen ein Längsfaserzug bemerkbar, anscheinend aus gratten Muskelzellen gebildet. Dieser nimmt an Dichtigkeit und Stärke zu, so dass er nicht mehr wie in Anfange aus getrennten bündeln besteht, sondern eine geschlossene Lage darstellt. Noch mehr aber fällt die Zunahme in der Menge und Dichtigkeit des Bindegewebes auf, welches z. Th. eine circuläre Anordnung annimmt. Die Schleimhaut legt sich in Längsfalten, und es bilden sich sogar Recessus aus, die zwar nicht als Drüsen bezeichnet werden liönnen, jecloch eine gewisse äusserliche Aehnlichkeit mit einfachen schlauchförmigen Drüsen haben.

Die Verbindung mit dem Darmlumen habe ich in allen Fällen erhalten gefunden, ja es bildet sich die Stelle der Einmündung in sehr charakteristischer W'eise um, indem sie in Form einer Papille in den Darm vorspringt, wie Fig. I5 der Taf. XI zeigt. Diese Papille ist nur von einfachem Darmepithel bekleidet, und es fehlen auf ihr die Zellen bezw. Leisten, sowie die Lieberkühn'schen Krypten.

Die Verbindung mit dem Dottersack habe ich gleichfalls, mit Ausnahme des einen oben erwähnten (p. 290) Falles, stets offen gefunden.

Die Epithelzellen, welche den Dottergang auskleiden, werden in allen Fällen in einschichtiger Lage getroffen, und man kann im Allgemeinen dieses Epithel als eine Zwischenstufe zwischen dem Darmepithel und dem Dottersackepithel bezeichnen. Genauer gesagt fand ich die Epithelzellen in der Mitte des Dotterganges am neunzehnten Tage kubisch, gegen das Lumen leicht gewölbt, gegen einander scharf abgegrenzt; am ersten Tage nach dem Ausschlüpfen niedrig cylindrisch; am fünften bis sechsten Tage schmal und hoch, an der Stromascite zugespitzt und an der freien Seite vielleicht clurch einen Cuticularsaum, jedenfalls aber durch eine sehr schurfe dunkle Grenzlinie ausgezeichnet. In dem letzteren Stadium lagen die Kerne in der Mitte der Zellen, und der der Lichtung zugewendete Theil der Zellen hatte durch Carminfärbung einen röthlichen Farbenton angenommen.

An dem Ostium intestinale des Dotterganges sowic in dem proximalen Abschnitte des letzteren hat das Epithel genau die Merk- 
male des Darmepithels; am ersten Tage, wo an den Zellen des letzteren der Cuticularsaum und sogar die Stäbchenstructur sehr deutlich ist, findet man hohe schmale Zellen mit Cuticularsaum auch bereits in Anfangstheile des Dotterganges. Der Uebergang dieser Zellen in die niedrigeren Zellen des Mitteltheiles vollzog sich an cinem Präparat vom vierten Tage nicht durch gleichmässiges Kleinerwerden der Zellen, sondern es traten in dem hohen Epithel zunächst Gruppen niedrigerer und dabei breiterer Zellen mit kugligen kernen auf.

Der Uebergang zu dem Epithel des Dottersackes wird daclurch zu einem noch mehr vermittelten, dass schon in Dottersacke sclbst, auf cler an das Ostium vitellinum des Dotterganges angrenzenden Region, die Zellen niedriger sind, als es den Epithelzellen des Dottersackes sonst zukommt. V'on diesen Zellen vollzieht sich dinn cler Uebergang zu denen cles Dotterganges stellenweise schneller, stellenweise aber auch sehr allmählich; z. B. an dem auf Taf. X1 abgebildeten Präparate des neunzehnten Tages folgen auf grosse blasige Zellen, welche nicht entfernt die Höhe der typischen Dottersacliepithelzellen haben, in zweiter I inie grosse blasige aber mehr breite als hohe Zellen; sodanı noch niedrigere und endlich stark abgeplattcte Zellen, die aber immer noch die typischen Merkmale ron Dottersackepithelzellen haben, nämlich blasiges Aussehen und bodenständigen Kern. An einem Präparate vom ersten Tage finde ich, anschliessend an die blasigen, gleichmässig gekörnten Zellen des Dottersackes, in dem distalen Abschnitte des Dotterganges cylindrische, jedoch nicht sehr hohe Zellen, welche den Dottersackepithelzellen durch ihre körnige Beschaffenheit, das Fehlen eines Cuticularsaumes und dic abgerundeten Kuppen, den Darmepithelzellen dagegren durch die Lage der Kerne in der Mitte der Zellen gleichen und zwischen beiden durch ihre Grösse stehen.

Nach dem, was ich mitgetheilt habe, sind die oben aufgestellten crei Fragen in folgender $W^{\top}$ cise zu beantworten.

I. In der Wand des Dotterganges ist allerdings ein Längsfaserzug von wahrscheinlich muskulärer Natur vorhanden; der Dottergang ist jecloch bis zum Ende der Brützeit viel zu schwach und vor allem viel zu kur\%, um irgend einen nennenswerthen Einfluss auf die \ufnahme des bottersaclies ausüben zu können.

2. Der Dottergang stellt so lange, als noch nennenswerthe Reste ron Dotter vorluanden sind, cine offene Verbindung von Dottersack bis in den I)arm dar. Es wäre also danach die Möglichkeit gegeben, dass dauernel Dotter in den Darm gelangte, um hier zur Aufnahme zul kommen. Ich muss jerloch, obwohl diese Verbindung bestcht, und obwoll ich gelegentlich in dem distalen $\Lambda$ bschnitte des Dotter- 
ganges 1)otterbestandtheile gefunden habe, in Uebereinstimmung mit Courty (4. p. 29) bestreiten, dass vom 1)arne aus l)otter resorbirt wird. Denn ich habe weder bei der Untersuchung des frischen (aus Detritus und abgestossenen Plattenepithelzellen bestehenden) Darminhaltes, noch bei der Untersuchung des mit Osmiumsäure behandelten Dünndarmepithels Anzeichen einer solchen Aufnahme gefunden.

3. Der Dottergang bilclet morphologisch anfänglich anscheinend ein Zwischenstück zwischen 1)ottersack und Darm; es enthüllt sich jedoch mit fortschreitender Entwicklung zunehmend die Zugehörigkeit desselben zum Darme.

Das fertige Dottersackepithel und das Epithel in Rückbildung.

Als "fertig" bezeichne ich das Epithel, wenn dasselbe einschichtig geworden ist. Das ist zunächst eine auf das äusserliche Aussehen begründete Abgrenzung, welche sich als praktisch brauchbar empfiehlt. Sie hat aber auch bis zu einem gewissen Grade einen inneren WTerth, indem das Epithel mit der Annäherung an diesen einschichtigen Zustand ungefähr dasjenige Nahrungsmaterial aufgearbeitet hat, welches es bei seiner ersten Bildung aufnahm. Das fertige oder einschichtige Epithel kann als die specifische Formation des Gefässbezirkes bezeichnet werden. Auch diese Bezeichnung hat nur einen Näherungswerth; denn einerseits greift zuweilen einschichtiges Epithel auch auf die Innenzone des Dotterhofes über, andrerseits kommt streckenweise innerhalb des Gefässbezirkes geschichtetes Epithel vor. Freilich muss man bei der Feststellung dieser Thatsache die grösste Vorsicht beobachten, und man muss bei der Anfertigung und Beurtheilung von Schnitten aufs Sorgfältigste in Auge behalten, dass durch die früher geschilderten (S. 254 f.) Wülste (Fig. 24, Tafel XII) die Gefahr von Schiefschnitten gegeben ist, welche sehr leicht ein geschichtetes Epithel vortäuschen können, auch wo classelbe nur einschichtig ist.

Das fertige Dottersackepithel ist nicht clas Epithel des "fertigen" Dottersackes, wenn man letztere Definition in clem oben angewendeten Sinne (S. 252) gebraucht; denn cler Dottersack ist erst fertig; d. h. im Besitze der ihn charakterisirenden Blätter oder Gitter, in dem letzten Drittel der Brützeit; das Epithel dagegen beginnt einschichtig zu werden schon im Stadium des ausgewachsenen Primitivstreifens oder doch der ersten Urwirbel.

Bei der Beschreibung des einschichtigen Epithels wird man wieder eine Trennung in das Epithel der Area pellucida und das der Area opaca machen, oder in das flache und das hohe Epithel, 
Es ist des allerdings, wie ich in den einleitenden Worten bemerkte, keine Trennung principieller Art, keine Scheidung zweier in WVesen verschiedener Zellformen.

Ich muss hier mit Rückisicht auf die Beclenken des Lesers, nicht aus dem Zusammenhange meiner Fragen heraus, eine Bemerkung einschieben, da ich den Unterschied zwischen dem Epithel der Area pellucida und dem der Area opaca so gering anzuschlagen scheine. Íon den vielen litterarischen Aeusserungen über diese Frage sei hier nur die ausführliche und durch die topographische Orientirung so wichtige Darstellung von 1) uval erwähnt (7.). Nach dieser ist bein Huhne die Keimscheibe im ungebrüteten Zustande und noch in den ersten Stunden nachher vom Dotter völlig geschieden, im I)otter aber liegt ron der Furchung her eine Anzahl von Kernen (man vergleiche besonders die Fig. 14, I 7, 2I-24 ron Duval); aus cler Keimscheibe entwickelt sich dann das Entoderm der Area pellucicla, um die Dotterkerne andrerseits sondern sich durch langsam fortschreitende Furchung die "Dotterentoblasszellen", und diese beiden

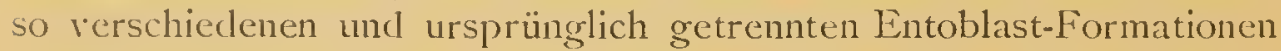
treten alsclann zu einer Einheit zusammen (man vergl. die Fig. 33 nebst 36,40 nebst 42,50 nebst $52,5^{8}$ nebst 59,63 nebst 64 ron Duval). Diese Darstellung von Duval hat etwas so Ueberzeugendes, als cine Darstellung von Dingen, die man nicht selbst gesehen hat, nur haben kann. Ich bin nicht durch eigene Präparate hinreichend unterrichtet, um selbst urtheilen zu können. Aber ich kann das auch hier unterlassen, denn für den augenblicklichen Zusammenhang kommt es clarauf garnicht an, da ja alle Beobachter darin übereinstimmen, dass die Area pellucida, einmal gebildet, sich später auf Kosten der Area opaca vergrössert, d. h. dass sich Zellen, die erst höher waren, in flache Zellen umwandeln.

Ich kann daher auch nicht einverstanden sein mit einer Citirung meiner Dissertation seitens F. u. P. Sarasin (24. S. r 06), wobei meine Angaben zur Stütze der Auffassung gemacht werden, dass cine scharfe Grenze zwischen dem Embryonalkeim und einem von jencn Verfassern behaupteten "Dotterkeim" (Lecithoblasten) bestehe. Un jedoch durch cine ausführliche Erörterung nicht aufzuhalten, die in eincm anderen 7usammenhange inehr Werth und Bercehtigung haben würde, bemerke ich nur the eine: Indem ich das, was man jetzt als „Entoderm der Area pellucida" bezcichnen würde, „Darmdrüscublatt" nannte, wic es in dem älteren Sprachgebrauche begrüudet war, liessen sich F. und P. Sarasin verleiten, zu glauben, dass dic (irenze des 1) armepithels und des Dottersackepithels mit dem Rande der Area pellucicla zusammenficle. Ich bedauere sehr, zu diesem Irthume Veranlassung gegeben zu haben, liann aber im 
Uebrigen nur an dic bekinnte Thatsache erinnern, dass dic Grenze ron Area pellucida und Area opaca auf dem Dottersacke liegt, und dass aus dem flachen Entoderm nicht nur Darmepithel, sondern auch ein Theil Dottersackepithel wird.

In der letzten brützeit hört, wie schon in der linleitung bemerkt wurcle, dic Areal.pellucida auf, als solche zu bestehen. Was flache Epithel derselben nimmt wieder an Höhe zu, und es vollzicht sich so das Gegentheil von dem, was wir in den ersten Brüttagen bemerken konnten.

An die Schilderung des fertigen Epithels wird sich sodann die des in Rückbildung begriffenen anzuschliessen haben.

I. Das hohe Epithel. - In meiner Dissertation ist auf S. 22 hingewiesen auf die ausserordentliche Grösse dieser Zellen, auf die Eigenthümlichkeiten ihrer Gestalt, die gerundeten Kuppen derselben, die grossen und fussständigen Kerne. Nachdem ich jetzt meine Untersuchungen zeitlich und räumlich ausgedehnt habe, indem ich den Dottersack ron den Anfängen seiner Entwicklung bis zum siebenten Tage nach dem Ausschlüpfen untersucht habe, kann ich meine früheren Angaben über das reife Epithel, welche sich auf den zweiten, fünften, siebenten und achten Tag bezogen, durchaus bestätigen und etwas ïber die Anordnung des Protoplasma hinzufügen; dagegen bin ich auch jetzt noch nicht in der I age, ïber den Inhalt etwas Endgültiges auszusagen. Das wird auch ohne eine ausgebildete Mikrochemic nicht geschehen können, und bis dahin mögen diese Dinge ruhen. Denn es wird uns wenig nützen, immerwährend von Körnern, Kugeln und Tropfen zu hören, über deren Natur wir nichts wissen, um so weniger, da wir nicht darüber urtheilen, welche $\checkmark$ eränderungen hier die Reagentien angerichtet haben.

Als ich meine Arbeit begann, hatte ich die Absicht, gerade das fertige Epithel mit grösserer Vollständigkeit zu schildern, um dieser Frage einen gewissen Abschluss zu geben. Hierfür wäre noch eine Reihe ron Abbildungen nothwendig gewesen. Da ich aber das Entgegenkommen der Herren Verleger in dieser Richtung schon in starlier WVeise in Anspruch genommen habe, so hielt ich mich nicht für berechtigt, noch weiter zu gehen, und ich muss daher den beschreibenden Theil dieses Abschnittes geben, olne ihn durch einen billlichen ergänzen zu können.

Der Lescr möge sich mit mir, um den Höhepunkt der Entwicklung kennen zu lernen, dem Eithel des zwölften und dreizchnten lages ruwenden und die Figuren 16 - ig der Tafel XI zu Rathe zirehen. Diese Zellen sind schr gross in jedem betracht, sie sind so- 
wohl hoch wie breit. In Flächenbilde (Fig. 16) sind sie unregelmässig polygonal mit geringer Neigung zu Abrunchung der Ecken, von ziemlich gleichmässiger Grösse; der Umriss erscheint oft doppelt, so class der Anschein dicker Zwischenwände entsteht, worlurch die Aehnlichkeit mit Pflanzenzellen noch grösseı wircl. Doch muss man bedenken, dass die Zellen sehr hoch sin 1 , und dass man daher an den Seiten der Zellen weit hinabsieht, wobei doch fast immer leichte Schiefbilder vorliegen; auch laufen die Begrenzungen einer solchen scheinbaren Zwischenwand nicht immer parallel, sondern überkreuzen sich. Leere Stellen zwischen den an einander stossenden Ecken dreier Zellen kommen nur selten vor, fehlen aber nicht sïnzlich. Was diese Zellenform auszeichnet, ist die ungeheuer scharfe Begrenzung, die geraden Trennungslinien und die scharfen Ecken, so dass wirklich Polygone entstehen.

Das geschilderte Bild hat vor allem Geltung für clie in der proximalen Hälfte des Dottersackes $z$ wischen den Wülsten gelegenen, also glatten, Theile der Wand; es erleidet jedoch einige Abänderungen: a uf den Wülsten sind die Polygone kleiner, die Zellen also schmaler, auch sind sie hier z. Th. von mehr wechselnder Grösse. Diese Schilderung der Flächenbilder ist hauptsächlich von Silberpräparaten entnommen. Am meisten verwickelt gestaltet sich das Bitd dort, wo die Seitenzweige der Venen in die Fläche der $\mathrm{IT}^{\top}$ and hinabsinken, und wo sich an ihre Richtung perlschnurartig aufgereihte rundliche Wülste anschliessen, cin Verhältniss, welches schon früher Erwähnung fand (p. 256).

In Seitenansicht haben diese Zellen, wofern sie nicht durch Inhalt besonders aufgetrieben sind, dic Grundform eines Rechteckes mit abgerundeten Ecken und sind oben kugelförmig gewölbt (Fig. 17); sind jedoch in ihnen Vacuolen enthalten, welche man sich vor der Behandlung mit Fett erfüllt denken muss, so werden solche \%ellen ausgebaucht, was je nach der Iage der T'acuolen entwerler am obern (Fig. Is) orler untern (Fig. 19) Ende geschieht. Natürlich müssen die Nachbarzellen nun ihrerseits die Spuren solcher Vortreibungen in Gestalt von Eindrücken zeigen. An Stellen, an welchen viele 7ellen mit Inhalt gefüllt sind und dieser verschieden vertheilt ist, da werden also auch grosse I Tnregelmüssigkeiten der Gestalten zu sehen scin, doch giebt es auf dieser Stufe der Entwicklung und an den vorausgehenden 'Tagen - vom siebenten hebt es meine Vissertation (p. 22) hervor - erhebliche Strecken, wo die rechteckige Form ziemlich ungrestört sich hält, so class wir die in Fig. 17 abgebilclete Ciestalt nicht etwa als eine abgezogene, sondern als die reale Grundform betrachten müssen.

1)as l'rotoplasma in diesen Zellen ist in der schönsten netzartigen 
Anordnung vortunden, woron die Fig. $16 \quad 19$ ein annäherndes Bild geben. Ein Hof um die Kerne und ein Wandbelag tritt besonders hervor, doch ist beides oft schwach entwickelt, manchmal fehlend. Das Lebrige denke man sich so: das l'rotoplasma umschliesst zunächst grössere Vacuolen; in den Knotenpunkten der Balken liegen wieder kleinere Vacuolen und so fort. Die Region der Kuppe ist besonders ausgezeiclinet, inden sie stets von lauter kleinen Vacuolen eingenommen wird. Alle diese Vacuolen sind rund, und wir müssen uns vorstellen, dass die vor der Behandlung hier anwesenden Fetttropfen durch ilıre wechselnde Grösse die der V'acuolen bestimmten. Ich glaube also, dass die Form der Protoplasmaanordnung in unserem Falle passir bedingt und darin nichts zu spüren sei von den activen Einflüssen, welche bei anderen Objecten geschildert worden sind. Deutlicher als die Fäden des Protoplasma selbst sind an ihnen haftende Körnchen, welche woll aus einem Niederschlage hervorgegangen sein mögen.

Der Kern ist gross und blass, sein Contour scharf. Der Körper des Kcrnes erscheint an meinen Präparaten leicht gekörnt; im Inneren liegt einer oder zwei oder auch eine Gruppe ron Nucleolen bezw. nucleolen-artigen Körperchen. Der Kern hält sich ausnahmslos im unteren Theile der Zelle auf, oft in ihrem Grunde; hier kann er, wenn ein grosser Fettropfen den Raum beengt (Fig. 19), so zusammengequetscht werden, dass er, von der Kante gesehen, spindelförmig und dunkel erscheint, gerade so wie die Kerne im geschichteten Epithel (p. 277), welche so oft die deutenden Beobachter irre geführt haben. Bei den Zellen mit kleineren Vacuolen, aber auch mit grossen, wofern diese nur hoch liegen, ist der Kern nicht so bedrängt; er findet dann seinen Platz im Protoplasma (Fig. I 8), oft mit einer Seite die Wand berührend (Fig. I 7), hängt in dem Protoplasmagerüste wie eine Spinne in ihrem Netze, und ist gelegentlich ron eckiger Form dadurch, dass er Vorsprünge gegen die Richtung der Protoplasmafäden bildet; worin ich jedoch keine active Formveränderung erblicke, sondern eine Einwirkung der ihn von allen Seiten drückenden Fetttropfen.

Von Einschlüssen dieser Zellen kann ich vier Arten namhaft machen.

I. Fetttropfen, die allerdings auf den Präparaten nur die Vacuolen zurückgelassen haben. Wenn man sie durch Behandlung mit Osmiumsäure darstellen will, so gewinnt man Nichts oder viclmehr, man verlict Alles, denn solche Schnitte sind rein schwarz und lassen Nichts erkennen. Makroskopisch erkennt man das liett, an welches auch der Farlostoff des Dotters gelunclen ist, an dem Aussehen der Wand, und ich will noch cinmal daran eriuncrn, dass in den späteren 
Brüttagen clie lichtreflectirende Wirkung so stark ist, dass auch nicht eine Spur von Blutfarbstoff durch das einschichtige Epithel hinclurchschimmert, sondern die Wand im reinen Gelb erscheint. Die Vacuolen finden sich in allen Zellen; das Fett war also in allen Zellen rorhanden.

2. Kügelchen oder Tröpfchen, welche vorwiegend in einer Randschicht an den Kuppen der Zellen angesanmelt sind, bilden den nächsthäufigen Einschluss. Oft sind sie an der genannten Stelle so dicht, dass sie sowohl die Protoplasmastructur wie die Zellgrenze rerdeclien, letzteres um so mehr, da den kuppen auch aussen solche Tröpfchen oft anhaften. Streckenweise haben alle Zellen diese Tröpfchen reichlich, streckenweise fehlen sie. Sie nehmen durch Carmin eine blasse Farbe an.

3. Blasse hyaline Tropfen kommen zuweilen, aber spärlich, vor. Da ich solche gerade innerhall von grossen V'acuolen gefunden habe, also an Stellen, wo vordem fettropfen gewesen waren, so ist der Befund nicht recht verständlich. Möglich, dass sie beim Auslaugen als ein Rüclistand blieben, eine Substanz, die mit dem Fette gemischt war.

4. Homogene oder leicht gekörnte Kugeln, welche sich mit Carmin ziemlich lebhaft färben, trifft man im Ganzen selten. Sie sind von verschiedener Grösse und nehmen in der Regel, aber nicht immer, die unteren Theile der Zellen ein. In Aussehen erinnern sie an die an zweiter Stelle genannten Kügelchen, von denen sie sich wesentlich clurch ihre Grösse unterscheiden; allerdings auch in ter Färbung, doch wäscht sich bei der Behandlung mit Boraxcarmin und nachherigem Ausziehen durch säurehaltigen Alcohol — von solchen Präparaten ist meine Beschreibung genommen - das Carmin aus grösseren Körpern colloider Substanz überhaupt schwerer aus. So entsteht die Vermuthung, dass beide Elemente zusammengehören, und wenn sie es thun, die Frage, ob die Kugeln aus den Kügelchen durch Vereinigung oder die zweiten aus den ersten durch Zerfall entstanden seien. Jedesfalls dürfen wir woll unsere Betrachtung über die Einschlüsse, indem wir die an dritter Stelle genannten hyalinen Tropfen wegen ilhrer Seltenheit unberücksichtigt lassen, dahin vereinfachen, dass wir von zwei Bestandtheilen sprechen, erstens von den Fettropfen, die jedoch durch die Behandlung entfernt sind, und zweitens von den Kügelchen und Kugeln. Es ist vielleicht auch nicht zu viel gewagt, wenn man vermuthet, dass erstere dem fettartigen, letztere dem eiweissartigen Körper des 1 )otters entsprechen, dass sie aus diesen hervorgegangen sind, mehr oder weniger veränderte Stufen derselben vorstellen.

Unsere Betraclitung drängt zu der Frage, in welchem $Z$ ustande 
der Inhalt von den Zellen a ufgenommen werde. Meine bisherigen Irfahrungen führen mich zu der Vorstellung, dass wir diese Betrachtung in zwei Betrachtungen zerlegen müssen, und ich möchte diese dem Leser vorlegen. Mir scheint es, dass es zwci Arten der Aufnahme von Dotterbestandtheilen giebt. Die eine, dic wir die primärc nennen können, vollzieht sich gleichzeitig mit der Bildung des Dottersackepithels in Keinwwall beziehentlich in der Aussenzone des Dotterhofes. Durch sie erhält jede Zelle einen reichen Bestand an noch unverändertem Dotter. Die Schilderung dieser Vorgänge nimmt den nächsten Abschnitt ein; hier will ich die Betrachtung nur soweit zurückführen, un den Anschluss an jene Darstellung zu gewinnen. $\mathrm{Zu}$ diesem Zwecke gehe ich an unserem Dottersacke vom zwölften Tage weiter distalwärts, bis zu ciner Stelle, die schon dicht am Bindegewebsringe, aber noch ror demselben liegt.

Hier finden wir das Epithel noch einschichtig wie vorher, aber nicht mehr so hoch; die Mehrzahl der Zellen ist auffallend klein, einzelne dazwischen sind grösser. Diesen Zellen fehlt es sehr an grossen, ja auch an mittelgrossen Vacuolen; nur die zerstreuten grossen Zellen enthalten auch grosse Vacuolen, in der Regel eine cinzelne solche. Dagegen sind röthlich gefärbte Kugeln als Inhalt hier nicht selten.

Gehen wir nun noch weiter distalwärts, auf den Mesoderm-Wulst selbst, so treffen wir hier bereits das Epithel geschichtet. Und in diesem fallen die röthlich sich färbenden Massen durch ihre Zahl und und auch durch ihre Grösse auf. Es tritt aber noch ein neuer Bestandtheil auf, bzw. eine andere Combination, nämlich Körper, deren Leib den röthlich sich färbenden Massen gleichzustellen ist, die aber in sich wieder Kugeln einschliessen, die von glänzenden Körnchen erfüllt sind. Solche Kugeln mit glänzenden Körnchen findet man auch frei, ja man findet auch die glänzenden Körnchen für sich, zu Haufen vereinigt.

Gehen wir scliliesslich noch über den Mesoderm-Wulst hinaus, so treffen wir in zunehmenden Maasse, sowohl in Hinsicht auf Zahl wie auf Grösse, die roth sich färbenden Ballen. Obwohl hier sicher nicht weniger Fett durch die Bchandlung ausgezogen wurde, so sind diese Zellen doch nicht leer, sondern jede von ihnen beherbergt einen grossen Körper, der seinerseits wieder kleine Körnchen enthalten kann.

Wenn wir die geschilderten Bilder vereinigen und uns vergegenwärtigen, dass das distal gelegene Epithel frühere Stufen der lintwicklung darstellt, welche das proximale schon zurïckgelegt hat, so dürfen wir wohl die neben einander liegenden Zustände als die liolgen cines Vorganges anschen, der sich, wie mir sclieint, in folgender 
IVeise abspielt. Die Zellen, welche von ihrer Bildung her, d. h. von der Gestaltung eines Dottersackepithels an, Dotterballen in sich besassen, beschäftigen sich mit der Yerarbeitung der letzteren; mit der L'msetzung seines fettartigen und seines ciweissartigen Bestandtheiles. Wie sich dabei der erstere verhalte, darüber sagen uns I ackpräparate sehr wenig, da an ihnen das Fett günzlich ausgezogen ist. Sicher ist nur, dass zum grossen Theile liett als solches, z. Th. sogar noch in Verbindung mit dem eigenthümlichen Farbstoffe des Dotters, in die Gewebe gelangt. Darauf lässt das Verhalten der Leber schliessen, sowic gewisse Erscheinungen an clen Zellen, welche die im lockeren Bindegewebe verlaufenden Gefässe begleiten. Von dem eiweissartigen Körper sehen wir an unseren Präparaten mehr: wir bemerken die anfängliche Häufigkeit, die zunehmende Abnahme der Grösse und Zahl der Ballen mit dem Fortschreiten ron distalen zu proximalen Regionen; eine Abnahme, die endlich zum völligen Schwunde führt. 1)iese Aenderung in Inhalte der Zellen triff an unseren l'rïparaten zusammen mit drei wichtigen anderen [Tmständen, mit einer Aenderung der Grösse, einer Aenderung der Schichtung und der Herstellung von Beziehungen zu den Gefässen. Allerdings sind alle dicse Aenderungen nicht so eng verbunden, dass sie genau auf demselben Striche eintreten: das Eithel ist noch geschichtet auf dem Mesoderm-Wulste, d. h. an der Gefässgrenze, clas Lpithel ist noch niedrig in einer schmalen Zone, in welcher es schon einschichtig wurde, und die Ballen hören nicht mit cinem Schlage sondern allmählich auf. Aber ich glaube, dass wir die Zusammengehörigkeit dieser Merkmale nicht verkennen dürfen. W'enn es nun richtig ist, class dic Zellen in Zustande des geschichteten Epithels mit der Verarbeitung der Dotterballen beschäftigt sind, die sie im Anfange aufnalımen, dass aber mit dem Uebergange in den einschichtigen Zustand dieses Material im Wesentlichen aufgebraucht ist, so können wir den vorher erwähnten Streifen von verhältnissmässig niedrigem einschichtigen Epithel als dic Zwischenstufe ansehen, welche von dem primären Zustande zu dem secundären, dem des einschichtigen hohen Epitels hinüberführt, in welchem nun clurch die Verbindung mit einem reichen Cicfïssapparat die Dotterverarbeitung weit heftiger von Statten greht. Ich komme auf diese Betrachtung noch einmal zurück.

H lier fragt sich nun, in welcher form werchen in diesem zweiten Stadium Dotterbestandtheile seitens der Zellen aufgenommen. Hierauf kann nichts Erschöpfencles, aber Einiges gesagt werden. In späteren Brütııen stösst (lis 1)ottersackepithel nicht an unverïnderten Dotter, sondern an einen "Dotterlorei" an, (l. h. es sind hier keine Dotterkugreln mehr vorhauden, sondern eine zusammenhängende auf Schnitten körnig erscheinende Masse. Dass in clieser Masse fettartige bestand- 
theile enthalen sind, ist gewiss; und dass diese sich z. Th. in der Form wirklichen Fettes oder Oeles gegen Schluss der Entwicklung vortinden, ersẹe ich aus makroskopischen oben mitgetheilten Befunden. Aber nie findet man im Dotter auf Schnitten etwa solche leeren V'acuolen, welche ausnahmslos clie Lage der Fettropfen in den Epithelzellen anzeigen. Daher muss angenommen werden, dass die fettartige Substanz sich in dem Dotter in feiner Vertheilung, etwa in Form einer feinen Emulsion vorfinde.

Wir fragen nun: werden Dotterbestandtheile in gelöstem oder geformtem Zustande aufgenommen? werden sie unter. Verïnderung ihrer chemischen Constitution resorbirt? werden sie gefressen? Hierzu möchte ich Folgendes bemerken. Ich habe nie Zeichen "amöboider Bewegungen" an den Epithelzellen, auch nie ein Offenstehen der dem Dotter zugewendeten Seiten oder hervorgestreckte Fortsätze bemerlit, sondern stets abgeschlossene, mehr orler weniger gerundete Kuppen der Zellen. Ich habe auch nie eine besondere Cuticularbildung oder Anhänge der freien Fläche bemerlit, sondern stets waren die Kuppen durch eine einfache Linie grezeichnet. Dagegen habe ich wohl auf den frühesten Stadien des einschichtigen Epithels gelegentlich, und zwar an sehr wohl erhaltenen Präparaten, unregelmässige Begrenzungen der freien Enden der Zellen getroffen und Bilder, als wenn protoplasmatische Fäden frei hervorragten (S. 275). Ich halte daher für diese frühen Stadien eine active Aufnahme geformter Bestandtheile Seitens des Protoplasma zwar nicht für bewiesen, aber doch für discussionsfähig; nicht aber ebenso für die späteren Stadien, cl. h. für die lange Zeit, in welcher sich die Hauptarbeit des Dottersackepithels abspielt.

Mit den durch das Vorhergehende gewonnenen Gesichtspunkten treten wir an die Betrachtung der letzten Brüttage heran, in welchen das Epithel des Dottersackes sich dem mehr und mehr eingedickten Dotter gegrenüber befindet.

Achtzehnter Tag. - Die Zellen sind zwar gross und blasig, aber niedriger als an zwölften Tage. Ihre Kuppen sind flach oder gerundet. Die Kerne liegen in halber Höhe der Zellen an die Wand gepresst. Die Zellen sehen eigenthümlich leer aus; es fehlt sowohl Protoplasma wie körniger Inhalt, man darf wohl annehmen, dass eine solche Zelle durch einen einzigen grossen Fettropfen ganz erfüllt war. Nur in den Kuppen der Zellen findet man, und auch hier nur selten, körnige Masse, welche der aussen anlicgenden Masse (Dotterbrei) gleicht, jedoch in Carmin einen blasseren Farbenton angenommen hat.

Neunzchnter Tag. - In den Zcllen liegt liörnige Masse, genau von dem gleichen Ausschen, welches der freie Dotter darbictet; sie 
füllt in erster Linie die Kuppen der Zellen aus, zieht sich von da dann weiter an den Seitenwänden hinab und auch an den Protoplasmabrücken hin, so dass diese, die spärlich sind - oft übrigens gänzlich fehlen - , den Eindruck plumper Balken ron körniger Substanz machen. Oft sind aber auch die Zellen gänzlich ausgefüllt. Da nun der freic Dotter andrerseits an die Kuppen der Zellen unmittelbar anschliesst, so ist oft eine Grenze von Zellen und Dotter überhaupt nicht sichtbar, in anderen Fällen ist sie es; im ersteren Falle entsteht das eigenthümliche Bild, als seien Iücken im Epithel entstanden, und der Dotter durch diese bis an das Bindegewebe vorgedrungen. Soweit diese körnige Masse die Zellen nicht erfüllt, sind dieselben durch grosse Tacuolen eingenommen, in denen wir uns wieder die Räume zu denken haben, die durch Auslaugen des Fettes frei geworden sind. Ton dem gleichen Dottersacke besitze ich übrigens Präparate, näher am distalen Pole gewonnen, an welchen die Zellen weniger körnige Masse enthalten und immer scharfe Grenzen zeigen. Die Kerne sind fussständig, elliptisch oder eckig.

Einundzwanzigster Tag. - Die Zellen sind kleiner als früher, besonders die an der Wand gelegenen; sehr aufgetrieben, blasig; mit Neigung zur Abrundung, welche nicht nur am oberen, sondern auch am unteren Ende frei zum Ausdruck kommt. Die Kerne sind verhältnissmässig klein, dunkel, an die Wand gedrückt, zuweilen eckig; sie liegen vielfach in halber Höhe, oft aber auch in unteren Ende. Protoplasma ist in Form von spärlichen, dicken Balken rorhanden; oft fehlt aber Protoplasma im Innern gänzlich, und es ist solches nur in Form eines Wandbelages vorhanden, der eine einzige grosse Vacuole (Fettropfen) unschliesst. Körniger Inhalt (Eiweiss) wird hier vermisst; doch ist zu bemerken, dass das Präparat mit Chromessigsäure behandelt war, wodurch das Eiweiss wahrscheinlich in I,ösung gegangen ist.

Wenn man das zusammenfassend betrachtet, was über den achtzchnten, neunzehnten und einundzwanzigsten Tag mitgetheilt wurde, so ergiebt sich, dass die Zellen kleiner geworden sind, was aber nicht als Zeichen der Rückbildung angesehen werden kann, denn wir treffen diese Zellen in voller Arbeit. Die Kerne erheben sich zun Theil bis zu halber Höhe, verharren aber im Ganzen noch im Grunde der Zellen. Die starke Errfüllung mit fiett macht sich makroskopisch durch die Farbe, mikroskopisch durch grosse Vacuolen bemerlibar. Die Anordnung des Protoplasma ist dadurch im Wesentlichen bestimmt. Körnig gerinnende Masse (Eiweiss?) wird oft in grosser Menge in den Zellen getroffen, und hier können wir auch etwas über die Aufnahme dieser Masse erschliessen. Da sie der körnig gerinnenden Masse im freien Dotter durchaus gleicht, so 
können wir annehmen, dass solche Substanz unverändert in die Zellen cinclringt. Hiermit ist es auch gut in Uebereinstimmung, dass innerhalb der Zellen die Substanz in erster Linie in den Kuppen getroften wird. Wir dürfen vermuthen, dass sie in dem Maasse umgewandelt wird, als sic in die tieferen Theile der Zelle eindringt. Was sich ausserdem noch der Betrachtung aufdrängt, ist, dass innerhalb der Zellen die körnige Másse und die Fettropfen (Vacuolen) gesondert sind, während das Gleiche im freien Dotter nicht zu beobachten war.

Diese Bemerkungen über den Inhalt der Zellen enthalten alles von Belang, was ich mittheilen kann, aber freilich nichts Erschöpfendes, kaum mehr als den Hinweis darauf, dass hier ein der Untersuchung würdiges und wohl auch zugängliches Problem vorliegt.

Das Epithel in Rückbildung. - Was ich über clie Rückbilclung des Epithels berichten kann, ist so wenig, dass es an besten gleich hier angeschlossen wird. Es stehen hier zur Verfügung Beobachtungen über drei Thicre einer Brut, vom dritten bis vierten, vom fünften bis sechsten, und vom sechsten bis siebenten Tage nach dem Ausschlüpfen; dazu kommt von einer anderen Brut cin Hühnchen vom vierten Tage, dessen Dottersack jedoch so stark verkleinert und verändert war, dass er wohl als der am stärksten rückgebildete gelten konnte. Ich führe sie der Reihe nach auf.

Drei bis vier Tage. - Die Zellen sind bedeutend kleiner geworden, obwohl verglichen mit anderen Embryonalzellen sehr gross; namentlich in der Höhe haben sie abgenommen, so dass sie als kubisch oder rundlich bezeichnet werden können. - Neigung zu kugeliger Abrundung macht sich besonders an den Kuppen bemerkbar, jedoch ist kein so starkes Vorquellen der letzteren vorhanden wie früher. Die Kerne sind von der gewöhnlichen Grösse, rund oder elliptisch und liegen fast durchweg in der Kuppe, of aber in cler Mitte, zuweilen im Fusse der Zellen. Das Protoplasma finclet sich in Form eines grobmaschigen, spärlichen Netzes im Innem der Zellen, hauptsächlich aber feinkörnig in den Kuppen, also in der Gegend der Kerne angehäuft. Geformter Inhalt wird gar nicht gefunclen; die Vacuolen darf man auch hier als durch Fett ausgefüllt ansehen.

Fünf bis sechs Tage. - Die Zellen sind wohl kleiner als vor dem Ausschlüpfen, jecloch noch immer gross und blasig und von der grössesten Regelmässigkeit. Die Kerne liegen säimmtich in den Kuppen der Zellen.

Von den Zellen des sechsten bis siebenten Tages gilt das Gleiche.

Vier Tage von einer anderen Brut. - Die Zellen sind blasig, mehr hoch als breit; sie sind sehr blass und ilure Umrisse eigen- 
thümlich unsicher, wie mit zittriger Hand gezeichnet. Die Kerne haben zwei bemerkenswerthe Eigenthümlichkeiten angenommen; erstens sind sie, jedoch nicht immer, an die Wand gedrüclit und hier stark abgeplattet, zweitens sind sie, jedoch auch nicht immer, in die Spitzen der Zellen gerückt. Wenn beide Merkmale sich in sehr ausgeprägter Weise vereinigt finden, so entsteht ein Aussehen, als sei die Zelle von einer dünnen Kappe von chromatischer Substanz bedeckt.

Betrachtet man zusammenfassend das, was über die Zeit nach dem Ausschlüpfen gesagt ist, so ist es nichts weniger als erschöpfend, und dies Wenige nicht so, wie man es erwartet hätte. Als die besonders auffallende Veränderung tritt die Umlagerung des Kerns hervor, der während der langen Zeit der Funktion der Zellen so typisch im Fusse der Zelle sich aufhielt und nun seinen Platz in der Kuppe gewählt hat. Aber auch hier bewahrt er bis zuletzt seine Gestalt. Lind ebenso halten auch die Zellen noch bei so starker Verkleinerung des Organes typische Merkmale ihrer Gestalt und Lagerung fest. Ich will keinesweges behaupten, dass meine Untersuchung erschöpfend war, aber ich muss doch hervorheben, dass mir Zeichen eines so zu sagen selbständigen Zerfalles nicht entgegengetreten sind. Hier muss ich nun eine Beobachtung heranziehen, über die an anderer Stelle (S. 289) schon berichtet ist, nämlich die, dass Epithelzellen anscheinend von dem schrumpfenden Bindegewebe und von Leukocyten umschlossen und erstickt werden, und ich muss wiederholen, dass es mir so scheint, als sei der Vorgang der Rückbildung des Dottersackes an das Bindegewebe geknüpft. $\mathrm{Ob}$ es ror der gänzlichen Vernichtung den Zellen des Dottersackes gelingt, ihre Rolle zu Ende zu spielen, d. 1. sämmtlichen Dotter zu verarbeiten, oder ob ein kleiner Rest des letzteren durch Leucocyten zur Resorption gelangen muss, vermag ich gleichfalls nicht anzugeben.

Nachdem ich das einschichtige hohe Dottersackepithel vom zwölften Tage bis zu seiner Rückbildung verfolgt habe, möchte ich nun rückschreitend von demselben Zcitpunkte an mich gegen die Anfänge seiner Intwicklung hinbewegen. Dabei möchte ich aber rorweg bemerken, dass, wenn wir die Epithelzellen in früheren Tagen von geringeren Dimensionen treffen, wir darin nicht ohne Weiteres Beweise einer noch nicht erlangten Reife erblicken dürfen. Es könnte ja wohl sein, dass das Epithel den Leistungen, die es am zweiten, dritten und vierten Tage zu vollbringen hat, wo es dem perilecithalen Spalt gegenübersteht, in dieser kleineren Modification gerecht wird, und dass erst die veränderten Leistungen der zweiten Hälfte der Brutzeit eine verinderte Gestalt wïnschenswerth machen. 
In dieser Hinsicht also müssen wir unserem Urtheil eine gewisse Zurücklialtung auferlegen.

Ueber den siebenten und fünften Tag mag dasjenige Geltung habcu, was ich in meiner Dissertation auf S. 2I, 22 und 23 mittheilte, nur möchte ich, wenn ich damals das Epithel des fünften Tages als "fast durchweg einschichtig" bezeichnete, dieses "fast" streichen und sagen, das Epithel ist einschichtig im ganzen Gefässbezirke, wahrscheinlich wieder mit Ausnahme des Randstreifens, welcher dem Mesodermulste auflagert.

Für den vierten Tag sei angemerkt, dass hier auf stark vorspringenden Gefässen die Epithelzellen stellenweise ausserordentlich abgeplattet sind, was sich allerdings sehr einfach dadurch erklärt, dass mit der Zunahme der Gefässe die Zellen sich nicht in gleichem Maasse vermehrten, was aber immerhin doch der Erwähnung werth ist, da in späteren Stadien die Zellen auf den Wülsten oder Blättern ebenso hoch ja zum Theil höher sind als an der Wand. Gerade auf der Arteria vitellina ist diese Abflachung und eine damit Hand in Hand gehende Verbreiterung sehr auffallend, und ich habe ein Präparat vor mir, in welchem eine Zelle acht bis zehn mal so breit als hoch ist. Der Kern ist trotzdem als fussständig zu erkennen und das Protoplasmanetz in dieser Zelle ist sehr deutlich. Auf der Vena vitellina posterior ist das Epithel auch flach, jedoch nicht in so extremer Weise. Ich habe diese Verdünnung des Epithels auf vorspringenden Gefässen mit Rücksicht auf den zweiten Tag schon in meiner Dissertation erwähnt und abgebildet (Fig. 3 meiner Diss.); auch jetzt finde ich wieder an Präparaten einer Keimscheibe mit I 3 (14) Urwirbeln (48 Stcl.) das Gleiche.

Ich möchte etwas verweilen bei Präparaten von Eiern, welche 3 Tage und 8 Stunden bezw. 3 Tage und 20 Stunden gebrütet waren. Denn hier schliessen die Epithelzellen des Dottersackes zum Theil Ballen ein, zum Theil aber entbehren sie solcher, so dass man am besten an diesen Präparaten ein Urtheil darüber gewinnt, welchen Einfluss diese Inhaltskörper auf die Form der Zellen ausüben; ein Urtheil, welches beim Stuclium des geschichteten Epithels (p. 320) wichtige Dienste leistet. Diese Ballen in ihrer typischen Form sind blasskörnig und finden sich zu einem in einer Zelle; es giebt jecloch mancherlei Abweichungen nach Form und Aussehen, nämlich kleinere Ballen, welche in der Zelle einen grösseren Raum frei lassen; zerklüftete Ballen; solche, die inmitten eines blassen Hofes einen Körnchenhaufen enthalten; ganz blasse. Ich glaube, dass alle diese Forman Stufen des Zerfalles und der Auflösung der erstgenannten Form sincl. Wir können also die Zellen als solche mit Ballen und solche ohne Ballen unterschciden. Oft aber sind die Ballen am erhärteten 
Präparat ausgefallen, worüber man am Flächenpräparate sehr schnell Gewissheit crlangt, und das hat cine gewisse kritische Bedeutung, denn an Schnittpräparaten müssen die betreffenden Zellen zerrissene kuppen zeigen und schcinbar offen stchen.

Sehen wir uns nach den weiteren Merkmalen un, so ist über die Grösse zu bemerken, dass die Zellen nicht nur nicdriger, sondern auch, wie Flächen- und Schnittpräparate übereinstimmend zeigen, auch schmaler sind, als wir es vom zwölften Tage kicnnen lernten. Das gilt auch für den sechsten Tag, und es sei hier mit Rücksicht auf diescn nachgetragen, dass die Zellen im Flächenbilde nicht die scharfen polygonalen fiormen mit gerade rerlaufenden Begrenzungslinien, sondern eine starke Neigung zu gerundeter Gestalt zeigen, der in weitgehender Wrise Rechnung getragen werden kann, da breitere Zcllen mit schmaleren gemischt sind. Bei den Präparaten des vierten Tages, die uns beschäftigen, kommt Achnliches auch ror, jedoch herrscht im Allgemeinen an einer Stelle übereinstimmende Grösse. Iis giebt jecloch stellenweise so schmale Zellen, dass im Fä̈chenbilde die Kerne aneinander zu stossen scheinen. Solche fand ich besonders in den distalen Abschnitten des Gefässbezirlies.

Uebcrhaupt möchte ich nicht unterlassen, zu bemerken, dass gerade auf dieser Stufe der Entwicklung des Dottersackes die localen Differenzen cine ausgeclehntere Untersuchung wünschenswerth machen, da man sonst leicht in Gefahr kommt, cine Beschreibung als allgeincin gültig zu geben, welche nur auf cinen Abschnitt der Wand passt.

Eine Zclle mit Ballen nimmt im Flächenbilde das Vier-, Sechsund Achtfache des Raumes cin, welchen eine Zelle ohne Ballen beansprucht.

Dic Grenzen der Zellen sind an den gefärbten Präparaten meistens scharf, oft aber scheinen sie gänzlich oder stückweise zu fehlen, oder erscheinen - anders ausgedrückt - nicht anders als die Fäden des Protoplasma. Man erinnert sich wohl der Darstellungen aus der I,itteratur, nach welchen es sich an der Innenseite des 1)ottersackes gar nicht um alogegrenzte Zellen, sondern um ein Netz von l'rotoplasma mit Kernen handeln soll. Da aber an Silber-Präparaten, welche ich für clieses Studium gar nicht genug empfohlen kann, die Grenzen bis weit in die Area vitellina hinein deutlich sind, so muss ich dic zellige Struktur des Epithels in ganzen Gefässbezirke mit roller Bestimmtheit behaupten.

In dem Verhalten des Protoplasma giebt es zwei Extreme; in dem einen ist der ganze Innenraum der Zelle ron einem Gerüst protoplasmatischer löiden erfüllt, in dem anderen sind diese auf eine dünnc Wandbekleidung leschränkt; zwischen den Extremen giebt 
es Uchergänge. Das Protoplasma ist zuweilen so feinmaschig, dass es fast köning erscheint, in anderen Fällen gröber; beide Arten können in einer Zelle gemischt rorkommen, in anderen Fällen findet sich nu1 die eine.

Die Kerne sind entweder von der gewöhnlichen bläschenförmigen Gestalt oder durch die Ballen platt an die Wand geclrückt, im letzteren Falle eckig oder, von der Kante gesehen, spindel- oder sichelförmig. Solche abgeplattete Kerne, wenn sie von der Kante gesehen werden, erscheinen dunkel. Im Flächenbilde liegen die Kerne in den ballenfreien Zellen in der Regel in der Mitte; im Schnittbilde findet man sie fast immer fussständig, zuweilen aber höher liegend, oft geradezu an den Fuss der Zelle angedrückt.

Von Inhalt kommen ausser den Ballen Tropfen vor, und zwar erstens in den Ballen, zweitens frei. Sic finclen sich nicht nur in grösseren, sondern auch in kleineren Ballen und licgen in ihnen zum Theil in Haufen, zum Theil mehr zerstreut. Die freiliegenden Tropfen kommen in einer Zelle in grösserer oder geringerer Zahl ror, oft nur wenige oder gar nur einer in einer Zelle, und solche freie Tropfen finclen sich auch in ballenfreien Zellen.

$\mathrm{Ob}$ ausser den Ballen und Tropfen noch ein dritter, durch dic Behandlung ausgezogener Bestandtheil in den Räumen der Zellen gelegen habe, die in den Präparaten leer erscheinen, möchte ich nicht wagen, zu entscheiden; namentlich möchte ich dic Behauptung, dass die Vacuolen der Epithelzellen in der z weiten Hälfte der Brützeit durch Fett ausgefüllt waren, nicht auf unsere l'räparate der ersten Hälfte übertragen. Denn in dem Stadium, welches uns beschäftigt, stösst ja das Epithel an den perilecithalen Spalt, also an Flüssigkeit an; es ist mir in der That wahrscheinlicher, dass diese leeren Räume in den Zellen auch im frischen Zustande leer, d. h. mit Flüssiglieit gefüllt waren, obwohl ich zugeben muss, class ich keine lieweise habe, um diese Ansicht zur Gewissheit zu erheben.

Sind die Zwischenräume, welche sich zwischen den grossen Ballen und der Wand funden, auch im frischen Zustande vorhanden, oder füllen die Ballen die Zellen vollkommen aus? Mir scheint das letztere wahrscheinlich, denn woher sollten sonst die Kerne in diesen Zellen so stark abgeplattet sein, wenn nicht durch den Druck der Ballen? Dass Dotterballen durch die Behandlung mit Alcohol schrumpfen, auch wenn sie vorher "fixirt" sind, wurde ja oben (p. 241) hervorgehoben. Die Frage. ist an sich für das vorliegende Stadiun gleichgïltig, aber wenn wir von dem geschichteten Fipthel sprechen (p. 320), hat sie Bedeutung, um die Form der Kerne zu verstehen.

Auch an Ende des zweiten Tages ist das Epithel im Gefiss- 
bezirke einschichtig. Ich kann mich hier beschränken, da die Angaben meiner Dissertation (p. 20) und die von Kölliker (Lehrbuch p. 173) vorliegen, welche in manchen Stücken genauer sind als die meinen.

Der schon oben (p. 235) erwähnte, im Bereiche der Vena terminalis gelegene "Grenzwulst des Gefässhofes" muss hier berücksichtigt werden. Derselbe ist den übrigen Abschnitten des Gefässhofes gegenüber dadurch gekennzeichnet, dass in ihn das Epithel geschichtet ist, und den angrenzenden Theilen des Dotterhofes gegenüber dadurch, dass er dicker ist. Es ist gar nicht leicht, sich ein so eigenthümliches Verhalten zu erklären, besonders wenn wir mit $r$. Kölliker annehmen wollen, dass das Entoderm in der Inncnzone der Area vitellina einschichtig ist. Denn wenn wir uns rorstellen, wie wir doch müssen, dass das weiter wachsende Mesoderm mit der Vena terminalis sich unter schon vorhandenes Entoderm hinunterschicbt, so bliebe uns nur die Vorstellung, dass sich über dem Mesodermrande eine fortschreitende zur Schichtung führende Proliferation des Entorlerms vollziehe. Ich finde jedoch an Präparaten rom Ende des zweiten Tages das Entoderm der Area vitellina zwar dünn aber geschichtet, und ich komme daher mit der Vorstellung aus, dass das schon vorher geschichtete Epithel durch Streckung seiner Zellen an Höhe zunimmt und dadurch den Wulst bedingt. Die Streckung der Zeilen ist aber nichts anderes als eine Vorbereitung auf das einschichtige Epithel des Gefässbezirkes. Uebrigens giebt es Fälle, in denen das Epithel hier gar nicht höher ist als in den angrenzenden Theilen, eine Hervorwölbung vielmehr nur durch die Vena terminalis erzeugt wird. Auch ist es in der Ordnung, diesen eigenthümlichen Grenzbezirk nicht nur am Ende des zweiten Tages zu betrachten und ich erinnere daher an das, was ich über denselben schon mit Beziehung auf den vierten Tag gesagt habe (p. 307). Es tritt hier an clie Stelle eines cinfachen ringförmigen W'ulstes cine reiche Bildung von Erhebungen, welche bis in die Area vitellina hineinreicht. Am sechsten Tàge, wie ich hinzufüge, steigert sich diese noch mehr und greift noch weiter in die Area vitellina über. Auch die Benrerkungen über das den Mesockermrand am zwölften Tage überlagernde geschichtete Epithel (p. 30I) müssen berüicksichtigt werden. Wenn ich nun die Schnitte, die ich vom letzten Vicrtel des zweiten Tages besitze, genauer betrachte, so finde ich nicht cinen einfachen glatten Wulst, wie ihn v. Kölliker abbildet (Lehrbuch Fig. 102), sondern einen breiteren, durch unregelmässige Èrhebungen der Zellen gekennzeichneten Vorsprung, in dessen distaler Jäifte die Zellen mit grossen Inhaltsballen fast gänzlich erfüllt sind, während in der proximalen Hälfte schon cine Verkleincrung des In- 
haltes stattgefunden hat. Ich kann nicht umhin, die Achnlichkeit herorzuheben, welche zwischen dieser Bildung und dem auf Fig. I und 2 meiner Taf. $X$ dargestellten, mit $l$ bezeichneten Ringe besteht, durch welchen sich die Entstehung der Wülste des Entoderms ankündigt; so dass es scheint, als fiele in diesem Stadium der "Grenz"wulst" mit dem Rande der Area opaca selbst zusammen. Nach allem können wir wohl sagen, dass in dem Kölliker'schen "Grenzwulste des Gefüsshofes" eine eigcnthümliche Bildung vorlicgt, welche auf besondere, auch von mir vielleicht noch nicht genau genug erkannte IVachsthumsverhältnisse hinweist.

Wir haben uns nun der Frage zuzuwenden, wann zuerst das Epithel der Area opaca einschichtig zu werden beginne. Da die Entwicklung in den proximalen Partien am meisten vorauseilt, so haben wir hier zuerst einschichtiges Epithel zu erwarten. Ich fülıre einige Befunde an, um die Grundlage eines Urtheils zu gewinnen.

Keimscheibe mit langem Primitivstreifen (24 Std.). - Der Uebergang des Epithels der Area pellucida in das der Area opaca ist ein sehr allmählicher. Man könnte schon hier, wenn man die höheren Zellen des Uebergangstheiles zur Area opaca rechnet, von einem einschichtigen Epithel der letzteren sprechen.

Keimscheibe mit cinem Urwirbel (25 Stcl.). -- Der Uebergang des Epithels der Area pellucida in das der Area opaca ist ein überaus allmählicher, so dass es an vielen Schnitten überhaupt unmöglich ist, anzugeben, wo die Grenze beider Höfe liegt. Jedesfalls aber trifft man in dieser Uebergangszone distal Zellen, welche mehr hoch als breit sind, in einschichtiger lage; ihre Kuppen sind gerundet, die Kerne näher den Fussenden. Allerdings werden sie demnächst, bei der weiteren Ausdehnung der Area pellucida in flache Epithelzellen umgewandelt werden; halten wir aber fest, dass sie vorher hoch waren.

Keimscheibe mit vier (fünf) Urwirbeln; Längsschnitte. - Das Epithel im Gefässbezirke der Area opaca ist zum Theil schon einschichtig, jedoch sind in dieser einschichtigen Region noch nicht alle Kerne fussständig. Die einzellige Anordnung tritt weniger deutlich an Medianschnitt wic an Seitenschnitten, also im Gebiete cler späteren Arteria vitellina hervor.

Keimscheibe mit fünf Urwirbeln (30 Stcl.). - Eine nicht selir breite Randzone der Area opaca hat einschichtiges Epithel. Die Wülste treten der Beobachtung hinderlich entgegen (s. p. 234).

Keimscheibe mit acht (neun) Urwirbeln (3 I Std.). - Ein ziemlich beträchtlicher Abschnitt des Gefïssbezirkes der Area opaca hat cinschichtiges Epithel. 
Keimscheibe mit neun Urwirbeln ( $4^{2}$ Std.). - Das Epithel der Area pellucida geht durch kubische Zellen ungeheuer allmählich in das der Area opaca über. In dem Gefässbezirke der letzteren ist es in weitem Umfange einschichtig, und wenn man den störenden Einfluss der Wülste auf die Beurtheilung der Schnitte berücksichtigt, darf man vielleicht sagen, es sei im ganzen Gefässbezirke einschichtig mit Ausnahme des Grenzwulstes.

Einige genauere Angaben über die ersten einschichtig liegenden hohen Zellen seien hier gemacht mit Rücksicht auf die eben erwähnte Keimscheibe mit acht (neun) Urwirbeln von 3 I Stunden. Die Zellen sind cylindrisch, aber nicht sehr hoch und zwar gleich hoch. Thre Grenzen gegen einander sind scharf, die Kuppen gerundet, oft aber kegelförmig und dann nicht scharf begrenzt, sondern anscheinend mit Protoplasmafäden endigend. Das Protoplasma bildet in den Zellen ein dichtes Netz, ziemlich gleichmässig, jedoch in den obcren Theilen der Zellen noch dichter; es ist deswegen so deutlich zu sehen, weil die Zellen leer sind. Die Kerne sind rund oder eckig; letzteres namentlich in schmalen Zellen, da sie sich dann an die Seitenwände stützen; sie liegen im unteren Ende, jedoch etwas über der Basis. Noch bei einer Keimscheibe mit dreizehn (vierzehn) Urwirbeln von 48 Stunden fand ich die Kerne in clem einśchichtigen Epithel des Gefässbezirkes nicht alle in den Füssen der Zellen gelegen, wo man sie doch in dem reifen Zustande der Zellen so typisch antrifft. Das erklärt sich aber ganz einfach daraus, dass zwar in einem Theile der Zellen die Kerne von Anfang an fussständig sind, weil diese Zellen im geschichteten Epithel aussen lagren; dass aber in anderen Zellen, nämlich denen, welche in geschichteten Epithel in der Mitte und innen lagen, die Kerne im Anfange weiter innen sich fanden. Die letzteren können erst allmählich, nachrlem die Zellen durch Schiebung einschichtige Lagerung angenommen haben, in die Fussenden hinabsteigen.

Ueber den Inhalt der 7ellen des einschichtigen Epithels in diesem frühen Stadium der Entwicklung ist Nichts bekannt; wir wissen nicht, was diese blassen und glänzenden, hyalinen und körnigen Ballen, Kugeln, Tropfen und Körner bedeuten. Auch ist ja ein endgültiger Aufschluss erst von der Mikrochemie zu erwarten. Es wäre daher auch natürlicher, hiervon einstweilen gänzlich zu schweigen. Doch können wir dies nicht thun, da die Vorstellung von der ersten Entstehung des Dottersackentoblasten mit der von der Natur der Zelleinschlüsse in einer innigen Verbindung steht. Es sei dalıer zunächst bemerkt, dass an Lackpräparaten der fettartige Körper des Dotters auch in den Epithelzellen dieser frülıeren Stadien aufzufinden ist; auf ihn dürfen wir wohl die glänzenden Tropfen 
oder kugeln bezichen, die wir im Innern von Ballen oder frei licgend antreffen, und die sich so geneigt zeigen, durch Pikrinsäure oder auch Platinchlorid cine gelbe Farbe anzunchmen; man findet aber auch öfters myelinartige Bildungen, welche den fettartigen Körper noch deutlicher anzeigen. Es ist also hier kein Fett oder Oel vorhanden, welches ja, wie uns die Präparate aus der zweiten Hälfte der Brïtzeit gezeigt haben, durch die Behandlung aus den Epithelzellen ausgezogen wird, sondern eine Substanz, welche dem fettartigen Körper des Dotters selbst näher steht. Wenn wir die danit gewonnene Vorstellung auf den gesammten Inhalt dieser Zellen übertragen, wie wir ja wohl können, so heisst das, dass in diesen Anfängen der Thätigkeit des Dottersackes diesem das Material in einem weniger vorgearbeiteten Zustande, so zu sáıen, mehr als Rohmaterial zugewiesen wird. Und diese Anschaunng hat zu ihrem anscheinend natürlichen Ausgangspunkte die Betrachtung, dass die Dotterentoblastzellen ursprünglich die zu verarbeitenden Dotterbestandtheile in gänzlich unverändertem geformtem Zustande aufnahmen.

Nun wolle man nur immer bedenken, dass der perilecithale Spalt nicht nur das Epithel des Gefässbezirlies sondern, auch das der Innenzone des Dotterhofes von dem Dotter trennt, dass also die Zellen ihren Inhalt — wenn sie ihn überhaupt als Rohnaterial aufnahmen - schon weit früher, nänlich schon damals, als sie im Keimwallstadium waren, müssen aufgenommen haben. Da wir nun allmählich mehrere hundert Zellenbreiten sich zwischen dic Keimwallformation (Aussenzone des Dotterhofes) und den Rand des Gefässbezirkes schieben sehen, und doch immer noch die Zellen des letzteren mit ihren Brocken nicht fertig sind, so dürfen wir wohl sagen, dass es mit dieser Arbeit recht langsam gehe. Da wir nun sehen, dass die Gesammtmenge des Dotters sich um diese Zeit nicht sehr verkleinert, während ungekehrt durch den reichlichen Erguss ron Filüssigkeit in den perilecithalen Spalt der von der Keimhaut umschlossene Raum sich sehr erheblich vergrössert, so erwäichst von dieser Seite her der Vorstellung keine Schwierigkeit, dass einzelne Zellen Tage dazu gebrauchen mögen, um den Rolıstoff, den sie im Jugendzustande aufnahmen, zu verarbeiten. Es sei dieser Gedanke zur Erwägung, nicht als Behauptung; hier vorgelegt.

Die Meinung, class die Dotterentoblastzellen ihren Inhalt im rohen Zustande aufnchmen, berührt sich in einem Punkte mit den Anschauungen von His, kann aber noch viel mehr als die Meinung R a uber's bezeichnet werden (21), dem ich mich, wie der nä̈hste Abschnitt zeigen wird, hinsichtlich der Entstehung des Dottersackepithelsin wesentlichen Punkten anschliesse. 
Eine Thatsache kann jedoch hier nicht unerwähnt bleiben. lch finde nämlich an Präparaten des zweiten und clritten Tages, dass auf der Innenzone des Dotterhofes, besonders auf distalen Abschnitten derselben, nur wenige Zellen Ballen enthalten, während die Zahl der letzteren sich mit der Annäherung an den Gefässbezirk steigert und im Rande der letzteren selbst am häufigsten ist. Flächenbilder sind hier weit mehr geeignet, dem Urtheil zur Grundlage zu dienen, da man in ihnen hunderte von Zellen schnell iiberblicken kann. Diese Thatsache erregte mir die schwersten Bedenken gegen die Ansicht, der ich mich anzuschliessen im Begriffe stand, denn es musste scheinen, da die Ballen in jüngeren Abschnitten des Entoblasten spärlicher, und in älteren reichlicher vorkommen, dass sic sich erst nachträglich bilden, so wie ja auch v. Kölliker von einem früheren Stadium des Dottersackentoblasten, nänlich von dem „Keimwulst", behauptet (Lehrbuch p. I75), dass die Zellen ihre Inhaltskörper in sich entwickeln. Die Ansicht, dass die Entoblastzellen innerhalb des Keimwalles unveränderte Dotterbestandtheile aufnehmen, scheint mir jecloch so wohl begründet, dass ich vielmehr nach einer Vorstellung suche, in welcher die erwähnte Thatsache neben ihr bestehen kann. Es wäre möglich, dass die Entoblastzellen mit dem Dotter, den sie vom Keinwallstadium her besitzen, bald fertig sind, class sie dann in den distalen Abschnitten leer erscheinen und dann von neuen Inhalt , in sich entwickeln." Eine zweite Möglichkeit wäre die, class bei dem anfänglich langsamen Wachsthum der Keimhaut alle Zellen Zeit finden, sich mit Dotterbestandtheilen zu beladen, so dass wir diejenigen Zellen, bis zu denen am Ende des zweiten Tages der Grenzwulst rorgedrungen ist, reich an Inhalt treffen, während weiter distal gelegene Abschnitte so schnell gewachsen sind, oder in dem geschichteten und vom Dotter schon getrennten Epithel eine so starke Vermehrung von Zellen stattgefunden hat, dass man nur einen Theil der Zellen mit Inhalt beladen antrifft.

Auf die Innenzone der Area vitellina komme ich noch zurück.

2. Das flache Epithel oder das Epithel der Area pellucida. - Das Epithel der Area pellucida ist his zur Mitte des zweiten Tages hin so vicl beschrieben worden, dass ich es nicht wieder zu thun brauche. Ich will nur zweierlei in die Erinnerung bringen; erstens dass in clen Stadien, wo das Mesoderm sich ausbreitet, die Zcllen des Entoderm vielfach in Fäden ausgezogen sind, welche sic an ihrer oberen Seite hervorstrecken; zweitens, dass man oft im bereiche der Area pellucicla, namentlich in der Gegend der sog. "mesodermfreien Stelle", Gruppen kleiner Wülstchen findet, in welchen die Entodermzellen kubische Gestalt und blasiges Aussehen annehmen. 
Fine derartige Gruppe ist in meiner Fig. 23 auf Taf. XII vor dem kiopfe zu selien.

Die Abplattung nimmt in den Tagen, die auf den zweiten folgen, nicht ab, sondern zu und erhält sich bis über die Mitte der Brützeit hinaus. Es ist daher auch sehr schwer, man kann sagen, auffallend schwer, von den Entoblast-Zellen der Area pellucida eine sichere Kenntniss zu erlangen. Nur um der ganz schematischen und blassen I'orstellung zu begegnen, die man von ihnen hat, gebe ich eine Beschreibung mit Rücksicht auf ein Stadium von 3 Tagen und S Stunden, indem ich mich von dem Gedanken leiten lasse, dass es auch hier nützlich ist, ron den ausgereifteren Formen der späteren Tage das licht rückwärts in die Anfänge der Entwicklung fallen zu lassen. In dem genannten Zeitpunkte erscheinen die Entoderm-Zellen der Area pellucida in zwei Abarten. In der einen Form sind die Zellen durch ein weitmaschiges Protoplasmanetz ausgezeichnet, welches schärfer ist als das der Zellen in der Area opaca, da es in dünnerer Iage liegt. Die Zellen sind in der Fläche grösser als die der Area opaca, da sie niedriger sind; die Grenzen sind scharf, obwohl manchmal stückweise unsichtbar. Die Kerne liegen central oder auch excentrisch, sind rund oder eckig; manchmal klein und dunkel, oft aber grösser als die der Area opaca.

Die zweite Form kann dengegenüber als homogene bezeichnet werden. Das Protoplasma ist hier gleichmässig, in Form einer leicht körnigen Substanz, vorhanden, welche so blass und dünn daliegt, dass man in ihr die Vacuolen schwer erkennt. Diese Vacuolen sind kreisrund, von verschiedener Grösse, aber alle sehr klein. Gerade in dieser Formation, in welcher ohne Zweifel die zellige Abgrenzung rorhanden ist, kann man von Zellengrenzen an gefärbten Lackpräparaten nicht das Geringste sehen.

Zwischen beiden steht eine sehr characteristische Uebergangsform. Hier ist ein Theil des Zellenterritoriums und zwar der, welcher den Kern umgiebt, von gröberen Vacuolen eingenommen, so dass hier das Protoplasma maschig erscheint; der Rest, d. 1. der Theil, mit dem die Zelle an andere Zellen anstösst, wird ron der homogenen oder blasskörnigen Masse eingenommen.

Grenze der Area pellucicla gegen die Area opaca. Aus einer Reihe oben mitgetheilter Befunde kann man ersehen, dass schon im Stadium des langen Primitivstreifens der Uebergang des Epithels der Area pellucida in das der Area opaca durch Zwischenformen vermittelt ist, und dass er sich in den bald darauf folgenden Stadien zu cinem sehr allmählichen gestaltet. Dic auf p. 312 von einer Keimscheibe ron acht (neun) Urwirbeln gescliilderten hohen Zellen sind deswegen interessant, weil sie, obwohl hoch, doch 
in den dichten Gefüge ihres Protoplasmas und in dem Mangel ron Inhalt Merkmale besitzen, welche den Zellen der Area opaca eigen sind; sie stellen also Zellen dar, die in Gestalt der Area opaca, in Beschaffenheit aber cler Area pellucicla zugehören und sich

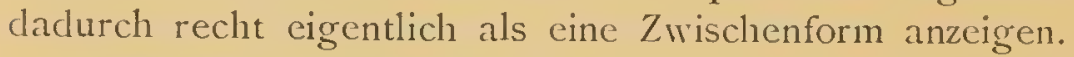

Dass cler Uebergang am Seitenrande ein weit mehr allmählicher ist, als am vorderen und hinteren Rande, zeigen Flächenbilder, und Schnitte in beiden Richtungen bestätigen es. Noch bei einer Keimscheibe mit 13 (14) Urwirbeln (48 Std.) fincle ich rorn und hinten den Uebergang sehr schnell sich vollziehend, hinten noch mehr als vorn. Dieses Präparat macht auch deutlich, wie es liommt, dass im Flächenbilde die beiden Epithelarten unvermittelt gegen einander abgesetzt zu sein scheinen können, während thatsächlich ein Uebergang vorhanden ist. Die Area opaca beginnt hier nämlich gleich mit einem Wulste und dieser Wulst hängt über.

Als ein Stadium, in dem die Ueberleitung der einen Epithelform in die andere eben beginnt, möchte ich die auf Fig. I der Taf. X abgebilclete Keimscheibe mit noch nicht ausgewachsenem Primitivstreifen $(27$ Std.) anführen. Hier kann bei einigen Schnitten wirklich im strengsten Sinne davon gesprochen werden, dass der Uebergang durch eine Zelle vermittelt sei, inden die Grenzzelle nach der einen Seite zugespitzt, nach der anderen hoch ist und sich hier gleich an einen niedrigen Wulst anschliesst; auf anderen Schnitten derselben Keimscheibe stösst allerdings die äusserste flache Zelle der Area pellucida unvermittelt an den Wulst der Area opaca an.

Nach dem zweiten Tage steigert sich nicht etwat das Allmälhliche des Ueberganges, sondern die Grenze ron Area opaca und Area pellucicla wird in Gegentheil schärfer. Daher kann ich, was ich in meiner Dissertation (p. 23) mit Rücksicht auf das Flächenbild des dritten Tages sagte, der Uebergang sei ., cin plötzlicher, nur clurch eine Zellenreihe vermittelt", nach neueren l'räparaten bestätigen und für den zwölften Tag das Gleiche behaupten. Nur muss ich hinzufügen, class am vierten Tage stellenweise doch ein mehr allmählicher Uchergang stattfindet, und dass am zwölften innerhalb der Area pellucida kleinc Gruppen blasiger Zellen angetroffen werden, die zwar weit kleiner sind, als die Zellen der Area opaca, doch aber als ein Anklang an jene betrachtet werden können. Bei genatuerem Zusehen liessen sich ohne Zweifel hier noch mancher1ei lïnzelheiten beibringen, die aber alle keine wesentliche Bedeutung haben können. 
Das sich entwickelnde Dottersackepithel.

Ich habe mit Absicht die Schilderung des fertigen Zustandes vor die der Entwicklung gestellt. Jedes Organ können wir in scinem ausgebildeten Zustande telcologisch begreifen, d. h. wir können seinen Bau aus sciner Aufgabe heraus verstehen. Jeder Entwicklungsgang muss uns als ein Weg gelten, um zu diesem Endziele zu gelangen. Der Weg kann an Anfängen beginnen, welche aus dem Endziele an sich nicht verständlich sind, die wir vielmehr vergleichend morphologisch beleuchten müssen; es können sich in seinen $V^{\top}$ erlauf Unwege cinschichen, welche vergleichend morphologisch erklärt "rerden müssen, aber wenn wir auf eine Berüclssichtigung des reifen Zustandes ganz verzichten wollen, so werden wir das wichtigste leitende Moment verlieren und in willkürliche Deutungen verfallen. Die Geschichte der parablastischen I,ehren stellt in dieser Hinsicht ein trauriges liapitel clar, und es ist wohl gestattet, dem Erstaunen darüber Ausdruck zu geben, dass das Dottersackepithel, nachdem es schon klar beschrieben in der Litteratur rorlag, von jener Seite noch konnte bestritten werden. Dass ein Dottersack existirte, das war doch wohl nicht zu leugnen; dass dieser Dottersack ein Epithel haben werde, war anzunehmen; dass dieses Epithel, wenn es da war, auch gebildet werden müsse, war gewiss; und wo sollte es anders gebildet werden als in der Gegend des sogen. Keimwalles? Es mag auch heute noch gestattet sein, zu erörtern, ob Mesoderm rom Entoderm abgegeben werde, wie es ron Gasser und von Zumstein geschah; dass die Blutzellen aus dem Keimwall hervorgehen, nehmen viele an, nicht nur Parablastiker; aber wenn ein Forscher das Dottersackepithel nicht erkennt oder das klar beschriebene nicht zu finden vermag, so stimmt mich das nicht günstig, ihm in jenen so viel schwierigeren Fragen Glauben zu schenken.

Dies geht in erster Iinie auf Disse, welcher die durch v. Kölliker und mich in die richtige Bahn geleitete Auffassung des „organisirten Keimwalles" (His) oder "Keimwulstes" (letzteres in Köllilier's Sinne) gänzlich wieder verschob in einer Arbeit (5.), welche sodann cine der empirischen Grundlagen für die parablastische Lehre Waldeyer's (3ı) abgab. Als ich meine Untersuchung der fraglichen Region anfing, beschäftigte mich natürlich auch die Frage, ob die feinen Linien im Keimwall mit den eckigen oder abgeplatteten Kernen, die ich in der "proximalen Zone" traf, grossen blasigen Zellen mit an die Wand gedrückten Kernen oder kleinen zwischen den Dotterbestandtheilen gelegenen Zellen entsprächen, ob hier der Zustand des "Dotters in den Zellen" oder der "Zellen im Dotter" beständc. 1ch erinnere mich noch lebhaft der Pein, die ich empfand, nicht zu einem sicheren Ergebniss gelangen zu können; und eben, 
weil mir das unmöglich schien, wendete ich mich späteren Stadien zu, die denn auch die erwünschte Klarheit brachten. Nun ist es sonst Brauch der Untersucher, dass wenn sie eine Ansicht bestreiten wollen, sie ihre Nachuntersuchung nicht nur in gleich ausgedehnter, sondern in ausgedehnterer Weise auf das fragliche Objekt richten. Diss e jedoch bestritt die blasigen Epithelzellen, ohne auch nur einen einzigen Schnitt, ich betone: einen einzigen Schnitt, von denjenigen Stadien gemacht zu haben, auf welche sich mein Urtheil in erster Linie stützte. Wenn Disse kernlose Blasen fand (p. 569), so erklärt sich das aus Schiefschnitten, und der Leser wird das verstehen, wenn er das, was über die Entodermwülste oben gesagt ist (p. 234 f.) berücksichtigt. Ich hätte dieses durch Disse angerichtete Missverständniss nicht erwähnt, wenn nicht die betreffende Arbeit als Grundlage des Waldeyer'schen Parablast-Aufsatzes und der Darstellung der Blutentwicklung im Hertwig'schen Lehrbuche eine unberechtigte Bedeutung erlangt hätte. Uebrigens wird man im Folgenden sehen, dass ich eine gewisse Strecke Weges in Disse's Gesellschaft bin.

Da wir nun mit dem einschichtigen Epithel eine einfache und klar erkannte Thatsache vor uns haben, so werden wir von hier aus rückwärts das Licht des Verständnisses auf die früheren Stufen der Entwicklung werfen. Wer nachher eine zusammenfassende Darstellung, etwa in einem Lehrbuche, giebt, dem ziemt es, von den Anfängen herab, scheinbar deducirend, die Vorgänge gerundet darzustellen.

Von dem einschichtigen hohen Epithele rückschreitend, kommen wir zu dem geschichteten Epithel, welches zwar in seinem Aufbau im Cianzen klar genug vor uns liegt, welches aber doch dem Verständnisse schon erhebliche Schwierigkeiten bereitet, wenn wir über die Abgrenzung der Zellen, und noch mehr, wenn wir über die Natur der Einschlüsse in's Reine kommen wollen.

A. Das geschichtete Epithel. - Das geschichtete Epithel ist die besondere Formation der Innenzone des Dotterhofes. Un diesem Satze seine richtige Abgrenzung zu geben, müssen wir die Berechtigung desselben nach beiden Seiten hin untersuchen und fragen, crstens, ob geschichtetes Epithel auch im Gefässbezirke der Area opaca vorkomme (ron der Aussenzone des Dotterhofes soll einstweilen noch nicht gesprochen werden); zwcitens, ob einschichtiges Epithel sich auch in der Area vitellina fincle.

Auf dic erste dieser beiden lragen ist zu antworten, dass in früheren Stadlien sich geschichtetes Epithel auch in den distalen $A b$ schnitten des Gefissbezirkes findet, und dass es in früheren und spä- 
teren Stadien über dem Randtheile des Mesoderms, in dem schon crwähnten (p. 310) Grenzwulste sich findet; vielleicht erhält es sich hier bis zur Verwachsung der bindegewebigen Wand des Dottersackes am distalen Pole; wenigstens habe ich, wie schon angeführt, (p. 301) am zwölften Tage noch auf dem Bindegewebsringe, der den Mesodermrand bildet, geschichtetes Epithel getroffen.

Auf die andere Frage ist $z u$ antworten, dass einschichtiges Epithel in der Innenzone der Area vitellina gelegentlich vorkommt, nämlich dann, wenn auch das Epithel über den Mesoderm-Rande einschichtig ist, dass aber diese Fälle so selten sind, dass man kieine Varianten des gewöhnlichen Vorkommens, sondern nur Ausnahmen ron der Regel erblicken kann.

Ich muss bemerken, dass es nach meinen Erfahrungen meistens sehr schwer und oft unmöglich ist, die Grenzen der Zellen genau festzustellen, und dass daher der zweite meiner Sätze der Kritik eine breite Angriffsfläche bietet. Ich möchte dies nicht verdecken, sondern in Gegentheil hervorheben, dabei aber auch bemerken, dass sich meine Behauptung auf eine die ganze Entwicklung umfassende Betrachtung und ein umfangreiches Material stützt, aus welchem ich hier einiges Weitere vorlege.

Nicht ausgewachsener Primitivstreifen (27 Std.). - Die in Fig. I und 2 der Taf. $\mathrm{X}$ wiedergegebene Keimscheibe zeigt die schon erwähnten (p. 235) Wülste am inneren Rande der Area opaca und jenseits derselben diesen Hof flach. Wie ich schon andeutete, erinnert dieses Verhältniss an das Bild, welches uns späterhin der "Grenzwulst" mit der distal davon gelegenen Innenzone des Dotterhofes bietet. Wenn daher auch eine solche Keimscheibe, wie ich sie in Fig. I abgebildet habe, selten sein mag _- ich selbst habe so ausgeprägte Wülste in dem Stadium des Primitivstreifens nur dies eine Mal gesehen -, so sehe ich sie doch nicht als abnorm an, sondern ich glaube, dass uns hier ein ganz normales Verhältniss nur in frühzeitiger und ungewöhnlich deutlicher Weise entwickelt entgegentritt. Die Wülste nun bestehen aus geschichtetem Epithel, aus rundlichen ocler polygonalen Zellen; sie sind drei bis vier Zellen hoch, die Kerne sind innerhalb cler Wülste in gleichmässiger Vertheilung. Die Ausdehnung der gewulsteten Zone in radiärer Richtung ist etwa zwölf Zellenbreiten. Distal anschliessend sinkt das Epithel auf halbe Höhe und ist hier noch deutlich geschichtet, dann aber nimmt die Dicke des Epithels so sehr ab, dass von einer Schichtung nicht mehr gesprochen werden kann.

Keimscheibe mit 1 Urwirbel (25 Stcl.). - Ueber dem Mesodermrande ist das Epithel geschichtet und diese Schichtung erhält sich unvermindert distal davon. 
Keimscheibe mit vier Urwirbeln ( $3 \mathrm{I}-32$ Std.). - Die Schnitte sind durch den Dotterhof in radiärer Richtung gemacht; der Dotterhof gehört der in Fig. 23 der Taf. Xll abgebildeten Keimscheibe an. Das Epithel in der Innenzone ist anfangs niedrig, dann erhebt es sich zu einem flachen Wulst, dann wird es allmählich niedriger bis zu starker V'erdünnung.

Der Wulst ist nur als eine unwesentliche Erscheinung, als eine Unregelmässigkeit aufzufassen. Er ist bedingt weniger durch V $V_{\text {er }}$ mehrung der Zellenlagen, denn es finden sich nur drei derselben übercinander, als durch Vergrösserung der einzelnen Zellen. Ich will hier gleich bemerken, dass ich auch am dritten Tage derartige Unregelmässigkeiten gefunden habe. In dem Flächenbilde der dann sehr dünnen und durchscheinenden Haut erscheinen sie als .Milchflecke", auf dem Schnitt zeigen sie sich sehr flach. v. Kölliker spricht von diesen Wülsten und giebt eine Abbildung davon (Lehrbuch Fig. IO3); ich nuss aber bemerken, dass an meinen Präparaten dic Wülste immer durch verhältnissmässige Grösse der Zellen, indirekt also durch ungewöhnliche Ansammlung von Inhalt bedingt waren, und dass die Abbildung, welche v. Kölliker giebt, auf der man kleine Zellen ohne bestimmt angegebenen Inhalt sieht, zu meinen Erfahrungen nicht stimmt.

In dem dünnen Anfangstheil unseres Schnittes ist das Epithel zweischichtig, in dem Wulst dreischichtig, distal davon zweischichtig, stellenweise aber auch dreischichtig. Diese Darstellung bedarf noch einer näheren Erläuterung; welche für manche der anderen Präparate gleichfalls gilt. Was man zunächst deutlich auffindet, sind natürlich die Kerne. Diese liegen erstens in fortlaufender Reihe aussen, d. h. dem Ectoderm zugewendet; zweitens aber ebenso in fortlaufender Reihe innen, d. h. dem Dotter zugewendet, of aber auch dazwischen, also in einer intermediären Zone. Wenn ich aber ron einer zweischichtigen, bezw. dreischichtigen Lagerung der Zellen und nicht nur der Kerne spreche, so bedarf das noch einer Begrïnclung, welche ich weiter unten versuchen wercle zu geben. Die zweischichtige Anordnung wird nun in unserem Präparate hartnäclig festgchalten, selbst an den dünnsten Stellen des Epithels. Hier platten sich die lierne ab und erscheinen elliptisch; und indem das Protoplasma, um die Kerne vorwiegend angehäuft, einen Hof bildet, und dieser sich mit den Kernen streckt, können wir zu der Meinung verleitet werden, spindelförmigé oder langgezogene sternförmige Zellen vor uns zu haben, eine Meinung, die allerdings durch dic Betrachtung des Flächenbildes sehr schnell ihre Verbesserung erfahren muss, da wir dann rundliche oder polygonale Zellen treffen, die chen nur im Durchschnitt spindelförmig crschienen, wic ja an- 
dere abgeplattete Zellen auch. Vinschlüsse sind in den Zellen der distalen Abschnitte fast gar nicht vorhanden; in dem Wulst sind alle Zellen mit Ballen gefüllt, und ebenso in dem distal anstossenden Theil; proximal sind die Zellen weniger voll.

Keimscheibe mit 5 Urwirbeln (30 Stcl.). - Das Epithel ist über dem Mesodermrande geschichtet, ohne einen Grenzwulst zu bilden; in den zunächst anstossenden Theilen der Area vitellina l)leibt die Dicke gleich und erhält sich die Schichtung.

Keimscheibe mit 8 (9) Urwirbeln (3 I Std.). - Der Befund ist genau der gleiche. Auch die Einschlüsse der Zellen sind in den Theilen des Dotterhofes, welche sich an den Gefässbezirk zunächst anschliessen, die gleichen wie dort.

Keimscheibe mit 9 Urwirbeln (42 Stcl.). - Das Verhalten ist rechts und links nicht das Gleiche; auf der einen Seite ist clas Epithel über dem Mesoderm-Rande einschichtig, obwohl es proximal davon geschichtet war, und bleibt auch einschichtig in clen zunächst folgenden Theilen der Area vitellina, dann aber wird es geschichtet und dabei höher; auf der anderen Seite ist dagegen das Epithel über dem Mesoderm-Rancle geschichtet und das Gleiche trifft man in der Area vitellina, wo es zugleich an Höhe etwas zunimmt und vier Kernreihen übereinander zeigt. Ein Grenzwulst fehlt. Ballen sind sowohl in dem Gefässbezirke, wie in der Area vitellina fast in allen Zellen rorhanden.

Keimscheibe mit I3 (I 4) Urwirbeln (4S Std.). - Während in meinen übrigen Angaben ron den Seitenschnitten der Keimhaut gesprochen wird, liegen hier Iängsschnitte vor. An ihnen erscheint in Mittellinie vorn über dem Mesoderm-Rande ein Wulst und geschichtetes Epithel, davor wird das Epithel niedriger, bleibt aber zweischichtig, und dieses niedrige Epithel nimmt nach sieben Zellenbreiten steigend an Höhe und Zahl der Schichten zu; hinten ist das Epithel über dem Mesoderm-Rande geschichtet, aber ohne einen Wulst zu bilden, dann wird es niedrig; bleibt aber zwei- bis dreischichtig. Als Inhalt finclet man vorn in den Zellen des Grenzwulstes kleinere, in denen des Dotterhofes grössere Ballen; hinten sowohl im Gefässbezirke wie im Dotterhof nur kleine und spärliche Inhaltskörper.

Keimscheibe mit I5 (r6) Urwirbeln. - Auch hier ist das Verhalten rechts und links nicht das gleiche. Auf der einen Seite ist das Epithel in einem Theile des Gefässbezirlies gescíichtet, so auch über dem Mesoderm-Rande, wo es etwas höher wird und einen schwachen Grenzwulst bildet; in der Area vitcllina ist es gleichfalls geschichtet und ist zuletzt, nachdem es sich ganz, allmählich erniedrigt hat, zweischichtig. Auf der anderen Scite fehlt der Grenz- 
wulst, bleibt die Höhe des Epithels in der Area vitellina dic gleiche, ja sie nimmt noch etwas zu, so dass hier sechs Kernreihen über einander liegen. Die Erfüllung der Zellen mit Inhalt ist in dem Epithel der Randzone und ebenso der angrenzenden Theile der Area vitellina eine reichliche.

Keimscheibe vom letzten Viertel des zweiten Tages. - Diese Keimscheibe, von der an früherer Stelle (p. 3io) schon gesprochen wurde, zeigt über der Randvene einen Grenzwulst mit unregelmässigen, durch gruppenweises Vortreten von Zellen bedingten Erhebungen, in denen die Kerne bis zu sechs Reihen liegen. Das sich anschliessende Epithel der Area vitellina ist ziemlich dick, dann nimmt es weiter ab, bleibt jedoch geschichtet. Als Inhalt treffen wir grosse Ballen reichlich in der distalen Hälfte des Grenzwulstes und in den angrenzenden Theilen der Area vitellina, dann nehmen diese Ballen an Zahl ab, finden sich aber immer noch vereinzelt, kleinere dazwischen.

Keimscheibe von zweiundzwanzig Urwirbeln (52 Std.). - Der Grenzwulst fehlt. Auf der Vena terminalis ist das Epithel einschichtig, ebenso in den angrenzenden Theilen der Area vitellina. Auch die Erfüllung der Zellen mit Ballen ist die gleiche.

Innenzone des Dotterhofes von zwei Tagen und einundzwanzig Stunden. - Das Epithel ist sehr dünn aber geschichtet.

Drei Tage und zwanzig Stunden. - Der Grenzwulst fehlt gänzlich; das Epithel wird in der Area vitellina ganz allmählich höher und hat auch schon neben dem Mesodermrande eine bedeutende Höhe. Dic Epithelzellen sind in den distalen Abschnitten des Gefässbezirkes sehr schmal und hoch; in dem Randgebiete selbst ist das Epithel geschichtet, und es bleibt so in der Area vitellina. Alle diese Zellen, sowohl die in den Randtheilen des Gefässbezirkes als die in der Area vitellina sind so dicht mit Inhalt erfüllt, dass die zellige Abgrenzung schwer zu erkennen ist; aber man trifft hier keine grossen Ballen, sondern nur mittelgrosse und kleine Tropfen oder Körner.

Der letztgeschilderte Befund ist so abweichend ron allem Vorausgehenden, dass ich bedauere, die Entwicklung der Innenzone nicht weiter verfolgt zu haben, um zu erfahren, ob nur eine individuelle Eigenthünlichkeit vorlag, ocker ob mit diesem Stiddium Acnderungen einsetzen.

In Uebrigen aber sind clie Befunde derartig, dass sie innerhalb des Zeitraumes, den sie umfassen, keine Entwicklung ron einer niederen zu einer höheren Stufe zeigen, sondern nur Schwankungen um einen gewissen Crundtypus herum, den wir uns bemühen müssen, aus der Variation herauszuhcben. Als charakteristisch be- 
zeichnen wir nur das eine, dass dies lipithel geschichtet ist, und dass wir an ilm Zellen der äusseren und inneren Flïche und intermediäre Zellen unterscheiden. Das geschichtete Epithel aber set»t sich auf den Randtheil des Gefïissbezirkes fort, wo es häufig, aber nicht immer, einen Grenzwulst bilclet. In dem Grenzwulst erkennen wir diejenige Zone, innerhalb clerer das Epithel noch geschichtet ist, die Zellen sich aber strecken und sich vorbereiten, zu den langen Zellen des einschichtigen Epithels zu werden. Die Dicke des Entoderms in der Innenzone der Area vitellina finden wir verschieden und zwar in Abhängigkeit von der Erfüllung der Zellen mit Inhalt. Diese ist am zweiten und dritten Tage zum Theil auffallend gering, was sich aber. einigermassen begreifen lässt, da diese Zellen nicht an den Dotter, sondern an die Flüssigkeit des perilecithalen Spaltes anstossen. Noch mehr verständlich wird die Spärlichkeit des Inhalts aus der Thatsache, dass die Entodermzellen in dieser Zeit, wo sie vielleicht keinen, jedenfalls aber nur wenig Dotter aufnehmen, sich stark vermehren. Auf eine solche Vermehrung kann man schon aus dem intensiven Flächenwachsthum schliessen, wir können sie aber aus den Mitosen direkt abnehmen, und ich will über die letzteren einiges mittheilen.

v. Kölliker bemerkt mit Recht (Lehrbuch p. I77), "dass das Flächenwachsthum der drei Keimhäute nicht an einer hestimmten Stelle seinen Sitz habe, wie etwa am Rande, sondern in allen Theilen derselben vor sich gehe." Von dem Rande werde ich weiter unten sprechen (p. 33I); hier rede ich nur von den Mitosen in der Innenzone des Dotterhofes. Diese finden sich am zweiten nnd dritten Tage zahlreich und sind hier um so leichter aufzufinden, da ja durch die geringe Dicke der Haut und die schwache Erfüllung der Zellen mit Inhalt die Schwierigkeiten fortfallen, welche uns bei der Aussenzone des Dotterhofes entgegenstehen. Die Mitosen finden sich in unregelmässiger Vertheilung. Jhre Aequatorialplatte steht senkrecht, sonst aber in keiner bestimmten Richtung. Die Zellen, in welchen sich Mitosen finden, sind verhältnissmässig klein, scharf begrenzt, gerundet, und ihr Protoplasma ist nicht weitmaschig, wie das der übrigen. In rler Regel sind diese Zellen leer, doch soll ausdrücklich bemerlit werden, dass Inhaltskörper und Vacuolen zuweilen auch in Zellen mit Mitosen gefunden werden.

Wenn wir diese reichliche Zellenvermehrung in der Innenzone der Area vitellina berücksichtigen, und annehmen, was viellcicht berechtigt ist, dass während der Zeit, wo das Epithel an den perilecithalen Spalt anstösst, dic Aufnahme des Dotters stockt, so wird es whl begreiflich, class wir eine Formation antreften, die so auf- 
fallend arm an Inhalt ist; und das ist sie in der That, wenigstens in weiten Abschnitten.

Ueber die Art des Inlhaltes sei hier nach einem Osmiumpräparat der Innenzone einer Keimhaut ron $5+$ Stunden Folgendes bemerlit. Dic Einschlüsse bestchen erstens in Ballen, deren grösscre ungefähr alle von gleicher Form sind, dicht und leicht körnig, zweitens in kugligen 'Tropfen, die weit kleiner sind als die Ballen. Die Ballen ändern ab nach Grösse und Aussehen, die Tropfen gehen hinab bis zu den kleinsten Volum. Die Ballen erscheinen an Präparate bräunlich gelb; oft geschwärzt, wo dann zuweilen eine gelbe Ecke hervorschaut, so dass man das Schwarz als von einem Ueberzuge bedingt ansehen kann; die Tropfen erscheinen schwarz oder schwarzbraun. Wahrscheinlich wird man die Ballen auf den eiweissartigen, die Tropfen auf clen fettartigen Bestandtheil des Dotters zurückführen clürfen.

Zum Schlusse dieser Betrachtung ist nun noch zu berücksichtigen, ob wirklich in der Innenzone eine zellige Abgrenzung vorhanden, und ob wirlilich das Epithel geschichtet sei. Wenn man Flächenpräparate dieses Epithels rom zweiten Tage betrachtet, so bemerkt man sehr oft an clenjenigen Stellen, wo der Inhalt spärlich ist oder fehlt, ein zierliches, ziemlich weitmaschiges Netz scharf erliennbarer protoplasmatischer Fäden, in welchem aber Zellengrenzen zu fehlen scheinen. In Wahrheit haben dic letzteren das gleiche Aussehen wie die Protoplasmafäden und sind daher kaum erkennbar. IV er aus einem solchen Präparate, welches ihm ausserhalb jeclen Zusammenhanges rorgelegt würde, ein netzartiges Plasmodium nit gleichmässig vertheilten Kernen diagnosticiren würde, vercliente keinen Tadel; wer aber clas Object aufsucht, um über dasselbe zu urtheilen und andere zu belchren, der übernimmt die Pflicht, die Fragen in ihrer Gesammtheit zu erfassen, nebenliegende Theile zu würdigen und cinen Gang der Entwicklung aufzufinclen. Ich nun urtheile nach Wägung alles mir zugängigen Materiales, class die Innenzone des Dotterhofes von abgegrenzten Epithelzellen durchaus aufgebaut sei, ich schliesse es zum Theil, zum Theil aber sche ich es, und darüber will ich noch einiges mittheilen.

Silberbilder vom sechsten und vicrten Tage -- leisler habe ich keine früheren gemacht - zcigen die zellige ununterbrochene $A$ bgrenzung deutlich, dic Zcllen vielfach klein; weniger eckig polygonal wie innerhall, des Gefïssbezirlies, vielnchr mit Neigung zur Abrundung, so dass zuwcilen kleine Iücken entstehen, durch welche man zwischen benachbarte Zellen hineinblicken kann. Am vierten Tage sind auch an gefärbten l'rïparaten die Cirenzen zum Theil äusserst scharf, namentlich an Strllen, wo die \%ellen klein und arm an Inhalt 
sind. Auch auf Durchschnitten sieht man an zweiten und dritten Tage die Zellengrenzen oft scharf, und man erliennt dann, dass die Zellen blasig und rundlich sincl.

Die Schichtung res Epithels aber ist theils aus der oben beschriebenen Lagerung der Kerne zu schliessen, theils unmittelbar zu sehen, und es platten sich an dünnen Stellen die Zellen of lieber ab, als dlass sie die Schichtung aufgeben. Das hindert jecloch nicht, dass eine Zelle, welche einen grossen ballen als Inhalt umschliesst, durch die ganze Dicke des Epithels hindurchreicht.

B. Entstehung des Dottersackepithels. - Die weitere Untersuchung; d. h. die der Entwicklung des Dottersackepithels, kann auf zwei Weisen erfolgen; erstens kann man eine bestimmte Stelle, nänlich den proximalen Rand der Area opaca, im Auge behalten und feststellen, welche Bildungen hier nacheinander auftreten -Untersuchung der zeitlichen Folge; zweitens aber kann man in einem weiter vorgerückten Stadium der Entwicklung die in dem peripherischen Theile der Keimhaut nebeneinander liegenden Stufen betrachten - Untersuchung der räumlich en Folge. Die Ergebnisse beider Untersuchungen muss man erwarten, oder, um mich vorsichtiger auszudrücken, darf man hoffen, in Uebereinstimmung zu finden, da ja die Randtheile der Keimhaut die jüngsten sind und daher die Zustände wiederholen, welche an Innenrande der Area opaca früher bestanden. Die Richtigkeit dieser Annalıme vorausgesetzt, müssen sich die eine und die andere Untersuchung gegenseitig controliren und ergänzen; es würde sich aber immer die Untersuchung des Nebeneinander d. h. der späteren Stadien besonders empfehlen, weil ja hier die Keimhaut eine grössere Ausdehnung gewonnen hat, und daher die einzelnen Phasen der Entwicklung über grössere Räume auseinandergezogen sind, während sich bei der ersten Entwicklung alles auf engem Raume drängt.

Die Annahme ist jecloch, wenn ich die mikroskopischen Bilder richtig deute, nicht erlaubt; $d$. h. es ist nicht zutreffend, dass an den Randtheilen älterer Keimhäute sich die gleichen Zustände des Dotterentoblasten finden, welche die erste bilclung desselben einleiteten.

Ueber die Zustände der ersten Bilchung kann ich auf Grund ron eigenem Material nicht völlig genau urtheilen, indessen bestimmt mich das, was ich gesehen habe und ror allem der Vergleich mit Amphibien und Reptilien, eine Auffassung anzunchmen, welche von verschiedenen Scitcn geäussert ist, die, dass schon bei der Furchung eine Anzahl von Kernen (mit Protoplasma natürlich) in den Dotter hineingelangt, welche später clurch zellige Abgliederung zur Bildung von "Dotterzellen", den Vorlüufern von Dotterentoblastzellen, führen. 
Man kann den dabei stattfindenden Vorgang einer verzögerten Zellenabgliederung in gewissem Sinne als „secundläre Furchung“ bezeichnen; ich sage ausdrücklich: in gewissem Sinne, da ja dieser Ausdruck in verschiedenem Sinne gebraucht wircl. Man könnte daher vielleicht besser das Wort „Dotterfurchung" anwenden, womit auch schon eine Beziehung auf das Dotterorgan ausgedrückt wäre. Diese Dotterfurchung (.,Dottertheilung") ist für das Huhn von Götte behauptet (9) und voll Rauber (2I) angenommen worden; vor allem aber hat Duval zur Kenntniss derselben den sicheren Grund gelegt, indem er $(7)$ die Vertheilung der Kerne im Boden der subgerminalen Höhle und im Dotterwall (. Keimwall" His) genauer topographisch ermittelt hat.

Dieser Vorgang der Dotterfurchung findet aber, wenn meine Deutung der mikroskopischen Bilder richtig ist, sehr bald ein Ende, und wird durch einen andern Vorgang ersetzt, bei welchem die Entoblastzellen gebildet werden, bevor sie mit dem Dotter in Berührung treten. Natürlich muss ein solcher Dualismus befremden, und bei Jedermann der I'unsch einer einheitlichen Auffassung sich geltend machen. Daher werden auch diejenigen, welche ein freies Vorwachsen des Entollasten unabhängig von Dotter vertreten, wie v. Kölliker, der Dotterfurchung nicht günstig sein; andere, welche die Bedeutung der Dotterfurchung bei niedrigeren Wirbelthieren aus der Litteratur oder aus eigener Anschauung kennen, werden umgekehrt geneigt sein, ihr eine sehr weitgehende Bedeutung zuzumessen, wie z. 13. Duval diesen Vorgang einer "secundären Furchung" in Anschluss an die Ausbreitung des "Dotterentoblasten" bis zu völliger Umschliessung des Dotters fortgehen lässt. Hier mag nebenbei erwähnt werden, dass die "secundäre Furchung“" Duval's ein ganz anderer Vorgang ist, sowohl in seiner Erscheinung als in seiner geweblichen Bedeutung, wie die secundäre Furchung Waldeyer's (31). Ich, wennschon ich mich über die erste Entstehung des Dottersackentoblasten nicht geäussert habe, hielt doch für mich die Köllikersche Anschauung wegen ihrer Einfachheit, und deswegen, weil sie zu den spätteren Stadlien so gut passte, für die richtige und würde which schwer entschlossen haben, der Dotterfurchung Bedeutung beizumessen, wenn nicht für letztere andere, weit klarere Beispicle bei Amphibien und Reptilien vorlägen.

Von Amphibien ist hier Ichthyophis heranzuziehen, bei dem, wie I. und P'. Sarasin auf's Klarste dargestellt haben (24), sich die Kcrne allmählich im Dotter ausbreiten, die zellige Gliederung aber innmer erst einige \%eit später eintritt, bis dieselbe schliesslich den gesammiten 1)ottersack ergriffen hat. Die Vermittelung von hier zu den Vögeln liefern die Reptilien, und es sind vor allem die Mit- 
theilungen von Strahl (26) über Lacerta heranzuzichen, welche allerdings den Zeitpunkt der vollzogenen zelligen Abgliederung, nicht röllig genau angeben, aber cloch mit genügender Deutlichkeit und für mich, angesichts eigener Erfahrungen, überzeugend clarthun, dass bei Lacerta die Dotterfurchung in ausgedehnter Weise zur Verwendung gelangt. Im Besonderen sei hier erwähnt, dass der Boden der subgerminalen Höhle in seiner ganzen Ausclehnung der Sitz eines derartigen Vorganges ist, während beim Huhn an genannter Stelle zwar der gleiche Process sich abspielt, jecloch wie Duval dargestellt hat ( 7. p. 35) in beschränkter Weise und wesentlich in den Randtheilen. Auch entwickeln sich aus dieser Furchung am Boden der subgerminalen Höhle und erhalten sich bei Ichthyophis und bei Lacerta "Dotterzellen", die späterhin zu Dottersackepithelzellen sich umbilden; wogegen beim Huhn die im Boden der Höhle entstehenden Zellen zwar in die Höhle eintreten, jedoch, ohne weiter eine Rolle gespielt zu haben, zu Grunde gehen. Diese bei Amphibien und Reptilien beschriebenen Vorgänge sind es vor allem, welche bei mir das Bedenken dagegen zurückgedrängt haben, dass auch beim Huhne die Dotterfurchung bestehe, dass auch hier "Dotterzellen" durch verzögerte Furchung gebildet werden. Aber, wenn ich die mikroskopischen Bilder richtig deute, so ist dieser Vorgang beschränkt und wird bald durch einen anderen ersetzt, bei welchem die Entoblastzellen erst gebildet werden, bevor sie mit dem Dotter in Berührung treten und dadurch "Dotterentoblastzellen" werden.

Es widersteht mir, wie jedem, anzunehmen, dass die gleiche gewebliche Formation auf zwei principiell verschiedenen Wegen sollte gebildet werden. Daher erwarte ich auch, dass sich zwischen beiden Vorgängen eine Vermittelung werde finden lassen. Bevor man jedoch an letztere herangeht, muss man das Thatsächliche erst genau kennen, und ich will nun schildern, was ich von der Entstehung des Dottersackepithels in den Randtheilen der schon etwas weiter entwickelten Keimhaut glaube erfahren zu haben.

Wenn man die Area opaca einer etwas fortgeschrittenen Keimscheibe untersucht, so kann man an derselben sechs Abschnitte unterscheiden:

I. den Keimhautrand,

2. die Region des flachen Entoblasten,

3. clie Region des in den Dotter cindringenden Entoblasten,

4. die Region des gleichmässig in Dotter verbreiteten Entoblasten.

5. die Region des geschichteten Fipithels,

6. die Region des cinschichtigen Epithels. 
Die erste dieser Regionen ist durch ihren Namen gekennzeichnet; die zweite, dritte und vierte trifft man in der Aussenzone des Dotterhofes, die fünfte in der Innenzone des Dotterhofes und im Grenzwulste des Gefässbezirkes, die sechste in dem Rest des Gefässbezirkes. Die dritte kann man im Anschlusse an die Bezeichnungsweise ron His der Formation des "sich organisirenden“, die vierte der Formation des „organisirten Keimwalles" gleichstellen.

Von der fünften und sechsten Region ist bereits gesprochen; es bleiben also vier. Von diesen ist die erste, die Region des Keimhautrandes, gut abgegrenzt, die drei folgenden gehen ohne scharfe Scheidung in einander über, doch ist es zweckmässig; die verschiedenen Stufen des Vorganges durch Namen zu trennen. Die vierte Region ist gegen dic fünfte gleichfalls bei der Untersuchung von Schnitten nicht scharf zu scheiden, weil, wie oben angreführt wurde, (p. 324) die Erkennung der Zellengrenzen in der Innenzone der Area vitellina oft Schwierigkeiten macht. Es ist also schwer zu entscheiden, wann die Formation des geschichteten Epithels rollendet ist, mit anderen Worten, wann an die Stelle des Zustandes, den wir mit den Wrorten: "Zellen im Dotter" bezeichnen können, der andere getreten ist, bei dem wir von "Dotter in den Zellen" sprechen können. Hier jedoch hilft uns ein makroskopisch nachweisbares Nerkmal über die Schwierigkeit fort, nämlich das Auftreten des perilecithalen Spaltes.

Der perilecithale Spalt, von dem schon gesprochen wurde (p. 233), breitet sich im Anfange, wie v. Baer schildert (2 p. 10), zum Theil durch Vermittelung ringförmiger, mit Flüssigkeit erfüllter Spalten aus, welche dann mit ihm zusammenfliessen und auf diese W'eise zu seiner Vergrösserung beitragen. Das Auftreten solcher peripherischer Spalten scheint mir anzuzeigen, dass die Flüssigkeit in loco gebildet und nicht von einem centralen Punkte, etwa ron der subgerminalen Höhle aus, peripheriewärts ausgebreitet wird; womit jedoch die Betrachtung nicht abgeschnitten sein soll, dass späterhin das fertige Epithel, unterstïtzt durch das in den Gefässen kreisende Blut, gleichfalls und vielleicht in viel ausgiebigerer Weise diesen Flüssigkeits-Erguss zwischen Keimhaut und Dotter besorgt.

Der perilecithale Spalt ist natürlich bei seinem Auftreten ausserordentlich schmal. Trotzdem kimn man sich aber makroskopisch sehr leicht ron seiner Anwesenheit und seiner Ausdchnung überzeugen. Demn soweit er reicht, lässt sich die Keimhaut - sei es im frischen Zustande, sei es nach vorausgegangener Einwirkung fixirender Flüssigkeiten - glatt und ohne Verletzung abheben. Das ist aber nicht der Fall in der Aussenzone des 1)otterhofes. Hier beobachtet man vichnehr Folgendes: wenn cine fixirende Flüssigkeit 
kurze Zcit cingewirkt hat, so dass nur das Ectoderm und eine dünnc Schicht des Dotters von ihr getroffen sind, so behält man beim Ablösen eine Schicht von Dotter am Präparat; wenn dagegen die fixirende Flüssigkeit länger eingewirkt hat, so dass der Dotter auf grössere Tiefe von derselben getroffen ist, so erhält man in der Aussenzone des Dotterhofes nur ein ganz dünnnes Häutchen, $d . h$. das Ectoderm mit Spuren von anhaftendem Dotter und Resten von Entoblastzellen. Niemals aber gelingt es, die Keimhaut vom Dotter zu trennen; es kann auch gar nicht gelingen, weil Dotter und Keim innerhalb der Aussenzone nicht von einander gesondert sind, sondern sich gegenseitig durchdringen.

Die mit Flüssigkeit gefüllten Spalten sind vermuthlich nicht die ersten Stadien im Auftreten von Flüssigkeit. Denn bevor es zu solchen mit freiem Auge wahrnehmbaren Ansammlungen kommen kann, müssen feinere mikroskopisch e Ansammlungen stattgefunden haben, und wir werden annehmen dürfen, dass kleine mit Flüssigkeit erfüllte Spalten in der Rindenschicht des Dotters auftreten. Welche Kräfte dabei wirken, ist nicht völlig sicher. Ohne Zweifel dürfen wir den Ectodermzellen eine Rolle zusprechen; wir dürfen annehmen, dass sie, die auch späterhin die Resorption des Eiweisses besorgen, schon jetzt dem Eiweiss Wasser entziehen; ob sie es aber unmittelbar in den Dotter ausscheiden, oder ob die Entoblast-Zellen an der Abscheidung betheiligt sind, muss dahingestellt bleiben.

Für die Durchsetzung der Rindenschicht des Dotters mit feinen von Flüssigkeit erfüllten Spalten in der Aussenzone des Dotterhofes haben wir ein makroskopisches Merkmal, nämlich das fleckige, weissliche, zerfressene Aussehen des Dotters im Gegensatze zu der gleichmässig gelben durchscheinenden glatten Beschaffenheit unveränderten Dotters. Es ist bekannt, wie sehr das Aussehen einer homogenen durchscheinenden Substanz geändert wird durch Beimischung einer zweiten Substanz von anderem Lichtbrechungsvermögen, die sich nicht mit der ersten zu verbinden vermag, sondern mit ihr eine Emulsion bildet. Wenn man Dotter mit Wasser oder Kochsalzlösung zusammenschüttelt, so nimmt er eine vollkommen weisse Farbe an, doch kann man ihm seine gelbe Farbe dadurch wiedergeben, dass man das Wasser verdunsten lässt. Aus der Farbe kann man also nicht schliessen, dass eine bestimmte Stelle die Beschaffenheit des „weissen Dotters" im histiologischen Sinne hat; so ist auch der Dotter, den wir in der Aussenzone des Dotterhofes am zweiten Tage treffen, kein "weisser Dotter", olwohl er makroskopisch so aussieht. Der weisse Dotter vermehrt sich nicht mit der Entwicklung, und daher tritt die Keimhaut, nachdem sie die Region des weissen Dotters überschritten hat, in gelben Dotter ein 
- histiologisch gesprochen, obwohl der letztere durch das Auftreten feiner mit Flüssigkeit erfüllter Spalten eine weissliche Farbe angenommen hat.

Die angeführten Ergebnisse der makroskopischen Beobachtung clürfen wir nicht aus den Augen lassen, weil uns dadurch gewisse Züge bekannt werden, die wir bei der mikroskopischen Beobachtung sehr leicht übersehen, ja nicht einnal sicher beurtheilen können, auch wenn wir auf sie achten. Die feinen intravitellinen Spalten lassen sich am mikroskopischen Präparate gar nicht sicher beurtheilen, weil, wie früher gesagt, der Dotter bei der Vorbereitung zur Herstellung von Schnitten unter dem Einfluss des Alcohols unfehlbar etwas schrumpft, und daher auch so schon Spalten auftreten. Selbst den perilecithalen Spalt liönnten wir an Schnitten nicht sicher erkennen, wenn sich derselbe nicht durch ein feinkörniges Gerinnsel verriethe.

In der Fig. 20 meiner Tafel XI ist ein radiärer Durchschnitt durch die Area opaca einer 24 Stunden gebrüteten Keimhaut bei zwölffacher Vergrösserung dargestellt; der obere Rand in der Figur bezeichnet das Ectoderm, der untere Rand ist unterbrochen; links, soweit die Linie p. S. reicht, findet sich unter dem Entoblasten der perilecithale Spalt, rechts bezeichnet die punktirte Linie im Dotter die Grenze, bis zu welcher Zellen in den Dotter vorgedrungen sind. Diese Linie endigt bei den beiden Punkten a und b, welche nur deswegen besonders aufgenommen sind, um die Lage der Zellen anzugeben, welche in Fig. 2 I und 22 dargestellt sind. Doch ist die Lage der Punkte a und b beachtenswerth; b liegt in der Flucht der Linie p. S., a dagegen ist noch etwas weiter gegen den Dotter vorgeschoben. Später wird davon wieder die Rede sein. Die Zahlen I bis 5 bezeichnen die aufeinander folgenden Stufen der Entwiclilung vom Keimhautrande bis zum geschichteten Epithel. Striche, welche die einzelnen Regionen gegen einander abtheilen, geben die Breite derselben an.

Die Entstehung des Dottersackepithels soll nun in zwei UnterAbschnitten besprochen werden.

I. Der Keimhautrand und die Region des flachen Entoblasten. - Die Region des flachen Entoblasten, wie ich sie kurz nenne, die aber besser die ., Region des noch nicht in den Dotter cingedrungenen Entoblasten" hiesse, muss mit dem Keimhautrande zusammen behandelt werden aus einem praktischen Grunde, nänlich weil man bei der geringen Breite beider schon von der zweiten zu sprechen genöthigt ist, wenn mán die erste darstellen will.

Der Keimhautrand erfreute sich cine Zeit lang lebhafter Beach- 
tung, nämlich damals, als man in ihm den Rand des "Urmundes" der Vogelkeinscheibe sah. Damals widmete ihm Rauber (21) eine besondere Besprechung: Nachdem man sich jedoch geeinigt hatte, den Urmund in dem l'rimitivstreifen zu finden, wurde der Keimhautrand zum .Umwachsungsrande“ degradirt und verfiel so ziemlich der Vergessenheit, ohne dass leider die Zeit seiner Berühmtheit hingereicht hätte, eine genaue Kenntniss über ihn zu erwerben.

Es giebt über den Keimhautrand zwei Ansichten; nach der ersten wird er nur vom Ectoderm gebildet, während das Entoderm erheblich zurückbleibt; nach der anderen reicht das Entoderm bis an den Rand, bez. bis in die unmittelbare Nähe desselben. Als Vertreter der ersten Ansicht ist Duval, als Vertreter der zweiten sind von kölliker und Rauber zu nennen.

Duval legt seiner Beschreibung die Verhältnisse des dritten Tages zu Grunde (6. p. 209-2 I 2 und Taf. IX Fig. 2, 3, 4, 5; man vergleiche auch Fig. 6, Io und auf Taf. X Fig. I4, I5, I6). Er stellt dar, class in der Aussenzone des Dotterhofes nur Ectoderm vorhanden sei, in der Innenzone dagegen Ectoderm und Entoderm; dieses Entoderm befinde sich im Zustande des "Dotterentoderms" (entoderme vitellin), d. h. es werde dargestellt von Dotter, in welchem Kerne ausgestreut seien. Diese Formation finde sich auch im Randtheile des Gefässbezirkes (vergl. Fig. 4, го, I4, I6). Diese Angaben kehren bei Duval öfters wieder und sind auch mit den zusammenfassenden Worten der Seite 2 I I auf die Seite 97 einer späteren Arbeit ( 7 ) übernommen, so dass man merken kann, dass Duval diese Anschauung für sehr wichtig und für zweifelsfrei erwiesen ansah. Die Ansicht ist jedoch durchaus falsch, sowohl in dem, was sie über die Innenzone als auch in dem, was sie über die Aussenzone enthält; mit Rücksicht auf erstere sei auf die vorausgehenden, mit Rüclisicht auf letztere auf die nachfolgenden Seiten verwiesen. Der Irrthum ist so auffallend, dass selbst, wenn wir annehmen, dass Dural seine Aufmerksamkeit wesentlich den topographischen und nur nebenher den geweblichen Verhältnissen zugewendet habe, und selbst wenn wir noch hinzufügen, dass die Präparate Duval's für gewebliche Diagnosen vielleicht ungeeignet waren; dass selbst dann der Irrthum noch nicht verständlich wird. Wir können aber vielleicht vermuthen - ich stelle dies nicht als Gewissheit hin, sondern ich spreche daron nur als von einer Möglichkeit, um mir die Duval'schen Angaben verständlicher zu machen -, dass in späterem. Stadien (nach dem vierten Tage) in der Umbildung des'Dotterentoblasten zum geschichteten lipithel eine Verlangsamung eintritt, so dass der vorwachsende Mesodermrand der Formation des Dotterentoblasten nahe kommt. Würden solche Verhältnisse bestehen, und würde Dural seine An- 
schaunngen ron diesen späteren Stadien gewonnen und sie auf den dritten Tag übertragen haben, so wäre damit der Irrthum etwas erklärt. Aber freilich finde ich auch am zwölften Tage noch auf dem Mesodermwulste und distal daron geschichtetes Epithel, so dass mir auch so der Duval'sche Irrthum nicht erklärlich wird.

In cler That ist bis zum vierten Tage, an welchem bereits der Aequator des Dotters ron dem Rande der Keimhaut überschritten wird - Rauber (21. S. I 7) lässt schon am fünften Tage clen Verschluss des Ectoderms und Entoderms am clistalen lole eintreten mit voller Sicherheit zu erkennen, dass das Entoderm bis unmittelbar an den Rand heranreicht.

Nun sincl hicr aber, wenn wir es mit der Beschreibung genau nehmen, wieder drei Möglichkeiten vorhanden. Erstens: der Randsaum, cl. 1. die äussersten Zellenlagen des Keimhautrandes, können durch indifferente Zellen gebildet werden, welche weder Ectoderm- noch Entoderm-Zellen zu nennen sind; zweitens: Ectodern sowie Entoderm reichen bis an den Rand heran (r. Kölliker, Lehrbuch S. 173 und in der Erklärung zu Fig. $5^{6}$ auf S. 126); drittens: clas Entoderm ist zwar an der Bilclung des Randsaumes betheiligt, wird aber in diesem rom Ectoderm überragt. Letzteres ist die Insicht von Rauber (21), welcher das Ectoderm bei ciner Ente von $2+$ Stunden um eine Zellenbreite (Fig. 25), bei einem Huhne rom vierten Tage (Fig. 24) un sechs Zellenbreiten das Entoderm überschreiten lässt.

Indem ich nun auf Grund eigener Präparate über den Keimhautrand einiges mittheile, geschieht es in der Meinung, dass die über die peripherischen Theile der Keimhaut noch schwebenden Streitigkeiten nur ausgetragen werden können, indem an dic Stelle schematischer Vorstellungen, die zum Theil noch bestehen, eine bis in's Einzelne gehende Kenntniss tritt. Auch hier bedauere ich sehr, das Wort nicht durch das Bild ergänzen zu können.

Man möge das Folgende unter dem Gesichtspunkte lesen, dass der Ḱcinhautrand im litufe der Entwicklung sein Aussehen wesentlich ändert - wic ja das schon von Rauber, wenn auch zu schematisch, dargestellt ist, - und class die Randzellen nicht die Gestalt indifferenter Embryonalzellen, auch nicht diejenige indifferenter Iictodermzellen, sondern eine specifische Randzellenform, bezw. EctodermRandzellenform besitzen.

Wenn man cinen Keimlatutrand im Flächenbilde betrachtet, so benerkt man dort, wo das gewöhnliche Ectoderm aufhört, noch zwci Zonen: cine proximale, die aus schmalen Zellen gebildet wircl, und eine distale, die aus grossen Zellen gebildet wircl.

Dic erstere fand ich nach 21 und 22 Stunden nur eben an- 
gedeutet, nach $3^{\mathrm{I}}$ bis 32 Stunden etwa sieben Zellenreihen breit; auf Schnitten zeigen sich diese Zellen anfangs kubisch, später noch hölucr, und wenn ich aus Duval's Angaben richtig schliesse, geschichtet. Dies sind unzweifelliafte Ectodermzellen.

Die grossen Zellen, welche den eigentlichen Randsaum bilden, fand ich schon früher angedeutet, ja ausgeprägt. Schon nach I5 Stunden traf ich vier bis fünf Reihen grosser Kerne hintereinander, freilich auch kleinere dazwischen; mit 2 I und 22 Stunden sind manche der Kerne von enormer Grösse, vom Vier- und Fünffachen des linearen Durchmessers gewöhnlicher Ectodermkerne. Mit 4 S Stunclen fand ich etwa zehn bis zwölf Reihen derartiger Kerne. Die: Zahl scheint sehr zu wechseln, auch im gleichen Entwicklungsstadium, doch ist immer zu argwöhnen, dass Theile des Keimhautrandes abgerissen sind. Die Abgrenzung der zu diesen Kernen gehörenden Zellen ist anfangs schwierig zu erkennen, doch glaube ich, dass sie stets vorhanden ist, vom dritten Tage an ist sie ganz deutlich. Dic Zellen haben noch weitere auszeichnende Merkmale. Sie sind schon mit 5 Stunden sehr blass und arm an Einschlüssen; dafür aber ist die Protoplasmastructur an ihnen sehr deutlich zu sehen, und zwar ist in einer Zelle das Protoplasma zum Theil weitmaschig, zum Theil dicht, letzteres besonders in der Nähe der Kerne. Durch diese Eigenschaften: Grösse, Blässe, Protoplasmastructur erhalten die Zellen ein Ausschen, welches allein an die Entoblastzellen der Area pellucidí erinnert. Eudlich ist noch eins zu bemerken, nämlich eigenthümlich lappenförmige oder zungenförmige Anhänge des freien Randes an den Zellen der äussersten Reihe, welche fast so breit sind, wie die Zelle sellost; diese Anhänge sind am zweiten und dritten Tage vorhanden. Sic sind ganz lomogen und eigenthümlich glänzend. Ergänzen wir das Bild dieser Zellen durch Schnittpräparate, so bemerken wir, dass diese Zellen nicht etwa extrem platt sind, so dass die Grösse in der Flächenansicht sich durch Abflachung erklären liesse, sondern sie sind wirklich gross. Am vierten Tage fand ich sie in drei- bis vierfacher Lage, aber kleiner.

Ob) Duval diese Zellen bemerkt hat, lässt sich aus seinen Angaben nicht genau entnehmen; seine Abbildungen (Taf. IX, Fig. 5 und 6) sind auch hier wieder 7, schematisch, um einen Aufschluss zu geben. Fragen wir nach der Bedeutung dieser Zcllen, welche den eigentlichen Randsaum bilden, so können wir uns in der negativen Acusserung v. Kölliker anschliessen, class diese Randzellen keine Proliferationszone für das Ectoderm und Entolerm rorstcllen; ja ich glaube sogar noch bestimmter angeben zu können, dass Mitosen hicr seltener sincl, als in anderen Abschnitten der Aussen- 
zone und Innenzone. Da, wie oben gesagt, auch der Inhalt dieser Zellen spärlich ist, so sind sie auch nicht an der Aufnahme des Dotters betheiligt. Doch lässt ihre eigenthümliche Gestalt darauf schliessen, dass irgend ein besonderes Moment hier bestimmend sei. Duval bezieht die Vorgänge des Ectodermrandes auf die späteren Tage der Entwicklung, und das mag wohl für die Erscheinungen, die vom vierten Tage an sichtbar werden, in vollem ausschliessendem Umfange gelten; aber ich glaube nicht, dass auch die beschriebene Eigenthümlichkeit der Zuschärfung des Randes der äussersten Zellen daraus zu erklären ist, um so weniger, da dieselbe mit dem vierten Tage abzunehmen scheint. Mir scheint, class wir hier eine Einrichtung vor uns haben, welche das rasche Vordringen der Keimhaut zwischen Dotter und Dotterhaut begünstigt. Diese Zuschärfung des Randes ist schon sehr frühe, ja schon in den ersten Stunden der Bebrütung sichtbar, wie von verschiedenen Seiten hervorgehoben wurde, wie z. B. von His verschiedenfach in Schrift und Bild dargestellt ist. Ich finde beispielsweise an einer Keimscheibe von sechs und einer halben Stunde, dass die am Rande gelegene Zelle sich auszieht in einen äusserst scharfen und labei homogen erscheinenden Saum. Wir haben hier gewissermassen ein Organ vor uns, welches die Ausbreitung der Keimhaut unterstützt.

Indessen im Zusammenhange der vorliegenden Arbeit interessirt vor allem die Frage, ob die geschilderten Zellen des Randsaumes ectodermaler oder indifferenter Natur seien. Hier muss ich mich nun auf Grund des mir vorliegenden Materials entscheiden, sie für ectodermal zu halten.

Auf die weitere Frage, die nach dem Verhalten des Entoblastrandes, kann ich zunächst die Auskunft geben, dass bis zum vierten Tage - weiter habe ich es nicht verfolgt - der Entoblast bis an den Randsaum heranreicht, ja ich finde auf Schnitten von einer Keimhaut von 24 Stunden und einer anderen von 49 Stunden noch unterhalb des Randsaumes bis fast an die äusserste Grenze des letzteren Zellen, die ich für Entoblastzellen halten muss. Die Ansicht von Duval muss also in dieser Hinsicht aufgegeben werden, und es kann sich nur darum handeln, zwischen Rauber und v. Kölliker die Wahl zu treffen; ich möchte mich an ersteren anschliessen.

Die Form dieser Zellen ist schwer zu erkennen; ich theile darüber nach meinen Präparaten Folgendes mit. Nur in einem Falle, bei einer Keimhaut von 49 Stunden, fand ich rundliche Zellen von blasigem Aussehen, mit wenig I)otterelementen gefültt bis an (bez. unter) den Randsaum gehend. In einer Keimhaut von 52 Stunden fand ich rundliche, aber nicht blasige, sondern mehr protoplasmatische, schlecht begrenzte Zellen bis an den Randsaum heran, aber nicht 
unter demselben, dagegen bei einer Keimhaut ron 24 Stunden niedrige blasse protoplasmatische Zellen bis unter den Randsaum reichend, in einer Zone von fünf bis sechs Zellenbreiten. Bei ciner Keimhaut von 42 Stunden platte Zellen und unterhalb derselben Kerne, die in feinkörniger Masse, aber nicht in Dotter eingeschlossen waren. Bei einer Keimhaut von 48 Stunden platte Zellen in einer Zone von sieben Zellbreiten. Endlich mit vier Tagen stark abgeplattete Zellen, in radiürer Richtung zwanzig hintereinander. Ich komme also zu der Meinung, dass der Entoblastrand vom I)otter getrennt ist. Auch His hat diese Meinung stets aufrecht erhalten (5. 2. B. I 2. S. I35).

Auf diese criähnten abgeplatteten Zellen komme ich bei der weiteren Besprechung der Aussenzone des Dotterhofes zurück.

II. Die Formation des sich organisirenden und des organisirten Keimwalles. - Ich kann an die weitere Beschreibung der Aussenzone des Dotterhofes nicht herangehen, ohne auf die technischen Schwierigkeiten hingewiesen zu haben, welche der Untersuchung hier entgegenstehen. Man hat zwei Möglichkeiten: das Präparat im Zusammenhange mit der Dotterhaut oder ohne dieselbe zu fixiren. Durch die Dotterhaut gewinnt natürlich das Präparat an Halt, aber ich habe gefunden, dass dann die oberflächlichen Schichten desselben etwas Undeutliches, ich möchte sagen, Gedrückites belommen; wahrscheinlich, weil die Dotterhaut, sowie eine dünne Schicht ron Eiweiss, welche sich von derselben nicht trennen lässt, durch die Behandlung eine Schrumpfung erleiden und sich dadurch fest auf die Keimhaut auflegen. Löst man aber, nach zunächst leichter Fixirung, die Dotterhaut ab, so hat das Präparat, welches ja, wenn man die Aussenzone des dritten und vierten Tages untersucht, sehr gross ist, nur den schwachen Halt, den ihm das dünne einschichtige Ectoderm bieten kann; und dem gegenüber stehen die verderblichen Einflüsse der Quellung und Schrumpfung, welche um so leichter eingreifen können, da wahrscheinlich schon im frischen Zustande feine Spalten in der Dotterrinde bestehen. Als Zeugen dieser Störungen findet man die Verbiegungen, welche ausnahmslos am Ectoderm solcher Präparate zu sehen sind, und durch deren Schuld man so häufig. Schiefschnitte an Stelle reiner Querschnitte crhält. Der schrumpfende Dotter bröckelt dann bei der Behandlung mit Alcohol gar zu leicht ab und reisst die Entoblastzellen mit sich. Auswaschen der Stücke mit Wasser oder gar mit Säure steigert die Gefahr; und die Fïrlbung mit Boraxcarmin im Stück, welche bei der Untersuchung des Selachier-Dotters so bequem und mit so glänzendem Erfolge angewendet wird, ist hier wegen des nachtrïg- 
lichen Auswaschens mit salzsäurehaltigem Alcohol höchst bedenklich. Am besten thut man noch, möglichst ohne Unwege von der Fixirung zur Einbettung fortzuschreiten und im Schnitte zu färben, wobei dann freilich neue Uebelstände hervortreten. Denn, wenn man Paraffin wählt und die Schnitte belıufs der Färbung aufklebt, so äussert sich die Fähigkeit des Dotters, zu quellen und zu schrumpfen, selbst jetzt noch, so dass derselbe aus den Schnitten grossentheils abfällt und Zellen oder, was noch schlimmer ist, Stücke von solchen mitnimmt. Schliesst man aber in Celloidin (oder Photoxylin) ein, so sieht man sich in der Wrahl der Farbstoffe beschränkt. Und dazu kommt noch die Neigung des Dotters, sich mit vielen Farbstoffen mitzufärben, was z. B. der Selachier-Dotter nicht in der gleichen Weise thut.

Ich beziehe mich nun im Folgenden hauptsächlich auf eine Keimscheibe von $2+$ Stunden und eine zweite ron 33 Stunden, an denen ich die Verhältnisse am deutlichsten finde; übrigens ist alles, was ich bis zum vierten Tage einschliesslich beobachtet habe, damit in Uebereinstimmung. Die erste dieser beiden Keimscheiben war mit Sublimat fixirt, in Celloidin eingeschlossen, die Schnitte mit Alauncarmin gefärbt; die andere war mit heissem Alcohol fixirt und mit Boraxcarmin durchgefärbt. Beide waren mit einer genügenden Partie Dotter in Verbindung gelassen, welcher noch eine Strecke weit über den Randsaum hinausragte.

Ich beschreibe nun zuerst die in den betreffenden Areae opacae vorkommenden Kerne und Zellenformen, dann den Dotter und dann das Verhalten der Zellen zum Dotter in ihrer topographischen Lagerung. Zum Verständniss der letzteren mag die Fig. 20 der Tafel XI und das, was über dieselbe auf S. 330 gesagt wurde, herbeigezogen werden.

Die Kerne des Dotterentoblasten — so können wir den Entoblasten nennen, so lange er sich im Zustande der Keimwallformation bezw. in Zustande der Formation der Aussenzone des Dotterhofes befindet - die Kerne sind klein und unterscheiden sich dadurch auffallend von den Kernen der Dottersackepithelzellen, die ja gerade durch ihre Grösse so sehr auffallen; sie sind sogar kleiner als die Kerne der Ectodermzellen, wie ich z. B. sehr deutlich an einem Dotterhof des vierten Tages bemerke. Auch besteht inter diesen Kernen eine fast rollkommene Uebereinstimmung, so dass man sie leicht als zusammengehörig erkennt. Thre Gestalt kann rund oder elliptisch sein, ist aber im Flïchenbilde doch überwiegend eckig oder gezackt, weil durch Dotterbestandtheile ein Druck auf die Kerne ausgeübt wird. Endlich drittens nchmen diese Kerne durch Farbstoffe einen dunkkeren Ton an wie die Kerne des Ectoderms, jedes- 
falls, weil in ihnen wegen ihrer Kleinheit dic färbbare Substanz rerdichtet ist.

Von Zellenformen möchte ich vier als charakteristisch hervorteben. Erstens cine Form, die wir als Siegelringform bezeichnen können, schon von Rauber mit Recht abgebildet. Diesc Form gleicht gewissermassen einer Fettzelle, nur ist der sichelförmige Protoplasmahof dicker, als bei einer Fettzelle gewöhnlich, und an Stelle eines liettropfens im Innern findet sich eine grössere oder mehrere kleinere Dotterkugeln.

Die zweite Form erscheint auf dem Schnitt spindelförmig und wurde oben schon erwähnt, da ich sie als "platte Entoblastzelle“* einführte. Auf Abbildungen von His glaubt man solche Zellen an der Aussenseite des Keimwalles öfters anzutreffen; doch sind die Figuren stets so unbestimmt, dass man sie nur als einen schematischen Ausdruck subjectiver Meinungen betrachten kann. Die Zelle dieser Art ist nicht etwa spindelförmig, wie man glauben könnte, sondern in Flächenbilde ist sie auch rund; es ist also nichts anderes wie eine Zelle der vorigen Art, nur abgeplattet. Nach manchen Befunden muss ich schliessen, dass solche abgeplattete Zellen in mehrfacher Lage rorkommen können, was wohl mit einem rapiden Flächenwachsthum zusammenhängen dürfte, indem dann die Zellen keine Zeit finden, sich mit Dotter zu beladen. Uebrigens wird man eine grosse Analogie mit dem früher erwähnten stark verdünnten, dabei aber doch geschichteten Epithel der Innenzone finden.

Dic dritte Zellenform ist in Fig. 2 I u. 22 der Taf. XI dargestellt. Dies sind kleine blasse Zellen, welche dort, wo der Raum zwischen den Dotterkugeln beschränkt ist, gequetscht und dadurch in Fortsätze ausgezogen erscheinen; dort dagegen, wo die feinen oben erwähnten Spalten weiter sind, also in der Nähe des perilecithalen Spaltes, eine gänzlich oder fast gänzlich kuglige Gestalt annehmen; sie sind in ihrer typischen Gestalt ganz ohne Inhalt und zeigen ein feines Protoplasmanetz, wodurch sie schon an ihre ausgewachsenen Nachliommen, die Epithelzellen (Fig. I 7) erinnern. Dies sind die Zellen, welche His, Disse und Waldeyer vorgelegen haben; ron His wurden sie r 868 entdeckt, ron Disse (5. p. 568 und Fig. 6) am bestcn beschrieben; ich stimme mit Disse gegen His darin überein, dass es sich um getrennte Zellen und nicht Kerne in Protoplasma handelt, und gegen Waldeyer, dass sie als Zellen in den Dotter eintreten, und dass nicht Kerne in die schon vorher vorhandenen "Keimfortsätze" gelangen. IVarum Disse den Dotter "nach oben gelangen" lässt $\left(\right.$ p. $\left.5^{6} 3\right)$ und nicht vielmehr die Zellen bei der Ausbreitung des Keimes in den Dotter vordringen, ist mir nicht verständlich. 
Die vierte Form endlich wird dargestellt durch etwas grössere, blasige, leere runde Zellen, welche den Kern im Centrum haben. Sie sind aber sehr selten und nur von Interesse zum Vergleiche mit denjenigen Zellen, deren Kerne in Mitose sind, worüber auch einiges gesagt werden soll.

Die Zellen mit Mitosen sind ganz genau ebenso, wie die in der Innenzone; sie sind blasig, scharf begrenzt, kuglig und leer. Solche Zellen findet man, wenn sich der Blick erst an das schwierige Object gewöhnt hat, in grosser Zahl, sowohl in Flächenbildern wie in Schnitten.

Der Dotter zeigt ein Verhalten, welches unserem Urtheil eine sehr wichtige Handhabe darbietet. Dort nämlich, wohin der perilecithale Spalt noch nicht gedrungen ist, also dort, wo sich in Fig. 20 die punktirte Linie befindet, ist der Dotter in der von Zellen durchsetzten Region völlig gleich dem angrenzenden zellenfreien Dotter, nur dass natürlich gegen die Oberfläche hin die Dotterelemente allmählich kleiner werden, was ja schon am unbebrüteten $\mathrm{Ei}$, wie oben erinnert wurde, der Fall ist; dort dagegen, wo sich der perilecithale Spalt findet, ist der Dotter zu beiden Seiten desselben von verschiedener Beschaffenheit, offenbar weil schon die Zellen Zeit fanden, den Dotter zu verändern. Aber wie die Keimscheibe von 33 Stunden zeigt, fällt das Ende des perilecithalen Spaltes nicht mit der distalen Grenze des veränderten Dotters zusammen, sondern der Spalt reicht etwas weiter, so dass also an dem Encle desselben sowohl oben wie unten gleich beschaffener Dotter anliegt.

Gehen wir nun auf eine Schilderung der Topographie der in Fig. 20 dargestellten Area opaca ein, so empfiehlt es sich, des Vergleiches halber auch den proximalen Rand zu betrachten, d. h. also den Abfall des Keimwalles gegen die subgerminale Hölle. Ich kann hier wörtlich aus meiner Dissertation (p. I\&) eine Beschreibung übernehmen, welche sich auf die gleiche Gegend einer sechzehnstündigen Keimhaut bezieht: "Genau eben solche Kerne (wie im Entollast der Area pellucida) findet man auch im Keimwulst und zwar erstens am freien Rande, zweitens an der dem mittleren Keimblatte zugewendeten Fläche, drittens, obwohl spärlicher, in der Masse mitten drinn. Ferner treten scharfe L,inien hervor, die sich zu polygonalen Figuren ergänzen, in deren Centrum die Kerne liegen." "Man sicht, dass man eine zellige Gliederung vor sich hat, die in den mittleren l'artieen vielleicht nur durch die starke körnige Trübung verdeckt ist, an den Rändern aber scharf hervortritt."

Ich kann im vorliegenden Falle noch etwas genauer sein. Am proximalen Rande, d. h. an dem Abfall des Keimwalles gegen die sul)germinale Hölıle, zeichnen sich wenige Zellen durch verhältniss- 
mässige Blässe und deutliche Abgrenzung aus. Dic Kerne dieser Zellen liegen in der Mitte, ihr Inhalt besteht aus ganz blassen, verhältnissmässig feinen Körnern. Diese Zellen mit ihren rundlichen, in die subgerminale Höhle vorspringenden Formen bilden das charakteristische Bild, welches man auf allen Abbildungen trifft, mögen nun die Verfasser eine Ansicht über den "Keimwall" (His) oder "Keimwulst" (v. Kölliker) gehabt haben, welche sie wollen. Die Mehrzahl der Kerne müsste ich in dieser Partie, welche an die subgerminale Höhle anstösst, auch diesmal, wie in Fig. I meiner Dissertation, an die obere Seite verlegen. Auch diesmal aber finde ich es schwer zu entscheiden, „ob die zellige Abgliederung sich über den ganzen Keimwulst - so nannte ich damals diese Partic im Anschluss an v. Kölliker - fortsetzt" (S. 19 meiner Dissertation). Doch kann ich einiges genauer bezeichnen und deuten. Die feinen Linien, welche man für Zellengrenzen halten darf, wenn dieselben auch nur unterbrochen sichtbar sind, verlaufen an der oberen (oder äusseren) Seite dieser proximalen Partie des Keimwalles mehr senkrecht zur Fläche, im Innern mehr unregelmässig; an der unteren Seite, d. h. gegen den perilecithalen Spalt, schliesst der Keimwall mit flachen, runden Wölbungen ab. Die Kerne stehen in der Nähe der oberen Seite in einer Linie, zum Theil hart an der Oberfläche, zum Theil etwas unterhalb derselben, in den übrigen Theilen des Wulstes sind die Kerne spärlicher und unregelmässig vertheilt; der Gestalt nach sind die des oberen und unteren Randes rund, die im Innern vorwiegend eckig, was durch anliegende Dotterkügelchen bedingt wird. Aus alledem ersehe ich z. T., theils ziehe ich den Schluss, dass diese proximale Partie zellig bereits abgegliedert ist, sich in der „Formation des geschichteten Epithels" befindet, ja dass schon an der oberen Seite die Hinneigung zum einschichtigen Epithel mit seinen cylindrischen Zellen wirksam zu werden beginnt. Zweierlei sei noch weiter bemerkt; erstens, dass am oberen Rande an Stellen, wo die Dotterbestandtheile schon geschwunden sind, zuweilen in Theilen von Zellen, aber nie in ganzen Zellen, die Protoplasmastructur sichtbar wird; zweitens, dass der Inhalt zuweilen aus blassen Kugeln mit glänzenden Inhaltstropfen, d. h. den typischen Gebilden des weissen Dotters, besteht, in der Regel aber nur aus blass glänzenden Tropfen, die, wie ich glaube, den Inhaltskörpern der Elemente des weissen Dotters entsprechen, während die blassen Kugeln selbst schon verdaut sind.

Von dieser Partie, der ich vorsichtshalber zunächst nur die proximale Hälfte des mit 5 bezeichneten Abschnittes der Fig. 20 zurechne, springe ich nach I., der Gegend des Randsaumes, über, welche in anderem Zusammenhange schon besprochen wurde. Hier 
findet sich das Ectoderm und der Entoblast an der Bildung des Randsaumes betheiligt, der Entoblast in Gestalt von abgeflachten, rom Dotter geschiedenen Zellen. In diesem Punkte besteht Uebereinstimmung zwischen His, Kölliker und Rauber.

Aus den dazwischen gelegenen Gebieten greife ich wieder das heraus, was am deutlichsten ist; das sind diejenigen frei liegenden Zellen, welche am weitesten gegen den Dotter vorgeschoben sind und deren Lage in Fig. 20 durch den Buchstaben a bezcichnet ist. Diese Zellen, welche oben geschildert und ron denen zwei in Fig. 2 I abgebildet wurden, sind deswegen gerade an der genannten Stelle so klar, weil sie zwischen grossen Dotterkugeln sich leichter erkennen lassen, wie zwischen kleinen, und weil sie in den Spalten, die hier gefunden werden, freier liegen. Hat man diese Zellen eimmal erkannt, so findct man sie auch in den äusseren (oberen) Abschnitten der mit 4. bezeichneten Region und in der mit 3. bezeichneten Region wieder auf. Hier liegen die Kerne und demgemäss auch die Zellen in einer einigermassen gleichmässigen Vertheilung, jedoch nicht gänzlich gleich vertheilt; vielmehr trifft man sie nicht nur einzeln, sondern auch in kleinen rundlichen oder länglichen Gruppen.

Man wird gegen diese Beschreibung von verschiedenen Seiten Bedenken haben, und ich möchte mich hier insbesondere an die Auffassung wenden, welche v. Kölliker vertritt, nach welcher der gesammte Entoblast aus rundlichen Zellen besteht und gegen den Dotter scharf geschieden ist. Ich mache gegen diese Auffassung geltend, erstens, dass die von mir geschilderten „Zellen im Dotter“ thatsächlich nachweisbar sind, besonders in den am meisten nach innen, gegen den Dotter zu, gelegenen Theilen, und zweitens, dass in der Aussenzone der Dotter ohne Unterbrechung, ohne Aenderung seiner Beschaffenheit bis an die Oberfläche reicht, so dass sich die Entstehung des "Dotterentoblasten" in der Aussenzone des Dotterhofes auch gar nicht anders als durch ein Eindringen zelliger Bestandtheile in den Dotter rorstellen lässt.

Die Zusammensetzung dieser Formation darf man sich nun aber nicht so denken, wie es für die Vorstellung freilich am bequemsten wäre, dass jemals der Kémwall oder die Aussenzone des Dotterhofes von lauter derartigen kleinen dotterfreien Zellen durchsetzt sei, wie sie in Fig. 21 alogebildet sind; dass jemals der Zustand der "Zellen im Dotter in schematischer Reinheit existire. I)ie Dotterentoblastzellen háben vielmehr ihrer Nitur nach, sobald sie gebildet sind, das Restreben, Dotter zu umschliessen. So wie Schafe, welche auf die $W^{r}$ cide gehen, nicht erst warten, bis sie in gleichmässiger Vertheilung ihre Standorte auf der Wiese gefunden haben, sondern schon auf dem Wege dorthin zu fressen begimen, so machen sich 
auch die Dotterentoblastzellen alsbald an die Arbcit, und man findet daher selbst in unmittelbarer Nähe des Randsaumes in den oberflächlichen Theilen der Aussenzone solche Zellen, die Dotter enthalten, insbesondere die oben erwähnte Siegelringform. Dass aber die Zellen, indem sie gebildet werden, leer sind, das kann man aus den Zellen mit Mitosen erkennen. Solche leeren Zellen werden dann in den Dotter eindringen und entweder schon in den oberflächlichen Schichten dotterhaltig werden oder bis zu grösserer Tiefe leer bleiben, wie eben die abgebildeten.

In einer weiteren Hinsicht ist der Punkt a der Fig. 20 noch interessant, darin nämlich, dass er jenseits der Flucht des perilecithalen Spaltes liegt. Diejenigen Zellen also, welche sich so weit vorgewagt haben, werden bei der Ausdehnung des Spaltes vermuthlich abgeschnitten werden und in ihrem Schicksal den Zellen gleichen, welche durch Dotterfurchung aus dem Boden der subgerminalen Höhle entstehen.

Zuletzt wenden wir uns zu der distalen Hälfte des Abschnittes 5 der Fig. 20. Hier liegen die Kerne nicht gleichmässig in der ganzen Dicke vertheilt, sondern am reichlichsten an der Seite des perilecithalen Spaltes, in einer Kette angeordnet, wie es von His schon 1868 geschildert worden ist. Das zu diesen Kernen gehörende Protoplasma hat die gleiche Beschaffenheit wie in Fig. 21 der Taf. XI. Ich glaube, behaupten zu dürfen, dass an manchen dieser Zellen die Begrenzung sichtbar ist, und dass sie theilweise kleinere Dotterkörner in sich enthalten, theilweise leer sind. Zwei solcher Zellen sind in Fig. 22 dargestellt von dem Punkte b der Fig. 20. Von diesen beiden 7ellen stösst die eine, nämlich a an den perilecithalen Spalt, bez. liegt in der Flucht desselben, die andere, nämlich b, findet sich dicht daneben, in dem in der Fig. 22 angegebenen Lage-Verhältniss im Innern des Keimwalles. Es ist jedoch sehr schwer, stets die zellige Abgrenzung zu erkennen. Dort, wo Zellen aneinanderstossen, entsteht clas Bild, als sei ihr Protoplasma zusammengeflossen. Da jedoch auch in späteren Stadien die zellige Abgrenzung sich an gefärbten Lackpräparaten oft so schwer erkennen lässt, beispiclsweise in der Innenzone des Dotterhofes, wo sie doch, wie Silberbehandlung zeigt, thatsächlich vorhanden ist, so möchte ich in dem Urtheil sehr zurückhaltend sein, doch aber eher glauben, dass die Individualität jeder Zelle sich erhält, um so mehr, da wir ja diese auch in dem weiter proximal gelegenen Abschnitt durch die scharfen Zellengrenzen wieder deutlich ausgeprägt sehen. Zunächst aber müssen wir z.u1frieden sein, wenn wir das Protoplasma dieser Zellen erkannt haben. Da zeigt sich dann gleichfalls, wie bei den Kernen, dass das Protoplasma besonders reichlich längs des perilecithalen Spaltes angrordnet 
ist. Es scheint so, dass die Zellen sich an der inneren Oberfläche gestreckt haben, so wie sie es ja an der äusseren schon vorher thaten, und gewissermassen in erster Linie darauf Bedacht genommen haben, das zu „organisirende" Gebiet gegen den Spalt abzuschliessen. In der proximalen Hälfte des Abschnittes 5, wo dic Formation des geschichteten Epithels durchgeführt ist, findet sich diese Lagerung der Kerne und des Protoplasma an dem perilecithalen Spalt nicht mehr vor. Derartige in der Richtung der Oberfläche gestreckte Zellen dürfen wir uns aber wieder nicht als spindelförmig denken, wie sie uns der Schnitt zeigt, sondern rundlich, aber abgeplattet.

Es ist jedoch ausserordentlich schwierig, in jedem einzelnen Falle die Ausclehnung einer Zelle zu bestimmen; zu entscheiden, ob das Stück Protoplasma mit Kern, welches wir vor uns sehen, eine kleine Zelle vorstellt, oder ein Abschnitt einer grösseren Zelle ist, welche in sich eine Gruppe von Dotterkörnern oder eine grosse Dotterkugel einschliesst. Denn auch hier zögern die Entoblastzellen nicht, durch reichliche Aufnahme von Inhalt ihrer Bestimmung gerecht zu werden.

Es ist claher auch nicht gut möglich, genau zu bestimmen, an welchem Punkte die Formation des geschichteten Epithels fertig ist; es mag sein, dass der Strich, welcher auf meiner Fig. 20 die Grenze zwischen dem vierten und fünften Abschnitt angiebt, etwas proximalwärts oder distalwärts verschoben werden muss, aber darauf kommt ja gar nichts an. Es ist auch möglich, dass an der Oberfläche die Abgliederung früher vollzogen ist, wie in der Tiefe, aber auch das ist von untergeordneter Bedeutung. Das Wichtigste ist in erster Linie, den Vorgang als solchen kennen zu lernen und die Phasen desselben zu verstehen.

T'm noch einmal zusammen zu fassen, so glaube ich, dass der Entoblast vorwächst, indem er bis an den Randsaum reicht, wenn er auch vielleicht an der Bildung des Randsaumes selbst nicht, oder in seltenen Fällen betheiligt ist; dass er hicr aus gesonderten Zellen besteht, die vom Dotter geschicden sind; dass in den an diesen Randtheil anschliessenden Abschnitten ein Eindringen von Entoblastzellen in den Dotter in "aufgelöster Formation" stattfindet, bis zu einer gewissen Tiefe; dass die typische Grundform dieser „Dotterentoblastzellen" die eincr kleinen, protoplasmatischen, leeren Zelle ist; dass aber schon bei der Ausbreitung dieser Zellen Dotter von ihnen umschlossen wird; und dass der Vorgang damit endigt, dass nach völliger Umschliessung des Dotters in dem Keimwall bez. in der Aussenzone des Dotterhofes blasige dotterreiche Zellen entstanden sind, die sich gegenscitig überall berühren, womit aus der Formation des „or- 
ganisirten Keimwalles" die des "geschichteten "pithels", aus der der "Aussenzone des Dotterhofes" die der "Innenzone" geworden ist.

W as an dieser Auffassung - nicht rom Standpunkte der Beobachtung, sondern von dem der Theorie - bedenklicli crscheinen kam, ist die Ausbreitung in "aufgelöster Formation". Wie können wir uns rorstellen, dass diese Zellen noch einem bestimmten Plane der Entwicklung folgen, sich so zu sagen noch als zu einem Verbande gehörig fühlen, wenn sic nicht ununterbrochen mit einander in Berülrung stehen? Hierzu ist zu bemerken, dass ja die Zeit der Isolirung der einzelnen Zelle nur eine kurze ist und alsbald mit der Vergrösserung der Zelle ihr Ende findet. Ferner ist aber auch daran zu erinnern, dass die Auflockerung des wachsenden Mesoderms kaum geringer ist, als diejenige, zu welcher der Entoblast sich durch den Dotter zeitweilig gezwungen sieht; ja dass wir auch von dem Entoblast der Säugethiere in dem zweiblättrigen Zustand der Keimblase des Kaninchens ein Stadium kennen gelernt haben, in welchem sich derselbe in starker Auflockerung, seine Zellen in sternförmiger Gestalt befinden.

Ob das Vordringen von Zellen in den Dotter ausschliesslich in senkrechter Richtung oder auch in tangentialer, bezw. also in schiefer Richtung geschehe, unternehme ich nicht zu entscheiden, doch scheint mir allerdings die letztere Auffassung die naturgemässere.

Ich habe nun noch meine Stellung zu anderen in der Litteratur geäusserten Ansichten darzulegen, sowohl vom Standpunkte der Beobachtung wie von dem der Theorie. Dabei kann natürlich von einer Berücksichtigung sämmtlicher über den Keimwall geäusserter Anschauungen keine Rede sein. Derartige sogen. „historische Betrachtungen" unterscheiden sich vom Historischen ebenso wie eine Mönchschronik von einem Ranke'schen Geschichtswerk. Bei der Frage des Keimwalles und des Parablasten nun gar müsste man soviel darüber sagen, wie sich die Forscher durch Kunstproducte haben täuschen, durch falsche Schnittrichtungen haben verwirren lassen, wie sie in der Auswahl der Stadien und der Stellen Missgriffe begingen, sich durch andere auf Abwege verführen liessen, wie sie schiefe Analogien herbeizogen und von fremdartigen Speculationen aus die Frage des Dottersackentoblasten vergewaltigten, dass mich nicht gelüstet, dieses schwarze Kapitel zu schreiben. Die Erfahrung zeigt auch, dass die vielen litterarischen Erörterungen über den Keimwall nicht im Mindesten zur Klärung der Ansichten beigetragen haben. Ich beschränke mich darauf, drei Verfasser anzuführen, welche die Frage in so abweichender Weise darstellen, dass daclurch die verschiedlenen Möglichkeiten zur Anschauung ge- 
bracht werden, Duval, His, v. Kölliker; und anzugeben, worin ich mit ihnen übercinstimme und ron ihnen abweiche.

Ich spreche zunächst rom Standpunkte der Beobachtung.

D) uval ist genau genommen in diescm Zusammenhange gar nicht zu nennen, da er ja in der Aussenzone des Dotterhofes überlaupt keine entoblastischen Elemente aufgefunden hat; es kann bloss ron ihm die Rede sein, wenn man sich auf das bezichen will, was er über die Innenzone bemerlit. Hier findet er eine Formation, welche er als "Dotterentoblast" bezeichnet und die nach seincr Angabe aus Dotter mit dazwischen gestreuten Kernen besteht. Tron Protoplasma sagt er kein Wort, während ich gerade glaube, dass hier alles von der genauen Beobachtung des Protoplasma abhängt. 1)ie Genaugkeit der Untersuchung in der Frage des Dottersackentoblasten ist aber überhaupt in Hinsieht der geweblichen Verhältnisse bei Dural nicht gross, denn dieser Forscher hat von der zelligen Abgliederung in der Innenzone und im Grenzwulste des Gefüssbezirkes nicht das Geringste bemerkt.

II enn ieh ron der Ansicht von His spreche, so wird der Leser es wohl verstehen, dass ich in eine erneute Erörterung darüber, ob dic Elenente des weissen Dotters zelliger Natur seien, nicht eintrete; chenso wird er es begreifen, class ich über die Parablastfrage ohne ein Wrort hinweggehe. Für mich ist der „organisirte Keimwall", wic nách dem Vorausgehenden nieht weiter begründet werden muss, eine Stufe in der Entwicklung des Dottersackentoblasten. Mas aber die Beobachtungen an dem organisirten Keimwall angeht, so war ich nicht wenig verwundert, dass meine Untersuchung mir in seh- wesentlichen Punkten eine Uebereinstimmung mit His zeigte, und ich gebe meiner Freude darüber Ausdruck, dass ich gerade dic ältesten der Beobachtungen von $\mathrm{His}$ in so grossem Unfange bestätigen kann. Freilich muss ich auch gleich hinzufügen, class His, obwohl er z.u verschiedenen Malen in dieser Frage das Wrort ergriffen hat, doch in derselben nicht weiter gekommen ist. Er hat zwar die Entstchung des Dottersackepithels aus dem Keimwalle ancrkannt (1 1. p. 2S5), aber nicht die Consequenz einer solchen Anerkennung gezogen, wclche darin hätte bestehen müssen, genau zu entscheiden, wie sich Parablast-Anlage und Epithel-Anlage $7 u$ einander im Keimwalle rerhalten. Die späteren Abbildungen ron His haben alle etwas Vages und seine Angaben in verschiedenen Aufsïzen sind schwankend, wie schon aus einer Zusammenstellung dersclben, dic v. Kölliker gemacht hat (16. p. 186), hervorgeht. Mit His stimne ich darin überein, class der Entoblastrand frei über dem botter liegt, diss soclann Entoblastzellen in den Dotter cindringen, uncl class diese 1)otter umschliessen; ja sogar in manchen Einzeln- 
heiten befinde ich mich im Einklang mit $\mathrm{H}$ is (man vergl. besonders 10. p. 75), obwohl ich die Fig. 8 auf Taf. VI der Monographie und die Figuren 15 und 16 der Taf. XIII der Arbeit im ersten Bande des Archivs für Anatomie und Entwicklungsgeschichte kaum für den Ausdruck der topographischen Vertheilung; geschweige denn für den der geweblichen Verhältnisse anerkennen kann. Nicht in Uebereinstimmung bin ich mit His in folgenden Punliten: erstens ist nach meiner Meinung das Eindringen von Entoblastzellen nicht an den weissen Dotter gebunden. Weder wird aller weisser Dotter ron "archiblastischen" Zellen durchsetzt, denn sonst müsste ja der Keim bis ins Centrum des Eies, in die Latebra hinabsteigen, um auch dort unten zu „organisiren“; noch beschränkt sich andererseits die Durchwachsung auf weissen Dotter, sondern, wenn der Entoblast das Grebiet des letzteren durchschritten hat, so greift er in das des gelben über, bis er am unteren Dotterpole angelangt ist. Mit His stimme ich ferner nicht darin überein, dass die Zellen zusammenfliessen, sondern ich bin der Meinung, dass dieselben getrennt bleiben, und dass auf dem einfachsten Wege, indem der sämmtliche in der durchwachsenen Partie enthaltene Dotter von den Zellen aufgenommen wird, die Formation des geschichteten Epithels entsteht.

Mit v. Kölliker stimme ich darin überein, dass die Zellen des Entoderm-Randes oberhalb (ausserhalb) des Dotters liegen. Allerdings ist diese Uebereinstimmung keine vollständige, da v. Kölliker (Lehrbuch S. 173) diese Randzellen für rundlich hält und sie "selbst in den Randtheilen noch zu zweien oder dreien sich decken" lässt; was, wie ich glaube, für spätere Stadien keine Geltung hat. In der Deutung der Endstadien, des anfangs geschichteten, dann einschichtigen Epithels befinde ich mich gleichfalls mit Kölliker in der Hauptsache in Uebereinstimmung, obwohl ich hier wieder der Angabe entgegentreten muss, dass das Epithel in der Innenzone des Dotterhofes einschichtig sei. Dagegen befinden wir beide uns im Gegensatze, wo es sich um die Deutung der $Z$ wischenstufe, der Formation des organisirten Keimwalles, bezw. der Aussenzone des Dotterhofes handelt. Nach v. Kölliker bleibt das Entoderm immer vom Dotter geschieden, ist immer durch aneinanderliegende rundliçhe Zellen dargestellt, und diese Zellen bilden „in sich dunkle runde Körper aus, die bald die Zellen ganz erfüllen in der Art, dass jede Zelle einen grossen dunklen Inhaltskörper und neben demselben noch eine gewisse Anzahl kleinerer enthält" (S. 175). Obwohl diese Darstellung durch ihre Einfachheit für sich einnimmt, so theile ich sie doch nicht; und ohne meine oben ausführlich dargestellten Ansichten zu wiederholen, führe ich nur noch einmal kur\%. an, rlass nach meiner Mcinung die mitotisch sich renmehrenden und 
nach der Theilung kleinen Entoblastzellen in den Dotter eintreten und dadurch zu einer Formation Anlass geben, auf wclche die Bezeichnung "Zellen im Dotter" passt; dass erst in dem Maasse, als diese Zellen durch Umwachsung der Dotterballen sich die Herrschaft über den Dotter erringen, der Zustand entsteht, auf den die Bezeichnung "Dotter in den Zellen" anwendbar ist. Somit kann ich auch die grossen Ballen und kleineren Körner bezw. Tropfen, welche sich in den Zellen des geschichteten Epithels finden, nicht als "Producte des Stoffwechsels" der Entoblastzellen ansehen, wie v. Kölliker will (S. I76), sondern ich sehe in ihnen die anfangs weniger, später stärker veränderten Bestandtheile des Dotters selbst.

Indem ich hier die Unterschiede hervorhebe, welche meine Ansicht von der Kölliker'schen trennen, bemerke ich, dass ich damit nichts von eigenen früheren Angaben zurüclizunehmen habe. Zu dieser Aeusserung veranlasst mich die unrichtige Beziehung, welche zwischen meiner früheren Mittheilung und den Arbeiten v. Kölliker's hergestellt worden ist, woran $\mathrm{D}$ isse clie Schuld trägt. Disse citirt in einer Arbeit (5), in welcher er die Kölliker'sche Ansicht von dem zelligen Aufbau des Keimwalles ("Keimwulstes"v. Kölliker) bekämpft, nicht weniger als fünf mal „Kölliker und H. Virchow" "H. Virchow und Kölliker", in dem Glauben, als müsse meine Arbeit, da sie in dem von Herrn v. Kölliker geleiteten Institute entstanden war, auch genau die Ansichten des Leiters enthalten. Hierzu bemerke ich, dass die Wahl meines Themas eine selbstständige war, und dass ich unabhängig zu meinen Ergebnissen und Anschauungen gelangte; ferner, dass die Präparate, auf welche sich meine Untersuchungen stützten, eigene waren, ja dass ich bis zum Abschluss meiner Arbeit auch nicht eines der Präparate, auf welche sich die Kölliker'sche Beschreibung bezog, gesehen habe. Wenn also zwischen unseren Mittheilungen Uebereinstimmung herschte, so war diese gerade so werthroll, wie sie zwischen zwei von einander unabhängigen Arbeiten immer ist. Andererseits aber nusste nicht nothwendig diese Uebereinstimmung eine rollkommene sein, wie sic es auch nicht war, denn v. Kölliker behauptete, dass der peripherische Entoblast ("Keimwulst") bis an den Rand heran zellig gegliedert sei; ich aber behauptete das nicht, sondern ich sagte, (mit Rücksicht auf die Keimscheibe von 16 Stunden): „Ob die zellige Abgliederung sich über den ganzen Keimwulst fortsetzt, oder ob sie auf die genannten Theile beschränkt ist, möchte sich schwer entscheiden lassen", d. h. meine Präparate setzten mich nicht in den Stand, ïber die peripherischen Abschnitte zu urtheilen, und so hielt ich mein Urtheil zurück. Das war aber für Disse nicht deutlich, vielmehr brachte dieser meine eigenen Worte - "Indessen ist es 
nicht möglich, zellige Gliederung auf grössere Strecken zu demonstrircn" - gespert gedruckt, um sie alsdann gegen mich, d. h. gegen die mir untergeschobene Meinung auszuspielen. Ich gebe zu, was ich auch damals nicht verborgen habe, dass meine Kenntniss eine unfertige war, und ich gebe auch zu, dass es ungeschickt war, den Ausclruck "Keimwulst", welchen v. Kölliker gebrauchte, obwohl er in anderem Sinne von Götte schon verwendet war, anzunehmen. Ich würde auf diese Missdeutung meiner Arbeit nicht zurückgekommen sein, wenn ich nicht später öfters nicht in meinem eigenen Sinne, sondern in dem Disse's angeführt worden wäre, z. B. ron Waldeyer (31. S. 60) und His (13. S. 77).

Ich versuche, den theoretischen Werth der Lehren von $\mathrm{His}$, Kölliker und Duval zu wägen. Die His'sche Lehre von den Schicksalen des Keimwalles kann wenig befriedigen; es dürfte schwer sein, sich eine Theorie auszusinnen, gegen welche eine grössere Fülle schwerer Einwände zu erheben ist. Anfangs war sie behaftet mit der Annahme von der zelligen Natur des weissen Dotters. Hiergegen sprach sich jedermann aus, und Waldeyer vollzog gewissermassen an der His'schen Parablastlehre die lebensrettende Operation, indem er die zellige Natur des weissen Dotters beseitigte; befreit von diesem Gewächs schien sich die Parablastlehre, von Waldeyer in dem bekannten Aufsatze Archiblast und Parablast erweitert, $z u$ neuer I,ebensfrische zu erheben. Indessen genauere Untersuchungen wiesen mehr und mehr die Entstehung "parablastischer" Gebilde aus der Embryonalanlage nach, und zur Zeit sind von der ganzen Gruppe wohl nur noch die Blutzellen übrig, denen viele den Ursprung aus dem Dotter oder Dotterentoblasten wahren möchten. Während so der Bestand des „Parablasten" immer mehr abbröckelte, da die Gewebe der Bindesubstanzgruppe sich anderweitig versorgt fanden, trat andrerseits das Dottersackepithel mit Ansprüchen an den Keimwall heran. His hat diese Ansprüche anerkannt, aber wie! Er machte, so zu sagen, einen Strich durch den Keimwall und theilte die obere Seite dem Parablasten, die untere dem Dottersackepithel zu, indem er erklärte (I I. P. 285): „Als Endresultat der beiderseitigen Umbildungen verbleibt einmal die Schicht der Gefässe und ein ihr von unten her anliegendes einschichtiges Epithel." So lässt sich der Dottersackentoblast nicht abspeisen! Allerdings ist das "Endresultat" ein einschichtiges Epithel, aber vor diesem Endresultat kommt das geschichtete Epithel, und dieses verlangt als sein Gebiet den Keimwall in seiner ganzen Dicke. Sollen also daneben noch andere Bestandtheile vom Keimwalle abgegeben werden, so wird erst noch sehr genau untersucht werden müssen, wie deren Ansprüche zu befriedigen sind. Hierzu konmt, dass, wie Waldeyer 
sehr treffend bemerkt (31. P. 18), His damit, class er die Herkunft des Dottersackepithels aus dem Keimwall einräumt, ja die Abstammung eines "archiblast ischen" Gewebes aus dieser Gegend zugiebt. In den letzten Arbeiten von $H$ is ist es denn auch von dem Dottersackepithel recht still geworden, und man fühlt heraus, dass die Anerkennung desselben von Seiten von $H$ is nie eine recht freudige war. Endlich ist dann noch zu erinnern, dass doch die „Keimwallformation", die späiter als Formation der Aussenzone des Dotterhofes sich immer weiter und zuletzt bis an den distalen Pol rorschiebt, räumlich nicht auf den weissen Dotter und zeitlich nicht auf die Periode der Blutbildung beschrïnkt ist; und welche Bestimmung hat sie denn dann, nachdem Blut und Gefüsse gebildet sind? Hieran scheint weder His noch irgend ein anderer der Parablastiker je gedacht zu haben.

Die Ansicht v. Kölliker's ist, vom theoretischen Standpunkte aus betrachtet, durch ihre Einfachheit überzeugeud und überdies daclurch, dass nur Entwicklungsvorgänge von gewöhnlichem Typus vorgefüht werden, gewinnend: der peripherische Entoblast (Keim"ulst" v. Kölliker) ist aus rundlichen Zellen aufgebaut, gegen den Dotter abgeschlossen und liefert nur Dottersackepithel. Indessen zwei Punkte lassen theoretisch unbefriedigt, erstens die Frage des Inhaltes der Zellen und zweitens die vergleichende Betrachtung. Der Inhalt der Zellen ist allerdings in proximalen Abschnitten (s. 5 in Fig. 20 meiner Taf. XI), soweit der perilecithale Spalt reicht, rerschieden von dem unterliegenden Dotter, dagegen in distalen Abschnitten 3 u. 4 meiner Fig. 20) hat der Dotter im Bereiche des Entoblasten clie gleiche Beschaffenheit wie unterhalb des letzteren. Das spricht dafür, dass der Inhalt von den Zellen in geformtem Zustande als "Rohmaterial" aufgenommen wird. Bei dieser Gelegenheit möchte ich bemerken, dass der Gegensatz in den Ansichten von Kölliker und $H$ is über die Zusammensetzung des organisirten Keimwalles (His) oder kieimwulstes (v. Kölliker) sich grossentheils darauf zurückführen lässt, dass beide Forscher nicht genau die gleiche Stelle der l'äparate bez. nicht die gleiche Stufe der Entwicklung zum Ausgangspunkte ihrer Erklärung machen. r. Kölliker behauptet zwar, dass der gesammte "Keimwulst" bis an den Rand heran zellig gegliedert und von dem Dotter abgeschlossen sei, aber seine beschreibung passt doch hauptsächlich auf den Abschnitt 5, um bei meiner Fig. 20 zu bleiben; His dagegen kennt zwar auch • (len Abschnitt 5, aber seine Auffassung stützt sich im Wesentlichen auf den Abschnitt 3 und 4 .

1) vergleichenden Betrachtung gegenüber lïisst clie v. Kölliker'sche Auffassung unbefriedigt insofern, als von diescm Entoblisten, 
(ler in rölliger Abgeschlossenheit gegen den Dotter fortwäichst, keine V'crbindung zu den Verhältnissen der Jotterfurchung hinüberführt, welche wir bei den Reptilien in ausgedehnter und bei Ichthyophis in uneingeschränkter $\mathrm{IV}^{\top}$ eise herrschend finden.

Die Ansicht ron Dural endlich zeichnet sich gleichfalls rurch grosse Einfachheit, wenn auch nicht durch ebenso grosse Einfachheit, wic dic v. Kölliker's aus; denn Duval lïsst auch Bestandtheile der Blutinseln aus der Gegend des Dotterentoblasten hervorgehen. IVas letzteres betriff, so verheisst Duval in seiner Arbeit vom Jahre $188+$ eine bereits abgeschlossene Mittheilung über die Blutentwicklung als unmittelbar bevorstehend; soviel ich weiss, ist eine solche nicht erschienen, so dass wir uns nur durch die graue Farbe der Blutinseln auf den Figuren des Atlas (8), welche mit der des Keimwalles übereinstimmt, können überzcugen lassen, wenn wir für einen derartigen Beweis zugänglich sind. Im Uebrigen aber: hat die Formation des "Dotterentoblasten", die wil" in der Darstellung Duvals vom proximalen bis zum distalen Pole in unveränderter Form fortschreiten sehen, keine anderen Beziehungen, als die zum Dottersackepithel. Der $Y^{\top}$ organg, durch welchen die eine Formation in die andere übergeleitet wird, ist der der ,secundären Furchung" (im Sinne Duvals, nicht Waldeyers) oder "Dotterfurchung"; und da wir diesen Vorgang schon im Boden und in den Rändern der subgerminalen Hölle wirlisam sahen, so verknüpft sich in der Darstellung von Duval das Spätere mit dem Frühesten; ja es verknüpfen sich auch die Zustände des Dotterorganes der Vögel mit denen der Dotterorgane von Reptilien und Amphibien. Die Darstellung Duval's gewinnt dadurch eine bedeutende theoretische Kraft, und wir wïrden ihr unbedingt geneigt sein, wenn sie nicht, wie angeführt wurde, (p. 344) nach der Seite der thatsächlichen Beweise so schlecht begründet wäre.

Ich gehe nun auf die theoretische Seite meiner eigenen Anschauung ein und sehe zu, wie sich das in dem vorliegenden Kapitel Mitgetheilte zu andercn Meinungen und sodann wie es sich zu den anderen Stadien der Entwicklung und zu vergleichend anatomischen Thatsachen verhält.

Ueber die Frage, ob aus dem Dotterentoblasten noch andere Bestandtheile, insbesondere Blutzellen, abgegeben werden, äussere ich mich nicht; betone jedoch, dass alle Erscheinungen, welche ich am Dottcrentoblasten beobachtet habe, ihre volle Erklärung durch die Beziehung auf Ausbildung des Epithels finden, so class die Erscheinungen, welche auf Blutzellenbildung oder andere Formationen zu beziehen sein sollten, von anderer, gewissermassen versteckter und bisher nicht genater bekannter Art sein müssten. Mit v. Kölliker stimme ich darin überein, rlass der Entoblast bis zum Keimlatutrande 
geht, dass der Entoblastrand vom Dotter getrennt ist, und dass sich aus dem Dotterentoblasten geschichtetes Epithel, die Vorstufe des einschichtigen entwickelt. Ich sehe auch die Abweichung, in welcher sich unsere Meinungen beziehentlich der Formation des Keimwalles („Keimwulstes" v. Kölliker) befinden, nicht als principiell an, da ja eine vorübergehende Aenderung der Zellenform von kciner tieferen Bedeutung ist (p. 343). Immerhin muss bemerkt werden, dass bei meiner Vorstellung eine gewisse active Locomotion der Entoblastzellen angenommen wird, welche über die Schiebung durch Wachsthum hinausgeht. Auch hinsichtlich der Einschlüsse weiche ich von Kölliker ab, da ich glaube, dass im Stadium des Dotterentoblasten der Inhalt im geformten Zustande von den Zcllen umschlossen wird. Ich kann jedoch andrerseits, im Gregensatze zu Duval und auch zu W alde yer, die beide von ,secundärer Furchung", obwohl in verschieflenem Sinne, sprechen, eine solche nicht finden, da die in den Dotter eindringenden entoblastischen Elemente von ciner zellig gegliederten Formation abstammen, da sie selbst in abgeschlossenen Zellen bestehen, und da ihre Vermehrung nicht durch Theilung freier Kerne sondern durch Theilung von Zellen geschieht.

Stelle ich das Gesagte mit demjenigen zusammen, was ich über andere Stadien und über andere Dotterorgane theils selbst weiss, theils in der Litteratur finde, so muss ich zwei Punkte selbst hervorheben, in welchen meiner Auffassung anscheinend die Einheitlichkeit fehlt; sie betreffen erstens den Vorgang der Bildung der Dottersackentoblastzellen und zweitens die Aufnahme des Inhalts. Ich will beides betrachten.

Dass die Dotterfurchung im Boden und in den Wänden der subgerminalen Höhle vorliommt, die weiterc Ausbreitung des Dotterentoblasten aber durch Einwachsen ron Zcllen geschehe, möchte als ein Widerspruch noch nicht empfunden werden; dass aber die Dotterfurchung bei Reptilien in so starker und bei Amplibien in ausschliesslicher Weise die Bildung von Dotterentoblastzellen bestimmt, das allerdings steht zu der von mir für das Huhn vertretenen Ansicht im Gegensatze und tritt uns noch bedeutungsvoller entgegen, da sowohl bei Reptilien wie bei Ichthyophis (24. p. 103) das Endergebniss des Vorganges ein einschichtiges Epithel ist wie beim Huhne. Aber eben hicraus schliesse ich, dass es sich um eine principielle Verschiedenheit beider Vorgänge nicht handeln kann. Ich muss es jedoch anderen Untersuchungen überlassen, diese Frage genater zu beleuchten.

Die Aufnahme von Inhalt geschieht in cler Formation des Dotterentoblasten so, dass grössere geformte Bestandtheile umschlossen werden, in der Formation des einschichtigen Epithels dagregen so, 
dass der Dotter in gelöstem oder liörnigem Zustande aufgenommen wird. Diesen Unterschied müssen wir festhalten und ihn als einen wcsentlichen bezeichnen. Die specifische Formation für den einen Zustand ist die "Formation des Dotterentoblasten" bezw. des "organisirten Keimwalles" bezw. der Aussenzone des Dotterhofes; die specifische Formation für den andcren ist das einschichtige Epithel. Die Zwischenstufe zwischen beiden ist das geschichtete Epithel oder die Formation der Innenzone des Dotterhofes. So lange noch das Epithel geschichtet ist, sind in demselben wcsentliche Bestandtheile ursprünglich aufgenommenen Materiales enthalten, und ich möchte auf dasjenige hinweisen, was über den Dottersack des zwölften Tages früher bemerkt wurde (p. 301). Es tritt aber noch ein wesentliches Merkmal der Unterscheidung beider Zustände hinzu: Die bindegewebige IVand und die in ihr liegenden Blutgefässe, zu denen das einschichtige Epithel in nahe Beziehung tritt. Auf dem Mesodermrande, in dem Kölliker'schen Grenzwulste, vollzieht sich die Umordnung des Epithels aus dem geschichteten in den einschich. tigen Zustand. So haben wir also vor uns zwei Formen des Dottersackentoblasten, von denen wir die erste die des "Dotterentoblasten" und die zweite die des "Dottersackepithels" nennen können; eine primäre und eine secundäre, eine niedere und eine höhere Form. Die niedere oder primärc Form erkennen wir bei Ichthyophis in ihrer vollen Bedeutung: Dotterzellen erfüllen den ganzen Innenraum; ein regelloser Haufen entsteht, ein Bild niederer ungeordneter Zustände. Dass es mit der verdauenden Thätigkeit der Dotterentoblastzellen langsam vor sich gehe, glaube ich nach dem, was ich über das Huhn mitgetheilt habe, annehmen zu dürfen. Hier muss der geordnete, wirksamere secundäre Zustand eingreifen, der sich durch die Vereinigung verschiedener Gewebsformen zu einem Organ, durch die einschichtige Lage der Zellen, durch die Ausbildung reicher Oberflächengestaltung und durch ein dichtes Gefässnetz als ein höherer ankündigt: Wir wissen nicht, in welchem Zeitpunkte dieser wirksamere Apparat zu arbeiten beginnt; vielleicht geschieht es erst von der Mitte der Brützeit an. Ich will darüber licine Meinung äussern. Aber es ist doch daran zu erinnern, dass bis dahin der Inhalt des Dotterraumes an Menge nicht ab- sondern zunimmt: Flüssigkeit wird an die Oberfläclie des Dotters ergossen, diesen aufzuschwemmen, vielleicht zu verändern; wir wissen leider nicht, ob die Flüssigkeit Fermente enthält; wäre das der Fall, so würde der Begriff des Dotterorganes noch um einen wcsentlichen Zug reicher werden. Während des zweiten, dritten, vierten Tages und wohl in den folgenden sehen wir in der Innenzone der Area vitellina reichliche Zellenvermehrung und dabei auffallende Niedrig- 
keit des geschichteten Epithels, I,eere der Zellen hier und grossentheils in dem einschichtigen Epithel. Anscheinend wird hier wesentlich an der Vergrösserung der Fläche gearbeitet, während die resorbirende Thätigkeit eingeschränkt ist, ja wohl stellenweise ruht. IVährenddessen setzt die Formation des Dotterentoblasten einstweilen ihre Aufnahme von Dotter im Zustande des Rohmateriales fort; dem Mesodermrande in der Umwachsung des Dotters vorauseilend, erreicht sie allmählich den distalen Pol. Da sie un so wirksamer sein muss, je zahlreicher ihre Zellen sind, so treffen wir diese in mehrfacher I agerung, während dagegen einschichtige Iagerung vortheilhaft ist für den höheren Zustand, bei welchem die an den Kuppen aufgenommenen Dotterbestandtheile in der Zelle verarbeitet, am anderen Ende den Gefässen zugeführt werden.

\section{Litteratur.}

1. Agrassiz (Clark), Contribution to the natural hist. of the Unit. St. of America. Vol. II Part. III. Boston 1857.

2. Baer, C. E. v., Ueber Entwickelungsgeschichte der Thicre. I. Thcil. Königsberg 1828 .

3. Bonnet, R., Grundriss der Entwickelungsgeschichte der Haussäugethiere. Berin bei Parey 1891 .

4. Courty, Annales des sc. matur. III. sér, vol. IX. 1848 .

5. Disse, Dic Entstehung des Blutes und der ersten Cicfïsse im Hühnerci. Arch. f. mikr. Anat. XVI. Bd. 1879.

6. Duval, Études histologiques et morphologiques sur les annexes des embryons d'oiscaux. Journal de l'anatomic et de la physiologie. XX. année 188 \& S. 201.

7. Duval, De la formation du blastoderme dans l'ocuf d'oiscau. Annales des sc. nat. zool. VI. sér. t. XViII p. I.

8. 1) « val, Alias d'enbryologic. Paris 1889 bei Masson.

9. Göttc, Beiträge zur Entwickelungsgeschichte der Wirbelthiere. Arch. f. mikr. Anat. X. Bcl. 1874 .

10. His, W., Untersuchungen über dic èrste Anlage des Wirbelthierlcibes. Leipzig 1868 bei WV. Vourel.

11. II is, W., Der Keimwall des Hühnereies und die Entstehung der parablastischen \%clien. 7.eitschr, f. Anat. u. Lintw. Bd. I 18,6 p. 274.

12. His, W., Neuc Untersuchungeu ülser dic Bildung des Hühnerembryo. Archiv f. Anat. u. P'hysiol., Anat. Alith. 1877 p. 112.

13. Ilis, W., I)ie Lehre vom Bindesubstanzkein (Parablast.) Arch. f. Anat. u. Phys., Anat. Abth. 1882 1.62.

14. Kölliker, $\Lambda$, Zur Entwickelung der Kcimblätter im IIühncrei. Verhandl. der phys.-med. Geselisch. zu Würzhure. N. F. VIII. Bd. 1875.

15. Kölliker, A., Entwickelungsgeschichte des Menschen und der höhcren Thiere. 1I. Aull. I.cipzig I870 bei W. Engelmann.

16. Külliker, $\Lambda$., Die conbrynualen Keimblätter und die Gewebe. Zcitschrift für wissicnsch. Zool. 40. Bd. 1) 179 . 
17. Koller, C., Beitrăge zur Kennuniss des IIülnnerkeims im Beginne der Bebrütung. Akid. der Wissensch. 8o. Bd. Wien 1879 .

Is. Kowalewski, M. v., Ueber die ersten Entwickelungsprocesse der Knochenfische. Zeitschr. für wissensch. Zool. 48. Bd. 1886 p. 434.

10. Leydig, F., Beiträge zur mikroskopischen Anatomie und Entwickelungsge. schichte der Rochen und Haie. Leipzig 1852 bei W. Engelmann.

20. Pander, Beiträge zur Entwickelungsgeschichte des Hühnchens in Eye. Würzburg 1817 .

21. Rauber, Die Stellung des Hühnchens im Entwickelungsplan. Leipzig I 876 bei WT. Engelinann.

22. Rindfleisch, Ed., Die Elemente der Pathologie. 2. Aufl. Leiprig r 883 bei W. Engelmann.

23. Sachs, J., Vorlesungen über Pflanzen-Physiologie. Leipzig 1882 bei W. Engelnann.

24. Sarasin P. und Sarasin F., Ergebnisse naturwissenschaftlicher Forschungen auf Ceylon. II. Bd. Zur Entwickelungsgeschichte und Anatomie der ceylonesischen Blindwühle lchthyophis glutinosus. Wiesbaden 1889 bei Kreidel.

25. $r$ Sieloold und Stannius, Handbuch der Zootomie. II. Theil. Die Wirbelthiere.

26. Strahl, Die Dottersackwand und der Parablast der Eidechse. Zeitschr. für wissensch. Zool. 45. Bd. 1887 S 282 .

27. Toldt, Lehrbuch der Gewebelehre. III. Aufl. Stuttgart 1888.

28. Virchow, H., Ueber das Epithel des Dottersackes im Hühnerei. In. Diss. Berlin 1875 bei G. Schade.

29. Virchow H., Ueber die physikalisch zu erlzlärenden Frscheinungen, welche am Dotter des Hühnereies bei der mikroskopischen Untersuchung sichtbar werden. Sitzungsber. d. Akademie d. Wissensch. Berlin 1888.

3o. Virchow, R., Ueber das ausgebreitete Vorkommen einer den Nervenmark analogen Substanz in den thierischen Geweben. Arch. f. pathol. Anat. u. Physiol. und f. klin. Med. Vl. Bd. I854 S. 562 .

31. Waldeyer, W., Archiblast und Parablast. Arch. f. mikr. Anat. 22. Bd. 1883 S. 1.

32. Zumstein, Ueber das Mesolerm der Vogelkeimscheibe. In. Diss. Bern 1887.
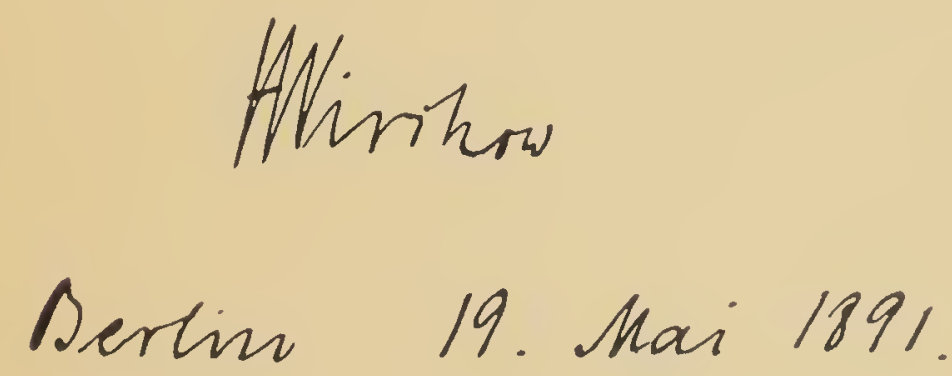

Tafel X.

Virchow: Der Dottersack des Huhnes. 


\section{Tafel X.}

Fig. 1. Keimscheibe von 27 Stunden, 13 mal vergrössert; s. S. 237.

P. Primitivrinne.

M. Mesoderm.

M' Mesodermrand.

W. Entoblastwülste in der Area pellucida s. S.

E. Kran\% von Entoblastwülsten im Randgebiet der Area opaca.

Fig. 2. Querschnitt durch die Mitte der gleichen Keimscheibe. Bezeichnungen wie bei Fig. I.

Fig. 3. Gitter oder Blatt des Dottersackes, epithelfrei; s. S. 255.

Fig. 4-2. Epithel des Eiweisssackes. Leitz VIII. O.; s. S. 275.

Fig. 4. Von einem Präparate des 12 . Tages. Nicdrig cylinctrisches Epithel.

Fig. 5. Von Präp. des i 3. Tagges. Kubisches Epithel; die platten Zellen senden Auslăufer in's Bindegewebe.

Fig. 6. Von Präp. des I3. Tages. Hoch cylindrisches Epithel; Kuppen und Seitentheile der Zellen protoplasmatisch, die Innentheile unterhalb der Kerne hyalin.

Fig. 7. Von Präp. des 13. Tages, Epithel von faden- und keulenförmigen Zellen; zottenbildend.

Fig. 8. Von Präp. des I6. Tages. Hohes blasiges Epithel.

Fig. 9. Von Präp. des 12. Tages. Grossl,lasiges Epithel, zottenbildend; in die Achse der Zotte steigt vielleicht, jedoch nicht sicher, zartes Bindegewebe mit Capillaren auf.

Fig. 10-15. Dottergang in zwölfmaligen Vergrösserungen; s. S. 29I. Fig. 10. Dottergang vom 14. Tage quer.
A. Arteria vitellina.
V. Vena vitellina.
D. Dottergang. 


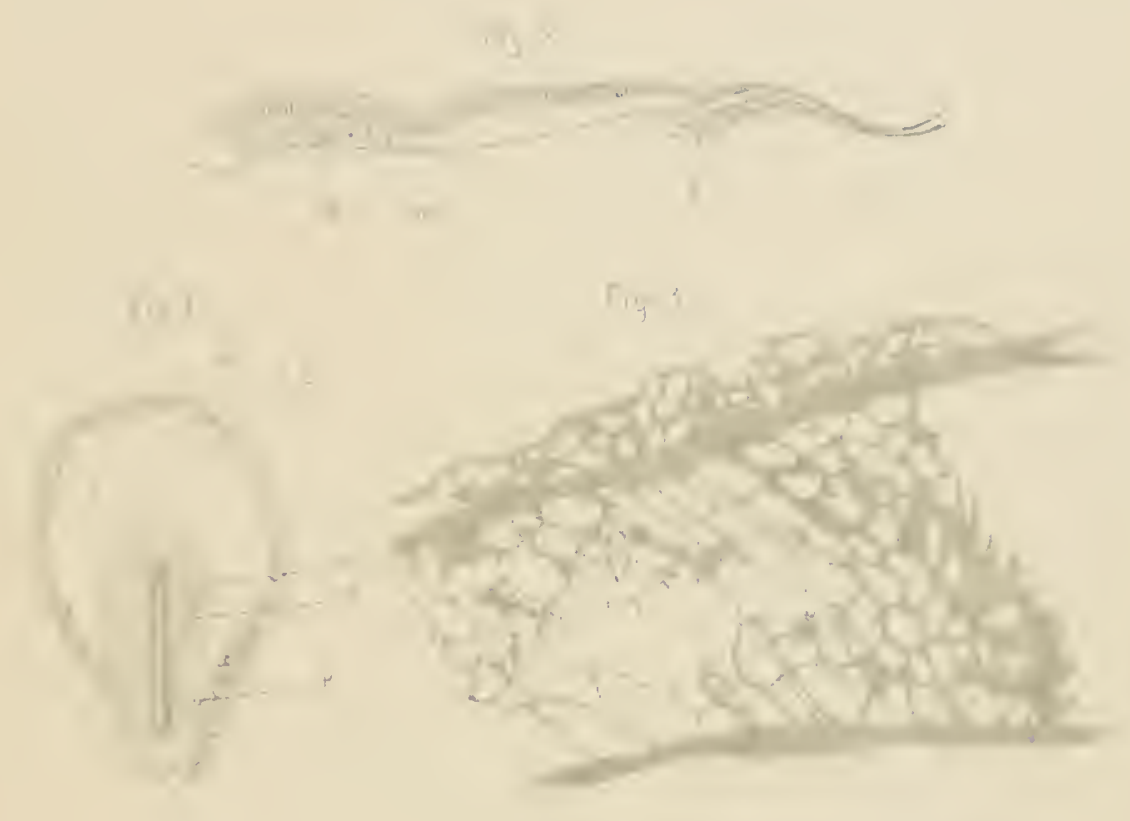

Fig 4

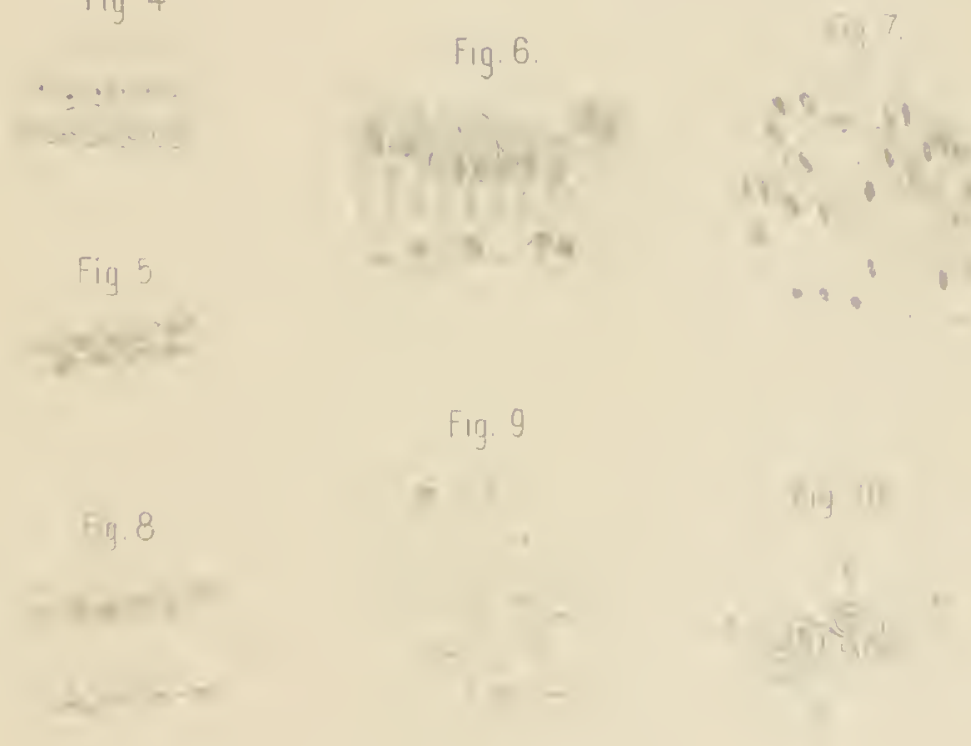

H Virchow: Der Dottersack des Hhhnes. 

Tafel XI.

$-$

Virchow: Der Dottersack des Huhnes. 


\section{Tafel XI.}

Fig. Ir. Dottergang vom 19. Tage quer.

A. V. D. wie in Fig. 10.

m. Längsfaserschicht, wahrscheinlich glatte Nuskelfasern.

Fig. 12. Dottergang vom 4. Tage nach dem Ausschlüpfen quer.

Bezeichnungen wie in Fig. 10 u. 1 .

Fig. I3. Dottergang vom 5. bis 6. Tage nach dem Ausschlüpfen.

Die kleinen runden Löcher sind Durchschnitte von schlauchartigen Ausstülpungen des Hauptganges.

Fig. I4. Dottergang vom 19. Tage längs, in den Dottersack sich öffnend.

A. V. D. wie in Fig. 10 u. Ir.

1)s. Dottersack.

Fig. 15. Dottergang vom ז. 'Tage nach dem Ausschlüpfen, Dünndarm und Dottersack verbindend.

D. Dottergang.

Ds. Dottersack.

I. Papille (s. S. oo.)

V. Leisten.

L. Lieberkühı'sche Drüsen.

Mes. Mesenterium.

Fig. I 6 bis i 9. Hohes Epithel des Dottersackes vom i2. u. 13. Tage. Leitz VIII. O. s. S. 297.

Fig. 16. Eine Zelle von der proximalen Gegend des Dottersackes in Flächenbilde.

Fig. 17 bis 19. Drei Zellen vom Aequator des Dottersackes in Seitenausicht.

Fig. 20. Radiärer Durchschnitt durch die Area opaca einer Keimscheibe nach $2+$ stündiger Bebrütung, zwölfmal vergrössert. Die Zahlen I bis 5 bezeichnen die auf einander folgenden Stufen der Entwickelung vom Randsaume bis zum geschichteten Epithel. Erklärung auf Seite 330 .

p. S. perilecithaler Spalt.

liig. 2 I und 22. Dotterentoblastzellen Leitz VIII. O.

Fig. 21. Von dem Punkte al der Fig. 20 S. S. 340.

Fig. 22. Von dem Punkte b der Fig. 20 S. S. 341. 

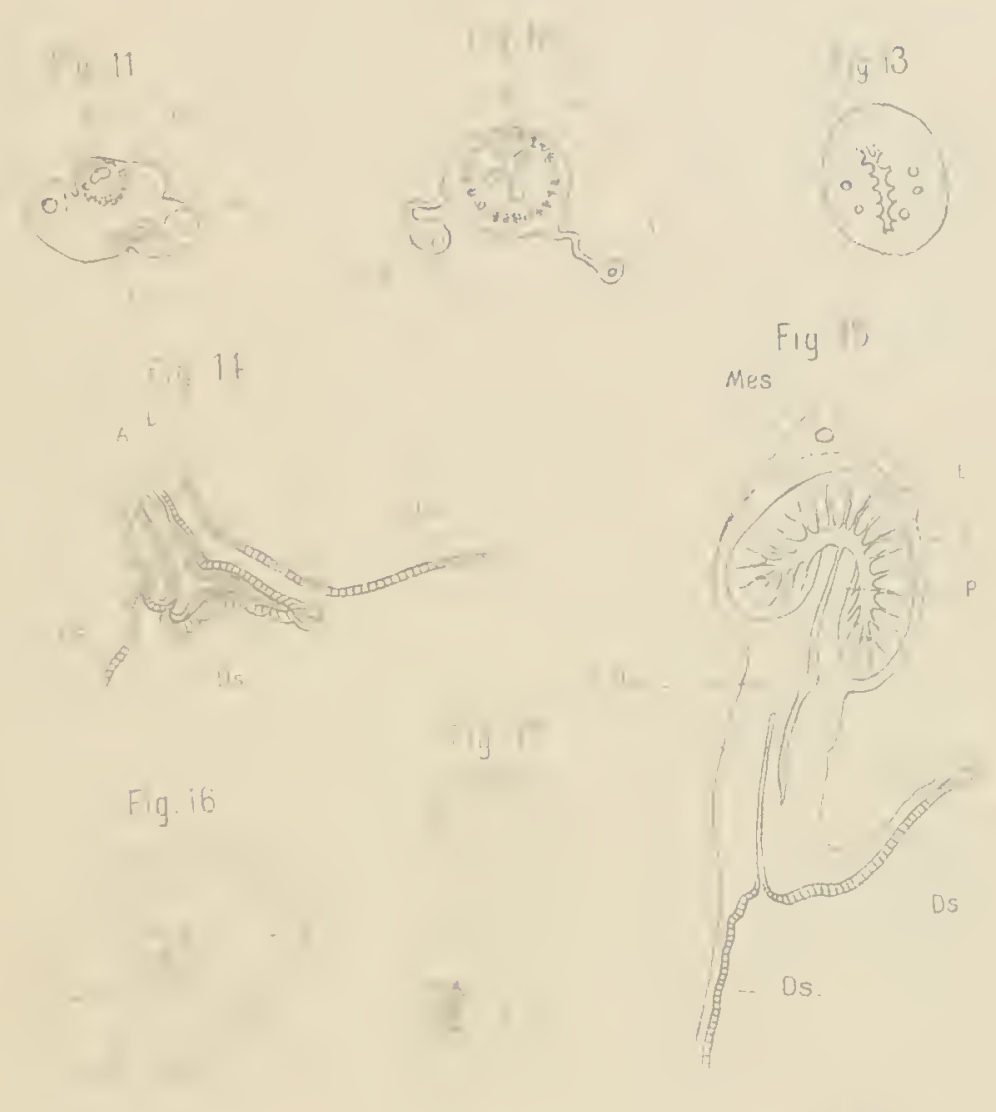

$F$ y 18

Fiy. 17

10.21

\section{$\operatorname{lig} .22$}

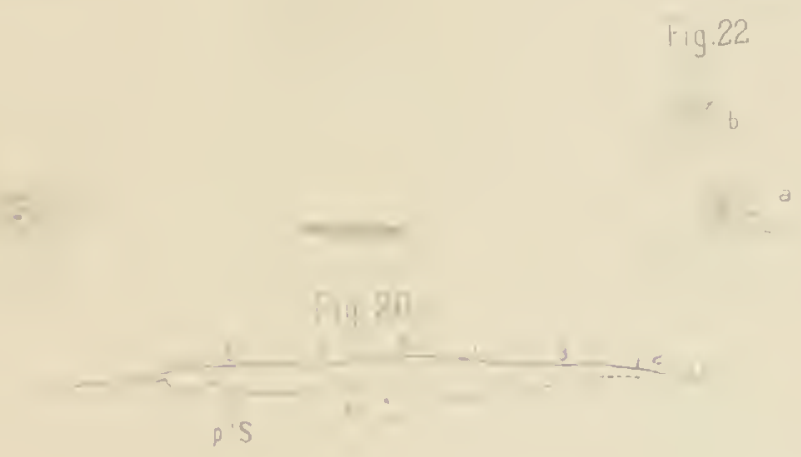

H.Virchow: Der Dottersack des Huhnes. 

Tafel XII.

Virchow: Der Dottersack des Huhnes. 


\section{Tafel XII.}

Fig. 23. Keimscheibe mit vier Urwirbeln, 31 bis 32 Stunclen gebrütet; achtzehnmal vergrössert. Nur die Blutinseln sind gezeichnet, aber nicht die Entoblastwülste; s. S. 234.

p. Kand der Area pellucida.

m. Vorwachsender Mesodermrand.

E. Entoblastwülste.

Fig. 24. Keimscheibe mit elf (zwölf) Urwirbeln, 46 Stunden gebrütet; vierzehnmal vergrössert. Nur die Entoblastwülste und nicht die Blutinseln sind dargestellt; s. S. 235.

W. Grenzwuist des Gefässbezirlies. 


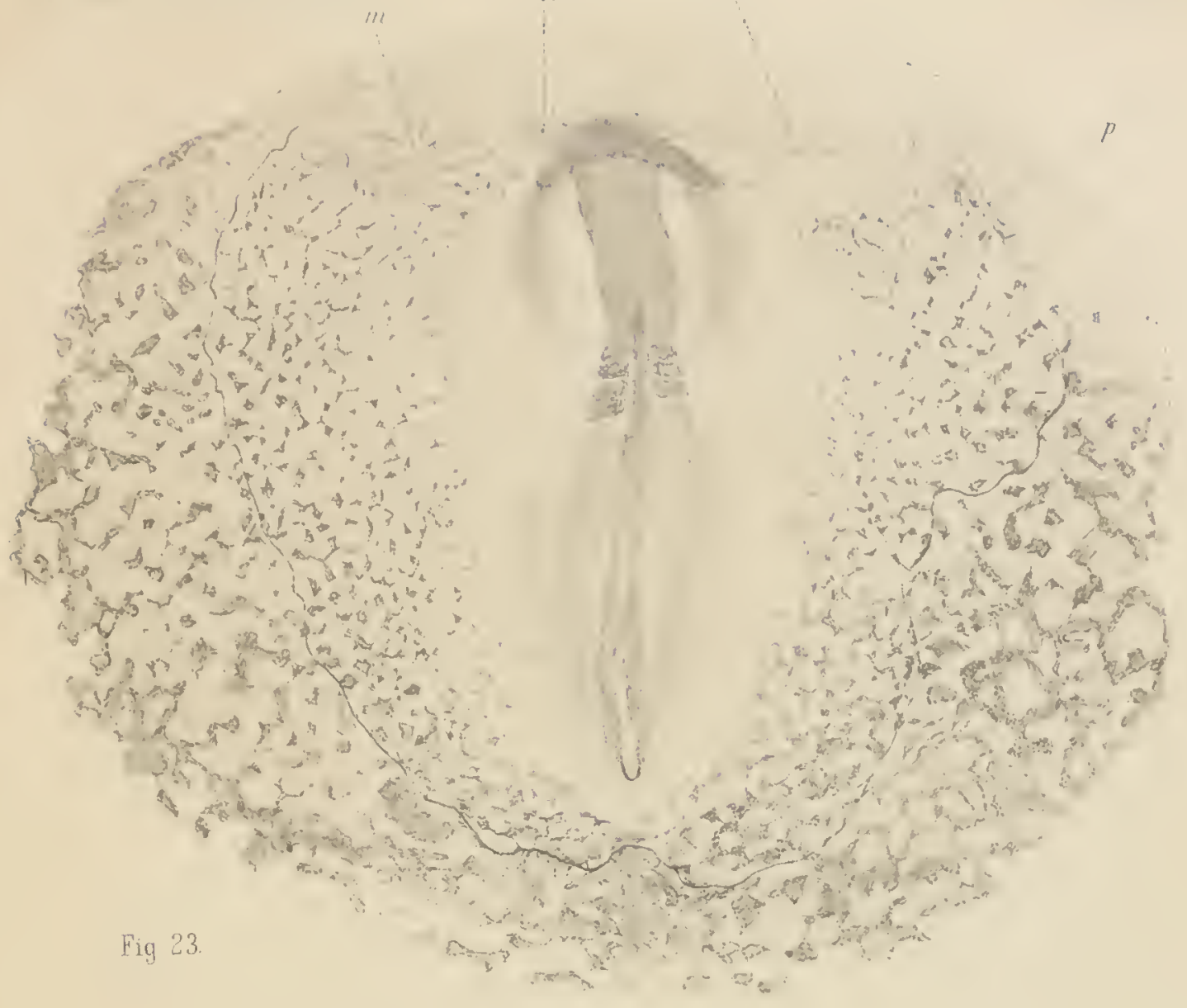

Fig 24

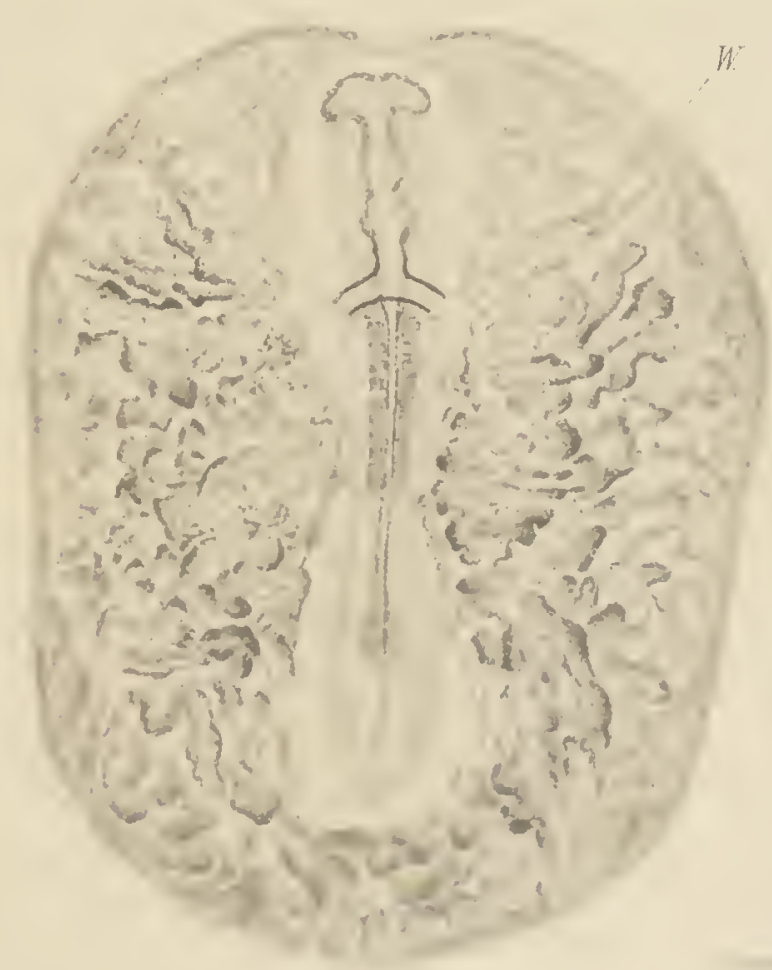

H.Virchow Her Dottersirk de's Huhnes 

Tafel XIII.

-

Virchow: Der Dottersack des Huhnes. 


\section{Tafel XIII.}

lig. 25. Stück des Hottersackes einer im Ausschlüpfen begriffenen Ente, zweimal vergrössert. Erklärung s. S. 254.

Fig. 26. Stück des Dottersackes eines zwölf Tage bebrüteten Hühnchens, 5,5 mal vergrössert. Erklärung s. S. 256.

A. Arteric.

V. Venenwulst. 
Fig. 25
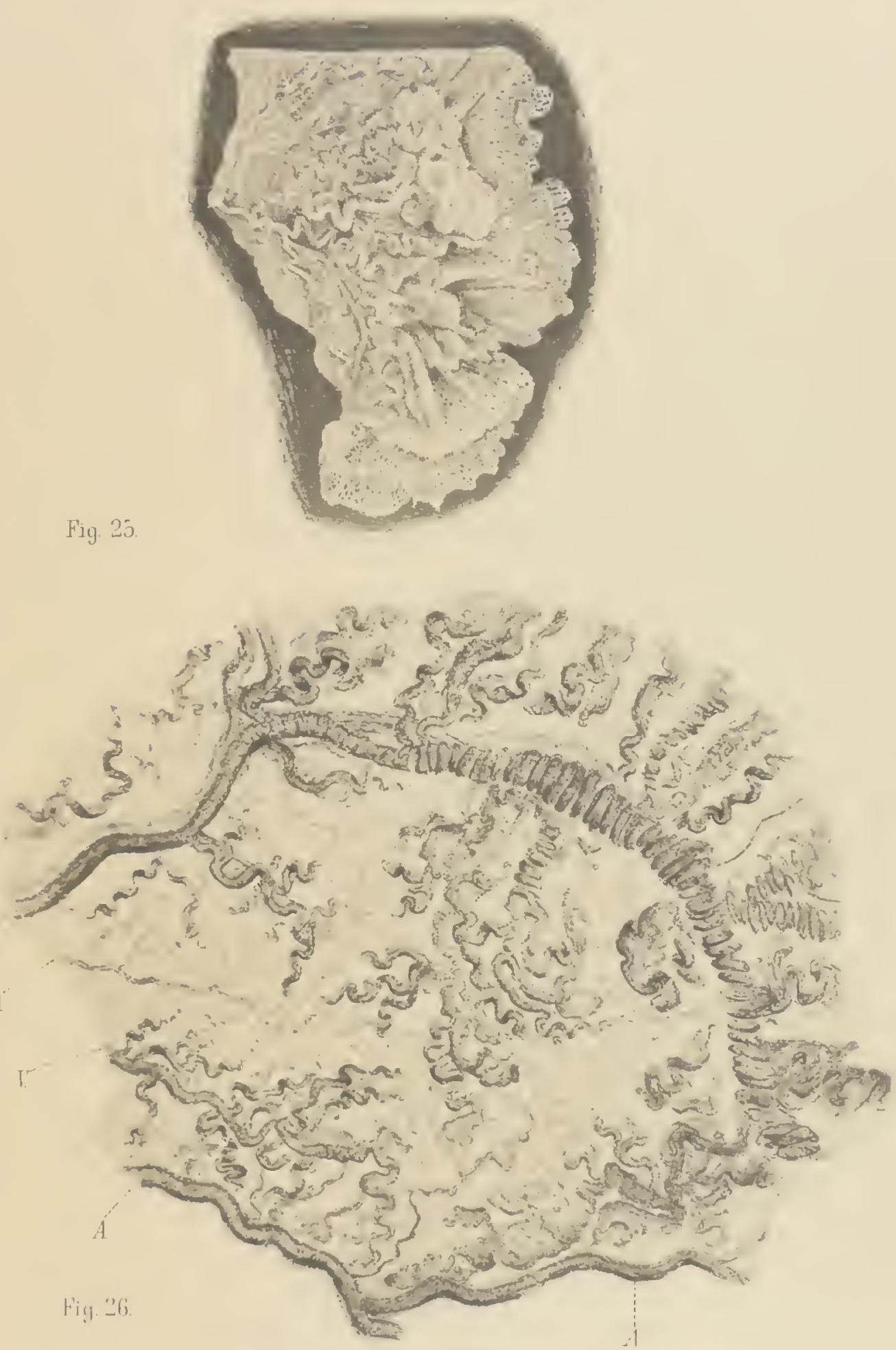

H. Virchow Hor Hollersacti des Huhnes 



\section{Tafel XIV.}

Virchow: Der Dottersack des Huhnes. 


\section{Tafel XIV.}

Fig. 27. Stück eines Blattes von dem gleichen Dottersacke wie in Fig. 26, fünfzigmal vergrössert; S. S. 256. Die Wand selbst ist vollkommen abgeschnitten, so dass nur das Blatt, und dieses in reiner Seitenansicht, vorliegt. Man sieht links die durch ihre Umhüllung von Epithelzellen hindurchschimmernde Arterie (A), rechts den Venenwulst $(\mathrm{V})$, innerhalb dessen die Vene, von Epithelzellen gänzlich eingehüllt und unsichtbar gemacht, steckt. Die Zellengrenzen sind durch Versilberung hervorgehoben.

Fig. 28. Ein Stück der Fig. 26, stärker, im Ganzen fünfzig mal, vergrössert; s. S. 256 . Die Zellengrenzen sind durch Versilberung hervorgehoben. Ueber die von einschichtigem Epithel bedeckte II and erhebt sich ein Wulst nebst Seitenwulst. Dort, wo der Wulst halb in Seitenansicht sichtbar wird, erkennt man, dass er von Löchern durchbrochen ist. In seinem gewundenen Rande (V) ist eine Vene eingeschlossen, in der glatt verlaufenden Basis sieht man eine Arterie (A) durch das Epithel hindurchschimmern. 


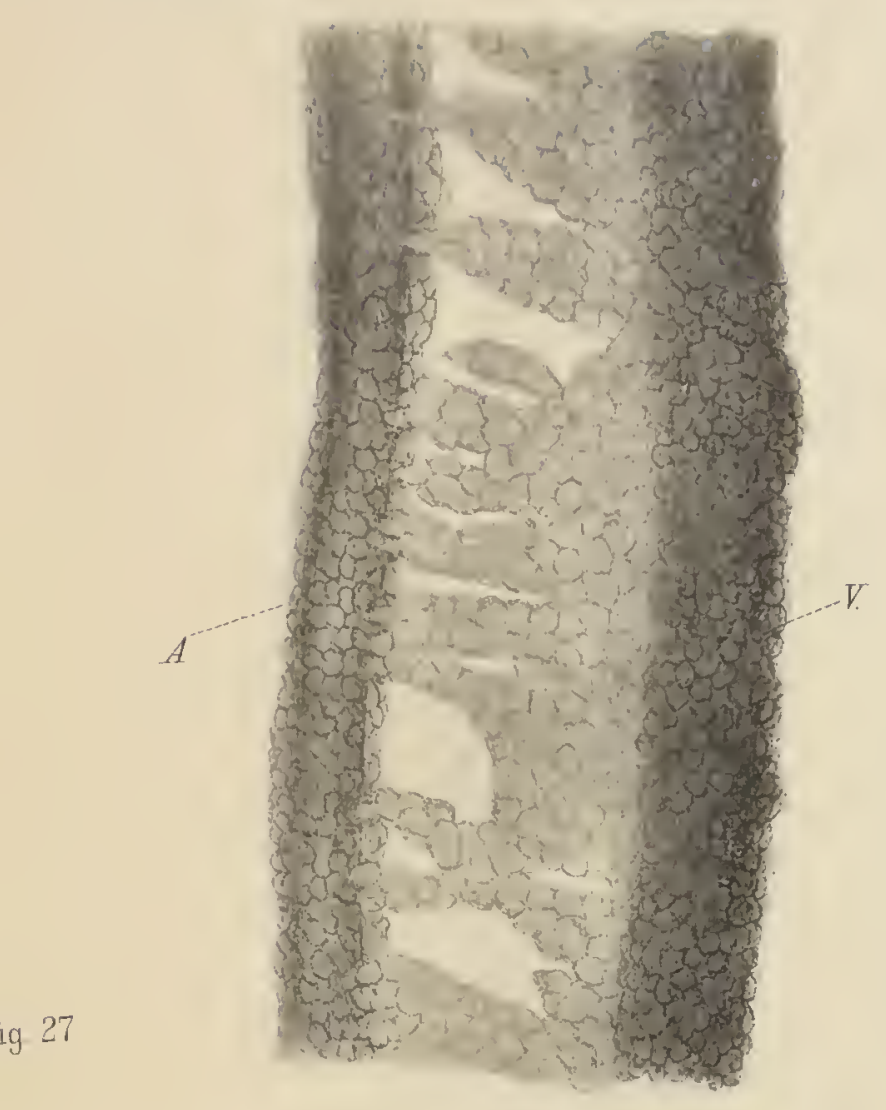

Fig 27

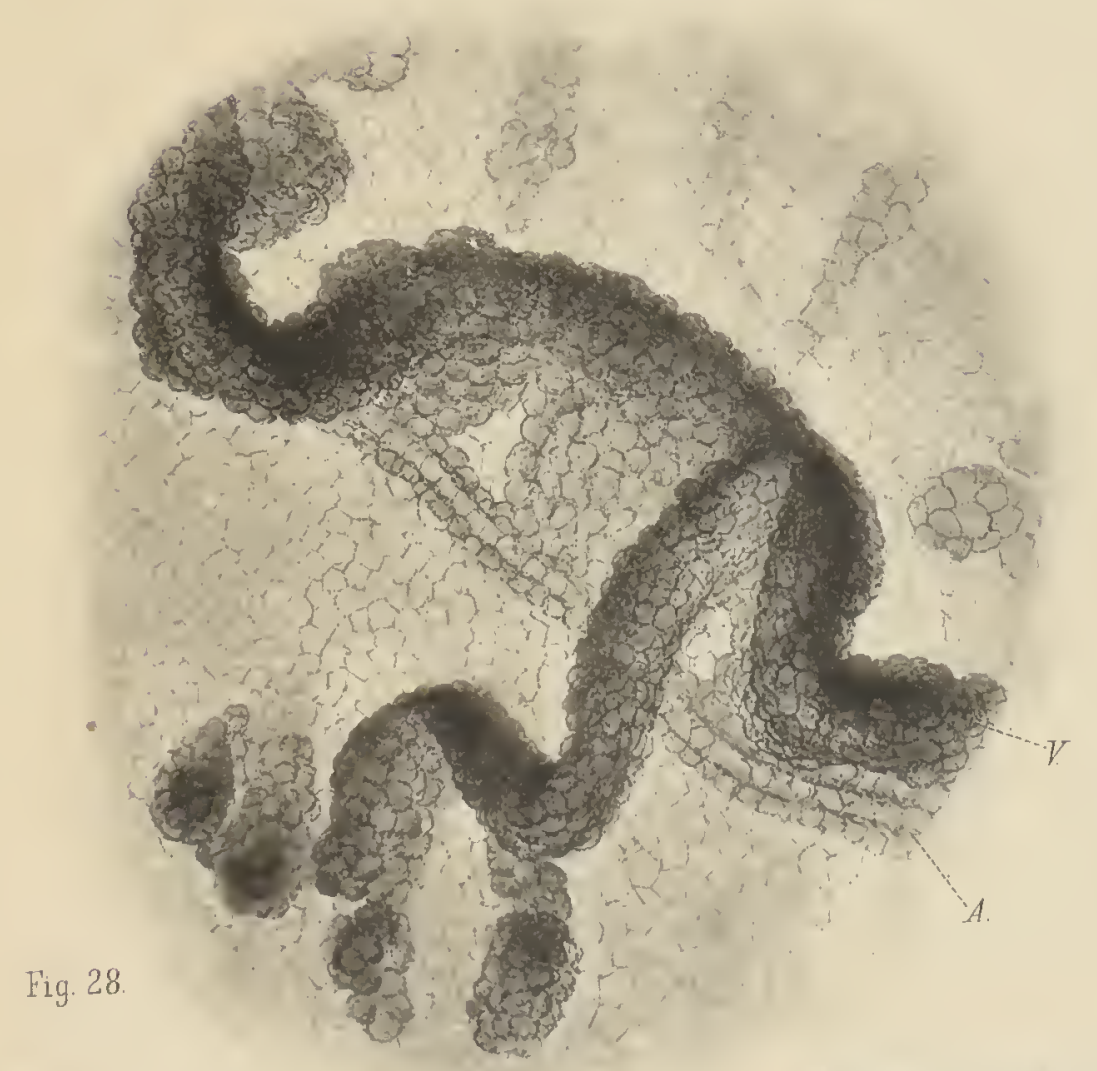

Fig. 28

H.Virchow: Der Dollorsack des Huhures. 


